\title{
CODESWITCHING AND IDENTITY AMONG ISLAND PUERTO RICAN BILINGUALS
}

\author{
A Dissertation \\ submitted to the Faculty of the \\ Graduate School of Arts and Sciences \\ of Georgetown University \\ in partial fulfillment of the requirements for the \\ degree of \\ Doctor in Philosophy \\ in Spanish Linguistics
}

By

Marisol Pérez Casas, M.S.

Washington, D.C.

December 9, 2008 
Copyright 2008 by Marisol Pérez Casas All Rights Reserved 


\title{
CODESWITCHING AND IDENTITY AMONG ISLAND PUERTO RICAN BILINGUALS
}

\author{
Marisol Pérez Casas, M.S. \\ Thesis Advisor: Thomas J. Walsh, Ph.D.
}

\begin{abstract}
The present sociolinguistic and ethnographic study focuses on codeswitching, the alternation of two or more languages in conversation. It investigates how a network of elite, educated bilinguals on the Island of Puerto Rico (PR) alternate between English and Spanish in everyday, casual conversations, and how this language practice relates to their social identities. Due to the intricate sociolinguistic situation and political status of PR, this context is ideal for looking into the meaning and social significance of codeswitching, and how this linguistic style contributes to identity creation.

This study was based on ethnographic interviews and observations, audio recordings of casual conversations, and a thorough account of speakers' socio-cultural realities. It explores the history and ideologies tied to each language, provides a thorough description of how participants invested in learning English, and gives a detailed account of language use in interaction to make visible important linguistic processes on the Island.
\end{abstract}

It was found that codeswitching constitutes an integral part of the linguistic repertoire of a network of elite, Puerto Rican bilinguals and that they employ a codeswitching style habitually in informal group encounters. Speakers did not engage in codeswitching as a deliberate choice, that is, a mindful way to index ideological 
associations of each language. However, the codeswitching practice of this network, as an overall pattern and stylistic option, strays from the community-wide discourse mode (Spanish), and therefore has important implications for the affirmation, and shaping of personal and social identities.

An analysis of prevalent language ideologies, and speakers' metalinguistic commentaries provided a better understanding of how their codeswitching style allows for the co-construction and negotiation of large-scale social identities such as: Puerto Rican, American, elite, and bicultural. Codeswitching, in this context, cannot be said to automatically index a hybrid, bicultural identity. Participants denied any relationship between their use of English and claiming an "American" identity. Codeswitching also allowed for a reinterpretation and novel conceptualizations of what it means to be "Puerto Rican.” The present study recognizes codeswitching not only as part of interpersonal communication, but also as part of historical and sociocultural processes. 


\section{ACKNOWLEDGEMENTS}

I would like to thank those who contributed to the completion of this project:

- My dissertation committee: Dr. Thomas Walsh, Dr. Ana De Fina, and Dr. Natalie Schilling-Estes for their excellent guidance and support.

- Participants of this study: For contributing with their time and insights. Amongst endless days of reading and writing, their words stood out as the heart of this work, and kept me intrigued enough to keep working.

- My family: For always reminding me that I could do this. A special thanks to my mother Marisol Casas Arsuaga, for her constant support and helping me find the strength to reach this goal; my stepfather Xavier González Goenaga, whose support made my studies at Georgetown University possible; my aunt Mari Angel Carrión Casas and my uncle Joey Carrión for their time, generosity and invaluable help; my brother Daniel Chardón Casas, for his encouragement when I needed it most; and my husband Mario R. Francisco for his much needed assistance with computer issues, but above all, for his unyielding love and patience.

- My friends and colleagues: Juanma, Judith, Kristi, Liselle, Leslie, Sheri, Verónica and Yanisa. Dr. Sandra M. Falcón, for helping me believe that I could take on the challenge of a Ph.D., and Dr. Víctor M. Torres Vélez, for his insights and guidance since my very first attempt at this writing this dissertation.

- The Holy Spirit: For guiding my writing every step of the way. 


\section{TABLE OF CONTENTS}

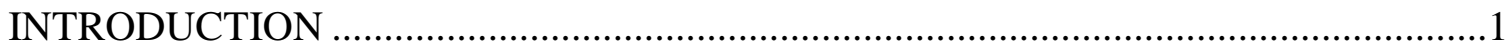

Chapter 1: A Sociolinguistic Approach to Codeswitching ……………….........................

Codeswitching Style and Identity ……………………...............................................

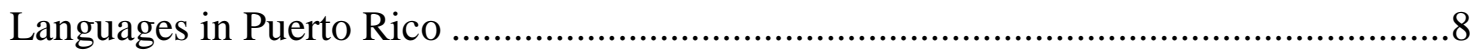

Puerto Rican Elite Bilinguals .....................................................................................10

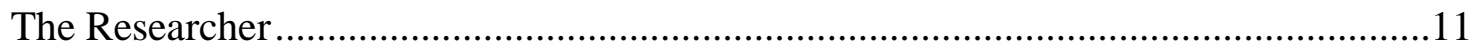

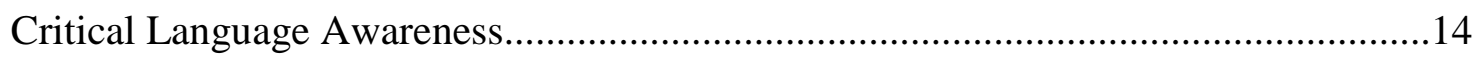

Chapter 2: Language Policy and Language Education ...................................................17

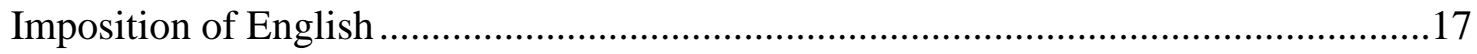

The Language Problem …………………………..................................................19

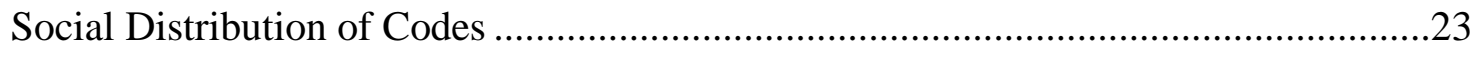

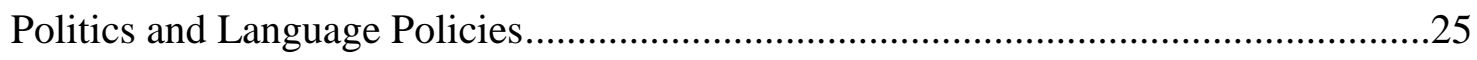

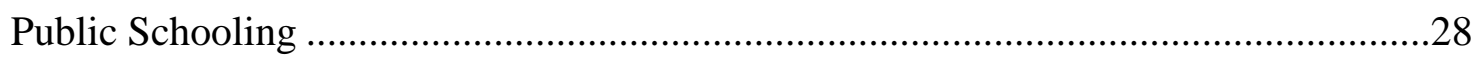

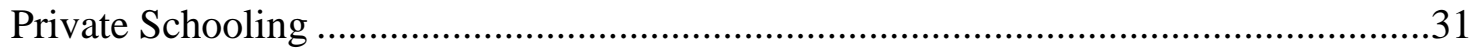

Chapter 3: Language Dynamics in PR...........................................................................

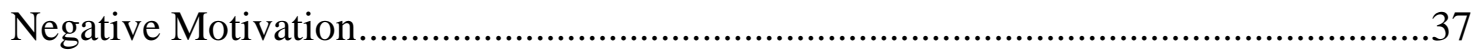

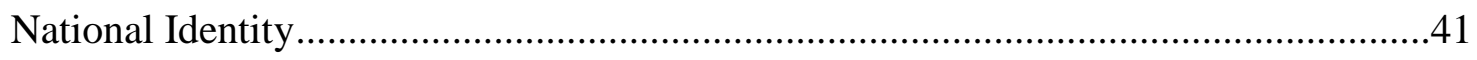

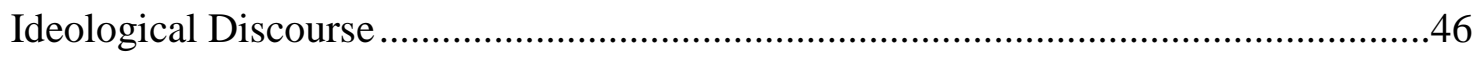

The Linguistic Market .............................................................................................49

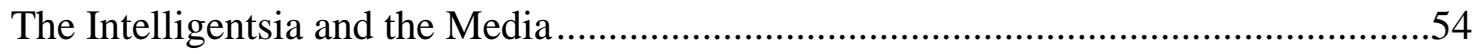

Chapter 4: Language Alternation ................................................................................61

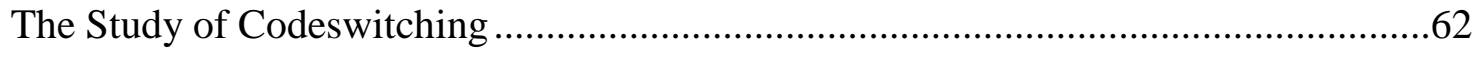

Sociological and Interactional Approaches .................................................................66

Codeswitching and Identity ................................................................................. 


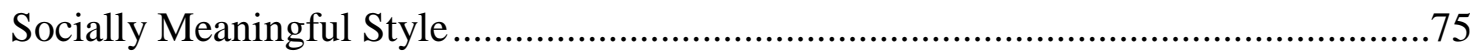

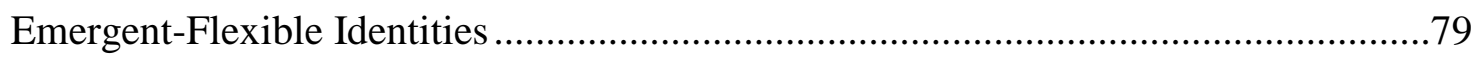

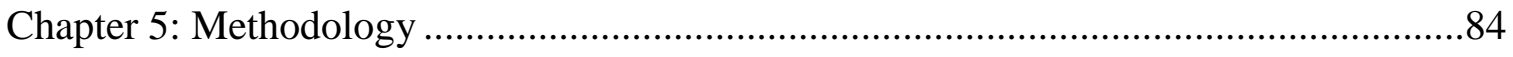

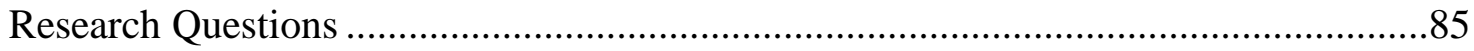

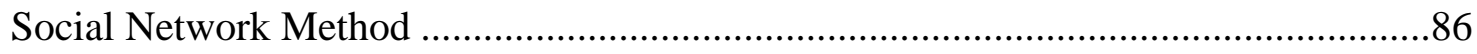

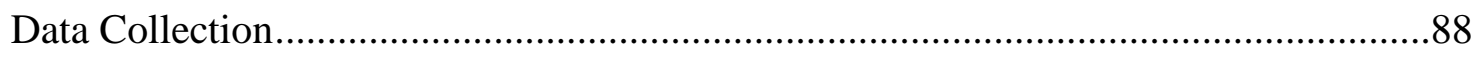

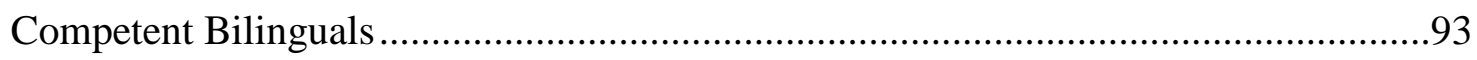

Chapter 6: Participant Profiles .................................................................................96

Private Schooling and U.S. College Education............................................................99

Private Schooling and P.R. College Education ...........................................................108

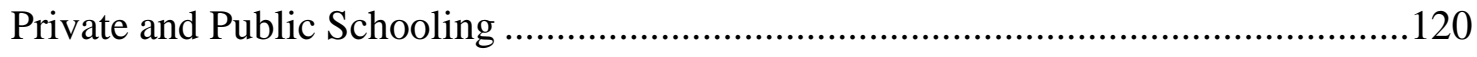

Public Schooling and English Attainment …………………...................................130

English Learning: Changing Trends ......................................................................

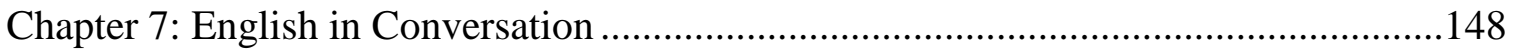

Language Distribution.............................................................................................148

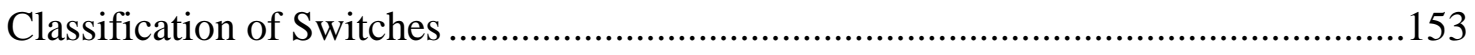

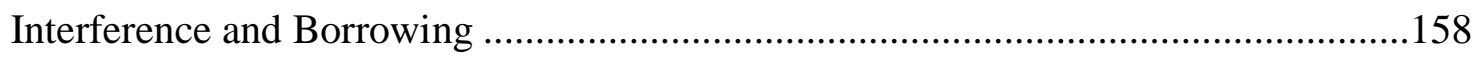

Borrowings in Puerto Rican Spanish ......................................................................161

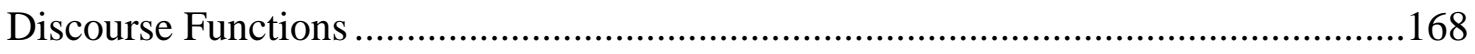

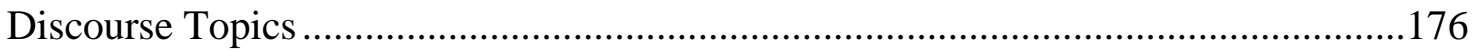

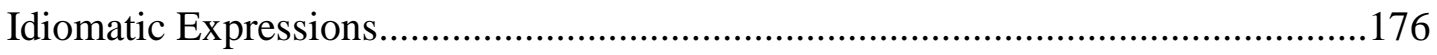

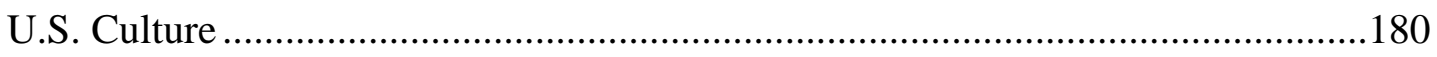

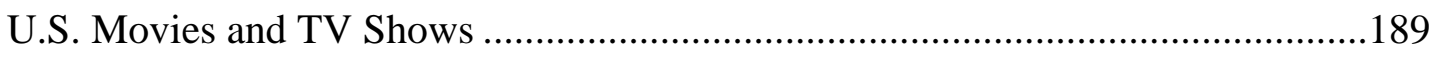

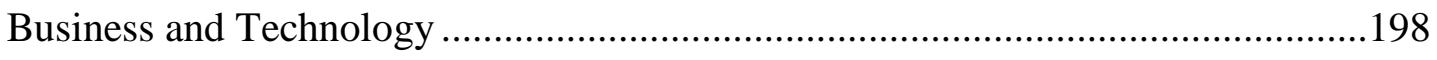

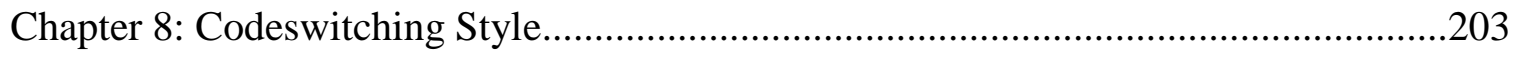

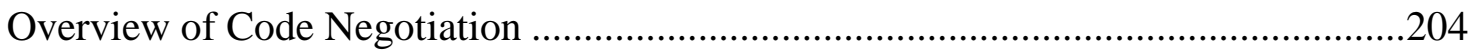




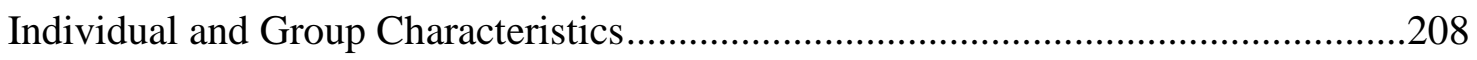

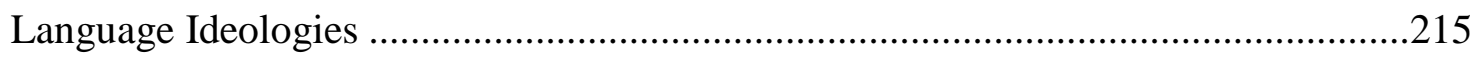

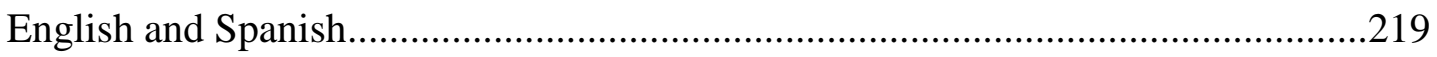

English and Spanish with Reservations............................................................226

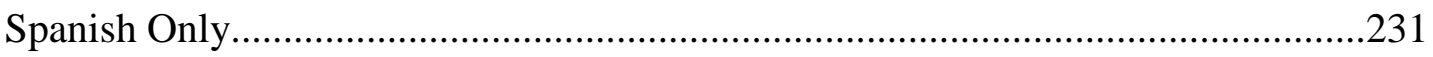

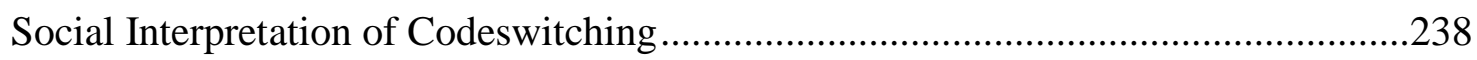

Chapter 9: Codeswitching and Identity ....................................................................252

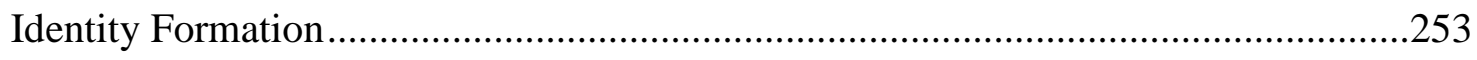

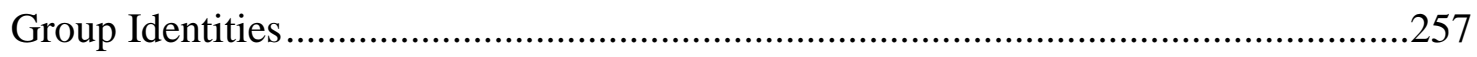

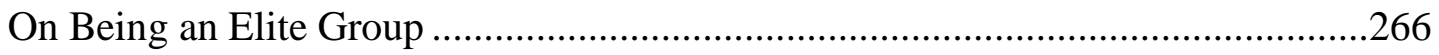

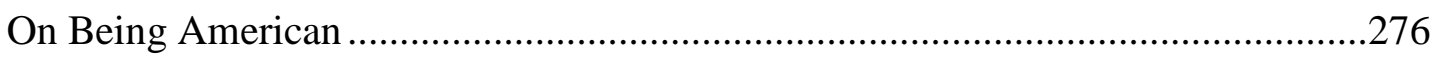

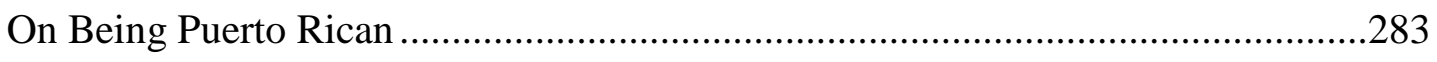

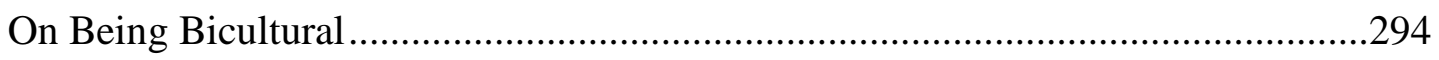

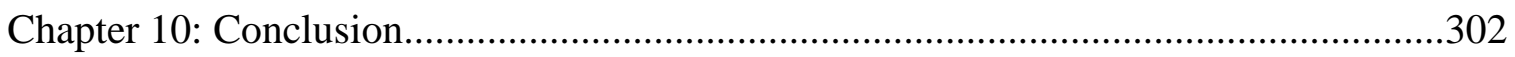

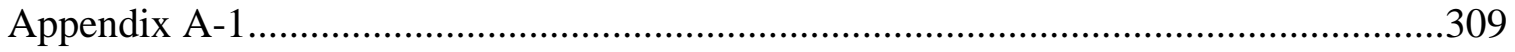

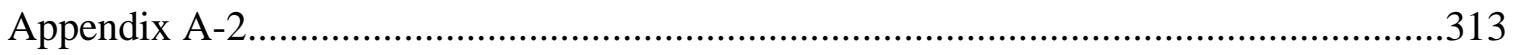

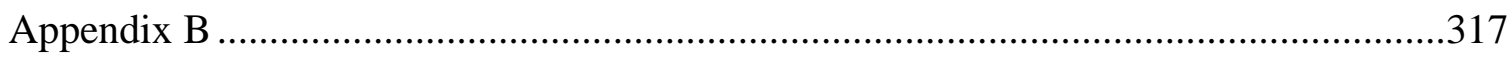

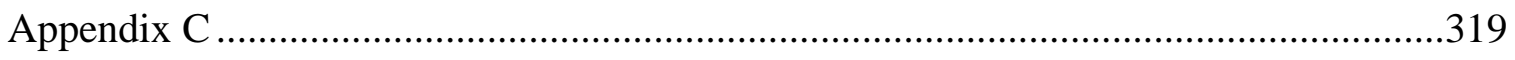

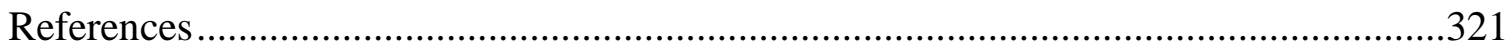




\section{LIST OF TABLES}

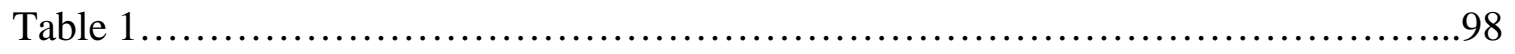

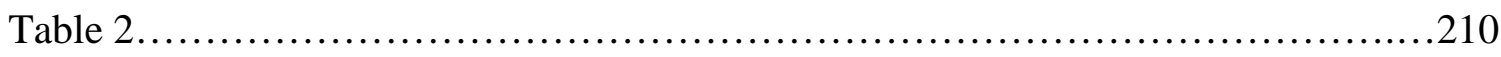




\section{INTRODUCTION}

This dissertation focuses on codeswitching, the alternation of two or more languages in conversation. Its central aim is to investigate how a network of elite, educated bilinguals on the Island of Puerto Rico (PR) alternate between English and Spanish in everyday, casual conversations, and how their choice of language relates to their social identities. This study explores the history and ideologies tied to each language, and gives a detailed account of their co-existence in interaction in order to make visible important linguistic processes on the Island. The complex relationship between Spanish and English in PR makes this context ideal for looking into the meaning and social significance of codeswitching, and how language use and collective social knowledge contribute to the creation of speaking styles. Ethnographic interviews and observations, audio recordings of casual, spontaneous conversations, and a thorough understanding of speakers' socio-cultural realities will shed light on the development of the communicative style of codeswitching, and its relationship to the shaping, enactment, and reproduction of social identities.

This dissertation contributes to moving the field forward in several ways:

1. Its analysis bridges the gap between the macro and micro sociological processes in codeswitching practices. At the macro level, it explores the historical and ideological trajectory of Spanish and English in PR, and relates it to the micro level or local practices of a network of speakers.

2. From the analyst's perspective this dissertation adds to our understanding of the origin and development of codeswitching, which may be characterized as a hybrid speaking style. Another important contribution is to find out how speakers themselves claim, accept, or reject identities that may be related to their bilingual speech style. 
3. Research on codeswitching and identity has yet to discover the full range of identities that may or may not be performed or negotiated through the bi- or multilingual speaking style of codeswitching. The current project adds to the growing number of local case studies which aim to fill this research gap by providing a typology of codeswitching styles in communities around the world. 


\section{Chapter 1: A Sociolinguistic Approach to Codeswitching}

Codeswitching has been a topic of investigation for more than half a century. Studies that focus on its socio-pragmatic correlates have demonstrated that codeswitching serves common stylistic and pragmatic functions in many regions across the world (Auer, 1998; Gumperz, 1982; Heller, 1988; Myers-Scotton, 1993a). Many of the findings also suggest that codeswitching is tied to ideological conceptions of language and group formation, and that to understand this phenomenon, it is necessary to consider societal structures in language contact situations (Acosta-Belén, 1975; Blommaert, 1992; Heller, 1992; Meeuwis \& Blommaert, 1994).

Effective approaches to codeswitching should include the larger societal background to explain what people do when they codeswitch, in terms of what is allowed or made possible. (Meeuwis \& Blommaert, 1994, p. 416). With that in mind, this dissertation will present a summary of the historical trajectory of Spanish and English in PR. and will then relate this macro context to the local codeswitching practices of a particular group of speakers. This project will contribute to the field by filling the gap left by studies that fail to link local interactions with broader historical/ideological trends. I will not focus solely on the local creation of meaning, but will also look into the construction of a distinct speaking style that may be linked to significant social constructs, such as identity.

There are contexts that may be highly complex with regard to the potential set of identities orchestrated in a given bilingual interaction. One such context is the island of Puerto Rico. Its political and sociolinguistic situation makes it an ideal location for the study of codeswitching and situated identity. The current project adds to the increasing number of local case studies which depict how speakers, in actual conversations, reflect or challenge the beliefs, 
ideologies and attitudes tied to each language. I will also explore speakers' perceptions, impressions and claims about their identity, and how these relate to their speaking styles.

Existing frameworks that have been applied to codeswitching, which take discourse as the starting point of analysis, run the risk of providing only descriptive accounts of interaction. Likewise, those which attempt a straightforward match between language and social structures lose sight of the heterogeneity of communication where many factors intersect to create or reproduce social groups, histories and identities. The present study recognizes codeswitching not only as part of interpersonal communication, but also as part of historical and sociocultural processes. This two-pronged analysis offers a picture of identity negotiation that takes into consideration micro and macro dimensions of social order.

In order to analyze codeswitching as a socially situated activity, this dissertation considers four basic and interconnected elements suggested by Layder (1993) as part of a resource map for social research: context, settings, situated activity and self (p. 72). His approach explicitly set out to organically integrate and incorporate macro and micro phenomena of interaction and behaviors. While maintaining this integrative approach throughout, the present investigation is divided into ten chapters. Chapters two and three offer a broad view of the Puerto Rican context, which refers to the macro social forms that provide the more remote environment for social activity. Chapter four provides a background on the study of codeswitching. This communicative style is present in certain settings, intermediate forms of social organization, that provide the arena for social activity. Chapters five and six describe methods of data collection and allow us to get acquainted with differences and commonalities in participants' linguistic histories. Chapters seven and eight look into the situated activity of codeswitching and provide a window into the daily linguistic practices of participants. These chapters offer a thorough 
characterization of their codeswitching style. Chapter nine concentrates on the self and the intersection of individual and collective identity. Finally, Chapter Ten summarizes key findings and implications for future research.

\section{Codeswitching Style and Identity}

The socially situated study of codeswitching can tell us much about identity. Speakers' language use can be interpreted as part of a larger set of strategies and practices through which they associate themselves with particular groups, and distinguish themselves from others, and in this process construct social categories/identities (Milroy \& Gordon, 2003). Current research on codeswitching and identity has yet to discover a full set of identities which may be occasioned by the bilingual speaking style of codeswitching. It is not enough to say that (x) language indexes (x) identity or identities. Each community or group of speakers who codeswitch may have different indexical associations with the codes in question. Myers-Scotton (1993a) has suggested that speakers choose a certain code because it indexes a set of rights and obligations that apply to the current interaction. This set of obligations is derived from situational factors, attitudes and expectations speakers have toward one another (p. 84-85). However, this may not hold true for all groups of speakers. For example, when Puerto Ricans in New York use Spanish over English in conversation they may do so not because they want to index the rights and obligations that Spanish (or English) allows in individual interactions, or because either code is expected in conversation, but because it accomplishes an important cultural goal, that of signaling their Puerto Ricanness (Zentella, 1997, p. 3).

Furthermore, several studies on codeswitching (Cashman, 2005; Gafaranga, 2005; Wei 2005; Williams, 2005) have challenged the notion of a hybrid social identity in which each code is said to automatically index specific ethnic or social categories. In her study of language 
alternation amongst a group of senior citizens of different ethnic and linguistic backgrounds in midwestern U.S., Cashman (2005) found that "regardless of who the speakers 'are' in some broader sense, the identities that they 'do' in interaction rely on the social structures that have been talked into being" (p. 311). She argued that it is through conversational structure (e.g., codeswitching) that social structure (e.g., group membership) is constituted, manipulated, ascribed, contested, and accepted. Cashman demonstrated that it would have been a mistake to categorize participants as 'Chicano/Latino' and 'Anglo' based on their codeswitching practices because these group memberships are not always there at the local level. Exactly which types of identity categories or groupings may or may not be revealed by the codeswitching style of bilinguals has yet to be explored by case studies such as the one presented here. This study sheds light on such identities, which may be indexed by the codeswitching style itself, and not by each code alone.

Speaking styles play a key role in defining situations and groups, and may signal, display, or shape aspects of identity, such as ethnicity (Milroy \& Gordon, 2003; Schilling-Estes, 2002; Schilling-Estes, 2004). The process of group formation happens as certain linguistic elements are recognized as defining or identifying features of a given community or network of speakers. Furthermore, a style, or particular way of speaking, has social meaning because it carries "the taste of its routine messages" (Bell, 1999, p. 525). These "routine messages" make salient the element of habit in the creation of a style.

Although there are common features that can be systematized and thus be said to constitute a specific linguistic style, this systematization is not a stable phenomenon. According to Bakhtin (1981), language will always be influenced by two types of forces: the centripetal (unification) and the centrifugal (differentiation) (p. 272). In this dissertation we will see how 
some speakers may position themselves in favor of maintaining the unity of language (in this case Spanish) and at the same time engage in the, sometimes inevitable, appropriation (Bakhtin, 1981, p. 293) of new words and meanings (in English) through codeswitching. When speakers appropriate linguistic items, they are doing much more than adapting or borrowing them, they are making them their own. The habitual inclusion of English in their day to day conversations means English words or phrases are no longer something foreign or separate. Codeswitching becomes part of what identifies speakers as individuals or as members of a group; it becomes part of their identities. For participants in this study, the appropriation of English allows for a distinctive speaking style that signals personal as well as group identity.

Furthermore, most participants have appropriated (Bakhtin) the English language to the extent of making it a normal part of their everyday interactions. Rey says: "It's much easier to use codeswitching than to speak solely in Spanish." This has significant implications for the topic at hand. The experience of bilinguals in Li and Tse's 2002 study is strikingly similar to that of participants in the present study. In their study, the researchers documented that Hong Kong bilinguals habitually included English expressions of various lengths in their matrix language, Cantonese. One of $\mathrm{Li}$ and Tse's respondents said: "Most of us are too accustomed to this 'strange' talking style. We cannot even communicate smoothly once we abandon this style” (p. 189). The same is true for most bilinguals in the present study. Their codeswitching style is their natural way of communicating with friends and peers, and eliminating English would entail eliminating an integral part of who they are and how they express themselves. They do not employ a codeswitching style only occasionally; it is an integral part of their communicative repertoire, which in turn reveals aspects of their identity. 


\section{Languages in Puerto Rico}

Puerto Rico has been a territory of the United States for more than a hundred years. Political and economic ties with the U.S. have had a significant effect on the linguistic climate of the Island. The official languages of PR are English and Spanish, but most of the 3,808,610 Puerto Ricans on the Island ${ }^{1}$ speak Spanish as their native language. Although the Spanish of Puerto Rico is grouped along with the other Spanish dialects of the Caribbean, it has some characteristics that set it apart, such as pronunciation and vocabulary. A distinguishing feature is the alternation of [r] and [1] as allophones of implosive /r/. Furthermore, after more than a hundred years of a close cultural relationship with the United States, and contact with the English language, the Spanish of PR exhibits some common effects of language contact, among them borrowing and codeswitching.

Borrowing refers to the incorporation of foreign features (in this case lexical items) into a group's native language (Romaine, 1995, p. 71). Because of the Island's close relationship with the U.S., there has been considerable speculation and outright worry about the effects of English in the Puerto Rican dialect. López Morales (1998) presented empirical evidence for determining English borrowing instances (anglicismos) in PR based on degree of integration. He studied words of English origin in the capital, San Juan, and the metropolitan area. Four hundred and eighty words were classified by their use in the community, and compared to use in Madrid and Mexico City. The number of anglicismos used in the study by Puerto Ricans was double or triple that of other Hispano-American zones. However, he clarified that out of every 100 words identified as borrowings, seven were of English origin and of those seven, four were already accepted as part of the Spanish language by the Spanish Royal Academy. According to López

\footnotetext{
${ }^{1}$ U.S. Census Bureau 2000. An estimated 3.4 million more Puerto Ricans reside on the U.S. mainland.
} 
Morales, much has been said about the situation of Puerto Rican Spanish with regard to the influence of English. Some say it is excessive and others equate it to the same influence in other Hispanic areas. Based on the above study, he concluded that the Puerto Rican situation is not critical if we take into account the sociopolitical status of the Island and the natural or artificial pressures it has endured (p. 204).

Although linguistic change that manifests itself in the adoption of new lexical items is the most notable, and therefore the most studied, Morales (2000) mentioned that semantic changes are perhaps more important because they go unnoticed by the average speaker. She explained that in PR there are many traditional Spanish words that are being used with different meanings. With regard to the overall influence of English in Puerto Rican Spanish, Morales also appeared to take a positive approach: English should be seen as a factor promoting linguistic change. Other than promoting simplification processes already present in the system, it occasionally broadens the array of variants available to the Puerto Rican speaker (p. 55).

It is important to clarify that in PR, as of today, we cannot speak of a process of language shift, where the native language of a particular group is abandoned in favor of another one, as a result of language contact. After a century of strong ties with the United States, not only has Spanish remained the dominant language on the Island, but the majority of Puerto Ricans are far from being bilingual. Fayer (2000) reported that in the 1990 census, 24\% of Puerto Ricans said they could speak English easily (p. 90). More recent figures show that $32.8 \%$ of Puerto Ricans between the ages of 18-64 say they speak English "very well" or "well." The percentage is lower for the 5-17 age group, where fewer than 19\% are bilingual (Census, 2000). Census data has its limitations. For instance, census findings are based on self reports which may or may not be accurate, and its numbers say nothing about when, where, and why English is being used. 
However, census information is useful in providing a notion of how language usage patterns change over time. In the case of PR, it seems that over the years, English has not been able to replace Spanish as the dominant language. However, phenomena related to language contact such as codeswitching may be attested among certain groups of bilingual speakers, a matter that will be further explored in the present study.

\section{Puerto Rican Elite Bilinguals}

In numerous language contact sites around the world there may be straightforward links between each language spoken in a community and a particular ethnicity. For example, in contexts of immigration it typically follows that speakers associate the majority language with a sense of belonging to the host country, while the minority language is associated with feelings of belonging to the place where they came from. This occurrence shows that language is commonly associated with feelings of nationalism and belonging. We may then be tempted to conclude that in PR the use of Spanish signals being "Puerto Rican" and the use of English signals being “American.” However, there are no straightforward indexical pairings of Spanish and English in bilingual conversation among Island Puerto Ricans. The presence of these languages in interaction seems to point to a set of identities that do not merely index a priori associations attached to each language. When interviewed for the present study, Laura (33) said: “I don't feel codeswitching is related to my identity as a Puerto Rican. I feel it's related to the fact that I had a lot of exposure to the English language while growing up. And I don't think it makes me less of a Puerto Rican in any way. It just makes me fully bilingual.” Like most Island Puerto Ricans, Laura is native speaker of Spanish, but unlike the majority on the Island, in everyday conversations she habitually mixes Spanish with English words and phrases. Codeswitching is 
part of her communicative style, a style that sets her apart from other Puerto Ricans who are not fully bilingual.

Alberto (34), Laura's husband, explained that when you codeswitch you are automatically setting yourself apart from the people who do not do it or are unable to do it, and that it is a status signal: "English is the cool language," he said. He also mentioned that there seems to be a limit on how much English you can include in your conversations. If you use too much English it is a clear sign that "you think you're better than others because you can speak English.” Laura and Alberto's words point toward the existence of complex and multifaceted identities among members of their social network. Codeswitching may signal aspects of their group identity: urban, educated, middle/upper class bilinguals. Of interest to the present study is the negotiation of identity as revealed by the codeswitching style of this group of bilinguals.

In later chapters I will describe and characterize codeswitching as an in-group style, and then investigate how it may index or become associated with personas or identities (Eckert \& Rickford, 2001; Rampton 1999b; Schilling-Estes, 2004). The type of identity work found in the codeswitching practices of elite, Island PR bilinguals reveals itself not as one that can be determined a priori, based on pre-existing social categories, but one that is constituted through social action and through language.

\section{The Researcher}

I believe it is important to explain the place that $\mathrm{I}$, as a researcher and bilingual Puerto Rican, occupy in my island's linguistic scene. My native language is Spanish. I grew up in San Juan and attended a Catholic private school, where I studied English as a subject in school since first grade. I was not aware, back then, of the future implications of that sixty-minute class. As it does for many Puerto Ricans, English greatly determined my educational opportunities, and 
continues to play a key role in the type of job I can have, the money I can earn, the things I do in my free time, the friends I have, and the way I talk. Ultimately, it defines aspects of my identity.

I come from what could be considered an upper-middle class family. We lived close to an affordable school which catered to residents of one of the most expensive housing developments on the Island. It never occurred to my mother to enroll me in public school. A good education in PR, especially one that would give a child the opportunity to learn English, meant private schooling, and for many parents, it still does. As the years went by, I learned English well. Nowadays, to be admitted to my former high school all students have to take an English placement exam. As a Senior I went on a trip to the east coast of the U.S. with twenty schoolmates to visit universities. After graduation, our teachers, school administrators, and most people in our social circle expected us to attend college in the U.S. However, the idea of leaving home did not appeal to me back then, so I decided to stay on the Island and continue my education at the University of Puerto Rico (UPR) at Río Piedras, San Juan.

The first few weeks in college I noticed I was different from many of the students who came from all parts of the Island, and one of the clues of this was the way I talked. In high school I codeswitched all the time with my friends and family, and did not think much of it. In fact, I had never been aware that the way I used my languages was "unique" until I began my studies at the UPR, and my classmates would say things like: "Why are you speaking English?", or I would notice blank stares when I used English words because the message did not get across. At that point, I became aware of the fact that English made me different from the "average" Puerto Rican, and that to fit in and not be considered "weird" or "a snob," I would have to stop mixing English and Spanish when I spoke. It was not easy at first, but I managed to train myself to suppress English in many situations. I realized at that point that codeswitching had something to 
do with who I was, and who I portrayed myself to be. It made me notice what I had in common with my friends and family, and I also realized that knowing English gave me a certain advantage over those who did not know it. As we shall see in this dissertation, my experience is shared by several respondents.

As I started delineating my research topic, I spoke to a friend who went to public school in PR. He had limited English proficiency when he began his studies at the UPR. He recalls overhearing groups of students codeswitching, and feeling very different from them, in part because of his linguistic background. His interpretation was that they used English because they wanted to seem more powerful: "I know English, therefore I am better than those who don't." It is possible that these groups of bilingual students were deliberately using their two codes to distinguish themselves from individuals outside their social circle. But it is also possible that they were not aware of the fact that their linguistic practice set them apart from others. Issues of how language contributes to group formation and shared identity will be further explored in this dissertation.

My experience as a bilingual living amidst a monolingual majority prompted one of the questions that initially motivated this dissertation: Are Puerto Rican bilinguals aware of their codeswitching practices, and are they aware of how language may set them apart from other Puerto Ricans? About three years ago, I went to a Government office with a friend to register the name of his new company. My friend went to a Catholic school, attended college in the United States, and belongs to PR's upper class. After a short wait, we sat before the clerk and told her the name of the company. She asked us where the name had come from, and my friend said: "No sé, nos lo inventamos on a whim" [I don't know, we came up with it on a whim.] After he said this, I witnessed her blank stare, accompanied by a hesitant “Oh, ok...” She obviously did not 
understand the phrase "on a whim.” After we left the office I asked him if he was aware of what he had said, and that the woman did not understand him. He shrugged and said he didn't even remember saying anything in English. Perhaps my friend was not being an efficient "codeswitcher," since he did not consider the contextual factors minimally associated with this social practice, that is, the presence of other bilinguals. There may also be issues related to my friend's social sensitivity. Moreover, there may be other implications. My friend set himself apart from this woman in many ways. Miscommunication here was indicative of different linguistic backgrounds and different identities.

There are several advantages to my being part of the community under study. During the data collection process, I had ideal open access to settings usually closed to outsiders, and was able to unobtrusively obtain systematic evidence of participants' linguistic behavior. I also have a thorough understanding of the cultural norms at play and how they may influence the linguistic behavior of informants. This "inside knowledge" is a definite advantage, since understanding and even personally experiencing speakers' realities and struggles allows me to identify and delve deeper into issues that need to be addressed in order to be better understood. One possible limitation of my being part of the community is that the closer the researcher is to the group under study, the more myopic he or she may become about the significance of everyday acts that the group takes for granted (Zentella, 1997, p. 7). I also had to be careful not to assume I already knew which insights could be drawn from the data before thoroughly examining the information.

\section{Critical Language Awareness}

In Puerto Rico virtually everyone speaks Spanish, some also speak English, and some appear to switch between the two. Alberto (34), one of the participants in this study, says: "It's okay to switch between languages, but you also have to be careful not to switch too much. I 
don't know where the percentage lies: 75\% Spanish and 25\% English maybe?" (Here he laughed indicating this calculation would be difficult.) "I don't know where you draw the line, but you have to be careful because too much English can turn you into a snob, even among others who also codeswitch." Alberto's comment is evidence of a "critical awareness" about what codeswitching can reveal in terms of identity and power relations.

Critical language awareness, a concept developed by Fairclough to understand the intricate relationship between language and power, "highlights how language conventions and language practices are invested with power relations and ideological processes which people are often unaware of" (1992, p. 7). Furthermore, critical language awareness has a great application in colonial societies in which issues of language choice are mediated through power relations (Pousada, 1996a, p. 21). Alberto observed that if you use too much English, you take on an air of superiority because you are making it all too clear that you know a language which is associated with "power" in Puerto Rico, a place which is often straightforwardly described as a colony. In colonial settings, conscious understanding and sensitivity to language issues becomes paramount if we wish to understand what lies behind linguistic choice. Bilingual Puerto Ricans may or may not be aware of how their linguistic practices, in this case codeswitching, may become a reflection of power struggles in their sociocultural setting, and how their linguistic choices may signal an identity or identities that differentiate them from other Puerto Ricans. One of the goals of this dissertation was to delve into speakers' perceptions of their linguistic practices and how they relate to who they are at the social and personal level.

The more I read about codeswitching, the more I realized that the social circumstances behind it determine substantial differences in the practice itself and in its repercussions as a language contact phenomenon. The group of bilinguals who participated in this dissertation has a 
linguistic and socioeconomically privileged position in PR. Exploring issues of power relations, codeswitching and identity among bilinguals can shed light not only on the complex language dynamics in PR, but also on the evolution of the Puerto Rican dialect. 


\section{Chapter 2: Language Policy and Language Education}

Before we discuss the local codeswitching practices of Island Puerto Rican bilinguals it is indispensable to explore the broader linguistic landscape of the Island. The form codeswitching takes and "the extent to which it can be seen to have social, discourse and referential significance, can only be understood by situating instances of codeswitching in the context of community-wide distribution of linguistic resources (the community speech economy)" (Heller, 1988, p. 3).

Codeswitching depends to a large extent on the composition of the linguistic repertoires that speakers have access to, and then actually employ. The analyst interested in explaining this phenomenon must understand both speakers' opportunities and motivations for gaining and maintaining access to the codes (languages) in question, and also the place each code occupies in both community and individual repertoires. The first step in this direction will be to explore (1) the historical trajectory of language policies in Puerto Rico and their effect on the quality and success of English education, (2) the relationship between Puerto Rican politics and language, and (3) English learning opportunities available on the Island.

\section{Imposition of English}

Puerto Rico had been under Spanish rule from 1493 until 1898, when it became a territory of the United States. Before the arrival of U.S. troops on the Island, Puerto Ricans had already been exposed to the values and culture of Spain for four centuries. From the very beginning of U.S. occupation, the teaching of English was instrumental in the efforts to 
Americanize the newly acquired territory. However, creating a bilingual population would prove to be difficult, and even to this day it continues to present considerable challenges. ${ }^{2}$

Victor Clark, president of the Insular Council of Education in 1899 believed that at that point in time, Puerto Ricans were still "passive and plastic," which meant they would welcome English instruction. He soon found that this was not the case. Clark thought that opposition to English was a result of educators' familiarity with the French and Spanish systems, but there were deeper issues involved. Throughout the years, that initial opposition turned into outright resistance to acquiring this second language: "Surely many Puerto Ricans perceived that learning English might prove beneficial; however, the aggregation of the many experiences under the United States (economic, political and other civil laws) exacerbated the imposing manner in which English arrived and, hence, contributed to the resistance" (Solís, 1994, p. 51).

It is common for languages that come into contact with each other to exhibit an uneven social distribution even from the start of this process. Victor Clark seemed aware of this situation and admitted that there "could exist a tendency on the part of the rich to monopolize English, using it both to maintain political and commercial control and to further oppress the lower classes" (as cited in Walsh, 1991, p. 11). Clark was indeed correct in identifying the class character of the early colonial schooling and English imposition. Until 1909 education in the countryside was primarily in Spanish, while urban and middle class sectors received an education with emphasis on English, and geared to the preparation of the professionals who were to become the voice of the colonizer, and promote a new form of cultural hegemony (Walsh, 1991, p. 11). Nowadays, we cannot equate access to English by the upper classes to an outright

\footnotetext{
${ }^{2}$ This chapter provides a summary of key developments in the history of the school system of PR, which will help in understanding language dynamics on the Island. More detailed accounts can be found in Beirne, 1975; Negrón de Montilla, 1975; Solís, 1994 and Walsh, 1991.
} 
promotion of American cultural hegemony. However, as we shall see later in this chapter, the class character of schooling in Puerto Rico has persisted to this day.

In 1900, Dr. Martin G. Brumbaugh, the first Education Commissioner for the Island, hired American teachers, instituted the celebration of U.S. holidays in schools, and named them after American patriots. The public school system would be the "door to the Federal Union" (Negrón de Montilla, 1975, p. 254). English became a subject in elementary school while it remained the language of instruction in high schools. Nevertheless, efforts to instill an American identity and values on Puerto Ricans were just beginning. The pro-American majority in PR's legislature passed the Official Languages Act of 1902 which made English and Spanish the official languages of Puerto Rico. From this moment on, the official policy became the bilingualization of the Island, and the clear goal of the education system continued to be the Americanization of its inhabitants. This message was felt loud and clear in 1904 when Roland Falkner, the new Education Commissioner, made English the only language of instruction in all grades. As mentioned above, in rural schools this policy was put in effect in 1909. Resistance grew among teachers and parents, who reacted negatively to this policy, and protests arose out of the awareness of what they believed was a pedagogically unsound practice (Schweers \& Hudders, 2000, p. 65).

\section{The Language Problem}

Luis Muñiz Souffront, who would later become president of the Puerto Rican Teacher's Association, called attention to Roland Falkner's errors and stated that his policies violated the most basic pedagogical principles. He described children's efforts to learn English as difficult, and exposed the problem of teachers' limited proficiency in a language they were supposed to use as a medium of instruction (Negrón de Montilla, 1990, p. 124). Primary school children were 
the first to rebel and refused to attend classes until they were taught in Spanish. Authorities tried to appease the rebellion by expelling them. Educators joined the struggle and founded a Spanish school, the José de Diego Institute, named after an influential intellectual who led many others in their struggle against the use of English in schools.

A few years went by, and in 1911 the Puerto Rico Teacher's Association was constituted. It openly opposed English as the medium of instruction. Politicians also contributed by introducing bills, some of which were approved by the legislature but vetoed by the governor. ${ }^{3}$ Before long, the U.S. authorities began to refer to what was happening as "the language problem" (Walsh, 1991). Again, U.S. officials had presumed that the "English only" linguistic policy would not meet with such resistance. One of the measures taken to counteract opposition was the inclusion of a military drill as part of the curriculum.

The year 1916 marked a turning point on the road to eliminating English as the sole medium of instruction. The then Education Commissioner, Paul G. Miller, had worked as a principal and superintendent for several years and was aware of the problems faced by the Department of Education. He made a few modifications in response to the language problem. Children were to be instructed in Spanish until fifth grade and then all instruction would be in English. The goal was for children to become bilingual while conserving their Spanish language (Negrón de Montilla, 1991).

During the decade of the 1920s Americanization policies were greatly strengthened under the direction of Juan B. Huyke, a former teacher and the first Puerto Rican Education Commissioner. He explicitly expressed his goal of integrating Puerto Ricans into the "national life" of the U.S., and led the fight against legislative attempts to eliminate English as the medium

\footnotetext{
${ }^{3}$ Until 1946 Governors were appointed by the U.S. Government and had all been American. In 1948, Luis Muñoz Marín became the first elected governor of Puerto Rico.
} 
of instruction. Ranking among schools was determined according to performance on English tests, and high school diplomas were given to those who passed an English oral exam. As a result, student and teacher protests increased (Walsh, 1991, p. 16).

Beginning in 1934, José Padín instituted Spanish in grades 1-8, with English as a preferred subject, and an all-English curriculum in high school with Spanish as a school subject. This step brought the matter closer to the end result of Spanish as the medium of instruction in PR schools. Even so, after four decades of controversy and failure to make PR's population bilingual, U.S. officials still held on to the idea that the main objective of language policies on the Island should be the mastery of English (Resnick, 1993, p. 263). In 1937 President Franklin D. Roosevelt said the following in a letter naming José M. Gallardo Commissioner of Education: Only through the acquisition of this language will Puerto Rican Americans secure a better understanding of American ideals and principles... Clearly there is no desire or purpose to diminish the enjoyment or the usefulness of the rich Spanish cultural legacy of the people of Puerto Rico... But bilingualism will be achieved by the forthcoming generation of Puerto Ricans only if the teaching of English throughout the insular educational system is entered into at once with vigor, purposefulness and devotion, and with the understanding that English is the official language of our country (as cited in Resnick, 1993, p. 264).

Roosevelt referred to English as the "official" language of the United States, a statement that would probably be questioned in light of the current debates about the language or languages “of the United States." Also, Roosevelt's invitation to use "vigor, purposefulness and devotion" seems superfluous when we consider the complex set of problems faced by educators and administrators in the public school system of PR. The "Curriculum Survey of Public Education 
and the Future of Puerto Rico, 1948-1949" recognized that the history of Puerto Rican education had been marked by plans, counterplans, and compromise plans that attempted to cope with the problem of teaching English to Spanish-speaking children. The survey did clarify that even if Spanish was adopted as the language of instruction, mastery of English continued to be an important educational objective. The following are some of the main educational objections in relation to measures which made English the medium of instruction, that had persisted during the first half of the twentieth century:

a) Teachers lacked sufficient command of English.

b) Even when teachers were able to teach in English, pupils coming from Spanishspeaking homes could not understand instruction.

c) Some teachers departed from official policy and used Spanish surreptitiously, thus affecting school morale.

d) When teachers did conform to English, they passed on faulty English habits to the children.

e) Spanish literacy was affected, and finally many pupils left school knowing neither English nor content.

f) Pupils left school after grade 3 (approximately half the school population).

g) English classes could not achieve satisfactory results for many reasons, including that children had acquired a distaste for English through its forced use.

In 1949, after a long history of struggle by parents, teachers, and intellectuals to solve the "language problem," Spanish became the medium of instruction in the public school system. The language policy in effect today calls for Spanish as the means of instruction from grades one through twelve, with English taught as a special and preferential subject. An official policy of 
bilingualism, in what could be described as Puerto Rico's colonial climate, not only failed to create a bilingual population, but resulted in a conflicting relationship between the two languages, which would reflect the evolving cultural and political ties between PR and the U.S.

The relationship between Spanish and English on the Island could be described as "colonial bilingualism," which entails not the possession of two languages or two tools of communication but the appropriation of two psychic and cultural realms. There are two worlds in tension and conflict - those of the colonizer and the colonized. This source of contention seems inevitable because the language of the colonizer is not a neutral alphabet. Its addition to the language of the colonized constitutes a linguistic drama (Memmi, 1991, p. 108). And indeed, we could describe the history of English imposition on the Island since the arrival of the U.S. as dramatic. This overall climate of resistance made its mark on the collective consciousness of Puerto Ricans and, to this day, the two languages continue to confront each other in the minds of many. This is reflected in the many political debates that use the issue of language to support pro- or anti-American sentiments, and a general concern about the influence of English on the Puerto Rican Spanish dialect.

\section{Social Distribution of Codes}

The link between socioeconomic class and English attainment seemed to be strengthened from the 1950s to the 1970s. The lower classes attended public schools while the middle and upper classes had access to an increasing number of Catholic schools operated by mainland religious orders. Beirne (1975) documented the objectives of the latter schools: extensive instruction in English, greater discipline and reputedly superior academic quality (p. 124). He concluded that Catholic schools did not deliberately take up the Americanization role held in the past by public schools. Rather, these schools had a large influx of mainland teachers ignorant of 
the language and culture of PR. This situation inevitably made English the medium of instruction in the early years. Still, it is true that, with regard to class divisions and access to education, the schools found themselves serving only the needs of the well-to-do and attracting students by offering better programs in English. At present, many private schools are still run by Catholic religious orders and cater to the privileged social classes.

In 1952, the Island officially became a Commonwealth (nonincorporated territory). This meant increased autonomy in matters of education. However, this freedom had its limits. Walsh (1991) interpreted this new pedagogical climate as one of covert imposition: "Colonial education had moved to a new phase; overt Americanization was transformed into a more subtle process of deculturation that involved the psychological implantation of U.S. values under the guise of capitalist expansion and economic advancement" (p. 23). This suggested link between language and economic advantages was not entirely new. Awareness of the need to learn English as the door to economic advancement had always been present in the psyche of the higher social classes: "Puerto Rico's socioeconomic and political elite has always realized that for them to affirm and maintain influence with both Americans and their own compatriots, they had to become bilingual" (Schweers \& Vélez, 1992, p. 14).

It is logical that most Puerto Ricans recognize the value of learning English as an international language. Most researchers who have investigated this issue confirm that the majority of Puerto Ricans do think of English as an asset (Resnick, 1993; Torres-González, 2002; Torruellas, 1990). However, only the members of the upper socioeconomic classes recognize this language as indispensable to their advancement. Pausada (1996b) describes this tendency: 
Highly competent bilinguals in Puerto Rican society tend to be middle and upper class member of the intelligentsia, the international commercial circle, and the military. Their social mobility is closely tied to economic benefits accruing from the mastery of English, and they have collectively deserted the public school system to go into private schools where English is more actively and effectively developed. (p. 502)

The connection between socioeconomic status and bilingualism has been brought up in research addressing language policy planning in PR. In her 1992 study of language policy on the Island, Strauch found that those on the Island "who classify themselves as bilingual primarily comprise two poles on the socioeconomic continuum: members of the socioeconomic intellectual elite, and predominantly lower socioeconomic status returned migrants" (p. 119). Therefore, language proficiency is definitely tied to social and occupational status. Most of the highest paying professions on the Island require English fluency. In support of this last statement, the 1990 Census showed that there is a high correlation between English speaking skills and income. In income levels above $\$ 10,000$ there was a sharp increase in the number of people who could speak English well. At the income level of \$50,000 and above, the percentage of those who speak English well was $83 \%$, those who speak it with difficulty was $11 \%$, and just $6 \%$ could not speak it at all (Fayer, 2000, p. 94).

\section{Politics and Language Policies}

The most obvious impact of politics on the linguistic climate of Puerto Rico is the government's control over public policies pertaining to education programs. Another area of concern are political debates which have an effect on key issues, such as national identity. Since the 1960s, there have been three major political parties in Puerto Rico: The pro-statehood New Progressive Party (PNP); the pro-commonwealth Popular Democratic Party (PPD); and the 
Puerto Rican Independence Party (PIP). Every four years, general elections are held and the first two parties dominate results. In the 2004 general elections, the PPD candidate for Governor, Aníbal Acevedo Vilá, obtained 48.4\% of votes, the PNP candidate, Pedro Rosselló, 48.2\%, and the PIP candidate, Rubén Berríos Martínez, 2.7\%. The Island generally has high voter turnout rates, and that year it was $81.7 \%$. In the 2008 elections the PNP candidate Luis Fortuño (a University of Georgetown graduate) obtained 52.10\% of votes, while Aníbal Acevedo Vilá, obtained $41.32 \%$ of votes. ${ }^{4}$ In his first speech as Governor-elect of PR, Luis Fortuño, mentioned his intention of promoting bilingual education on the Island.

In a climate of political uncertainty, language has been used as a weapon in the battle over what the relationship between the U.S. and Puerto Rico should be. In 1991, Governor Rafael Hernández Colón, a Commonwealth supporter, signed a law making Spanish the sole official language of PR, thus revoking the Official Languages Act of 1902. The distribution of Senate votes, for and against this measure, was split along party lines, which reflects the politicization of linguistic ideals. The six votes against the "Spanish only" measure were cast by pro-statehood members. Seventeen Commonwealth supporters and one independence supporter voted in favor, and there were three abstentions. In its coverage of the signing of the new law, The New York Times (March 6, 1991) cited Gilberto Rivera Ortiz, a member of the Governor's Popular Democratic Party: "We are not rejecting the English language. We accept that we have to promote the English language to our students because it is essential to promote our economic development." Moreover, Carlos Romero Barceló, a statehood proponent, said that the bill was an attempt to portray the Island as a "different nation," with a separate culture that could not be easily assimilated.

${ }^{4}$ Official Reports, 2004, 2008. Puerto Rico Commonwealth Elections Commission. 
Those who supported the measure, put forth as their main arguments the relationship between language and identity, and the important cultural heritage that Spanish represents for the Puerto Rican people. Many correlated this political move to a defense of Spanish and an effort to withstand the possible imposition of English in the future. This was not surprising given the prospect of Puerto Rican statehood in the midst of the "English Only" movement in the U.S. (Strauch, 1992, p. 112). The debate stirred by this law showed once again that, at some level, most Puerto Ricans do recognize the value of English, even though public instruction has not resulted in widespread societal bilingualism.

One of the main arguments against the bill that proposed the de-officialization of English was based on fear that the government would eliminate English instruction in schools. This would eliminate altogether the opportunities for economic mobility of children of less privileged classes. The elite, to which most of the politicians pushing the law belonged, would of course, continue to send their children to private schools with superior English language instruction. The bill was then amended to guarantee that English language instruction would not be affected. The issue of class and bilingualism was debated publicly, and it was suggested that the real colonizers on the Island were the local legislators and elite since bilingualism has traditionally been reserved for the elite (Strauch, 1992, p. 120).

In 1993, statehood supporter Governor Pedro Rosselló revoked the law making Spanish the sole official language, and today both English and Spanish remain the co-official languages of the Island. This new law left intact the public education system, where Spanish continued to be the principal means of instruction. Nevertheless, it did once again stir nationalistic sentiments among Puerto Ricans who interpreted Rosselló's actions as a challenge to Puerto Rican identity. 


\section{Public Schooling}

One of the most recent debates regarding language and the public school system took place in 1997 when the "Bilingual Citizens Project" was put forward by the Secretary of Education, Víctor Fajardo. The plan emphasized the importance of situating the Island within the global economy, and included the following suggestions: developing English reading skills by the second semester of first grade; teaching mathematics and science in English on a voluntary basis; and offering teachers opportunities for professional advancement and participation in exchange programs in the United States (Torres-González, 2002, p. 359). The situation regarding bilingual teachers in PR seemed critical. The Project reported that of the 10,000 English teachers, barely over 50\% were certified. The situation was made worse by the high number of bilingual teachers who left (and continue to leave) the Island in search of better opportunities and salaries. The base salary for a teacher in PR was $\$ 18,000$ a year in 1997 . This situation has not changed and, in the years 2006-2008, one of the most hotly debated issues in the Puerto Rican press was teacher demands for higher salaries, which had not been adjusted in more than ten years. The "Bilingual Citizens Project" was instituted in a few schools, but was dismissed soon after, because the Popular Democratic Party won the elections.

Education on the Island could be said to be divided along socioeconomic lines, and between public and private schools. In general, economically privileged students attend private schools, while those with fewer economic advantages attend public schools. According to the Puerto Rico Department of Education (PRDE) there were 1,522 public schools in 2003 vs. approximately 100 private schools. Roughly 20 percent of the approximately 800,000 schoolaged children attended private schools. While private school children enjoy the privileges of better facilities and resources, children who attend public schools experience the constraints of 
any system where needs outpace budget levels. In sum, "within the public school system in Puerto Rico 'achieving equity' means countering the differences brought about by class and socioeconomic status. That includes such things as establishing the same level of safety, or aiming to achieve the same high levels of language competence, as can be found among students in private schools" (National Science Foundation, 2003, p. 7).

The public school system in PR has one bilingual education program where the goal is similar fluency in the two languages. However, there are only 12 schools in this program. These schools are part of a pilot plan put into place in 1997 by statehood supporter Governor Pedro Rosselló's administration. In 2005, a bill was presented by Margarita Nolasco, President of the Senate's Education Commission, which called for the development of more bilingual schools on the Island. Within three years of passing the new law, each school district would have at least one bilingual school. One of the main arguments presented by the Commission was the following:

There are social, intellectual, cultural, economic and political circumstances that demand and require the use of English for communication. The Puerto Ricans of today and of the future, in order to be successful in the work force, must have communication skills in English and Spanish. The Government of Puerto Rico is responsible for guaranteeing the progress of its citizens and giving them the tools they need, which includes knowledge of both languages. (p. 3$)^{5}$

The President of the Teacher's Federation, Rafael Feliciano, opposed the bill and stated that English Instruction should be improved in all schools, not just in a few, and equated the existence of these specialized schools to creating a private school system within the public one

\footnotetext{
${ }^{5}$ Commonwealth of Puerto Rico. Senate. S.P. 191, January 20, 2005.
} 
(Primera Hora Newspaper, 2005). The law was never passed, but it was a clear indication of concern for the lack of English attainment in public schools. Partly as a result of this concern, in 2007, San Juan became the first municipality to create its own public education system. One of the main goals of "The San Juan School" is the development of oral and written skills in both English and Spanish.

If bilingualism is to become an option for Puerto Ricans from all social classes, a dramatic reform will be needed in the public education's program of English instruction (Schweers \& Hudders, 2000, p. 70). The results of the "Puerto Rican Tests" (Pruebas Puertorriqueñas) confirm that most public school students are not leaving school proficient in English. These tests are administered yearly by the Puerto Rican Department of Education (PRDE), and measure Spanish, English and mathematics skills. From the year 2002 to 2006, the San Juan Region results showed that between $17 \%$ and 22\% of students in eleventh grade have advanced levels of English, 30\% to 33\% have proficiency in English, and 46\% to 50\% have only basic skills. The other nine educational administrative centers overseen by the PRDE show similar results. ${ }^{6}$

In 2001, the "Education, Science and Culture Commission" of the Puerto Rican Senate produced a 200-page document titled "Final Report on Language in Puerto Rico."7 The Commission, which relied on input from local and international linguists and educators, concluded that although Puerto Ricans want to learn English and value the fact that the public school system promotes learning it, there is a definite distrust of its ability to achieve this objective. Many parents then place their children in private schools, where the potential for

\footnotetext{
6 "Resultados Pruebas Puertorriqueñas" 2002-2005. Department of Education.

7 "Informe Final sobre el Idioma en Puerto Rico" S.R. 1, January, 2, 2001. Presented by Margarita Ostolaza Bey, President of the Education Science and Culture Commission.
} 
acquiring English proficiency increases. Despite the public and private discourse in favor of English, "the Department of Education has not been able to withstand the persistent resistance to this language" (p. 48). Ex-secretary of education César Rey confirmed this resistance: "Why is it that when people talk about English they always refer to it as 'el difícil' [the difficult one]. Puerto Rico has shown that it will not renounce its language. There has been resistance to assimilation" (Delgado, 2007).

\section{Private Schooling}

Pousada (2000) reported that it is common for many high school students to enter the university lacking sufficient proficiency in English to carry out the most basic communicative functions (p. 104). Despite this situation, Pousada was amazed by a small but significant group of students who mastered English and used it effectively. She also mentioned numerous professors of all intellectual and ideological persuasions at the University of Puerto Rico campus who could be characterized as competent bilinguals. ${ }^{8}$ In order to determine the overall parameters of this situation, she selected 30 bilingual individuals connected to the university and carried out in-depth interviews in an attempt to isolate the factors that played a critical role in their development and maintenance as bilinguals.

Pousada found that among the personal factors involved in their linguistic formation, school was by far the most important factor. In second and third place were personal talent and travel experiences. Parents and occupation ranked in fourth place. Place of residence, marriage, political ideology, military service, and child-rearing were very important to 27 percent or less of the sample (p. 111). These findings called for a more thorough examination of schooling in the linguistic development of participants. Pousada confirmed that "it is almost a truism at the

\footnotetext{
${ }^{8}$ Pousada defines competent bilinguals as highly functional bilinguals, equilinguals or balanced bilinguals.
} 
University of Puerto Rico that public school students do poorly in English, and private or Catholic school students do better" (p. 112). In fact, most of the competent bilinguals in her study attended private and Catholic schools. However, we cannot conclude that all Catholic or private school students do better in English, since many also fail to attain high levels of English proficiency.

Although the socioeconomic elite in PR is most likely to become bilingual, the motivation for learning English is a conflictive, complex construct even among students in the upper classes. Many have the opportunity to learn English in private institutions, but still do not become bilingual. Torruellas (1990) set out to understand the reasons why Puerto Rican students with the best of educational opportunities would not leave school with a thorough knowledge of their second language. She explored ideological, pedagogical and social factors bearing on the teaching and learning of English in three private Catholic schools. (The medium of instruction in these schools is Spanish, with English as a preferred subject.) One of the schools was Colegio San Juan, ${ }^{9}$ which catered to the highest social class and produced students capable of communicating effectively in English. Students from the other two schools showed poor command of English. Torruellas made key observations of classroom behavior at Colegio San Juan. Teachers at this school did not attempt to depoliticize English and emphasize its "universality." Instead, they presented English as the language "of the United States," which students needed to master if they wished to obtain a professional education there. They also made it clear to students that learning English did not mean that they had to give up their Puerto Rican identity. "The perception of English and Spanish as distinct, yet complementary languages would partly explain why Colegio San Juan students do not experience a strong conflict in their

\footnotetext{
${ }^{9}$ The author changed the names of the schools to protect their anonymity.
} 
values regarding the learning of English" (p. 299). But these teachers' encouragement and approach was not the only factor that influenced students' motivation to learn English. These children and young adults were also aware that their family and school expected them to continue their education in the United States, and to be employed in the highest paying professional fields, both of which require the mastery of English (p. 302).

Torruellas' analysis opened an excellent window into the dynamics of English learning on the Island. All three schools transmitted the dominant ideology of English as an important social asset. However, in two of the schools, a large number of students subverted this ideology through their "expressive opposition" to English in their English classes. They rarely spoke English in their classes, and, for many, proficiency levels in high school were akin to that of beginning language learners. Students in these two schools took on the same antagonistic stance to English observed in the larger social context (p. 291-292). Yet, the students in the most socially elite school did not oppose, but reinforced, the dominant school paradigm of the significance of English learning. This student culture developed in response to their class-based intuitions as to how prominent English would be in their future success (p. 8). Torruellas emphasized that the advantage which Colegio San Juan students enjoy in learning English is "not purely an educational question, but an important social issue. It stems from students' particularly elite status, and bears on the transmission of social privilege in Puerto Rican society" (p. 307).

In Colegio San Juan's classrooms, Spanish and English were viewed as complementary languages, while the other two schools mirrored the contradictions in the larger society. At some point, consciously or unconsciously, the students observed by Torruellas in Colegio San Juan must have put aside the view of English as an imposed foreign element, and replaced it with a view of English as a positive resource. This is an example of "additive bilingualism," which has 
been defined as the ability to study a second language without feeling that one's identity is threatened, but rather as a recognition of the value of biculturalism (Lambert, 1979, p. 191). In Lambert's study, middle class Anglo-Canadians were highly successful in the acquisition of French. These students belonged to "high prestige ethnolinguistic groups" who were culturally stable, highly motivated and supported by homes where parents recognize the values of biculturalism.

Another of Torruellas' observations is of great significance to the present study. In Colegio San Juan, students often inserted phrases in English during conversations in Spanish, and took pride in their advanced linguistic abilities (p. 297). Codeswitching here was a reflection of the positive views of both languages and their acceptance in students' communicative repertoire. A mixture of class values, excellent learning opportunities, scholarly effort, professional goals, and continued exposure to the language, may have contributed to the balanced bilinguality which gave way to students' ability to mix English and Spanish in conversation.

At this point, it would also be useful to consider the concept of investment in second language learning, developed by Pierce (1995). "When learners invest in a second language they do so with the understanding that they will acquire a wider range of symbolic and material resources, which will, in turn, increase the value of their cultural capital" (Pierce, 1995, p. 17). Bilinguals in the most socially elite schools in PR seem to invest in learning English because they have internalized the idea of English as a symbolic resource, a form of cultural capital (Bourdieu, 1991, p. 170). For Bourdieu, linguistic utterances always have a value, and some have more value than others. Puerto Ricans of the highest socioeconomic levels understand the symbolic power of English, and this translates into their perspectives on learning this second 
language. As demonstrated by Torruellas' in-depth study of classroom dynamics in elite schools that cater to the highest social class, the disposition to invest in learning English is based, for the most part, on an awareness of the continuation of their privileged position among the more affluent and influential groups.

Before ending our discussion on schooling in PR, I will add one more element to the equation. Among the approximately 100 private schools on the Island, there are at least ten schools, mostly in the San Juan metropolitan area, that set themselves apart from the others in their emphasis on English. Most of these schools have English as the medium of instruction, and Spanish is taught as subject. They are also expensive for the average Puerto Rican. As of 2008, tuition at Saint John's School in San Juan could cost up to $\$ 12,000$ a year, plus the cost of books, fees and other expenses. Baldwin School in Guaynabo could amount to $\$ 10,000$ in tuition, plus a building fund of $\$ 1,600$, and other expenses. The student population of these schools is composed mainly of children of American executives who come to Puerto Rico for work reasons, and of Puerto Rican children who belong to families that can easily afford them, or manage to do so in the hope that their children will receive a strong English education. A concern for some parents who send their children to these schools, especially Puerto Rican ones, is that children develop their English at the expense of their Spanish. Although in PR the percentage of students who become English dominant through schooling remains significantly low, their presence in society is one more indication of the class division of language on the Island.

Some institutions in PR, most of them private, appear to have been successful in producing student populations with proficiency in English. Nevertheless, we cannot assume that those students who went to a "good" school automatically become bilingual. The interaction of 
many factors will ultimately influence who becomes bilingual on the Island. We may safely infer that many who do become bilingual have invested in the learning of English, be it during their formative years or later on as adults, as we shall see later on in this dissertation. 


\section{Chapter 3: Language Dynamics in PR}

There are four topics pertaining to language dynamics in Puerto Rico that merit further explanation. A better understanding of the social factors behind the distribution of linguistic repertoires on the Island is crucial for further discussions of codeswitching, as manifested in this particular context. The first issue we must address is the failed bilingualization of the Island, and the reasons that have been put forward to explain this situation. Some of the main factors that have influenced, and possibly continue to influence resistance to learning English are: motivation, hispanicity ideologies, politics and conflictive attitudes toward English. Second, the topic of language in Puerto Rico entails a discussion of language ideologies, especially that of Spanish as a central component of Puerto Ricans' national identity. The third area of importance is the composition of PR's linguistic market, that is, how the economic climate is linked to linguistic performance. The concept of "elite closure" will help clarify the class character of language use in PR. Finally, we cannot ignore the significant role of the intelligentsia and the media in shaping language ideologies on the Island.

\section{Negative Motivation}

Many linguists and educators have addressed the failed bilingualization of the Island (Barreto, 1995; Clachar, 1997; Clampit-Dunlap, 2000; Figueroa, 1972; López Laguerre, 1997; López Morales, 1998; Negrón de Montilla, 1975; Nickels, 2005; Resnick 1993; Shweers and Hudders, 2000; Schweers and Vélez, 1992; Torres González, 2002; Vélez, 2000; Walsh, 1991). The United States was successful in assimilating territories like Guam, the Philippines, the Virgin Islands and Hawaii, but Puerto Rico presents a different case. English penetration has not had a significant effect on the Island, both by number of English speakers and by English 
achievement in most schools. The overwhelming majority of Puerto Ricans has always had and, it seems, will continue to have, Spanish as their native language. In 2005 , only $15 \%$ of the population reported speaking English "very well" and, if we consider only those people born in Puerto Rico, the number went down to 13\% (Census Data, 2005).

Although there is a near consensus among the Puerto Rican people with regard to the utility of English as a language of wider communication, few actually master the language. The "Final Report on Language in Puerto Rico" (2001) listed several of the main problems affecting English learning:

1) Elementary school teachers are not specialized in English, and some resist the language because they do not master it.

2) Deficiencies in the process of teacher certification for English teachers.

3) Shortage of English teachers, which results in lack of preparation to teach the subject. Some English classes are taught in Spanish.

4) Wrong methodologies. English is taught as a first language, which is not congruent with the Puerto Rican context.

5) Texts also respond to the teaching of English as a first language. Teachers themselves do not understand them well, let alone the students.

6) The teaching of English is homogeneous and ignores the diverse socioeconomic background of students. Support for English learning at home is basically nonexistent for a high percentage of students. Problems of poverty and illiteracy put these students at a disadvantage.

7) There are no opportunities for practicing English outside the classroom. 
8) English instruction focuses on grammar and not on the development of communication skills, which could be a result of teachers' lack of mastery of the language. (p. 49)

Resnick (1993) stated that many studies, like the one cited above, have been commissioned to investigate the failure of the language policy of bilingualization in PR, and they all come to the same general conclusion: deficiencies in textbooks, inefficient methods, and lack of teacher preparation (p. 265). However, he identified deeper reasons why Puerto Ricans resist learning English: 1) There is no need for another national language, 2) There is a nationalistic loyalty to Spanish (p. 267), and 3) There is fear that language shift may lead to language loss in favor of English (p. 269). While the public school system may benefit from improvement, the reasons why the majority is not learning English may lie in motivation. As Resnick explained, "motivation transcends methodology, since the ability of the Puerto Rican culture to withstand the spread of English has been stronger than the ability of language planners to bring about the planned spread" (p. 271). The role of motivation in language learning cannot be ignored. In many cases, speakers are motivated to learn that which they need to learn, and language needs for the average Puerto Rican may be met with only Spanish: "Puerto Ricans have never seen a real need for a second national language. The internal linguistic needs of Puerto Rico have always been met with just one common language appropriate for all spoken and written registers and domains" (Resnick, 1993, p. 267).

Clachar (1998) provided an explanation for the failed bilingualization of the Island by considering the effects of imperialism on second language learning. She compared the Puerto Rican situation with that of Estonia. Both have strong nationalistic traditions, but have responded in dramatically different ways to the pressures of learning English and Russian respectively. In 
Estonia most people became fluent speakers of Russian in a relatively short period of time, and with less favorable attitudes toward Russian than those found in PR toward English. Clachar concluded that the unsuccessful anglicization of PR is due to the following factors:

1. Linguistic tolerance vs. linguistic hegemony — Soviet language policy initially supported Estonian and other national minority languages. By contrast, in Puerto Rico, U.S. language policy was openly assimilationist from the very beginning (p. 104).

2. Instrumentalities of tight control vs. non-totalitarianism - The Soviet government put into place an elaborate system of controls which enforced compliance with the technical issue of learning Russian. Russian was used in administration, and great importance was placed on language teaching methods. Meanwhile, the U.S. government focused on language policies that forced the Puerto Rican population to adapt to an agrarian capitalist economy. Learning English became synonymous with U.S. imperialist domination and the erosion of the Puerto Rican cultural identity (p. 106).

3. Industrialization and mass media - In the domains of industry and mass media, there was a significant increase in the functions of Russian as a lingua franca between Estonia and other nationalities of the Soviet Union (p. 113), while in PR, English was used to support the new face of capitalist expansion. Knowledge of English became essential only for the elitist segment of the population with direct contact with Americans, thus reinforcing the learning of English as promoting class differentiation and imperialist ideologies (p. 114).

The failure of the colonizing agenda of the U.S. at the turn of the twentieth century gives us a clue to the resilience of the Puerto Rican culture, especially with regard to language. In order to implement this agenda, it was necessary to ignore the notion of Puerto Ricans as a group of people with a distinct culture and ideals already in place. This was not easy, since five 
hundred years under Spanish rule had already shaped the linguistic climate of PR, in which Spanish was the preferred and legitimate language. Puerto Ricans were not ready, and still today appear not to be ready, to change this: "The Island continues to maintain a very separate cultural identity, marked most distinctively by the use of the Spanish language in all societal domains" (Clampitt-Dunlap, 2000, p. 25). While this statement is true for most Puerto Ricans, the present study brings our attention to the presence of English, intermixed with Spanish, in casual spoken registers among certain networks of speakers. As they learn English, these speakers do not participate in the widespread negative motivation to learn this language. On the contrary, they have a strong motivation to succeed in becoming bilingual. These individuals have a strong sense of belonging to the Puerto Rican culture, and Spanish is their native language, but they differ from the average Puerto Rican in their advanced bilingual skills and linguistic practices. One of the issues that will be explored in later chapters is how English use may influence informants' conceptions of national identity. In light of the widespread association of English with "theyness" and Spanish with "we-ness" on the Island, it will be imperative to discover whether codeswitching serves to index or foreground an "American" identity, and explore the relationship between language use and participants' conceptualizations of Puerto Rican national identity.

\section{National Identity}

The concept of national identity is based on the prevailing political organization in the world today. Individuals who are said to belong to a "nation" typically share a common identity. Within this national identity there may be a common culture, religion, descent and language. Although Puerto Rico is not an independent political entity, Puerto Ricans refer to their island as their "nación" [nation] or "país" [country]. Nevertheless, there is a certainly ambiguity in the use 
of the term "nation," and some even identify the Island as a "state" (López Morales, 1998, p.

193). Also, many Puerto Ricans resist referring to the Island as a "colony," while others use this term openly, and assert that the Island has had more than half a millennium of colonial history, which started with the Spaniards and continues to this day (Trias Monje, 1999, p. 1). Puerto Rico is officially a commonwealth or "semi-autonomous territory" of the United States. ${ }^{10}$

Despite its close relationship with the United States for more than a century, and an everpresent process of "Americanization," the Island has maintained a unique and separate character and a strong allegiance to Spanish: "Some aspects of the American cultural life have infiltrated Puerto Rico. However, the Island's identity remains quite distinct from the various cultures of English-speaking North America" (Barreto, 1995, p. 70). There is a wide array of distinguishing features that make up the Puerto Rican national identity. Examples are: the national food (cocina criolla) which includes rice and beans, plantains and roasted pork; local holidays (patron saint festivals, Three Kings Day, Discovery of Puerto Rico); music (bomba, plena, danza, salsa) and language (Spanish, with unique characteristics such as phonological features and African and Taíno vocabulary). ${ }^{11}$ Sepúlveda (1993) noted that language is perhaps the most important element of nationalist sentiments on the Island: "With limited sovereignty, a large part of its territory used for military bases ${ }^{12}$ and an economy that is totally dependent on the continent, national identity has made defending its cultural traditions and language the most important element of self-determination" [my translation] (p. 462).

\footnotetext{
${ }^{10}$ The United Nation's Decolonization Committee has addressed Puerto Rico's case since 1972.

${ }^{11}$ Taíno is an arawakan language originally spoken in Puerto Rico. The Taínos called their land "Boriquén" which means "the land of the mighty Lord." All Puerto Ricans or "Boricuas" know the term "Boriquén" or "Borinquen" and use it in songs and poems as an endearing name for their Island.

${ }^{12}$ In May, 2003 Puerto Ricans celebrated the end of nearly 60 years of U.S. bombing exercises in Vieques, a small island-municipality of PR in the north-eastern Caribbean with a population of approximately 10,000.
} 
In her 1995 book about Puerto Rican culture, politics and identity, Nancy Morris examined national identity through the eyes of political elites. She interviewed politicians and young activists in order to explore their experience of national identity, and to understand the extent and nature of U.S. influence on their Puerto Rican identity. Participants in her investigation represented the main political ideologies on the Island: statehood, commonwealth and independence. One of Morris' main arguments was that, contrary to commonly held assumptions, external pressure on collective identity may strengthen it rather than diminish it. Despite the ongoing substantive and symbolic conflicts over such issues as language and political structure, Puerto Rican identity has remained distinct, while adapting to the pressures placed on it (p. 7).

In the data gathered by Morris, the most consistently cited element of Puerto Ricanness was the Spanish language. It was a defining aspect of identity for respondents of all political views. Statehood supporters were less likely to rank Spanish as an element of highest importance to their conception of Puerto Rico, but they did not dismiss language, and confirmed its importance even when defending the use of English on the Island. The following citations in Morris' book reflect how significant the Spanish language is to Puerto Ricans:

Statehood supporter: "We are not going to renounce our Spanish for anything in the world, ever."

Statehood supporter: "As a Puerto Rican I participate in some common experiences with other Puerto Ricans, such as the vernacular, the language that defines me and characterizes me as Puerto Rican" (p. 82).

Commonwealth party interviewee: "No doubt the principal expression of our culture is our language, our Spanish language." 
Commonwealth party focus group: "[the language] is the essence of the Puerto Rican."

Independence party focus group: "There is something fundamental, which is our

language. That comes first of all."

University of PR focus group: "The language is primordial, because that is what identifies us."

Commonwealth focus group: "Our language, Spanish, is a thing that distinguishes us...

We couldn't be Puerto Rican speaking “American”, that is, speaking English.” (p.

Morris also found that there was a clear perceived threat of displacement in discussions of language, which was considered central to her informants' sense of identity. For many, this translated into an overt and covert resistance to the English language. The power of Spanish as a defining element in Puerto Rican identity was “evidenced by respondents' repeated references to an attempt by the US to impose English as a language of instruction in schools, an issue that continued to resonate forty-two years after Spanish was reinstated as the school language" (p. 144).

Further proof of the major role of Spanish in the construction of a national identity for Puerto Ricans is the importance Puerto Ricans living in the United States give to this language. Several studies have thoroughly and systematically explored the linguistic behavior of Puerto Rican communities in the United States both from a linguistic standpoint (Poplack 2000; Torres 2002; Zentella 1982) and in relation to identity (Zavala, 2000; Zentella, 1997). Other studies have explored language use by Puerto Rican return migrants on the Island (Clachar, 1997; Clachar, 2000; Haiman, 1993). All of these investigations mention Spanish as a marker of a distinct Puerto Rican identity, irrespective of place of residence. 
Communities in New York are among the most studied by linguists interested in investigating U.S. Puerto Ricans' use of Spanish. This language is used in the community as a way to construct a primary ethnolinguistic identity separate from the mainstream standard English-speaking identity. Zentella (1997) pointed out that children are encouraged by the community to use English and Spanish in conversation in order to weave their bilingual identity (p. 15). She also emphasized the prominence of codeswitching as a marker of bicultural identity. Frequent embedding of small constituents in Spanish "had the effect of continually reasserting and recreating children's dual New York-Puerto Rican identity. Because they had a foot in both worlds, they never spoke in one for very long without acknowledging and incorporating the other, especially in informal speech" (p. 120). The exclusive use of Spanish was not a possibility for the community Zentella studied, given that most of the children attended English speaking schools. Therefore, without the choice of communicating fully in Spanish, codeswitching became the marker of their Hispanic identity. Far away from their homeland, Puerto Ricans in the U.S. have always held on to Spanish, as a reminder of their heritage, and as an effective way to find a sense of belonging.

Back on the Island, linguistic needs are influenced by a sociocultural nationalism which has Spanish as a central component. According to Clachar (1997), Puerto Rican nationalism has been considered as the most incisive explanation for resistance to the study of English leading to a successful bilingualization of the Island (p. 70). It is believed by many that learning and using English, "the language of the United States," may at some level endanger not only Spanish itself, but the core of their nationality.

Thus, English and Spanish are metaphorically paired as irreconcilable adversaries and Puerto Ricans are challenged to defend their heritage and vernacular. From the 
perspective of Puerto Ricans who view the issue in this light, the learning and use of English and an official policy of bilingualism represent a genuine threat to the survival of Puerto Rican culture (Schweers and Vélez, 1992, p. 14).

There are contradictory pressures: Puerto Rican national identity and U.S. influence. These pressures are manifested in a widespread, established, protective attitude toward Spanish against the intrusion of English. Of interest to the present study is how elite, educated, Puerto Rican bilinguals sort out these contradictory pressures, and interpret prevalent linguistic ideologies. What is the role of Spanish in shaping national identity? What does English have to do with who they are as Puerto Ricans? Answers to these and other questions, will open a window into how participants assimilate or contest established ideologies through language. This in turn will reveal the social meanings of their linguistic practices, and especially what they mean in terms of national identity.

\section{Ideological Discourse}

There are three major themes in the Puerto Rican ideological discourse: national pride, political status, and language. "Of the three, it has been in the defense of Spanish where islanders have been able to generate what approximates a true consensus" (Velez, 2000, p. 14). Solís Jordan (2000) also recognized the ideological importance of issues of language on the Island: "Defending the extreme importance of Spanish is a matter of self-preservation, while advocating English is seen as a matter of rational development and possibility" (p. 165). Thus, ideologies that foster intergroup distinctiveness may be responsible for the blocked spread of English and the continued defense of Spanish, despite English's obvious economic and social advantages. There seem to be conflicting ideologies, given the desire to preserve the Spanish language on the 
one hand, and the perceived instrumentality of learning English, on the other (Clachar, 1997, p. 94).

The uncertain political status of PR is closely related to language issues. Politics plays a major role in the lives of Puerto Ricans. In everyday conversations, and especially every four years when a new governor is chosen, heated debates are common among those who want statehood for the Island, those who want to become an independent nation, and those who want to maintain the Commonwealth status. Debates over political ideals are often linked to language. This can translate into resistance toward English, which, for the independence supporters, represents closer ties to the U.S. Ironically, Commonwealth, and even Statehood supporters, who would be expected to support English, end up resisting it also, and have insisted that Spanish should continue as the dominant language under either status (Solís Jordán, 2000, p. 166).

One case worth comparing to the Puerto Rican situation is Hong Kong. Tsui (2004) recounted that Hong Kong had been under British colonial rule for more than 150 years until, in 1997, China regained sovereignty (p. 97). English had been the official language until 1974 when it was changed to Chinese, after considerable public pressure. Under British rule, children were taught in Chinese in primary schools and in English in secondary schools. In 1990, a government advisory committee recommended that the mother tongue should replace English as the medium of instruction in secondary schools (p. 98). When this policy was announced every sector of the community opposed it. Parents thought their children's future would be jeopardized, and the business sector claimed that a decline in English standards would compromise the city's economic competitiveness. Tsui suggested pragmatic and political reasons for this reaction: "Most people in Hong Kong see English not as the language of colonization but as the language of international commerce, and many see mother tongue education as a sign of narrow 
nationalism that suggests that even the act of learning a language other than the mother tongue means that one is no longer truly Chinese" (p. 109). Hong Kong's linguistic situation is too complex to be fully expounded here, but this last statement is relevant to our understanding of Puerto Rico's case. Parents and students on the Island have traditionally thought of English, the language of the colonizer, as a tool for a better economic future. Nonetheless, unlike the people of Hong Kong, many Puerto Ricans have also seen English as a threat to their cultural and nationalistic integrity. One end result of this view is resistance to learning it.

Nationalistic pride and hispanicity ideologies may have much to do with the negative attitudes toward learning English. "It's a case of being damned if you do (you're betraying your Hispanic heritage and giving in to the forces of Americanization from the North) and damned if you don't (you're severely limiting your potential for socioeconomic mobility)" (Schweers \& Vélez, 1992, p. 13). For many Puerto Ricans, there seems to be an ideological rivalry between the two languages, where Spanish is the language of PR and English is the language of the United States, rather than the language of other countries around the world and the lingua franca of many others. This view is influential to the current status of English on the Island since, for many, accepting English equals the death of Spanish, which in turn threatens the very essence of Puerto Rican identity (Clampitt-Dunlap, 2000, p. 26).

Thus, there seem to be contradictions in attitudes toward English on the Island of Puerto Rico. From one standpoint it is seen as an imposed language that threatens Spanish, identity and culture, and from another standpoint it is obvious that English has political and economic power. "The relationship between Spanish and English in Puerto Rico has often been conflictive and also highly polarized. For this reason their relationship is frequently represented as the 'battle of the languages"” (Torres-González 2002, p. 387). These conflicting ideologies have found their 
way into classrooms throughout the Island and may be a factor in students' lack of proficiency in English. Societal bilingualism in PR may be faced not only with language planning obstacles, but also with ideological ones.

Going back to the Hong Kong example, in this former colony, the prevailing ideology is that of English as a commodity that everybody desires. Parents see English as the golden passport to a successful future for their children (Tsui, 2004, p. 110). All of the bilinguals interviewed for this dissertation also think of English as absolutely necessary for their professional achievements, and that of their children. These Puerto Rican bilinguals do not partake in what could be considered a "narrow nationalism" that would contribute to blocking their knowledge and use of English in PR. The presence of English in these speakers' linguistic repertoire is indicative of their success in circumventing the prevailing political and ideological discourse against English. A series of factors unique to their immediate social milieu allow for this apparent "immunity" to the complex political and ideological context that surrounds them. One important factor is their socioeconomically privileged position.

\section{The Linguistic Market}

In the previous chapter we mentioned the concept of cultural capital (Bourdieu, 1991). Linguistic competence (like any other cultural competence) functions as capital (Pachev, 2002, p. 2). The English language, as cultural capital, enjoys a privileged position within the PR "linguistic market." Those who know this language well have a definite advantage when it comes to education, occupation and social mobility. One has only to open the employment section of the main newspaper of the Island, El Nuevo Día, to find that a significant number of jobs listed require English proficiency. Furthermore, the highest paying professions require high proficiency in the language, not just basic skills. The situation we find in Puerto Rico, is that 
English has traditionally been a scarce form of cultural capital, in part reserved for the highest social classes. There is a type of "elite closure" where those persons in power maintain their privilege via linguistic choices (Myers-Scotton, 1993b).

The connection between language use and material conditions has been explained in the work of linguists such as William Labov (1972), who studied variations in speech according to the speaker's socioeconomic class, among other variables. Another familiar construct in sociolinguistics is the view of a speech community as having a repertoire of ways of speaking that may be indexically associated with social groups, roles and activities. There are many studies on how linguistic diversity indexes social diversity (e.g. Irvine, 1989). However, fewer studies "attempt to explain the correlation, why a particular linguistic variety should mark a particular social group" (p. 251). Reviewing the historical trajectory of Spanish/English in Puerto Rico has helped us understand the reasons why English and Spanish have come to be associated with certain ideologies and social groups, and how the linguistic market of the Island has come about. I have shown that there are historical processes unique to the Island that have influenced its linguistic climate and the formation of distinct social groupings associated with different linguistic outcomes. This situation occurs in part because linguistic differentiation and social differentiation are not arbitrary. They bear some relationship to a cultural system of ideas about social relationships, including ideas about the history of persons and groups (Irvine, 1989, p. 253).

The focus of this study is the practice of codeswitching by a group of Island Puerto Rican bilinguals. Blommaert (1992) argued that codeswitching may be stylistically motivated, and that it always has a larger dimension consisting of group relations. He studied the informal in-group speech (termed Campus Kiswahili) of the academic staff at the University of Dar es 
Salaam in Tanzania, because he was struck by its systematic mixing of Swahili and English, a language learned as a subject in school. Speakers of Campus Kiswahili employed a linguistic repertoire that was not accessible to all members of their society. Thus, Blommaert emphasized the social side of codeswitching and its contribution to group relations. He found that codeswitching signaled a social identity that was not purely situational or a one time phenomenon but it was "bounded by larger-scale structures that have to do with the historical development of social differences in Tanzanian society" (p. 68).

The concept of "elite closure" (Myers-Scotton, 1993b) may help us understand the presence of different English competencies in PR. This type of social mobilization strategy is potentially present in all communities in the world. It is accomplished when the elite successfully employ official language policies and their own nonformalized language usage patterns to limit access of nonelite groups to political positions and socioeconomic advancement (Myers-Scotton, 1993b, p. 149). There are three sociolinguistic universals which make elite closure possible:

a) Not all people in the same community speak the same linguistic varieties.

b) The linguistic varieties in use in any community are generally allocated to different situational uses.

c) All varieties are positively or negatively evaluated by community members, according to their use in a specific type of interaction. (p. 149)

There may be a form of elite closure in PR, since most Puerto Ricans learn the basics of the English language, but only a few achieve a high level of proficiency. Although the elite do not straightforwardly limit access to English, the language has become a commodity reserved to those privileged members of society who have access to certain educational opportunities, who are aware of the opportunities this language may provide, and who are in a position to reap those 
benefits. We should not forget that during the first five decades of American rule in Puerto Rico, there were many disruptive changes in the public school system from Spanish-medium to English-medium, especially in the lower grades. However, "at the secondary level, where the economically affluent (the elite) had access to higher learning, there was a stable and consistent language policy to use English as the medium of instruction - a factor which conferred prestige and status on the English language and created an environment in which English became associated with social class differentiation and elitism. (Clachar, 1998, p. 111). The effects of this elite closure are evidenced by the lack of English fluency in the lowest socioeconomic levels of society and the failed bilingualism of the Island.

One crucial point in Myers-Scotton's argument was that lack of access to a linguistic variety needs to be present in order for "strong" elite closure to be present. Myers-Scotton listed three requisites for strong elite closure: "a) when the varieties necessary for socioeconomic mobility are nonnative for many, b) when universal education is not available, and c) when those varieties are not taught extensively in schools" (p. 152). The first requirement can be found in Puerto Rico. English is indeed the language associated with economic mobility, and it is nonnative for the majority of the population. The last two requisites are not met straightforwardly, but still have some application in the Puerto Rican context. There is English education in schools available for all, but availability does not transfer into learning and mastery of the language.

There is one more element in Myers-Scotton's analysis that is useful to our understanding of the linguistic situation on the Island. The researcher stated that in many cases the nonelite unconsciously choose not to acquire a language because they see that the costs are higher than the rewards. Knowing only the official language (or the language of power) "does not benefit them if they do not posses a package of attributes, of which linguistic repertoire is only one part. 
Other crucial attributes are the 'right' school, the 'right' level of education, and above all, the 'right' social network" (p. 154). We have learned that most competent bilinguals in Puerto Rico are individuals who meet the following criteria: a) they have attended the "right" elite private school (Torruellas, 1990), b) they may not have attended an elite school, but they have achieved the "right" level of bilingualism (Pousada, 2000), and c) they belong to the "right" social network, which encourages fluency in English, as it is required for the highest paying jobs and professional opportunities (Resnick, 1993). Although the Puerto Rican nonelite recognizes the prominent place of English in its linguistic market — namely, it is necessary for international communication, socioeconomic mobility, and university study, among other benefits- this segment of society may be unconsciously choosing not to learn English. The reasons for this resistance or negative motivation, as discussed earlier in this chapter, are complex and may include "a belief that the costs are higher that the rewards" (Myers-Scotton, 1993b, p. 154). Most Puerto Ricans seem to believe that their investment (Pierce, 1995) in learning English will not produce enough benefits or future rewards. Resnick (1993) explained the limited functions and domains of English on the Island:

For the vast majority of the residents of Puerto Rico, the need for communicative competence in spoken English is and always has been minimal. The Puerto Rican can live his or her life perfectly well, raise a family, progress economically and socially, participate in the institutions of the Island, all without speaking English. Up to a point. The best professions require fluency in English: advertising, executive management, executive secretary, law, medicine, technology, and so on. (p. 269) Codeswitching could be considered a reflection of the workings of the PR linguistic market. The balanced bilinguality which underlies the ability to mix English and Spanish in 
everyday conversation is closely related to an elite status of a socioeconomically privileged network of speakers. Later chapters will revisit the concept of elite closure and further explore how it relates to the social interpretation of speaking styles and the creation of in-group identity. Let us turn now to a final discussion on the intelligentsia and the media, which have had a notable effect in shaping the Puerto Rican linguistic market.

\section{The Intelligentsia and the Media}

Intellectuals have occupied a privileged position in PR, and have assumed a big responsibility in terms of language issues because they serve as authority figures who master linguistic capital. In his interview for the present study, Alberto (34), said that he does not worry about the preservation of the Spanish language because "that's up to those who care about the language, those who work at the university." Similarly, Janet (34) said that she does not think codeswitching is wrong, but her teachers would be very upset if they heard her mix the two languages. Most informants have a sense of the "correct" way of speaking Spanish, and recognize the intellectuals who are responsible for preserving and promoting it, including professors, teachers, linguists and writers.

The unilateral imposition of English following the arrival of American troops on the Island in 1898, and throughout the first half of the twentieth century, disturbs many intellectuals who are sensitive to PR's political and potentially linguistic subordination to the United States. The old policies which may be characterized as linguistic imperialism are considered an offense to Puerto Rican dignity, a sign of U.S. arrogance, and a result of a belief in racial and cultural superiority. Many feel that the presence of English in schools is a constant reminder of PR's continued colonial status (Schweers and Vélez, 1992, p. 14). 
One crucial fact that may have influenced the presence of an intelligentsia eager to defend the cultural and linguistic distinctiveness of the Island is that, unlike most of the other territories acquired by the U.S. during the expansionist period, Puerto Rico already had a highly educated, active group of intellectual elites at the time of occupation. Clampit-Dunlap (2000) wrote that the native intelligentsia at the time may have been particularly influential with the general population because of their public expression of national pride in the mass media and politics. Many leading poets and novelists were also journalists for local newspapers and several also had active roles in the political arena. Thus, they had many channels through which they could defend the language and culture of PR. Defenders of language represented Spanish as an essential element of Puerto Rican ethnocultural identity. Muñoz Rivera, Fernández-Vanga and López-Galarza spoke of Spanish as a reflection of something that was distinctively Puerto Rican. It represented its soul, personality, idiosyncrasy, and history as a nation (Clampit-Dunlap, 2000, p. 30). The role of the intelligentsia was also crucial in resisting the imposition of English in schools. For example, they supported teachers in public schools during the 1930s. The José de Diego Institute, a Spanish school, was named after an influential intellectual who led many others in their struggle against the use of English as the language of instruction. The intelligentsia has also participated in a number of movements defending Spanish. In 1992, for example, they made their opinions known after the law that made both English and English the official languages of the Island was passed.

Clampitt-Dunlap (1995) conducted an in-depth comparative study of the three territories that were ceded to the United States in 1898 as a result of the Spanish-American war. This study confirmed the powerful influence of the intelligentsia in the outcome of English imposition in Puerto Rico at the turn of the twentieth century. She found that these three places exhibited three 
of the possible scenarios that can result from the language contact phenomenon. In Puerto Rico the native language was maintained in all societal domains; in the Philippines, English was adopted in specific domains while the vernacular and national languages occupied others; and in Guam English became the language of almost all societal domains, while fluency in the native language, Chamorro, decreased as a result of English influence (p. 201). Clampitt-Dunlap concluded that in spite of almost identical plans to spread English through the school system, the different outcome in Puerto Rico may have been due to the presence of an educated group who played a policy-making role and contributed to a collective awareness about the need to preserve the native language. Preserving Spanish was equated to preserving the national identity (p. 206). "Only in Puerto Rico was there a negative connotation associated with English together with a firm defense of the native language. There was a clear sense of menace attached with the presence of English on the Island" (p. 207).

In her dissertation on the attitudes of intellectuals in PR toward Spanish and English in the past century, Falcón (2004) described the emancipatory/self-empowering discourse of this community, where Spanish has been closely tied to a Puerto Rican identity. As we know, the coexistence of English and Spanish on the Island has been traditionally seen by many as a threat to Puerto Ricanness. In light of the recent movement from essentialist conceptions of national identity to a more constructivist approach, Falcón set out to explore if Puerto Rican scholars still uphold a belief in the link between language and nationalism. She found that although the linguistic-nationalistic discourse operates on a more implicit and less explicitly alarming level, there are areas in which it has remained fundamentally unchanged. Intellectuals on the Island still appear to unyieldingly link Spanish and Puerto Rican identity (p. 125), a link that in turn serves as a statement of cultural and political separateness in the face of U.S. hegemony on the 
Island. Unlike other contemporary communities willing to define their identity in heterogeneous ways, many Puerto Rican intellectuals remain resistant to embracing new, hybrid identities. "It is understandable that, in the face of such shifts, nationalists in a situation of colonialism, where language and culture have been such a powerful symbolic mainstay of their identity, will appear to persevere in their support — be it implicit or explicit— of what they have stood for over the course of several generations" (p. 138). Falcón concluded her dissertation by reflecting on the fallacy of linguistic unity on the island: "The truth is that the notion of a unified Puerto Rican Spanish on the island has effectively ignored regional, class, gender and even racial differences. Therefore, the hegemony of Puerto Rican Spanish is contested and disrupted in many ways within Puerto Rico" (p. 138). The disruption of a "unified Puerto Rican Spanish" is precisely at the center of this dissertation, which highlights how the linguistic practice of codeswitching disrupts the generally expected "Spanish only" discourse mode on the Island.

There is also much to be said about the influence of mass media in the preferences and habits of Puerto Ricans and thus its potential to have an impact in their linguistic practices. The extent to which U.S. influence on national identity has happened through commercial culture and mass media has been a topic of constant debate in Puerto Rico (Morris, 1995, p. 1). There are three main Spanish language daily newspapers on the Island: El Nuevo Día, Primera Hora and El Vocero. The Island's primary English language newspaper, The San Juan Star, closed operations in June of 2008, due in part to low readership and advertising. The Puerto Rico Daily Sun took its place in October, 2008. Its first Editorial read:

Puerto Rico does not deserve to be without an English-language newspaper. Not having one is unacceptable. The premise has nothing to do with politics, weak patriotism or 
being servile. It's pure common sense and based on the need to be fully multilingual as we move on toward $21^{\text {st }}$ century globality.

On the radio, Spanish-language Latin American and local music is heard along with English-language U.S. popular music. Movie theaters show mostly American movies. Only two of them, in San Juan, show Latin American and foreign movies, and only a select audience frequents them. The government recently began to promote and fund the ongoing production of local films, which had been only sporadic in the past.

There is a television set in virtually every home in PR. Since the 1950s there has always been a distinct Puerto Rican Spanish-language mass media production. Local stations transmit Puerto Rican productions, particularly comedies, children's shows, daytime and late-night variety shows and Spanish-language soap operas. Local stations also transmit many dubbed U.S. movies and shows. Cable television is dominated by English language channels originally intended for U.S. audiences, and there are a few international Spanish language channels. Cable television penetration was only about $25 \%{ }^{13}$ in 1996 and most of its subscribers reside in the San Juan metro area. Despite its relatively low penetration, cable TV has been mentioned as a potential threat to the integrity of the Puerto Rican culture (Morris, 1995, p. 142). Indeed, the media has had a tremendous impact on the daily lives of speakers and their linguistic practices. Most of the respondents in this dissertation admitted to being exposed to television, radio and magazines solely in English on a daily basis. Most of them did not watch Puerto Rican shows and only tuned in to cable television programming.

Informants in Morris' study expressed fear that imported television programming may influence young people by easily familiarizing them with U.S. customs and lifestyles. This fear

\footnotetext{
${ }^{13}$ Information found online in The Museum of Broadcast Communication, "Puerto Rico," by Rudolpho B. Popelnick. http://www.museum.tv/archives/etv/P/htmlP/puertorico/puertorico.htm
} 
was coupled with another expressed fear, the displacement of the Spanish language which, once again, many consider as the most important cultural symbol. Morris summarizes her findings regarding the potential pressures on identity through partial integration with the U.S.:

Puerto Rico has imported the cultural products that are held to weaken national identity receiving large quantities of films, television programs, and recorded music from the United States virtually since the invention of those technologies... As much as any society, Puerto Rico has been exposed to forces of globalization, through deliberate coercion, through integration into U.S. market culture, and through continuous exposure to imported media products. (p. 11)

The import of cultural products has had a complex impact on Puerto Rican society. For example, Puerto Rican youths may watch the same movies as American youths, and may include in conversation a few phrases in English learned from the big screen, but they are still very much "Puerto Rican," in that they conserve a separate social and national identity. While U.S. cultural products have greatly influenced the Island, we may question the notion of a "weakening" of national identity. Morris' argument was precisely that outside pressures may have strengthened PR's national identity.

Two opposing points of view influence the ideological climate of the island. On the one hand, the intelligentsia serves as the formal, conservative and non-yielding regulator of linguistic behavior. On the other hand, the media serves as a mainly informal, fluid entity that not only is not interested in regulating language behavior, but contributes to the continued influence of English in PR's linguistic scene. All participants in this study have been influenced in one way or another by the topics discussed in this chapter. Their schooling, socioeconomic position, motivation to learn English, views of politics and nationalism in Puerto Rico, assimilation and 
interpretation of prevailing linguistic ideologies, and exposure to the media, all have had an impact in their linguistic practices and preferences. Not a day goes by in the lives of these individuals without having some contact with the English language through movies, television programs, books, magazines, computers, family members and friends. Most of them use it at work on a daily basis, and virtually all of them have made English a part of their daily lives in the form of codeswitching. The next chapter will provide an overview of codeswitching as a topic of study. The analysis of codeswitching which will be adopted here recognizes its undeniable place in the historical processes outlined in previous chapters. It will emphasize the historicity of each language, which is reflected in everyday language use. 


\section{Chapter 4: Language Alternation}

The use of two or more languages in a given society is much more common in the world than monolingualism. In fact, a third of the world's population routinely uses two or more languages for work, family life and leisure, and there are even more people who make irregular use of languages other than their native one. Here we could mention bilinguals who have learned foreign languages at school and only use them for specific purposes (Wei, 2000, p. 5). The term "bilingual" is commonly used to refer to someone who can function in both languages in conversational interactions. This functionality allows the person to choose from two linguistic codes (languages) depending on factors such as setting, subject matter, and addressee. If the addressee is also a bilingual who possesses a similar linguistic background, it is very common to switch from one language to the other within the same conversation (Wei, 2000, p. 16).

All over the world, there are communities which engage in the practice of codeswitching: English and French in Canada; Wolof and French in Senegal; Cantonese and English in China; Basque and Spanish in Spain; Japanese and English in Japan; Spanish and English in the United States, and many others. Language alternation highlights the heterogeneous nature of linguistic practice, where speakers use grammatical and pragmatic options from two linguistic systems. There are several basic characteristics of codeswitching: 1) It is not random, since it responds to syntactic limitations and pragmatic objectives, 2) It can vary depending on topic, setting, and linguistic competence of speakers, 3) It can be considered a stylistic resource, and a social practice among a network of speakers, and 4) It typically indexes social constructs beyond language itself, such as personal and social identity. In the following sections I will first provide a review of the main approaches to the study of the social meaning of codeswitching, and will then discuss the relationship between codeswitching and identity. Next, I will characterize this 
practice as a socially meaningful style, and finally, I will relate this style with the creation of emergent-flexible identities.

\section{The Study of Codeswitching}

Linguists who study codeswitching often choose to focus on one of two aspects: the grammatical, which deals with the internal structure of the language (syntactic/morphological constraints) ${ }^{14}$ and the discourse/pragmatic, which views codeswitching as a discourse phenomenon, and can include a closer look at the functions of codeswitching in conversation. Among research that has focused on the pragmatic aspects of codeswitching, Gumperz (1982) stands as the most influential work. He provided one of the most widely accepted definitions of conversational codeswitching:

The juxtaposition within the same speech exchange of passages of speech belonging to two different grammatical systems or subsystems. Most frequently, the alternation takes the form of two subsequent sentences, as when a speaker uses a second language either to reiterate his message or to reply to someone else's statement. (p. 59)

In the 1950's, codeswitching was viewed among linguists as a sign of incompetence. Weinreich (1953) described the ideal bilingual as "someone who can switch from one language to another in appropriate speech situations but certainly not in an unchanged speech situation and within a single sentence" (p. 73-4). Codeswitching was far from the ideal. While modern linguists have abandoned the idea of codeswitching as an aberration, many monolinguals and bilinguals still share this negative appraisal of codeswitching, and do not necessarily consider it a

\footnotetext{
${ }^{14}$ This study will focus on the socio-pragmatic aspects of CS. Toribio (2002) lists some of the most influential research that explores the grammatical properties of CS: Gumperz (1976), Gingras (1974), Timm (1975), Wents and McClure (1975), Aquirrre (1977), Jacobson (1977), Pfaff (1979), Poplack (1980), Woolford (1983, 1984), Lipski (1985), DiScullio et al. (1986), Belazi et. Al. (1994), Bhatia and Ritchie (1996), Toribio and Rubin (1996), and Toribio (2000).
} 
constructive skill. Perhaps, like Weinreich and others of his time, many still believe that codeswitching is the result of the inability to master the languages in conversation, instead of fluency in both, or they may simply resist the idea of mixing languages in conversation. "Indeed, in probably the majority of communities where it has been studied, some social stigma has been attached to this mode of speaking by both the community as well as outgroup members, e.g. educators" (Romaine, 1995, p. 291).

A seminal study on dialects in Norway by Blom \& Gumperz (1972) marked the beginning of codeswitching as a respectable research subject. They promoted a positive view of codeswitching, and defined it not as random or inferior, but as a legitimate element of linguistic repertoires of skilled individuals. Both researchers had backgrounds in social anthropology, which explains their emphasis on social relationships as indispensable for interpreting linguistic behavior: "In order to interpret what he hears, the investigator must have some background knowledge of the local culture and of the processes that generate social meaning" (Blom and Gumperz, 1972, p. 434). Five of the main approaches that have been put forward in the study of the social meaning of codeswitching are: the interpretive approach to conversation (Blom and Gumperz, 1972, Gumperz, 1982); the markedness model (Myers-Scotton, 1993a); codeswitching as a social process (Heller, 1988, 1992); codeswitching in class and cultural contexts (Zentella, 1990, 1997); and codeswitching as a conversational practice (Auer, 1984, 1998; Wei 1998).

Once we place codeswitching within the realm of social interaction, Gumperz (1982) posited that bilinguals, like monolinguals, have choices for communication, and codeswitching provides a set of discourse functions, an additional set of strategies, which become part of their communicative repertoire. Codeswitching, as part of this repertoire, is dependent on variables such as setting, situation and type of event, and can be metaphorical and situational. In the latter, 
switching is prompted by a change outside the interaction, be it a change in participants or the social setting. In metaphorical switching the setting stays the same, but what changes are topics, or the subject matter of a conversation (Blom \& Gumperz, 1972, p. 425). Gumperz' extensive fieldwork in communities that include India, Austria, and the United States, made a considerable contribution to the field. His research was based on naturally occurring data and small group interactions. Gumperz found that codeswitching serves basic pragmatic functions for speakers, such as quotations, reiteration, message qualification, interjections, and personalization vs. objectivization, among others. He believes in studying codeswitching while bearing in mind the linguistic norms active in each speech community, since speakers may show different backgrounds and social values that lead them to choose a specific conversational style.

Before presenting her theoretical model, Myers-Scotton (1993a) recognized the value of Gumperz' contribution to the study of codeswitching and provided a useful summary of the premises at the heart of his model: 1) Small group interactions are the proper research site and naturally occurring data are the object of study and 2) The social meanings of language use are a function of situated contexts (p. 56). There is indeed much value to Gumperz' contribution to the study of codeswitching, and in particular to the present project. This dissertation concentrates on small group interactions and on the social meaning of this practice. Its focus on identity creation stems from an interest on the intersection of linguistic signs and social knowledge. Like Gumperz, I believe that to understand "the role of language in social processes in general, we need to begin with a closer understanding of how linguistic signs interact with social knowledge in discourse" (Gumperz, 1982, p. 29).

Going back to Myers-Scotton's framework, she has written extensively on the purely grammatical/syntactical aspects of codeswitching. Concerning its socio-psychological uses, she 
was intrigued by finding patterns in interactions that can be generalized to different communities. Myers-Scotton spent more than twenty years doing research in East Africa. Many of the examples that supported her theoretical standpoints come from codeswitching between Swahili and English. Her markedness model provided a framework from which the social functions of codeswitching may be derived. Within this framework, speakers are aware, typically unconsciously, of a marked or unexpected choice and an unmarked or expected code: "They have a sense of markedness regarding available linguistic codes for any interaction, but choose their codes based on the persona and/or relation with others which they wish to have in place" (Myers-Scotton, 1993a, p. 75). Crucial to the markedness model is the concept of rights and obligations (RO sets) between participants in a given interaction. Unmarked RO sets are derived from whatever situational features are salient for the community for that interaction, e.g. the speaker, the addressee, the topic, or the setting (p. 84). Marked choices are not usual and constitute a dis-identification with what is expected (p. 151).

One of Myers-Scotton's main critiques of studies that addressed the functions of codeswitching based on Gumperz's model is that any attempt to specify all the situational features that will be salient in all speech communities is futile. She claimed that some factors such as social identity of participants, topic and setting, will be present in most determinations of the unmarked or expected RO set, but not all of them can be predetermined. She contended that in all communities, interaction types are more or less conventionalized, and that speakers have some sense of script or schema for how interactions are to be conducted in an unmarked way. (p. 152).

Meeuwis and Blommaert (1994) contended that Myer-Scotton's model could not account for why codeswitching could occur in one segment of a speech community as opposed to another 
segment of the community. They argued that in Myers-Scotton's model the "indexical values of linguistic codes, and the overall social meaning of codeswitching strategies in a specific community, are all a-priori given factors that are simply brought into a conversation" (p. 400). The problem with this conceptualization of codeswitching is that it may result in a static view of indexicality and social behavior where there is no room for potential individual dynamics in a community. The rules for appropriateness of codeswitching and its meaning in interaction cannot be pre-determined. This social phenomenon cannot be completely abstracted and generalized across every community. It is only through an ethnographic anchoring that codeswitching can be better understood. There will always be community specific details that will contribute largely to its practical significance.

\section{Sociological and Interactional Approaches}

Several approaches to codeswitching place greater emphasis on the premise that to understand this phenomenon one must not neglect the relationship between macro-level social processes and linguistic ones. Heller (1988) pointed out that this relationship is important to the researcher on codeswitching because he or she needs to have an understanding of community speech economies. The analyst needs to investigate how social boundaries limit or allow access to linguistic resources, and where individuals are located in relation to these resources (p. 3). She emphasized a double context composed of the speech economy of a multilingual community and the verbal repertoires of individual members of that community. Codeswitching then becomes "an important part of social mechanisms of negotiation and definition of social roles, networks and boundaries" (p. 1).

Heller's work is mainly anthropological and sociological in nature. Her ethnographic studies of French and English in Ontario, Canada, led her to conclude that codeswitching is "tied 
to political economic analysis of the relationship between availability and use of linguistic varieties, on the one hand, and the production and distribution of symbolic and material resources on the other" (Heller, 1992, p. 123). Her analysis builds on Bourdieu's concept of symbolic capital and symbolic market. She conceptualizes codeswitching as a means of drawing on symbolic resources and deploying them in order to gain or deny access to other resources, symbolic or material (p. 124). To illustrate this process, Heller described the boundary-making process related to codeswitching practices in Ontario. People who do not codeswitch lack access to the necessary linguistic resources, or are mainly concerned with maintaining ethnic boundaries, even if they do have access to the necessary linguistic resources. Those who do codeswitch have the right verbal repertoire and feel compelled to exploit it by mixing languages. Heller interpreted these practices in terms of both individual repertoires and political ideologies (p. 130). In the present study I have already addressed the social boundaries that allow or restrict access to linguistic resources in Puerto Rico. In upcoming chapters I will concentrate on the social meaning of drawing on these resources in interaction. I will present ethnographic case studies that address questions on codeswitching as a social process.

Zentella (1990) also took an ethnographic and sociological approach to codeswitching. Her work with Puerto Ricans in New York stands out for its thorough representation of the linguistic reality of a community that is a product of colonial language policies, revolving-door migration patterns, and lower-working-class, nonwhite individuals (p. 76). Zentella studied the linguistic behavior of Puerto Rican children at El Barrio in New York City's East Harlem. She devised a framework to explain their verbal interactions, which included the following factors: "on the spot," "in the head," and "out the mouth" (Zentella, 1997). She clarified that there was 
no mechanistic link between these variables, and that they were a product of a creative and cooperative interaction.

1) The first factor, "on the spot," includes the linguistic proficiency of the person to whom the children were speaking, and the language requirements of the "setting." Thus, language alternation conformed to the dominant language of their different interlocutors, and took place in the children's primary networks, such as the home (p. 91).

2) The second variable, "in the head," takes into account speaker's communicative knowledge, which includes awareness of the importance of respecting social values in the community, the status of interactants, and the symbolic value of the languages (p. 83). This "in the head" knowledge of how to manage a conversation, allowed children to use codeswitching to accomplish at least twenty-two conversational strategies, which gave them greater communicative power and social bonding (p. 92).

3) The last classification, "out the mouth," reveals children's knowledge of Spanish and English grammars. It responds to lexical limitations and syntactic constraints. For example, the syntactic boundary of the switch point is an example of "out the mouth" factors because it defines the form that particular instance of codeswitching will take (p. 115).

Zentella's contribution to codeswitching research is important, because it makes a strong case for the connection between the larger discourse and social context in the analysis of bilingualism. Each of the children's use of codeswitching “made a personal bilingual-bicultural statement which was best understood when quantified data were interpreted in the light of 
ethnographic observations about the language history, bilingual behavior, and social status of each child" (p. 135).

Auer, another key researcher in the field, has also contributed to the understanding of the pragmatics of codeswitching by postulating an individualistic approach in which interlocutors shape and give meaning to their utterances in the process of interaction. Auer admitted that we should refer to community norms and macro-social circumstances to describe the resources available to a bilingual, but concentrated on the conversational aspects of code alternation. Those who follow a conversation analysis (CA) approach to codeswitching (Auer, 1998; Stroud, 1992; Wei, 2002) place greater importance on the sequential examination of switches as they occur in interaction. Auer (1998) believes that macro-social, sociolinguistic investigations of codeswitching that restrict themselves to analyzing the social meaning of the languages themselves are not sufficient to account for this phenomenon, and neither are grammatical approaches which mostly concentrate on syntactic constraints within the framework of a particular grammatical theory. Auer emphasized the gap that these two traditions leave, due to the fact that macro-sociolinguistic aspects of speech situations never completely determine language choice and there are local processes of language negotiation that influence code choice. He concluded that an understanding of codeswitching within interaction episodes is not only possible, but necessary (p. 3). Nonetheless, the precise nature of the balance between the social and the conversational structure, as well as how this varies across contexts, still remains to be explored.

Along the same lines of Auer, Wei (1998) attempted to explain one of the key questions in bilingualism research: Why do bilingual speakers switch from one language to the other? His answer, again, did not deny the presence of macro level values, but emphasized that bilingual 
speakers do this because the switching itself signals how they wish their utterances to be interpreted on each interaction. To Wei, the meaning of codeswitching lies in the interactive process and cannot be analyzed independently from the conversational context. Wei (2005) made clear that: "those who adopt the CA approach to code-switching argue that one must not assume that, in any given conversation, speakers switch languages in order to 'index' speaker identity, attitudes, power relations, formality, etc. Rather, one must be able to demonstrate how such things as identity, attitude and relationship are presented, understood, accepted, rejected, or changed in the process of interaction" (p. 382). This approach has one key component which is especially pertinent to the present study: It moved away from automatic assumptions regarding the symbolic associations that may be tied to each language. The present analysis does not assume automatic connections between language and symbolic constructs, but rather relies on ethnographic analysis and participant perceptions to determine plausible indexical pairings in one particular context.

Unlike the CA approach, the present investigation does not concentrate on minute details of conversation which are thought to reveal why speakers choose language A instead of B in a particular turn. Rather than focusing on the possible meaning of individual instances of language alternation, this study explains codeswitching as a communicative style which carries social meaning. There are two aspects that should always be intertwined in the analysis of any codeswitching phenomenon: the social and the individual. The data gathered for the present study is discussed using a multilayered analysis that takes into consideration the social context of a particular group of Puerto Rican bilinguals. It provides a window into their conversations, and explores identities that may be related to their codeswitching behavior. 


\section{Codeswitching and Identity}

"The language spoken by somebody and his or her identity as a speaker of this language are inseparable" (Tabouret-Keller, 1997, p. 315). In addition to recognizing the strong link between language and identity, Tabouret-Keller reminded us that identity is endlessly created according to social constraints, social interactions, and wishes that may be subjective and unique (p. 316). This view corresponds to recent tendencies in the social sciences and sociocultural linguistics, which move away from essentialist conceptions of identity and are closer to a more constructivist approach. Hall (1996) explained the ongoing, fluid and subjective creation of identities:

Identities are never unified and, in modern times, increasingly fragmented and fractured; never singular but multiply constructed across different, often intersecting and antagonistic, discourses, practices and positions. They are subject to a radical historicization and are constantly in the process of change and transformation. (p. 4) In bilingual or multilingual contexts there is great potential for the creation of such identities, which are not unified and static, but dynamically constructed. In the case of codeswitching, bilinguals have access to two linguistic codes, and each of those codes provides a wealth of potentially harmonizing or antagonistic symbolic associations which constitute the very fabric of identity construction.

Early research on codeswitching found that in many bilingual and multilingual communities around the world there is a "they" code (majority language) associated with formal, less personal, out-group relations and a "we" code (minority language) associated with in-group informal activities (Gumperz, 1982, p. 66). According to Gumperz's framework, bilinguals choose one or the other language in order to index the identities associated with it. In light of 
recent nonessentialist conceptualizations of identity, this straightforward association of language and identity is open to questioning. Still, one strong point in Gumperz's proposal is that he insists on avoiding generalizing his findings across communities. He argued that "we need to be able to deal with degrees of differentiation and, through intensive case studies of key encounters, learn to explore how such differentiation affects individuals' ability to sustain social interaction and have their goals and motives understood" (Gumperz, 1982, p. 7). Gumperz's emphasis on intensive case studies is an inherent part of his approach, since key social values need to be uncovered for analysis: "Encounters involving style or code switching are analyzed to demonstrate how known differences in social values and grammar and lexicon are exploited to convey new information" (Gumperz, 1982, p. 6). Thorough, nonessentialist analyses of codeswitching may reveal how different social values are interpreted, accepted or contested by speakers, and in this process create group memberships or identities. The task of the analyst who takes a constructivist approach to codeswitching and identity is to uncover the composition of identities brought about by the exploitation of linguistic resources.

Another approach to codeswitching and identity was brought forth by Myers-Scotton (1993a). She posited that speakers are aware, typically unconsciously, of a marked (unexpected code) and an unmarked (expected code). Myers-Scotton also identified situations where "overall switching" is the unmarked choice. In this type of behavior, each switch does not necessarily have a special significance, but rather the overall pattern of using two varieties carries social meaning. Speakers may alternate between two or more languages in order to simultaneously index two identities. An example of this type of codeswitching is found among Puerto Ricans in New York. This group appears to be interested in simultaneously recognizing their American (English) and Puerto Rican (Spanish) identities. For them, using English and Spanish in a 
switching pattern is the unmarked choice (Myers-Scotton, 1988, p. 164). These two models

(Gumperz and Myers-Scotton) are successful in identifying the relationship between codeswitching and identity in terms of the symbolic associations tied to each language used in interaction. However, in keeping with a constructivist approach to identity, it is important to question the assumption that speakers necessarily have these social meanings in mind when they use their languages. Sebba and Wootton (1998) were concerned about this straightforward association between language and social meaning. They found that there is a multiplicity of identities to be evoked and manipulated in interaction. Language itself may be part of the identity but we cannot assume a fixed relationship between social identity and the language of the utterance: “The notions of 'we' and 'they' may now be subsumed within more local, and changeable social identities which are made salient from time to time in conversation" (p. 284). Sebba and Wootton's work moved away from essentialist conceptions of language and identity to focus on emergent meanings within interaction.

In response to several analytic approaches that have begun to address the complexities of the relationship between identity and bilingual interaction, Auer (2005) called for the study of codeswitching as a language style itself which indexes some kind of social membership beyond the membership indexed by monolingual varieties involved (p. 406). This recommendation moves us away from the initial we/they dichotomy proposed by Gumperz and Myers-Scotton's marked/unmarked code distinction, and closer to a more constructivist approach, which takes into account the diversity inherent to bilingual speech styles. Wei (2005) pointed out that the concern raised by Auer would set the agenda for codeswitching research in the years to come. Several studies have begun to take on the task of exploring the relationship between codeswitching and identity in terms of ongoing, situated social actions. 
Gafaranga (2005), for instance, argued that previous accounts of code choice among bilinguals have responded to the notion of 'language as a reflection of society.' He stated that existing codeswitching frameworks may be successfully applied to situations in which speakers associate an external social structure, specifically an ethnic identity, with language choice. However, problems arise when we encounter communities in which there is no straightforward link between language choice and the wider social structure (p. 287). Gafaranga suggested that language is not there to be correlated with the social structure. Linguistic identity can be understood as social identity, and this identity structures society, not the other way around. His argument is summarized as follows: "Social structures, and therefore social identities, are not fixed and stable objects out there waiting to be correlated with linguistic objects. Similarly, linguistic phenomena are too flexible and changing to allow any straightforward correlation" (p. 291).

The topic of construction and reconstruction of social roles and identities was taken up once again by Williams (2005). This study demonstrated that macro-level social structures by themselves cannot account for the type of codeswitching found between a mother and daughter who were members of the Detroit Chinese American community, since this community had no specific 'marked' or 'unmarked' codes for particular contexts. Williams promoted a method of analysis that does not assume a straightforward relationship between language alternation and social structure at a given point in the conversation, but rather allows for it to be discovered in the conversational context. In a similar vein, Zhang (2005) examined the relationship between macro-level sociolinguistic structures and micro-level conversational structures. She documented code choice in a radio program in southern China conducted in Potunghua (the standard dialect) and Cantonese (a regional dialect) (p. 355). Zhang found that individual acts of speech allowed 
participants to 'play out' the social structures relevant to specific speech events. She concluded that whenever a switch to Putonghua was made in the radio program, the potential meaning brought about was a social one involving the higher status of Putonghua relative to Cantonese (p. 371).

Following a constructivist approach to identity, in the present analysis of codeswitching and identity, I do not assume a straightforward relationship between language choice and identity, where each language automatically signals social categories, group memberships or ethnicities. The ultimate goal of studies that take into consideration the sociocultural foundations of codeswitching should be to seek an approach that integrates language use and social action. The present study does not solely describe the macro-social determinants of code choice. Nor does it attempt to explain the micro-level sequential development of Spanish and English within each interactional exchange. Instead, the present analysis adds to our understanding of codeswitching by concentrating on its use as a social style of communication through which speakers construct and covey aspects of identity.

\section{Socially Meaningful Style}

Isolated switches into another language in an otherwise monolingual interaction do not constitute codeswitching. For this phenomenon to be identified and studied as such there must be some kind of interactional pattern and social cohesiveness that gives meaning to mixing languages. In cases where this habitual pattern of communication and coherent social ties are present, language alternation then becomes a practice, a convergence of linguistic resources that can be interpreted together. When speakers make use of at least two codes habitually, with certain speakers, and in certain situations, it can be said that they employ a codeswitching style. Eckert and Rickford (2001) defined style as "a clustering of linguistic resources, and an 
association of that clustering with social meaning" (p. 123). The present investigation reveals how Island Puerto Rican bilinguals deploy their linguistic resources in conversation, in this case English and Spanish, and in this process create a style that indexes socially relevant identities. Style plays a significant role in the creation of identities (Irvine, 2001). Styles are "part of a system of distinction, in which a style contrasts with other possible styles, and the social meaning signified by the style contrasts with other social meanings" (p. 22). Irvine stressed that in order to explore the characteristics of a particular style we must pay attention to distinctiveness: the contrasts, boundaries and commonalities with other styles. We must also remember that styles are ideologically mediated. Ways of speaking may index social formations (groups, categories, activity types, etc.) of which they are characteristic. These indexes depend on participants' social position and point of view, which are typically culturally variable (p. 22).

This principle of differentiation or distinctiveness is not only accomplished linguistically, but also includes a set of behaviors and preferences: "The interpretation of a linguistic feature is often supported by (and sometimes made possible on the basis of) its co-occurrence with other features with which it forms a social style" (Auer, 2007, p. 8). Furthermore, linguistic practices are part of a stylistic complex that includes how people dress, their demeanor, and adornment (Eckert and Rickford, 2001). Such extralinguistic variables should not be ignored as they are intimately related to linguistic practices, and add to the creation of identities.

It is possible to predict (to a certain degree) if codeswitching will figure as an available linguistic resource for the creation of a bilingual speaking style by considering speakers' habitus. Languages, for bilinguals, are psychological carriers of meaning that exist in their minds, and in their habitus or patterns of interaction (Bourdeiu, 1991). Auer confirmed that "in the widest sense, style becomes similar to life-style as described by Bourdieu, as the surface correlate of 
habitus" (Auer, 2007, p. 12). Codeswitching is evidence of bilinguals' appropriation of each language in their habitus, and also of the skill and mastery in aptly deploying each language in a social action. Wertsch (1998) added that languages in our habitus serve as cultural tools which offer certain affordances and constraints. Without the affordance provided by a specific cultural tool, the action cannot be completed. Similarly, a cultural tool will pose constraints on what can be accomplished. For a bilingual, each language provides a distinct set of affordances and constraints that are present in interaction with other bilinguals. Each language empowers and limits them. This process is evident in codeswitching. The availability of two languages increases the tools for constructing meaning in interaction. Bilinguals "mix" or "switch" their tools depending on the affordances and constraints they provide.

The extent to which communication relies on language as a cultural tool becomes clear when these tools are not available. A study by Li and Tse (2002) demonstrated how this can manifest itself in codeswitching. Twelve Hong Kong bilingual students who habitually mix English and Cantonese were asked not to use any English for one day, and to record those expressions which they wanted to use but could not. All participants felt that the artificial rule of speaking only Cantonese was problematic: "These problems cover a broad range, from communication breakdown to inconvenience, from fear of damaging interpersonal relationships to avoidance of certain discourse topics involving English" (p. 179). All informants found it difficult not to be able to use English in their informal conversations with friends and peers. They also reported using English sometimes unconsciously, despite the artificial 'Cantonese only' rule of speaking. The experience of these bilinguals is easily explained in terms of cultural tools and habitus. In Li and Tse's study, English provided certain affordances at the moment of interaction. The use of English was an integral part of their habitus. Wertsch (1998) reminded us 
that when using the cultural tools, we usually do not operate by choice. Instead, we inherently appropriate the affordances and constraints associated with the tools we employ (p. 55). Auer (2007) echoes this statement by saying "what can be said and cannot be said is a central part of a social-communicative style" (p. 12).

We have seen that codeswitching, as a habitual part of social action, becomes a style that can be associated with personae or groups. Alternating languages can be a resource for identity construction, but how do speakers actually construct those personae? Languages have ideological indexical potential. This indexicality implies positioning oneself in a social space. When speakers employ a speaking style, they are inevitably affiliating or disaffiliating themselves with ideological positions present in the wider community. In any group situation there is always an assessment process, sometimes beyond speakers' awareness, of the social acceptability of stylistic choices. Eckert (2004) explains that speakers inspect the social landscape and after interpreting this landscape, they construct their place and stance within that landscape: "An important part of this meaning-making is the social characterization and evaluation of people and groups out in that landscape, and of their stylistic practices. It is in this process of meaningmaking that speakers assign meaning to stylistic resources" (p. 52).

Codeswitching, as seen in this dissertation, is evidence of how PR bilinguals 'take up' and 'consume' the linguistic/cultural tools they have available. This process creates a speaking style that may be associated with social identities. At this point, it is vital to remember the “emergent" side of communication. These speakers' bilingual abilities do not predict the alternation of languages in interaction. These individuals do not communicate in a fixed pattern that we can predict. Claiming this would be a way of essentializing. On the contrary, speakers 
are constantly negotiating their stylistic strategies, and codeswitching is just one of the many linguistic resources available to them.

\section{Emergent-Flexible Identities}

Language alternation may be devoid of identity-relevant meaning in some contexts, and yet in others, it may be extremely rich in the identity work it accomplishes (Auer, 2005). The linguistic situation of Puerto Rico, and especially the presence of a codeswitching style among an elite network of speakers, is ideal for illustrating the shifting and complex relationship between language use and identity in modern times. Stuart Hall (1996) invites us to situate debates about identity within those "historically specific developments and practices which have disturbed the relatively 'settled' character of many populations and cultures, above all in relation to the processes of globalization" (p. 4). The Island of PR is representative of populations which integrate two or more languages/cultures/ways of being in the world. Competence in codeswitching among the bilinguals in the present study may signal the true appropriation (Bakhtin, 1981, p. 293) and internalization of two languages and cultures. This process of appropriation is, at the same time, rich in its potentiality for the creation of new identities, and the re-articulation of existing ones.

Codeswitching styles, in which two languages are used, may be characterized as hybrid ways of speaking which symbolize social identities that are equally heterogeneous, flexible, changeable, and malleable. In an attempt to avoid fixed, a priori relationships between language and identity, the current study approaches identity as an emergent sociocultural phenomenon, present in local discourse contexts of interaction, rather than a stable structure located solely in the individual psyche or in fixed social categories (Bucholtz and Hall, 2005, p. 586). The definition of identity set forth by the two authors, and which will be adopted here, is 
comprehensive enough to encompass a broad scope of analyses: the social positioning of self and other (p. 586). The proposed sociocultural linguistic perspective on identity is concerned with the intersection between language, culture and society.

The following principles outlined by Bucholtz and Hall (2005) will guide the conceptualization of identity in the present study: the Emergence Principle, the Positionality Principle, the Indexicality Principle, the Relationality Principle, and the Partialness Principle. What follows is a brief description of these principles, and how they relate to the present investigation:

1) Emergence Principle

This principle rejects identity as a static construct, and places it on the social ground on which it is built, maintained or altered (Bucholtz and Hall, 2005, p. 587). Although in the PR context English and Spanish may have ideological associations with being, for example, 'American' or 'Puerto Rican,' these associations may or may not be relevant for speakers. A codeswitching style is not static in the sense that it does not always lend itself to the same interpretation. Thus, identity emerges from the particular conditions of linguistic interaction, and is fundamentally an emergent sociocultural phenomenon.

2) Positionality Principle

Identity is composed not only of broad social categories such as age, gender and social class. There are also more local categories that speakers may also orient to, such as 'joke teller' or 'engaged listener.' The principle of positionality emphasizes the importance of ethnographic work in identity research. Interviews with participants, as well as close examination of the locally developed codeswitching style will allow the discovery the social identity categories relevant to participants in the present study. Speakers may have access to the same linguistic 
resources, but may show different preferences when it comes to deploying them in interaction. This may manifest itself in the creation of individual speaking styles. What must not be ignored is that the way speakers use these linguistic resources entails certain positionings in interaction and within society.

\section{3) Indexicality Principle}

Indexicality refers to the connection between linguistic forms and social meanings. "In identity formation, indexicality relies heavily on ideological structures, for associations between language and identity are rooted in cultural beliefs and values - that is, ideologies - about the sort of speakers who (can or should) produce particular sorts of language" (Bucholtz and Hall, 2005, p. 594). Indexicality is an important mechanism because it allows identities to be constructed and identified as such. This mechanism explains how linguistic forms can be used to create identity positions. The present study explores the beliefs and values associated with Spanish and English, which may influence speakers' acquisition and use of these languages, and in turn, contributes to how they become different kinds of individuals. As discussed in Chapter Three, the proposed analysis takes into consideration the role of cultural authorities such as intellectuals and the media in shaping these values and beliefs.

\section{4) Relationality Principle}

This principle focuses on the relational aspects of identity. There are two main points to consider when discussing the range of relations that are forged through identity processes. First, “identities are never autonomous or independent, but always acquire social meaning in relation to other available identity positions and other social actors"; and second, we should "call into question the widespread but oversimplified view of identity relations as revolving around a 
single axis: sameness and difference" (Bucholtz and Hall, 2005, p. 598). These authors outlined how the following identity relations play out in interaction:

a) adequation/distinction - For groups or individuals to be positioned as alike, they do not have to be identical, but must be sufficiently similar for current interactional purposes. In the present study, we may find that not all participants codeswitch with the same frequency, Furthermore, the mere presence of the codeswitching communicative style amongst the recorded groups may serve to align these individuals with a network of bilingual speakers, and separate them from the identity of a monolingual Spanish-speaking Puerto Rican.

b) authentication/denaturalization - Identities are authenticated when they are discursively verified. One of the first concerns of the analyst is to ascertain what sort of language is authenticated or counts as (appropriate, genuine, right) for a given purpose in the target context. Authentication should be seen as a social process played out in discourse. In the present study participants themselves determine what is authentic in their discursive practices: When is it appropriate or inappropriate to speak only English? When is it appropriate or inappropriate to speak using a mixture of Spanish and English? Is it appropriate or inappropriate to speak only Spanish? The second process, denaturalization, may occur when assumptions regarding the seamlessness of identity are disrupted; when an identity appears which violates ideological expectations. For example, a participant may be insistent on the importance speaking 'pure' and 'correct' Spanish to show his Puerto Ricanness, but find himself constantly using English words and phrases in conversation, thus upsetting the widespread essentialist assumption on the Island that Puerto Ricans should be able to communicate solely in Spanish.

c) authorization/illegitimation - This pair of relations involves the affirmation or imposition of an identity through structures of institutionalized power and ideology. Ideologies 
about Puerto Ricanness and language promoted by the intelligentsia or the media may influence how speakers use their languages. Shared ideologies may permeate the most ordinary interactions. The task of the present study is to ascertain how these linguistic ideologies are accepted, contested or rejected by a specific network of speakers. Illegitimation refers to how identities are censored by those structures of power and ideology. The Puerto Rican intelligentsia which embraces purist ideologies may not be willing to accept or legitimize the presence of multifaceted identities that are occasioned by the practice of codeswitching.

5) Partialness Principle

The last principle explores the issue of intentionality in identity creation. Construction of identity may be either deliberate (a product of agency) or habitual, and therefore not fully conscious. Sociocultural linguists have proposed a way to deal with this dilemma by placing less emphasis on the degree of intentionality and concentrating on agency as social action. Agency is then conceptualized as a result of individual action, and also distributed among social actors who co-construct identity. At the same time, individuals engage in patterns of interaction that become part of their habitus (Bourdieu). Bucholtz and Hall (2005) explained that "habitual actions accomplished below the level of conscious awareness act upon the world no less than those carried out deliberately" (p. 606). Thus, identity creation is both the product of deliberate decision and of a less conscious action. This principle urges us to recognize and explore how both community and individuality influence communication (p. 607). 


\section{Chapter 5: Methodology}

This dissertation documents and analyzes the codeswitching behavior of an elite group of bilinguals on the Island of PR, and interprets its contribution to creating boundaries and contrasts in language use on the Island. These boundaries are closely related to ethnic, social and personal identity. The study encompasses four major threads:

1) Portrayal of Historical and Ideological Matrix (English and Spanish in PR)

2) Identification of Patterns of Language Use

3) Description of the Codeswitching Style

4) Discovery of Links between Language Choice and Identity

Chapters Two and Three summarized the history of Spanish and English in Puerto Rico, while highlighting key educational, political, and ideological concerns. This information provides the basis to understand the ideological intersection of these two languages on the Island. This background will also guide the upcoming analysis of codeswitching and identity in the PR context. Chapter Four served to conceptualize codeswitching as a socially co-constructed style, and emphasized its role in the creation of emergent, flexible identities. Interactions in the present study are interpreted both in the context of the events themselves as well as in the broader social context (Heller, 1988). This top down/bottom up approach permits an analysis which deals not only with the explanation of codeswitching in a given setting, but also with the discovery of the contribution codeswitching makes to group-level social processes. A thorough analysis of codeswitching should take into account historical and ethnographic variables as well as individual verbal repertoires (p. 268). 
This chapter will address: 1) the research approach, which includes three research questions, and the main elements of the social network method of participant selection, 2) details about data collection, and 3) a basic characterization of participants.

\section{Research Questions}

This study is based on a combination of audio recorded conversations, ethnographic observations, and interviews with a small network of elite Island-raised Puerto Rican bilinguals who share ties of friendship, work or family. Twenty-seven participants, whose ages ranged from the late twenties to the late thirties, were recorded in casual, in-group, spontaneous interaction. Three research questions guided this dissertation. What follows is an overview of how each will be answered in Chapters Seven, Eight and Nine.

-The first research question is: How is English being used by elite Island Puerto Rican bilinguals in informal group encounters? The answer to this question will lead to a description of the linguistic practices of a network of elite bilinguals in the Island of PR, which set them apart from the monolingual majority, noting group tendencies and individual differences in language use with regard to English. I will document language distribution in conversations; classify types of codeswitching; identify common discourse functions; and, finally, list and explain recurrent discourse topics in codeswitching examples.

-The second research question is: What constitutes speakers' codeswitching style and how is it interactionally negotiated by each individual? It relies on the assumption that speakers regulate group membership, i.e. multiple identities, through particular patterns or styles of linguistic behavior. I will provide a window into the language ideologies that are relevant for this network of speakers and explore how they may contribute to the creation of the observed codeswitching style. I will also recognize possible differences between participants in terms of 
how they negotiate and deploy their linguistic resources in interaction. A wealth of information on the main language ideologies relevant to this group of speakers was obtained with the help of questionnaires. Awareness of these ideological constructs is necessary for understanding the variables at play in the construction of a codeswitching style. A final explanation of the social interpretation of codeswitching will lead to further discussions on identity.

- The third research question is: How is codeswitching linked to participants' identities?

Individuals will display a codeswitching style and in this process create a particular set of identities for themselves. The proposed analysis will provide insights into these identities, which cannot be determined a priori but have to be evidenced by ethnographic methods which document both the individual and collective use of available linguistic resources. There are many identities that could be ascribed to participants, such as 'American,' 'Puerto Rican,' or 'elite.' The answer to this research question identifies and describes several multiple, flexible and changing identity positionings that may be indexed in peer interactions through the codeswitching style, and appear to be relevant to participants.

\section{Social Network Method}

The concept of 'social network' is valuable in linguistic analyses, since social networks are not rigid, like political organizations or stratified social classes. It is also a practical descriptive tool since strict taxonomies of social class or status may be controversial. In dealing with social networks "we need only accept the fact that individuals have social contacts with other individuals, because social networks are about individuals and the relationships that can be contracted between them, and not primarily based on predefined group structures" (Milroy \& Milroy, 1992, p. 84). The social network method for identifying participants was employed in the present study. A social class criterion for the selection of informants would have been limited 
and problematic. At the time this research was conducted, participants shared what could be considered Puerto Rican upper-middle class and upper class values, beliefs and ways of doing things. However, some informants had more humble upbringings. In fact, two of them had trouble with being considered members of an "elite" group, since they did not appear to have assimilated the elite character of their educational and economically privileged position in Puerto Rican society. Bilinguals who participated in the present study belong to a social network with strong ties that result from friendship, family, education or work relationships. As members of a specific social network, these bilinguals have the capacity to maintain and even enforce local conventions and norms, including linguistic norms, that differ in some respects from those of the wider Puerto Rican population.

Speakers in the present study have Spanish as their native language. Three of them were born in the U.S. but returned to the Island with their parents as small children. About half of them lived in the U.S. for a period of four to seven years. Despite their exposure to English in the U.S., their primary means of learning the English language was as a subject in school. Extensive exposure to U.S. culture (on the Island) through books, magazines, television, music, and movies was also likely to contribute to their acquired bilinguality. Participants are native speakers of Spanish and have native-like proficiency in English. In addition, they are different from three groups of Puerto Ricans who have been previously identified and studied: a) the monolingual majority on the Island, b) Puerto Ricans who are born and raised in the U.S., many of whom have never lived on the Island (Poplack 1999; Torres, 2002; Zentella 1982), and c) Puerto Ricans who grow up in the U.S., or spend most of their lives abroad, and then return to the Island (Clachar, 1997; Clachar, 2000; Haiman, 1993; Pousada, 1994). 
Data collection techniques based on the concept of social networks often rely on participants themselves to shape a sample of speakers. Researchers often make initial contacts, which then pass them on to others until sufficient speakers with the desired characteristics are obtained and a network structure is created (Milroy, 2002, p. 553). My initial contacts consisted of friends and family members, who then suggested other possible candidates for my study. Since I am interested in small group dynamics, and in being able to detect the patterns of language learning and language use, my initial goal was to obtain between fifteen and thirty participants. The final number was twenty-seven. A larger sample of speakers would not have allowed the intended qualitative analysis, which explicitly addresses the links between macro and micro aspects of life, without undervaluing or overstressing either of them (Layder, 1983, p. 108).

\section{Data Collection}

Casual observation of language use in everyday life is often the starting point of sociolinguistic studies. In fact, it can also be used to complement customary sociolinguistic interviews (Labov, 1972, p. 43). In the case of sociolinguistic studies that focus on codeswitching, the emphasis on language use in everyday life becomes paramount because language alternation is in its essence a spontaneous conversational activity. Thus, the starting point in the analysis of codeswitching is recording situations in which participants are engaged in natural, everyday conversations. However, a natural speech sample is difficult to obtain if speakers are being recorded. In fact, it is rare to find studies of this kind in which the researcher has no direct participation in the taping episodes. This is a problem that has been referred to in the literature as the "observer's paradox" (Labov, 1972). A way to control this is to study the subject in his or her own natural social context interacting with his or her family or peer group 
(p. 43). Most of the conversations recorded for this study took place in participant's homes or at restaurants while having lunch or dinner with friends. I was present in several conversations. For all others, I provided the recording equipment, asked participants to record themselves, and then return the recorder with the conversation. Arranging data gathering sessions was relatively easy, since most of the participants were recorded while interacting with family or friends whom they see frequently in social situations. There were a total of nineteen hours of recorded speech. Participants were asked to speak freely and carry on normal conversations, to provide evidence of how they would normally speak in that context. Whether I was present or not, I made sure I obtained details of events that accompanied the recordings, such as the place, time, and who was present. I used an ipod portable MP3 player/recorder and an RCS digital voice recorder. The sound quality provided by the recording devices was satisfactory for the current purposes, since phonetic analyses were not needed. Participants were asked to sign a Consent Form which briefly explained the topic of the investigation (bilinguals in Puerto Rico) and details about confidentiality.

Transcription of the data to be analyzed was a meticulous and time consuming process. In most conversations there was no background noise and participant voices were loud and clear. Although the technology employed in recording these conversations is not ideal for rigorous phonological analyses, it is evident that when speakers switched languages they were faithful to English pronunciation. In fact, in their responses to the questionnaire, Laura, Diego and Marla mentioned that a certain degree of phonological accuracy is important in codeswitching, and that they do not like it when people mispronounce words when they codeswitch. The next chapter will further discuss the importance these speakers attribute to English pronunciation. 
To triangulate the data, interviews were conducted with each participant. I prepared a questionnaire that provided insights on individual linguistic backgrounds, beliefs and ideologies that contribute to their observed codeswitching styles. Interviews were transcribed and recurring themes were identified. The interviews served to check findings generated from participant observation. I documented participants' linguistic behavior not only during the recorded conversations but also in different scenarios: at work, with family and friends, with strangers on the street, and so forth. Cross-situational observation of speakers' patterns of language use allows us to abstract individual idiosyncrasies, and how sets of linguistic variables group together to signal different kinds of identities (Podesva, Roberts \& Campbell-Kibler 2002). I gathered the language history of each individual since childhood, as well as present exposure to the language, including movies, TV shows, books, places to socialize, and past and present travel opportunities to English speaking countries (mainly the U.S.) The interviews provided the information needed to make important connections between participant experiences and macro-level language patterns present in the PR context. They were interviewed in person rather than asked to write down their answers. This was a useful strategy since interaction with participants gives the researcher the opportunity to clarify responses, and keep the respondent from straying from the subject, a common shortcoming of open ended written questionnaires. Interviews with the twenty-seven participants lasted an average of forty minutes each, with some extending to more than an hour.

Interviews were conducted in Spanish. Although all participants are bilingual, Spanish is their native language and the language of everyday life in Puerto Rico. It would certainly have seemed strange to me, and to them, to address participants in English. Conducting the interviews 
in Spanish also gave participants the opportunity to codeswitch spontaneously, which added to the corpus of data drawn from the recorded, naturally occurring conversations.

The questionnaire is divided into six sections:

I. Profile: Provided basic information about participants (age and occupation), as well as information that may have had an effect on their linguistic practices (travel experiences and political ideals).

II. Language Learning: Gathered information about first contact with the languages, language use at home, type of schooling and its possible influence on language attainment, and motivation to learn each language.

III. Present Internal and External Functions of language: Included: 1) Contexts of language use, 2) Exposure to media in each language, 3) Internal Expression

IV. Language Alternation: This set of questions offered detailed information about codeswitching and was useful in identifying speakers' attitudes toward the phenomenon.

V. Identity: Explored possible connections between codeswitching and personal, ethnic and other social identities.

VI. Language Ideology: Fifteen of the main ideological Discourses ${ }^{15}$ related to languages in Puerto Rico were identified, based on the research conducted on their historical and ideological underpinnings. Participants were asked to comment on each statement. Their positive, negative or conflicted reactions revealed to what extent they share,

\footnotetext{
${ }^{15}$ Gee (1996) distinguishes Discourse, with capital 'D' from 'discourse.' The latter means 'a stretch of spoken or written language' or 'language in use.' Gee explained that “a Discourse is composed of ways of talking, listening, reading, writing, acting, interacting, believing, valuing, an using tools and objects, in particular settings and at specific times, so as to display or to recognize a particular social identity" (p. 10).
} 
resist, fight, or remain indifferent to dominant ideologies in their immediate and broader linguistic context. (See Appendix A-1 and A-2.)

The questionnaire was designed to provide insight on the role of codeswitching as a linguistic resource for these bilinguals, and to gauge their attitudes toward this practice. Language attitude research techniques such as the one employed here may provide an idea of general trends in language behavior and the variables that may play a role in it. Fasold (1984) explained that it may be possible that if we know "a person's attitudes, we would be able to make predictions about her behavior related to those attitudes with some degree of accuracy" (p. 148). Many linguists have explored phenomena that could be influenced by attitudes, such as sound change and second language learning. Similarly, attitudes can affect the linguistic resources that we allow in interaction. They help explain the very existence of a speech style that may differ from other styles, and from the speech norms of the society to which speakers belong.

The typical limitation of questionnaires, like the one used here, is that there may be a disparity between expressed attitudes and overt behavior (Wolfram \& Fasold, 1974, p. 69). In the case of codeswitching, this situation is, in fact, expected. Jacobson (1977) affirmed that negative attitudes toward codeswitching do not seem to inhibit its practice as long as it happens in an informal, relaxed, intimate atmosphere (p. 134). This was indeed the case in the present study. Some speakers expressed negative attitudes toward codeswitching, but this did not prevent them from using English in casual conversations with close friends and family. Chapter Eight will further explore the relationship between expressed attitudes and opinions, and codeswitching practices. 


\section{Competent Bilinguals}

Along with the monolingual majority on the Island, there are Puerto Ricans who are very fluent in English. Alicia Pousada (2000) defined them as "competent bilinguals," a term which encompasses highly functional bilinguals or balanced bilinguals. These speakers are communicatively competent in the two languages and can move smoothly between them. Many definitions of bilingualism have been provided in the field of linguistics. Bloomfield (1953) defined it as "the native-like control of two languages" (p. 56). Many of the definitions proposed since then range from native-like control of two languages to minimal proficiency in a second language. Similarly, researchers may encounter difficulties when operationalizing their constructs, and finding empirical support for classifications of bilingualism. For example, how do we measure language competence? How do we quantify competence in vocabulary, phonology, and grammar? Are these the only aspects central to competence? The many dimensions of bilingualism make it difficult to measure. Hammers and Blanc (2000) recognized this limitation and stressed the need to approach bilingual behavior from the functions it serves, both social and psychological. Bilinguality is then the "psychological state of an individual who has access to more than one linguistic code as a means of social communication" (p. 6). Degrees of access to linguistic codes will vary according to many variables, among them, sociolinguistic and sociocultural ones.

From the perspective of research on codeswitching, Poplack (2000) interpreted her research findings as indicative of different degrees of bilingualism. Intrasentential switching was indicative of high competence in the two languages. This type of switching was identified as the most difficult one, and bilinguals with low fluency in either of the two languages tend to avoid it. Poplack stated that in order to produce this sort of switch the speaker must know enough about 
the grammar of each language, and the way both languages interact, to avoid ungrammatical utterances (p. 247). Moreover, from the perspective of the pragmatics of codeswitching, measuring bilingual competence becomes a secondary concern. Although bilingualism is crucial in the ability to access two languages, what becomes even more paramount is the ability to effectively engage in this practice in interactive exchanges between members of a bilingual speech community. Auer (1995) summarized this point of view and concluded that the linguist is not to measure and test bilingualism, but to reconstruct the social process of displaying and ascribing it: "As a feature of conversational interaction, bilingualism provides specific resources not available to monolingual speakers for the construction of socially meaningful verbal activities" (p. 115).

In terms of language proficiency and degree of bilingualism, participants in this study are able to achieve an array of communicative goals provided by English. Most of them use English for work reasons on a daily basis. Even those with less proficiency in English have been forced to use this language because it is necessary for their professions. Some of the highest paying jobs in Puerto Rico require English fluency (medicine, law, accounting, technology, etc.) However, as mentioned earlier in this chapter, socioeconomic status was not a determining factor in identifying participants, since many variables could potentially influence language attainment and subsequent membership in bilingual social networks. In the case of PR, we could mention close contact with the United States as a factor that may play a role in bilinguality. Individuals who may not have had access to English education in school may have acquired their language as students abroad or may have lived on their own or with their families in the U.S. for limited periods of time. Although bilinguals of different social and educational backgrounds are 
represented in the present study, their occupations currently allow them to enjoy the distinctive lifestyle of the middle and upper classes in Puerto Rico.

Participants in this study belong to the educated elite of the Island of Puerto Rico. They are all professionals with a college education, who live and work in the San Juan metropolitan area. Following the Hollingshead Index of Social Positioning (Hollingshead \& Redlich, 1958), speakers belong to the upper or upper middle classes. This means that they can be described by the following occupational and educational categories: a) Occupational Scale: higher executives of large concerns, proprietors or major professionals or business managers, proprietors of medium-sized businesses, and lesser professionals; and b) Educational Scale: professional (MA, MS, ME, MD, PhD, LLD, etc.) or four-year college graduates (BA, BS, BM).

The social prestige and socioeconomic positioning of the social network that engages in codeswitching is important in many ways. An historical overview of the language situation in Puerto Rico since the arrival of the United States in 1898, shows that the Island's socioeconomic and political elite has always considered bilinguality as a prerequisite for maintaining influence with both Americans and Puerto Ricans. Since the establishment of an English-speaking colonial government learning English has come hand in hand with the ideal of upward social mobility (Schweers \& Vélez, 1992, p. 14). However, no study up to now has investigated the linguistic practices of this educated elite, specifically in relation to their codeswitching style. This elite group is important because of its powerful and influential socioeconomic position. These speakers are also leaders and trend-setters with the potential of influencing the language dynamics in their immediate social circle and beyond. 


\section{Chapter 6: Participant Profiles}

The first step in explaining codeswitching, as manifested in a network of Island PR bilinguals is to familiarize ourselves with participants' linguistic backgrounds. Codeswitching cannot be generalized across every community. Ethnographic work allows us to uncover community-specific details that contribute largely to the practical significance of codeswitching: "Not all that happens in communication is negotiable; some of it is already established before the actual communicative event begins, and this varies according to the social structure of the community, and can hence only be inductively determined on the basis of ethnographic observation" (Meeuwis and Blommaert, 1994, p. 407). Among the variables at play in communication among this group of bilinguals are: access to and quality of education; personal and parental motivation; family and peer environment, and one element that perhaps lies further from their control, societal power relationships and the symbolic means through which these relationships are enacted. In the Puerto Rican context, ultimate English attainment is greatly influenced by power relations. English, as cultural capital, is not equally distributed among the population, and a form of elite closure regulates ultimate learning and access to the language. This chapter will delve deeper into the variables that influence English learning, which have already had an impact on several generations of Puerto Ricans. Identifying the commonalities and differences in the twenty-seven participants in this study will allow a better understanding of the factors that influence becoming bilingual in Puerto Rico, and its manifestation in codeswitching practices.

To discover the social meaning of style, it is often necessary to carry out "ethnographic investigation to uncover groups that may seem homogeneous through a wider analytic lens, but become sharply differentiated when ethnographic details are brought into close focus" (Bucholtz 
and Hall, 2005, p. 597). A closer look at participants' linguistic formation and their views on language learning reveals the intricate social dynamics that underlie the codeswitching style present in interactions. I will provide a thorough characterization of the participants according to the most salient circumstances in their linguistic formation. This chapter is divided into four sections, according to type of primary and secondary schooling and college education: 1) Private Schooling and U.S. College Education, 2) Private Schooling and P.R. College Education, 3) Private and Public Schooling, and 4) Public Schooling and English Attainment. Other factors that are crucial in participant classification are: socioeconomic standing, time spent living in the U.S. and motivation to learn English. The last section of this chapter focuses on the possibility of changing English learning trends on the Island. This discussion stemmed from participants' responses to questions related to this topic. Most of them mentioned that their experiences with English in the Puerto Rican context are not necessarily shared by younger generations.

Table 1 helps illustrate the composition of this social network and the circumstances behind their bilinguality and codeswitching practices. The categories presented take into account speakers' exposure to the English language, how they learned it, and how often they use it in their daily life in the form of codeswitching. 
Table 1: Participant Profile

Public $=$ Public School in PR; Private $=$ Private School in PR; BA/PR $=$ Completed Bachelor's Degree in PR; BA/US = Completed Bachelor's Degree in the U.S.; MA-JD/PR = Completed Master's Degree or Juris Doctor in PR; MA-JD/US = Completed Master's Degree or Juris Doctor in the U.S.; Lived U.S. = Lived in the U.S. - not for study reasons; CS+= Engages in codeswitching - Sometimes to All the time; CS- = Engages in codeswitching Hardly ever to Never.

\begin{tabular}{|c|c|c|c|c|c|c|c|c|c|c|}
\hline Name & Age & Public & Private & $\begin{array}{l}\text { BA/ } \\
\text { PR }\end{array}$ & $\begin{array}{l}\text { BA/ } \\
\text { US }\end{array}$ & $\begin{array}{l}\text { MA- } \\
\text { JD/PR }\end{array}$ & $\begin{array}{l}\text { MA- } \\
\text { JD/U.S. }\end{array}$ & $\begin{array}{l}\text { Lived } \\
\text { U.S. }\end{array}$ & $\begin{array}{l}\mathrm{CS} \\
+\end{array}$ & $\begin{array}{l}\text { CS } \\
-\end{array}$ \\
\hline Darío & 29 & & & & & & & & & \\
\hline Jacqueline & 30 & & & & & & & & & \\
\hline Leo & 28 & & & & & & & & & \\
\hline Lucas & 28 & & & & & & & & & \\
\hline Rey & 39 & & & & & & & & & \\
\hline Graciela & 28 & & & & & & & & & \\
\hline Diego & 27 & & & & & & & & & \\
\hline Marla & 24 & & & & & & & & & \\
\hline Helena & 32 & & & & & & & & & \\
\hline Sandra & 30 & & & & & & & & & \\
\hline María & 33 & & & & & & & & & \\
\hline Juan & 30 & & & & & & & & & \\
\hline Alejandro & 40 & & & & & & & & & \\
\hline Rafael & 28 & & & & & & & & & \\
\hline Juliana & 33 & & & & & & & & & \\
\hline Valeria & 33 & & & & & & & & & \\
\hline Viviana & 35 & & & & & & & & & \\
\hline Jaime & 38 & & & & & & & & & \\
\hline Walter & 37 & & & & & & & & & \\
\hline Janet & 29 & & & & & & & & & \\
\hline Laura & 33 & & & & & & & & & \\
\hline Adrián & 31 & & & & & & & & & \\
\hline Ana & 34 & & & & & & & & & \\
\hline Manuel & 33 & & & & & & & & & \\
\hline Alberto & 34 & & & & & & & & & \\
\hline Lourdes & 30 & & & & & & & & & \\
\hline Carlos & 40 & & & & & & & & & \\
\hline
\end{tabular}




\section{Private Schooling and U.S. College Education}

This study confirmed that type of schooling and socioeconomic class are key components in the development of bilingual ability in Puerto Rico (Pousada, 1996; Schweers \& Vélez, 1992; Torruellas, 1990). The following twelve participants attended private schools in the San Juan metropolitan area. (All but Juan attended college in the U.S.) ${ }^{16}$ The education received in their respective private schools allowed them to develop their second language fully. The role of school in the Puerto Rican context is crucial for language attainment, since opportunities to actually speak English on the Island are considerably limited. School then becomes the main source of language input for most young learners. Two other important elements in language acquisition were the influence of family and the composition of the social network these children and young adults were immersed in as they grew up. In many cases, parental and societal influence on their motivation to learn English appears to have been vital. Similarly, the choice to leave the Island to continue their college education was, in most cases, something that was expected by their school, family and community. Mastery of English achieved through schooling on the Island and abroad appears to be a class-based aspiration. This study confirms Torruellas' (1990) finding. Attending college in the U.S. is a very powerful element in the process of elite training in Puerto Rico and the expected postsecondary choice among the upper class (p. 299).

Diego (27), Marla (24), Helena (32), Sandra (30) have a native-like command of English, and engage in the practice of codeswitching with regularity. Diego completed his Bachelor's degree in English Literature at the University of Notre Dame in Southbend, IN, while Marla

\footnotetext{
${ }^{16}$ Although Juan studied at the University of PR at Mayagüez his codeswitching style closely matches that of participants in the present section.
} 
obtained a Bachelor's degree in English from Loyola University, in Chicago. They are currently law students at the University of Puerto Rico. Helena has a Bachelor's degree in Public and International Affairs from Princeton University, and Sandra completed a Bachelor's degree in Liberal Arts at Harvard. Helena and Sandra both obtained their Juris Doctor degrees at the University of Puerto Rico and now work at one of the top law firms on the Island.

These four speakers developed their English skills in prestigious private schools in San Juan which cater to the highest socioeconomic classes. Marla and Sandra attended an all girls Catholic school, Academia María Reina. Diego attended Academia Perpetuo Socorro, a Catholic elementary school, and then Colegio San Ignacio, an all boys Jesuit college preparatory high school. Helena studied at Saint John's School, which has an all-English curriculum. These participants mention that they were always aware of a strong expectation of continuing their studies in the United States. Diego says that most of his classmates, if not all, left the Island to complete their bachelor's degrees. These four bilinguals do not recall the process of learning English, because it was something they took for granted. It was strongly supported and encouraged by their schools, families and social environment. Most, if not all, students that graduate from the aforementioned high schools attain high levels of English proficiency. However, as Torruellas emphasized in her 1990 study, not all private schools in Puerto Rico are created equal.

Darío (29) and Jacqueline (30), a married couple, have similar backgrounds. They both attended private schools which differ from the schools mentioned above in that they cater to a wide array of social categories, from lower middle class to upper class students. When asked about their experience learning English at their schools, Darío and Jacqueline commented on the difference between their level of English, and that of many of their classmates. Darío mentioned 
that at Colegio Marista in Guaynabo, there was a certain level of English attainment that was satisfactory, and there was no real effort from teachers or students to move beyond that level and reinforce bilingual skills. He remembers vividly the day he realized that his level of English was different from that of his peers:

I remember it well, it was in twelfth grade, I remember listening to someone read his book report and it was terrible, he couldn't speak English. I questioned that... Wow! Nobody had trouble understanding the teacher, but when they had to write it, it was terrible, terrible. (I thought) this guy has had the same education as I, the same years at (Colegio) Marista and I know more English than him. I don't know... I guess it had to do with taking advantage of the opportunity. Television, maybe... If (Colegio) Marista wasn't responsible for my knowing English to the level that I did, it must have been because of external factors. Television, movies...

Lo sé porque lo tengo marcado, fue en cuarto año, me acuerdo haber escuchado un book report de alguien y el tipo, fatal, no podía hablar inglés. Y me cuestioné eso...Wow! La maestra hablaba inglés pero nadie tenía problemas con inglés, pero a la hora de escribir, eso era fatal, fatal... Este tipo tuvo la misma educación, los mismos años en Marista y yo sé más inglés que él. No sé... Tuve que achacarlo a eso, a aprovecharlo. Aprovechamiento. Televisión, tal vez... Yo sacándome de allí... entonces si no es Marista el que me hizo llevarme al nivel que yo sabía de inglés, tienen que haber sido otras cosas externas. Televisión, películas...

Darío's thoughts confirm that school alone is not responsible for language attainment. It is true that quality of education is crucial, but there are also many interrelated factors that influence success in language learning. These factors include the social networks to which 
students belong, external and internal motivations for learning English, and even reinforcement of language skills through the media, such as cable TV. Television was mentioned by Darío and his wife Jacqueline as a possible reason for the disparity in English learning in students in their private schools. The next chapter will discuss the marked influence of the media in these bilinguals' linguistic repertoire.

Even though Darío's second language proficiency was more developed than that of his classmates, he still had passive knowledge of English. It was not until he went to the U.S. to continue his college education that his English improved to the point of being fluent. Only a few of Darío's classmates continued their education in the States, and Darío decided to do this after two years of college in Puerto Rico. He followed the example of his uncles who studied computer science at the same university he applied to, Florida Tech in Melbourne, FL. He does not regret this decision, even though he still faces many years of paying off student loans. For Darío, investing in his college education was also an investment in learning English. He says that he consciously decided to make English-speaking friends in college to improve his second language. He knew that his language would later be indispensible for his professional success. He currently works as a computer software salesman for the Caribbean region and uses English seventy percent of the time in his daily work.

Jacqueline's experience was similar to Darío's. She recounts that her school, Colegio Sagrado Corazón in San Juan, offered Conversational English and Business English, but aside from those courses, there was very little English practice. Despite not taking those courses, her English was still better than that of some of her classmates: "I remember asking myself why they were so bad at it... Some didn't know it at all, I don't know why." Upon graduation, Jacqueline had a firm grasp of grammar, but she had trouble communicating in her second language. 
Jacqueline thinks that television had something to do with her English competence: "I watched many TV shows in English as I was growing up because I wasn't that interested in the Spanish ones, so I watched a lot in English. Many of my classmates watched local TV, because when you talked about those shows, not all of them were familiar with them." Jacqueline decided to continue her college education in Florida. Once there, her English improved considerably, and she mastered all four skills: comprehension, reading, writing and speaking. Jacqueline's story includes a key element: she was the first member of her family to attend college in the United States. In sharp contrast to the first four speakers I described above, and even Darío, who had family members who had studied abroad, Jacqueline had never considered continuing her education outside of Puerto Rico until a school counselor mentioned it. She applied to the University of Central Florida and got accepted. With financial help from her grandfather, as well as student loans, she completed a Bachelor's degree in Human Resources. Both Darío and Jacqueline spent several years in Florida after graduation. They moved to Puerto Rico roughly at the same time, met shortly thereafter and got married. They are already teaching English to their eighteen month old daughter who sings "Happy Birthday" in English, and repeats "sorry" every time their parents use this word in English. Darío and Jacqueline's English improved considerably during the time they spent in Florida, to the point that they even had trouble separating the two languages after returning to the Island. Codeswitching is still an integral part of their communicative repertoire.

Leo (28) and Rey (39) attended the same school as Darío, Colegio Marista, however, they left high school with very high proficiency in English. This was not a random occurrence. As they were growing up, their parents recognized the importance of English, and had the means to make sure their children learned the language. Both Leo and Rey attended summer camps in the 
U.S. for several years. They both recognize this opportunity as crucial to their English learning. Leo completed a bachelor's degree in computer science and electrical engineering at the Massachusetts Institute of Technology (MIT), and now works for IBM. Leo's case reveals that parental support and encouragement is a crucial element in learning English for students in private schools. Leo says his father always told him English was important:

My parents always told me I had to learn English because it was the language of business and business dealings were conducted in English and so forth... He always told me that. He made it a point to tell me that English was very important and I had to learn it, I had to learn to speak it. I wasn't really consciously saying to myself: I have to learn English. I understood that it was important to learn it.

Mis papás siempre me decían que tenía que aprender inglés porque también era el lenguaje de business y mucho business se hacía en inglés y qué sé yo... Siempre me lo inculcó, o sea, me enfatizó que el inglés es súper importante, tienes que aprenderlo, tienes que aprender a hablarlo. No era como que consciously, ah, tengo que aprender inglés. Entendía que era importante aprenderlo.

Leo's wife Graciela (28) studied at the Colegio Puertorriqueño de Niñas in Guaynabo. She says she learned English in school and practiced it occasionally with an uncle who lived in England and came to visit the family once in a while. Following the trend we have seen so far, Graciela says that she and her classmates learned English well at school, and many went to the U.S. to continue their education. Graciela also studied Computer Engineering at MIT. When I asked her if she had any special motivation to learn English she said: "No, it was like, we had to learn to speak English." Learning English was expected in her social circle. She had an excellent education and access to the right networks, which helped her develop her language skills. 
Graciela codeswitches constantly with her husband and friends, but makes it a point not to do it with some family members, who do not live in the San Juan area, and are not fluent in English.

After graduating from Colegio Marista, Rey (39) went on to study business at Babson College in Wellesley, M.A. He now owns a profitable business. Rey is among the several bilinguals in this study who codeswitch most often. I will mention him here and in subsequent chapters because his points of view and codeswitching practices differ in some ways from those of the other twenty-six participants. However, when it comes to the relationship between socioeconomic class and English attainment, he fits the profile perfectly. He comes from a wellto-do family who owns property and businesses on the Island. Rey's father knew that English would be crucial for his son's future success, so he always encouraged him to learn and use the language:

My father lived and studied in New York, and for him it was very important that we spoke English and that's why he instituted the English nights. Every Wednesday if we wanted to eat we had to ask for food in English. This started when I was very small, four or five years old, and it went on for many years, and in my house there were always cleaning ladies that usually came from the (Virgin) Islands and they spoke in that messy language, but anyhow, I had to speak to them in English because they would not understand my Spanish. Mi padre vivió y estudió en Estados Unidos en Nueva York y para él era muy importante que hablásemos inglés y por esa razón estableció los English nights, eran los miércoles, y nos obligaba a que si queríamos comer teníamos que pedir las cosas en inglés. Desde muy chiquito, cuatro o cinco años y duró por muchos años y en casa siempre había empleadas domésticas que típicamente venían de las islas y lo que hablaban era el revolú 
ese, pero como quiera yo tenía que hablarles en inglés porque en español no me entendían.

Next, I will talk about three more participants and their revealing experiences with English. Juan (30) was also one of the participants who codeswitched most often in the recorded conversations. He was born in Puerto Rico, attended a small English speaking preschool in San Juan, and then finished elementary school and high school at Academia Perpetuo Socorro in San Juan. He then completed a Bachelor's Degree in Computer Engineering at the University of Puerto Rico (UPR) at Mayagüez. This university has premier engineering and science programs, and is the top Hispanic graduating university in the U.S. and Latin America. Many U.S. companies come to the UPR-Mayagüez to recruit engineering and science graduates. Upon graduation, Juan moved to Seattle, Washington, to work for Microsoft.

Since Juan and his parents lived close to an all-English school, Saint John's, many of Juan's friends were English dominant. I have mentioned that social ties and the social network to which speakers belong greatly influence linguistic practices, and Juan's case is no exception. In the following passage he recalls the vast exposure to English he had during his childhood:

While growing up I had a neighbor, we were about the same age, and he studied at St. John's. In elementary school I would go the park where I always rode my bike with the children there, many of them from St. John's. Now that I think of it, I had a lot of exposure. These children were mostly Puerto Rican but they studied at Saint John's and they spoke English and played in English.

Pues mira fíjate growing up yo tenía un vecino que teníamos la misma edad y el estudió en St. John's. Igual me pasaba en escuela elemental yo llegaba aquí, iba a la placita donde siempre corría en mi bicicleta y la mayoría de los niños eran muchos de St. Johns. 
$Y$ ahora pesándolo bien, yo tuve bastante exposure. Los otros niños eran puertorriqueños en su mayoría pero estudiaban en St. Johns y hablaban y jugaban en inglés.

María (33), the last participant in this section, codeswitches constantly with friends and family. She was born in Puerto Rico, went to Saint John's School's preschool, and then spent five years in New York (from first to sixth grade) while her father finished his medical training. Back in Puerto Rico she continued her education at Saint John's. María went on to study art in New York and recently enrolled in a Translation Master's program at the University of Puerto Rico. Using the informal codeswitching style that characterizes her, María talks about the choices her parents made which had an impact on her linguistic formation. She emphasizes that her parents spoke Spanish at home all the time, even in the States because they are truly Puerto Rican. She makes an explicit connection between Puerto Ricanness and Spanish. She recalls: At home we spoke Spanish because they are hard-core Puerto Ricans and you ask yourself, why did they stick me in St. John's... because they're so Puerto Rican. I think it was because of the education, they realize we live in a world that is very competitive and nowadays, because of globalization, it is important to know both languages well. En mi casa me hablaban en español porque ellos son puertorriqueños de pura cepa y uno también se pregunta, why did they stick me in St John's.... because they're so Puerto Rican. Me parece que por la educación, entienden que vivimos en un mundo sumamente competitivo y es importante hoy en día por el globalization, estar duro en los dos lenguajes.

María makes reference to an established trend in PR. The highest socioeconomic classes send their children to schools where they can be sure their English will be effectively developed. Furthermore, even the ones who are not so well off financially make sure their children attend 
private schools. One such case is Lucas (28). His mother made sure her children attended good schools so that they could develop their English: "My mother always spoke English to us and she said it was important." Lucas studied at Colegio Notre Dame in Caguas, a town east of San Juan, and then studied computer science at the University of Florida at Gainesville. He now works as a systems analyst at a local bank. His English is excellent and he mixes it with Spanish in his everyday interactions with friends, coworkers, and family.

The twelve participants mentioned in this section attended private schools in the San Juan metropolitan area. The quality of education they received in these institutions, parental and personal motivation, and the values and expectations of their social network contributed to their bilingual abilities. Except for Juan (30), the speakers mentioned in this section went to the United States to complete their college education. This had important implications on the way they use their languages. Not all of them gained complete English fluency at school, but their education in the U.S. gave them additional practice and an appropriate context for developing their second language competency. English played and continues to play an important role in their professional advancement. Furthermore, codeswitching is now a normal part of their lives. Some of them even expressed having difficulty speaking solely in Spanish. In addition to the development of English competence, their U.S. college experience had a significant influence in shaping their identity as young adults. In Chapter Nine I will talk about how participants' contact with the U.S. culture made a mark in their personal and social identities.

\section{Private Schooling and P.R. College Education}

The following six participants have at least two things in common: they attended private elementary and high schools in Puerto Rico, and continued their university education on the Island. In terms of their linguistic backgrounds, they differ from the previous twelve participants 
in that they did not have four years of college in the United States during which they could build their English proficiency. Still, they have well-developed oral and written abilities in their second language.

Rafael (28) had the opportunity to study one year of college in Pennsylvania. He received his primary education at Colegio Mater Salvatoris in San Juan and Colegio San José, a Catholic college preparatory school for boys, also in San Juan. At Colegio San José, Rafael had much exposure to English because the "brothers" were mostly American and many classes would be conducted in English. After high school, Rafael enrolled at the University of Puerto Rico at Mayagüez. He recalls his parents were always very intent on him learning English:

At home they would always tell us: "you need to speak English because the world will end up being in English."And that was the mentality, we had to learn to speak it. And my parents are not too good at speaking it, but they wanted us to speak better English. We are three siblings and we all did the same exchange program in different universities (in the United States.) My parents told me: "We can't pay for a four year university education, but you will go for one year." Mayagüez is a great university, I don't regret it at all.

En mi casa siempre te decían: "tienes que saber hablar inglés porque el mundo va a acabar siendo inglés”. Y esa era la mentalidad, pues sí, uno tiene que hablarlo. Y mis papás no son muy diestros hablándolo, pero ellos querían que nosotros sí saliéramos hablando mejor inglés. En casa somos tres y los tres hicimos el mismo programa de intercambio en distintas universidades (en Estados Unidos). Mis papás me dijeron: "No te podemos pagar la universidad los cuatro años pero vas un año”. Mayagüez es tremenda universidad, yo no me arrepiento para nada. 
Rafael's parents did not have the opportunity to learn English well, but recognized the importance of this language, not just in their immediate context but also internationally. This was etched in Rafael's mind, and he insists that making an effort to learn English is synonymous with looking for improvement and a better future. Rafael's last comment about not regretting his decision to study at the UPR at Mayagüez suggests that, within his social circle, there are many who consider studying in Puerto Rico as somewhat inferior to studying in the U.S. His parents would have wanted a U.S. college education for him, but could not afford it. This appears to be a common belief among many private school parents and students, especially those who belong to the upper classes. They tend to think PR institutions are inferior, and that those who choose to stay on the Island are compromising the quality of their education (Torruellas, 1990). Because of these ideologies, Rafael felt he needed to defend the University of Puerto Rico at Mayagüez as an excellent school.

After finishing his college degree, Rafael moved to Chicago for work reasons, and his English improved. However, he admits that during both the college exchange program in Pennsylvania and his three years in Chicago, he had so many Spanish speaking friends that he is sure he spoke more Spanish than English. Rafael's environment on the Island and abroad seem not to have been conducive to fully developing his English competence. Despite having the opportunity to improve it, and his efforts to learn it, English did not become "second nature" to Rafael. Crucially, his parents and friends did not have English as a "natural" part of their everyday life. This is reflected in Rafael's codeswitching, which is not as ubiquitous as that of Juan and Lucas (mentioned in the previous section), who work with Rafael at a local bank. Rafael finds it easy to control how much English he uses in conversation: 
It's rather easy for me to avoid it, the codeswitching, because maybe my exposure to English was not intense. It's not that difficult for me to block it, up to a point. Juan and Lucas do it much more than I. They end up speaking English all the time. I come back to Spanish. What I do is insert phrases here and there. About ten percent of the time, if we're talking percentages.

Se me hace bastante sencillo evitarlo, el codeswitching, porque tal vez mi exposure al tiempo en inglés no fue exagerado. No se me hace tan difícil el bloquearlo hasta cierto punto. Juan y Lucas son mucho más que yo en ese aspecto, acaban hablando todo el tiempo en inglés. I come back to Spanish. Lo mío son frasecitas aquí y allá. Como un diez por ciento, si estamos hablando de por ciento.

Alejandro (40) is another example of how social environment can be a decisive factor in English attainment. He studied at Colegio Nuestra Señora de Belén in San Juan. Alejandro says watching television shows in English served as motivation to put some effort in learning the language. However, he had no real need for English outside school, so he learned the basics, and that seemed to be enough. He had passive knowledge of English when he finished high school. Alejandro contemplated going to the U.S. to continue his education, but his family did not have the financial means to help him do this. He decided to begin engineering studies at the University of Puerto Rico at Mayagüez. He quit after two years to join the U.S. Army. He recalls his English was good enough to do well in his new military environment, but some of his Puerto Rican peers had to go to English school. His years in the army were ideal for developing fluency in spoken English, and he admits his competence improved considerably. Many of his friends codeswitch habitually and he sometimes does it also: "I don't know why I do it. The word doesn't come to mind in Spanish, and it comes to mind in English. It happened a lot when I came 
back from the Army, that sometimes I couldn't find the right word in Spanish.” Alejandro's experiences in the United States, and in U.S. military bases were important for his bilingual development. The inclusion of English in conversations is now a normal part of his life. Still, Alejandro has no difficulty speaking solely in Spanish, especially with those who never codeswitch, like his friend Jaime.

Jaime (38) says that growing up in Bayamón, a town west of San Juan, he did not need to speak English. He did not even need to understand it. Cable TV became available in his town when Jaime was already a teenager. Before that, he had zero motivation to learn English. His private school formation was disastrous. He spent the first eight years at Academia Claret in Bayamón, where American nuns made an effort to teach the kids but, according to Jaime, were not successful. He then finished high school at the Escuela Superior Católica, also in Bayamón. He learned English grammar, but got terrible grades. He says he was just not interested. He liked mathematics and excelled at it, so after high school he enrolled at the University of Puerto Rico at Bayamón, which offered a good computer science program. All the books were in English and he did well in understanding them, but his English grades were as bad as ever. It was not until he started working at a software company that his English was put to the real test. His job required him to travel to the Virgin Islands and give technical support to English-speaking clients. Jaime made use of the little grammar he had managed to learn, and worked on developing his oral English skills. Although Jaime developed his English competency to the level of being able to successfully communicate with clients at his job, he did not develop it to the point of having 
balanced proficiency in the two languages. He is one of the two participants on this study who does not codeswitch. ${ }^{17}$

It is evident that English was never part of Jaime's life. He resisted learning it, and the people around him, parents and friends, did not have a real need to make it a part of their life either. In contrast to the first group of speakers I described, learning English was not expected of him and he had no motivation to do so. Nowadays, Jaime has a high paying computer management position at a local company and lives in San Juan with his wife Valeria, whom we will talk about shortly. Jaime's wife and some of their friends habitually codeswitch between Spanish and English. Jaime is aware that some of them have had a lot of exposure to English, and he is accustomed to their codeswitching. Still, when he encounters new people, he cannot help but wonder why some of them need to include English in their conversations:

If I come into a group and someone does it, and speaks a lot of English, I ask myself why they have to speak that way. It has happened to me, actually. I mean, I've been somewhere and someone starts speaking English and then Spanish... Ah, yes! With Pedro and Charlie, they start speaking Spanish and continue in English, and I always say, what the heck, speak Spanish or speak English, and stop your stuck-up attitude. Si yo entro a un grupo y una persona lo hace y habla mucho inglés, tú dices por qué tiene que estar hablando así. Me ha pasado de hecho. O sea, donde yo estaba... que estén hablando inglés y yo me preguntaba, empiezan a hablar inglés y después español... ;Ah, si!, con Pedro y Charlie, que empiezan en español y siguen en inglés, y yo digo, qué diablo, habla español o habla inglés pero no estés con esas come mierderías.

\footnotetext{
${ }^{17}$ Codeswitching, as defined in this study, is carried out by competent bilinguals, that is, individuals who have a balanced competence in their two languages.
} 
Chapter Eight will discuss why Jaime thinks speaking English has snobbish or arrogant connotations. For now, let us turn to Jaime's wife, Valeria (33). She grew up close to Garden Hills, an affluent community in Guaynabo, and attended Academia San José, also in Guaynabo. In elementary school, Valeria was placed in a special group that emphasized English instruction. All classes were conducted in English except Spanish. When asked if she ever had a special motivation to learn English she said:

It seems that it was always present indirectly, I think that my mother never told me: "You have to learn English because it will open doors for you." I don't remember hearing that until I was older. When I reached high school and that awareness was there, because I remember Geswaldo and all those other teachers saying: "English is important. You don't take it seriously." Then it was more of an academic thing. You needed to learn English, English, English, English. I took it to heart.

Yo digo que como que siempre estuvo presente de alguna manera indirecta. Yo creo que nunca fue mami diciéndome: "Tienes que aprender inglés porque eso te abre puertas". Yo no recuerdo haber escuchado eso hasta después de grande. Ya en high school ya había esa conciencia, porque yo recuerdo a Geswaldo y todas esas maestras: "El inglés es importante. Ustedes no lo cogen en serio”. Ya era una cosa más académica. Hay que aprender inglés, y el inglés, y el inglés, y el inglés. Y yo lo cogía bien a pecho.

Valeria, like many of the bilinguals mentioned in the previous section had internalized the importance of English and her environment was conducive to learning it. Valeria remembers that all the TV shows she watched as a child were in English. For her, a world where people were not bilingual was practically inconceivable. This was evident when she enrolled in the School of Education at the University of Puerto Rico in Río Piedras. Although most of her 
friends went to the U.S. to study, she decided to stay in PR. She remembers the first classes that she took at the university, and her shock at the fact that other students were not fluent in English: The professor would say: "Here you have the readings, I apologize because some of them are in English.” And I thought: "I apologize?, Why?" And they said: "But professor, can you give us copies of related readings that are at the library?" As if she needed to provide alternatives for those who did not know English, and for me that was something I could not understand. Because in my ignorance, because it was ignorance, I didn't know some people had not been exposed to English.

La profesora decía: “Aquí tengo unas lecturas, les pido disculpas porque algunas son en inglés”. Y yo pensaba: “¿les pido disculpas?, ¿por qué?” Y ellos decían: “Pero profesora, denos copias de lecturas parecidas que estén en la biblioteca”. Como buscándole alternativas para los que no conocían inglés y para mí eso era una cosa que yo no podía entender. Porque dentro de mi ignorancia, porque era ignorancia, yo no sabía que la gente no había estado expuesta al inglés.

English was such a normal part of Valeria's life that she had a difficult time envisioning a monolingual society. What seems striking is that this potentially monolingual society was right next door to her, and it was comprised of fellow Puerto Ricans who were not competent in English. Her studies at the University of Puerto Rico did not allow her to continue developing her English skills as well as she would have wanted. Valeria regrets that her English skills declined after high school, especially her written English. This is one of the reasons why the experience of studying in the U.S. was so crucial in the bilinguality observed in the first group of speakers I described. As they entered adulthood, English became a means to define their future personas; it became an even more integral part of their identity. In Valeria's case, her English 
fluency did not translate into everyday codeswitching until recently. The main reason for this change in her linguistic behavior is that Valeria recently accepted a job as an elementary school teacher at Baldwin School in Guaynabo. Now, her everyday work life is completely in English. She conducts all classes in English, and is exposed to the language constantly. As a result, she is alternating more and more English with Spanish. Valeria finds that this increase of codeswitching is "dangerous," perhaps because of her awareness of what "correct" Spanish should be. However, she does recognize the advantages of bilingualism. Since her daughter was born, she instituted a daily "English hour" where she addresses her child only in English. This hour is already yielding results. Valeria's four year old has already begun talking to her in English.

Juliana (33) also studied at Academia San José in Guaynabo, but spent her first five school years at Colegio San Miguel in Bayamón. English education there was not strong. When her parents enrolled her at San José in sixth grade, Juliana was behind in this subject, and had to make an extra effort to pass the class. As in Valeria's case, Juliana's parents never emphasized English learning. On the contrary, her parents were working class Cuban immigrants who always emphasized the "correct" way of speaking Spanish, which responded to their Cuban dialect, and did not include many of the "sloppy" characteristics of Puerto Rican Spanish. These included pronunciation features and anglicisms. Juliana went on to obtain a bachelor's degree in Business Administration from the University of Puerto Rico in Río Piedras and a Master's Degree in Marketing from the Interamerican University in San Juan. She is now the marketing director for Puerto Rico at a U.S. pharmaceutical company. Although she went to the same private high school as Valeria, Juliana's experience at the University of Puerto Rico did not include an 
element of surprise because of students' lack of English knowledge, and lack of codeswitching, and here is why:

What happened was that I was in Business Administration and in Business Administration there were many students who came from Colegio San José, etc.

Codeswitching was normal, and that's why for me it wasn't a shock. Because we were a large group, and I remember my friends came from those same private schools, María Reina, San Ignacio...

Es que lo que pasa es que yo estaba en Administración de Empresas y en Administración de Empresas había mucha gente que venía de Colegio San José, etc. El codeswitching era normal, por eso para mí, no fue un choque. Porque éramos un grupo grande y yo me acuerdo que mis amistades eran de los mismos Colegios éstos, María Reina, San Ignacio...

Juliana's social network in college included people of similar linguistic backgrounds. Their everyday use of language included codeswitching. Although her initial English instruction was poor, Juliana's benefited from the intense second language instruction at Academia San José. Codeswitching, to a certain extent, is now part of her personality. She sees it as normal and appropriate in informal situations but admits to only doing it occasionally. However, Juliana admits that many bilinguals around her codeswitch far more than she does.

Viviana (35), the last participant in this profile category, attended Colegio Bautista located at Carolina, south of San Juan. She attributes the deficiencies she still has in English to the poor English education she received at this school. It was not until she began her studies in advertising at University of Puerto Rico in Río Piedras that she improved her English skills. The 
UPR requires two years of compulsory English for its students. If students do well in the College Board entrance examination they can skip first year English:

Where I learned good English was at the university because I had a teacher, in advanced English, because you take exams. Instead of taking basic English and waste my time, I got an advanced English teacher who gave great language labs where you practiced with headphones and such, and I say that the conversational English that I know today, I learned with her. In a year I learned what I hadn't learned in twelve.

Donde cogí buen inglés fue en la universidad, porque me tocó una maestra, siempre en inglés avanzado, porque tú coges unos exámenes. En vez del básico para perder el tiempo, me tocó una maestra de inglés avanzado y nos daba unos laboratorios bien chéveres y te conectabas y eso, y yo digo que el inglés conversacional que yo sé hoy día lo aprendí con ella. En un año aprendí lo que no aprendí en doce años.

Viviana took advantage of the opportunity to improve her English because she realized that it was important for her professional future. She explains that her motivation to learn English did not come from her parents or her environment; it came from her own awareness of the value of English for her future success. She refers to English with the word 'asset' and then ironically labels the use of this codeswitched word as "good Spanish":

Above all, because I knew that for the business world it is super-important. And especially for the advertising industry, knowing English was an asset, in good Spanish. Because later on you will have clients that will speak to you in English and you will have to present your ideas in English. It is not enough to read it or write it, you need to be able to conduct yourself in the other language... 
Más que nada porque sabía que para el mundo de los negocios es súper importante. $Y$ sobre todo en el campo de la publicidad, era un asset, en buen español, saber inglés. Porque después vas a tener clientes que te van a hablar inglés, vas a tener que presentar en inglés. No es suficiente saberlo leer y saberlo escribir, tienes que saberte conducir en el otro idioma...

Although Viviana found herself buying into a utilitarian perspective of English, she emphasizes the need to change this view. She thinks Puerto Ricans are not seeing beyond the dimensions of the Island, 100 miles long and 35 miles wide. Viviana has a broader perspective in mind, one in which English is an asset, not in terms of money, but in terms of intellectual enrichment. Viviana's thoughts reveal the prevalent treatment of English in Puerto Rico as a form of cultural capital. Elite social classes on the Island have the means to make sure their children have access to this language and can take advantage of this asset. Parents of the highest social class send their children to English summer camps and to schools where they can be sure their English will be developed. The six participants in this section reveal clear differences among private school students. Only Valeria, who attended a school that catered to the highest socioeconomic class, had the opportunity to develop her English fully since childhood. All others had personal motivations to learn the language and made a conscious choice to learn it. Their decision to continue their college education on the Island also had an impact on their second language competence, and on their everyday use of English. In terms of incorporating English in their habitus, there is indeed a difference between this group of speakers and those who had the opportunity to go abroad and be immersed in an English speaking environment. Nevertheless, this second group of participants did attain high levels of bilinguality and all but Jaime admitted to codeswitching daily with friends and coworkers. 
Bilinguals in this section are less influenced by standards of success that consider U.S. education superior to the one that can be obtained in PR universities. They are not Harvard or MIT graduates, but they are successful professionals who are highly competent in English, and recognize its value. However, their codeswitching practices do reveal a more detached relationship with English. They have less difficulty separating the two languages than the previous group of speakers, and it is easier for them to separate their everyday "self" from English use.

\section{Private and Public Schooling}

This category is one of the most interesting and revealing in terms of language attainment in Puerto Rico. I will talk about four individuals whose linguistic formation was influenced by both private and public schooling. Their experiences reveal the contrast between these two systems, especially in terms of the disparity of prevailing ideologies concerning the English language.

Walter (37) is married to Juliana (33), who was mentioned in the previous section. Walter's early schooling lacked stability. He attended preschool at Colegio La Inmaculada in San Juan and then studied at several public schools in Bayamón and Carolina, two towns close to San Juan. He describes English instruction in those schools as "terrible." When Walter reached ninth grade, his parents moved to San Juan and enrolled him at Colegio Calasanz. It was then when he really began learning English. As soon as the school year started, he noticed his level of English was not equal to that of his classmates, and he felt ashamed of this. Worried that others understood English and he did not, he began taking tutoring in English. His teacher made him read books in English with a dictionary, and encouraged him to join an essay writing club that competed with other private schools, such as Saint John's School and Robinson School: 
I had to do essays. It was a challenge for me, and I put in a lot of effort and it paid off. I don't have the best English in the world, but I understand it perfectly and can write it somewhat well. With the speller I can write a hundred percent well. And I speak it well. I have no problem expressing myself. My accent is probably quite bad, but I speak it. If I practice, I can speak better.

Era como hacer unos ensayos. Fue como un challenge para mí, y ahí puse de mi parte y salí adelante. No tengo el mejor inglés del mundo, pero lo entiendo a la perfección, lo escribo ahí más o menos. Con el speller lo escribo al cien. Y lo hablo bien. Yo no tengo problema al expresarme. El acento puede que lo tenga medio chiringa, pero lo hablo. Si lo practico, lo hablo mejor.

Walter explains that his parents are not fluent in English, and that his high school environment was not conducive to learning English to the extent that he did. He says he put in the effort because of his competitive nature. The others knew some English, so he decided he needed to learn that, and more. Walter explains that his high school did not focus on English like other private schools, where children become fully bilingual. He is very aware of which private schools focus on English instruction, and mentioned two of them.

Walter earned his Bachelor's Degree in Business Administration at the University of Puerto Rico in Carolina and then completed a Master's Degree in Finance at the Interamerican University in San Juan. He now works as an insurance agent and says that English is an integral part of his job. All contracts and insurance policies he handles are in English. As far as he knows, only one company in PR has policies in Spanish. All the courses and tests he has taken to move ahead in his career have been in English, and he also has English speaking clients. Walter presents a peculiar codeswitching profile. As he himself admitted, his English is not the best. $\mathrm{He}$ 
does not have a balanced competence in his two languages. However, Walter makes it a point to learn phrases in English and incorporate them in his daily language. Since his business partner is fully bilingual and habitually codeswitches, Walter hears these phrases and tries to learn them in order to use them later. Two examples he gave me were the term "newly rich" and the phrase: "You can take the girl out of the ghetto, but you can't take the ghetto out of the girl." Walter admits that some of his clients do not understand the English phrases he likes to use. When this happens, he refrains from using them. However, when they meet with clients, his business partner, Raúl, is sometimes not aware of the linguistic demands of the situation. When Raúl uses too much English, Walter has to intervene and explain the same thing to the client in Spanish. He describes Raúl's tendency to codeswitch with clients: "He starts talking to a client and I have to tell him: This one is not understanding you, don't you get it? Stop those codeswitchings, because this person does not understand them."

Although Walter does not codeswitch with Raúl's naturalness and spontaneity, and that of many of the other participants in this study, he grasps two important pragmatic aspects of codeswitching. First, Walter has a keen awareness of the potential breakdown in communication that may occur when both interlocutors do not share the same linguistic resources. Second, Walter understands the potential semantic and stylistic incongruence that may result from translating languages. When asked to explain the reason for his codeswitching, he mentioned the impossibility of translating an English phrase into Spanish without sounding strange:

(The word or phrase) fits perfectly! Too good to be true. How do you say that in Spanish? I don't know how to say that in Spanish. I tried to say that in Spanish yesterday and I wasn't able to. Too good to be true, ¿muy bueno para ser verdad? It's a translation that doesn't fit well in the sentence, it doesn't really make sense. I think it makes more 
sense to say: Too good to be true ... ¿muy cierto para ser verdad? No, that one doesn't work either...

(La palabra o frase) cae ahí, ipap! Too good to be true, ¿cómo tú lo dices en español? Yo no sé cómo decirlo en español. Lo traté de decir ayer en español y no sé cómo decirlo. Too good to be true, ¿muy bueno para ser verdad? Es como una traducción que como que no se acopla a la oración, como que no hace sentido. Yo encuentro que hace más sentido Too good to be true... ¿Muy cierto para ser verdad? No, eso no...

Another reason Walter gives for codeswitching is sounding "cool." This explanation may seem unimportant, but it is definitely not. This comment taps into one of the main issues dealt with in this dissertation: ideological conceptions of Spanish and English, and their relationship with identity. Walter relates codeswitching with high class, educated people. Those who are "cool" are also bilingual. He makes it clear that he wants to be linked with this group of people, and by using English he is asserting the fact that he belongs to this group. He can speak like them so he "is" like them. Chapter Nine, will address Walter's conceptualization of codeswitching as an "elite" code. This has important implications for codeswitching as a style that can be employed by bilinguals and can play an active role in shaping their social identities. Walter's use of English is not as automatic as that of the bilinguals in the first two categories of speakers in this chapter. English is not second nature to him, he did not learn it as a given, and his family is not bilingual. Given the right tools when he was a teenager, which included a private school that could support his English, he made a conscious choice to learn it. Now, as an adult, he recognizes the prestige associated with this code and he makes conscious efforts to deploy it in interaction. When asked if codeswitching had anything to do with his personality Walter chose to answer the question from the perspective of what others would think of his use of English: "Yes, 
everything's cool, creative. I'd like people to say: Walter is very creative. It's not what the country can do for you, it's what you can do for the country, do you get it?" ["Sí todo cool, creativo. Que digan: qué creativo es Walter. It's not what the country can do for you, it's what you can do for the country, ¿entiendes?”] In his answer to my question, Walter decided to include a phrase in English. Although he changed an article in John F. Kennedy's quote, he got the gist of it, and remembered it well enough to include it as an example of his English competence.

Janet (29) also experienced the contrast between public and private education in Puerto Rico. She admits that her first seven years of elementary education were deficient, especially when it came to English instruction. She attended three public schools in Caguas, east of San Juan. Janet explains why she learned practically no English in those seven years:

Well, in public school, English was incredibly basic. Year after year, instead of progressing, it's like you stay behind, in my opinion, you continue to remain in the basics. Therefore you never become bilingual if you limit your education to English in public school.

Bueno, en la escuela pública, el inglés era exageradamente básico. Y año tras año, en vez de tú ir progresando, como que te sigues manteniendo, en mi opinión, te sigues manteniendo en lo básico. Entonces nunca logras desarrollar ser bilingüe si solamente te limitas a la educación de la escuela pública en la parte del inglés.

When Janet was in seventh grade, a family tragedy resulted in her going to live with her aunt, who was a teacher at Colegio Notre Dame, a private Catholic school in Caguas. Naturally, she began her studies at that school. At first, she struggled to get good grades and catch up with her peers. English classes were extremely difficult for her because they were actually conducted 
in English. Thanks to vocabulary workshops, grammar lessons and intense reading, she learned all the English she had failed to learn growing up. Before moving in with her aunt, she had never watched TV shows in English, and she remembers that she started watching them in an effort to improve her second language. After graduation she enrolled at the University of Puerto Rico at Mayagüez to study Engineering but changed her concentration midway and finished a degree in Business Administration. Her English was useful in college for reading all mathematics and science books, and for succeeding in courses with professors who only spoke English. Later on, English became necessary for Janet's job, since all the financial reports she writes are in English. She also deals with many suppliers and clients from the U.S. and has to communicate with them in English. Since high school, her second language became an important part of Janet's life, and she internalized it to the point of finding it hard to avoid using English words in her everyday life. She codeswitches constantly with friends and coworkers. She says the only time when she does not codeswitch is when she is speaking English. Janet's life circumstances made her experience two worlds, one where students go to public school and don't learn English, in part because they don't need it, and one where English is an asset, an important part of education, and a tool for future success.

Adrián (31), the third speaker in this category, had friends who attended an all-English school while growing up (Saint John's School). However, in contrast to his childhood friends, Adrián came from a lower-middle class family. His parents knew English because they had lived in New York for several years before he was born. Adrián attended one public elementary school and two private high schools. He began his college education on the Island, but left school to dedicate himself fully to his business. Adrián's parents were Buddhists and because of their religious affiliation they had friends who only spoke English, and whose children studied at Saint 
John's School. While his parents socialized with other parents, he became friends with their sons and daughters. Adrián says part of the reason why he learned his second language well was because of his contact with English speaking peers. However, he is conscious of the fact that he did not come from the same socioeconomic background as his English speaking friends.

Adrián is now fluent in English and codeswitching is a regular part of his life. He attributes his codeswitching to the influence of his wife, María. He explains that some of his friends, the ones who do not speak English fluently, find it strange that he uses so much English. He, himself, finds it strange when he unconsciously uses English with clients at his art studio: I'm with my friends and I speak English and they look at me and say: "What's wrong with you?" But they're used to it already. María and I have been together nine years now. But my friends still find it strange: "Listen, why are you speaking English"? And I say: “Oh, sorry.” And it's all because I got it from María. María is the one responsible for the way I talk... Even with my clients. I'm talking normally and I'm explaining something: "Look at this molding, its color I think blends better with the art," and suddenly I'm like, what did I just say!, but María is the one responsible for it. Yo estoy con mis amistades y hablo en inglés y ellos me miran como que: “Qué pasó?” Pero ya están acostumbrados. María y yo llevamos nueve años, vamos a cumplir ahora. Pero mis amigos todavía se asombran. "Mira, por qué tú me hablas en inglés”. Y yo, “Ah, perdón”. Y es a consecuencia, porque María me lo pegó. María, eso a mí me lo pegó... Hasta incluso con los clientes. De momento yo estoy hablando, y le estoy explicando: "Mira, esta moldura, tiene un color que I think blends better with the art", y de momento yo, así mismo sigo, como que, iqué yo acabo de hacer! Pero eso sí, sí, básicamente, María es la culpable de eso. 
Two things stand out from Adrián's words. First, his childhood exposure to English through English-speaking peers was key in the development of his bilinguality. This becomes evident when he says that the friends he made in school did not develop the same linguistic abilities, and even comment on his use of English. Second, the social and shared aspect of codeswitching stand out in this case. Adrián's contact with English-speaking peers during his childhood and his wife's bilingualism are in part responsible for the incorporation of English words in his daily life. If it were not for these influences, Adrián could have remained a competent speaker of English, but not one that would use it in his everyday life.

Laura (33) is the fourth and final speaker in this category. Her first language is Spanish, but she has native-like competence in English. She figures that she learned Spanish at home with her mother and father, but she also remembers the presence of English since early childhood in the form of TV Shows and movies that she watched daily. Laura began her elementary education at Cupeyville School in San Juan. All classes were in English except for Spanish class. In fourth grade her family moved to the small town of Lares. She did her fourth grade in a public school and half of fifth grade in a Catholic private school. Her family then moved once more to San Juan and for half of her fifth grade, and her sixth grade Laura studied at the Josefita Monserrate de Sellés School, an excellent private school in San Juan. By this time, Laura had advanced second language competency. It appears that her first three years in an all-English school had made a mark in her bilingual development. Teachers at the Josefita Monserrate School realized that Laura was already fluent in English, and instead of having her study what she already knew, they asked her to do book reports and special assignments.

In middle school, her parents enrolled Laura at the University of Puerto Rico High School. This is a public school by definition, but the education children receive there far 
surpasses that of most other schools in the system. Students have to pass an entrance examination, and only the highest scores are accepted. Its curriculum includes advanced English courses. Laura took great advantage of these courses: "I learned more because people actually read the books that were assigned and they actually participated in class. And you obviously learned more." ["Aprendía más porque la gente se leía los libros and they actually participated in class. Pues obviamente, ahí aprendías más”.] Laura always loved reading. She collected comics and cartoon books (in English). She liked reading so much that her parents had to put a limit to how many books they bought each month. When Laura graduated from high school she continued her education at the University of Puerto Rico. She completed a Bachelor's Degree in Communications and later a Juris Doctor. She now occupies a managerial position at an advertising agency in San Juan.

Laura codeswitches all the time with everybody in every context. The only time when she refrains from including English in her speech is during professional presentations because she thinks this may undermine her credibility. All but one of the participants in this study agreed with Laura that codeswitching is not appropriate for professional situations. (The only participant who disagreed was Rey (39), a businessman who usually does business with other entrepreneurs who also codeswitch.) Laura's native-like competence in English had a great deal to do with her schooling, social environment and individual effort. Laura prides herself on her intellectual achievements and thinks codeswitching is a sign of intelligence, and of someone who knows his or her languages so well they that can pick and choose the appropriate words from each language as appropriate. Laura recognizes that to achieve her level of bilinguality in Puerto Rico, specific circumstances had to be in place: 
To have the level of English that I have, you need to have had cable TV, have attended a good school, preferably a bilingual one. You need more money to have good English skills. There are always exceptions, of course, but if we generalize, that is the case. Para tener el nivel de inglés que yo tengo, tienes que haber tenido cable TV, ir a una buena escuela, preferiblemente una escuela bilingüe. Tienes que tener más dinero para tener un buen inglés. Siempre hay excepciones, obviamente pero si vamos a generalizar, pues sí.

One of the exceptions Laura refers to is her husband, Alberto (34), whom I will talk about in the next section. He always attended public schools and has a very high English competence. Laura's case supports the hypothesis of the advantages of early language acquisition. Her childhood experience in an all-English environment, along with her innate aptitude, facilitated the balanced bilinguality she enjoys today. Laura did not participate in the "English as a given" mentality of private schooling which we saw in the first two sections. Her experience in the University of Puerto Rico High School gave her an open perspective on English as a sign of individual intellectual achievement. Nevertheless, Laura does recognize that English is in fact a commodity in Puerto Rico, and not all Puerto Ricans have the means to learn it. The four bilinguals in this section, Walter, Janet, Adrián and Laura, have unique linguistic histories. They are prime examples of the ideological underpinnings of English in Puerto Rico. As a teenager Walter strived to learn English and now makes it a point to use it in his daily life because he recognizes its value in PR's linguistic market. Adrián and Janet's experience emphasizes the role of school in regulating access to English as linguistic capital in PR. Ultimately, Janet and Laura's access to private schooling, without a doubt, played a significant role in their current bilingual abilities. 


\section{Public Schooling and English Attainment}

The last five participants all attended public elementary and high school in Puerto Rico. Manuel, Alberto, Ana and Lourdes have native-like proficiency in English, while Carlos has high competence in the language. In each of their lives there were unique circumstances that prompted their acquired bilinguality. Ana and Lourdes were born in the U.S.; Manuel and Alberto had exceptional motivations to learn English; and Carlos increased his English proficiency as an adult prompted by the need for this language for his profession.

Alberto (34) went to a public elementary school and in sixth grade he was accepted at the Escuela Libre de Música in San Juan. This school is part of the public school system of Puerto Rico and is focused on developing musical abilities of students on the Island. Alberto does not think his schooling was the reason behind his bilinguality. He mentions several factors that allowed him to learn English from an early age. The first crucial factor was his family environment. While other children enjoyed the easy retrieval of information from the Salvat encyclopedia in Spanish, Alberto remembers the long grueling hours he and his sisters spent translating the World Book encyclopedia for school assignments. Alberto explains why his father bought the English encyclopedia: "My father, although he was an independence supporter and a heavy nationalist, he always had the foresight of saying: It's important for you to learn that language." [“Mi papá con todo y que era independentista, nacionalista heavy, él siempre tuvo ese foresight de decir: Ese idioma es importante que lo conozcas".] Alberto's comment suggests that independence supporters, and those who have strong Puerto Rican nationalist sentiments are less likely to recognize the importance of English and promote its learning. His father's support of English would be seen by many, including Alberto, as contrary to nationalist principles. However, his father was capable of looking beyond the fact that English was the language of the 
colonizing power. He was successful in making English a normal part of his home and his children's lives, but not without some resistance:

I never felt that I had to motivate myself to learn English because it was something normal. I mean, I remember acting out and making a scene or two because I was stuck with the World Book and not the Salvat. But since my sisters also used it and they were older than me, then I thought I guess, that's the way you do it. I never saw it like: "I need to learn English."

Nunca sentí que tenía que motivarme a aprender inglés porque era como normal. I mean, yo me acuerdo haber peleado, una o dos rabietas de por qué tenía que usar la World Book y no la Salvat. Pero como mis hermanas también la usaban y eran mayores y yo era el menor, pues, pensé I guess, that's the way you do it. Yo nunca lo vi como: “Tengo que lograr aprender inglés”.

Alberto and his sisters learned English the hard way with the help of the infamous World Book encyclopedia, but Alberto's exposure to English was just beginning. He remembers that English class was easy for him at school. His house in Bayamón was one of the first to get cable TV and in order to understand the TV shows he liked, he had to learn English. By the time he reached high school he understood English well but had no one to speak to in this language. When Alberto was seventeen, he started traveling to the U.S. with his uncle, who took him along for product conventions and meetings with clients. He knew he needed to improve his English even more, because, as he puts it, he was now in the "big leagues." Alberto finished high school and began engineering studies at the Polytechnic University in San Juan. He quit school to find a job, and while working enrolled in the Interamerican University, also in San Juan, where he finished a degree in marketing. Although Alberto developed high proficiency in English, his 
classmates growing up were another story. It was clear that he was different from them in his linguistic abilities and that he owed that difference to his parents:

I always noticed that no one knew English, either they didn't get the jokes, or it was always evident... Believe me, I was terrible at many other subjects, because I didn't pay attention. In English, I always knew the answers. To me it was something normal. Knowing English, in my case, comparing myself with my peers, with the people with whom I studied.... The reason why I have some mastery over English and the ability to express myself better in the language, and all the opportunities I have had because of that, has to do with my parents... I mean, comparing myself to those who went to the same school, comparing myself to those people, not to those who had a private school education, with better classes and better opportunities. That's why my family made it a point for me to really learn English. I am an exception. When I see my graduating class and see the people there. There are only seven or eight of all those people who are at the same level as I in their ability to understand and communicate in English.

Siempre yo notaba que nadie sabía inglés, o no entendían chistes, o siempre notaba... Créeme, en un montón de otras materias, yo era horrible. Como no prestaba atención. El inglés, siempre sabía. Para mí, era como normal. El saber inglés, en el caso mío, comparándome con los peers, la gente con la que yo estudié y eso... La razón por la cual yo tengo un dominio del inglés, y la capacidad de expresarme mejor en él y todas las oportunidades que tengo por eso, tienen que ver con mis papás... O sea, comparándome con los de mi misma escuela, comparándome con esa gente, no con gente que tuvo educación de escuela privada, con clases mucho mejores, con muchas mejores oportunidades. Por eso mi familia se empeñó en asegurarse de que yo le metiera mano al 
inglés. Yo soy una excepción. Cuando yo me reúno con mi clase graduanda y yo veo la gente que hay. Solamente siete u ocho de toda esa gente son gente que está en el mismo nivel en términos de su capacidad de entender y comunicarse en inglés.

Parental involvement and the right home environment can have a great impact on learning a second language. Alberto's classmates did not see the need to learn English as he did. His parents made sure that he made this important investment. When he expressed this situation, I suggested that public school students needed to find additional motivations to learn English. Alberto answered: "In public school there is nothing that will motivate you." His words are drastic, but the next participant's experience seems to prove him right.

Carlos (40) admits that when he graduated from high school his English was terrible. His only exposure to English up to then had been one hour a day in public schools in Bayamón. When he reached the college level, at the Interamerican University in San Juan, he was forced to study more English because the books were in English. But it was not until he started working as an accountant that he really began to polish his English skills. When it came time to take the CPA exam, he realized there were many basic words he did not understand. He had to sit down with a dictionary and look them up. He passed the exam and in his first job as an accountant he had to deal with American clients. His employer helped Carlos take the first of many individual English courses to improve his English. Once he started working with "Big Five" firms like Ernst and Young, the need to learn English was essential for his career, so he continued to invest considerable time in taking private English courses. His linguistic skills improved, and English is currently one of the most important tools for his daily work tasks and for professional advancement. 
For Carlos, the need to learn English to be successful in his chosen career field was a total surprise. There was nothing in his upbringing that gave him clues as to how important English would be in his future plans. His parents, who do not speak English, encouraged him to do well in school but never placed any special emphasis on English. After high school, Carlos found out that if he wanted to advance in his career, he would have to add English to his skill set. When he first tried to look for a job, they told him that if he did not speak English they could not hire him. That's when he realized he would have to look for ways to improve his second language.

The high value of English in PR's linguistic market is evident in Carlo's story. He invested in English as an adult, and is now capable of employing English, as linguistic capital, to his benefit. However, his acquisition of English did not translate into an everyday use of this code in casual interactions. He does not have a balanced proficiency in English and Spanish. The only time Carlos uses English interspersed with Spanish is when he talks about work topics, since in PR's accounting industry many terms are used solely in English. Carlos observes that there are groups of Puerto Ricans who are more likely to codeswitch. These groups are comprised mainly of people whose education, from an early age, included constant exposure to English, mainly in private schools. He also mentions the presence of codeswitching among those who are Puerto Rican but leave the Island for a while, come back, and exhibit that exposure to English in their daily linguistic practices.

Carlos mentions the migratory nature of Puerto Rican society as contributing to English attainment. Early and constant exposure to a language is key to bilingual development. For this reason, a Puerto Rican who was born in the U.S. or lived there as a child, is likely to have a higher level of English competence. Among the participants in this study who codeswitch most 
often is Carlos' wife, Ana (34). She was born in Boston. Her mother and father spoke Spanish to her since birth, and her first contact with English was at a bilingual preschool. She learned the basics of English in school and practiced it with her three older brothers. She was six years old when they moved back to Puerto Rico and settled in Río Grande, a town about an hour east of San Juan. At public school in first grade, other children made fun of Ana and her brothers because sometimes they spoke "Chinese," which reveals how foreign English sounded to the other Puerto Rican children. Ana had two excellent teachers in public school, her fourth grade teacher and her twelfth grade teacher. The others were, in her opinion, not very good. Growing up, Ana watched a lot of television shows in English and remembers well the day when she heard one of the characters in the Cosby Show use the word "insane." She stood up during commercials to look up the meaning of the word.

Ana enrolled at the University of Puerto Rico at Río Piedras. Since her English scores on the college entrance examination were high, she was placed in second year English. It was then that Ana went through the "trauma" of realizing her English was not as good as she had thought. Up to that point, she had been comparing her skills to those of the other public school students. But now, in college, she got a "C" on her first essay and realized her written English needed a lot of improvement. Ana still has the books she read for that class, and now thinks the words she looked up in the dictionary back then were incredibly basic. She also had an American roommate with whom she practiced her English.

Ana finished a BA in Communications and later completed a Juris Doctor, both at the University of Puerto Rico at Río Piedras. She worked for several years at an advertising agency and now works for one of PR's top law firms. All of the firm's employees have to be bilingual because they deal constantly with American clients and handle cases in English with the U.S. 
Federal Court. Ana mentioned that everyone at her firm needs to be proficient in English to work there, and they all codeswitch when they talk amongst themselves. I was able to verify this when I visited the firm as part of my research for this study. Because of the confidential nature of work at the firm, it would have been extremely difficult to obtain permission to record conversations, but I did take note of one exchange between Ana and a coworker regarding April Fools' Day. The three minute exchange included constant intrasentential and intersentential codeswitching. In Ana's case, codeswitching is an integral part of her personality. When I interviewed other participants in her social network, they all mentioned her as an example of someone who constantly alternates languages, maybe even too much. Ana has thorough knowledge of her two languages, from a casual oral register to complex written, academic discourse. She has not always embraced codeswitching, and a few years ago, the idea of mixing languages worried her to a certain extent. In the following comment, she admits to have considered codeswitching as a threat to the "correctness" of Spanish:

I started worrying about not being correct in Spanish or in English. I wasn't being faithful to either language. But I am now a bit more relaxed, and actually at work they make fun of me because I do it a lot... Obviously, everyone does it, everyone. And it's very funny because some people have an excellent English accent and obviously codeswitch, and there are others, like Luis for example, who have a very, very strong Puerto Rican accent. He codeswitches a lot and I don't understand him. He then has to repeat what he says, but it's because his pronunciation is not easy to understand. Me daba la cuestión de que no estaba siendo correcta ni al español ni al inglés. No le estaba siendo fiel a ninguno de los dos. Pues ya estoy un poquito más relaxed y de hecho, en el trabajo hasta me gufean porque lo hago mucho... Obviamente, todo el mundo lo 
hace, todo el mundo. Y es bien gracioso porque hay gente que tiene un acento excelente en inglés, y obviamente hacen codeswitching y hay gente, por ejemplo como Luis que tiene un acento bien, bien, bien marcado boricua. Él hace codeswitching mucho y no lo entiendo. Y entonces me tiene que repetir las frases otra vez, pero es porque su pronunciación no es la más fácil de entender.

It is clear that codeswitching is an accepted discourse style in Ana's work environment. However, most of Ana's coworkers are Puerto Rican and their native language is Spanish. Ana makes reference to "accent," or particular phonological characteristics of English spoken by native speakers of Spanish. Several other respondents also made comments about pronunciation. Some said a perfect "all American" pronunciation of English is not acceptable in codeswitching, but, as Ana mentioned, an "extreme Puerto Rican" pronunciation is not acceptable either. Phonological analysis of codeswitched instances and their social interpretation lie beyond the scope of the present study. However, a preliminary observation is that bilinguals in this study cannot deny the influence of Spanish on their English, and they are not interested in doing so. It seems OK to use English in conversation, but sounding too "American" seems objectionable. Similarly, as we will see in Chapter Eight, including too many English words in codeswitching is also unacceptable.

The linguistic background of Lourdes (30) is similar to Ana's. She was born in Puerto Rico, but her parents moved to New York when she was three weeks old. She came back to PR with her parents and began her second grade at a public school in Guaynabo. At first she excelled in English and would do everyone else's homework. However, there came a point where she realized she was not good at writing in Spanish or in English. Despite her shortcomings in this area of proficiency, she was still a fluent English speaker, when comparing herself to her 
classmates. Her home environment was also different from that of her peers. In high school she found it strange that her classmates did not watch the same English TV shows that she watched. Now, as an adult, she is thankful that she acquired her second language in the U.S. Lourdes recognizes the need for English to "get ahead" in Puerto Rico.

The last participant we will meet is Lourdes' husband. Manuel (33) is a journalist, filmmaker and film professor. He has always been fascinated by movies. The first movies he watched as a very young child were in English. He lived in the Dominican Republic with his Spanish father and Puerto Rican mother until he was seven years old, when they moved to Puerto Rico. Manuel believes that he learned English from movies because he did not study English before coming to the Island. Nevertheless, he took the entrance examination to be accepted at the University of Puerto Rico elementary school and he passed the English section with flying colors. Once in high school Manuel was part of the advanced English group. He continued being an avid fan of American movies and practiced English daily with one of his best friends. He went on to study Communications at the University of Puerto Rico. He then spent a year in New York taking film workshops. From New York he moved to California where he enrolled in Chapman University where he finished an MA in film production. He spent a total of six years in the U.S. Although it is debatable whether children can learn languages from watching movies or television, Manuel identifies his love for movies as the main motivation to learn English. The fact that his school is a "model" public school and not the typical one also contributed to his academic achievement, including his success in English. Now, as an adult, Manuel uses English on a daily basis. He tells me that he uses English habitually with his wife Lourdes to talk about movies and TV shows. English is an integral part of Manuel's life. When asked about the reason why he codeswitches he said: 
I can handle both languages fairly well; it's a form of expression. It's like having two tools. If I want to express something I can choose either of those tools to express what I need to express. That's why I don't overanalyze it. Because I simply have them available in such a way that I don't have to think about it (in order to speak). Yo manejo los dos idiomas bastante bien; es una forma de expresión. Son como dos herramientas. Yo si quiero expresar algo pues puedo escoger cualquiera de las dos herramientas para expresar lo que quiero expresar. Por eso es que no es sobre analizado. Porque simplemente yo las tengo accesibles de una forma que no hay que pensarlo (para hablar).

The five bilinguals in this section represent varied outcomes of bilinguality within the same social milieu, just as the rest of the speakers who participated in this study. A thorough characterization of participants showed that two main factors contributed to their linguistic development: motivation, and early exposure to English in the U.S. Alberto's father was the driving force in motivating him to learn English, but he also made it a point to develop his English skills, while Manuel's early love for American movies had an impact on his linguistic development. Ana and Lourdes both had the opportunity to begin their English learning in the U.S. However, ultimate language attainment was determined by their personal investment in the language. Lourdes never really polished her English skills, while Ana made it a point to continue investing in the language that would later be an invaluable tool for her professional goals. Carlos is also a prime example of personal motivation and investment in language learning. He spent several years perfecting a language that would determine his professional success.

Three elements stand out in the linguistic development of participants in this dissertation. First, school is an indispensible element in the development of bilinguality in PR. Different 
degrees of bilingualism are, to a certain extent, determined by the quality of instruction, and permeating school ideologies regarding English. Second, the social network of the individual and the linguistic expectations of school, family and peers also play a role in ultimate English achievement. Third, as we saw in Walter, Janet and Laura's cases, individual effort in the mastery of the language is crucial. The tools provided by the school, the social circumstances that promote or hinder its development, and individual investment in language attainment, are necessary ingredients of Puerto Rican bilinguality.

\section{English Learning: Changing Trends}

Virtually all respondents in the present study mentioned changing trends regarding the increased presence of English in Puerto Rican society. Most participants were born in the late sixties and seventies. Their experience growing up and learning English is different from the current generations in many respects. For instance, Carlos (40) says that everyday Puerto Ricans are getting increasingly familiarized with the American culture and young children are the ones most exposed to this influence. He thinks his parents were more exposed to what made them Puerto Rican: traditions, Spanish and so forth. But as time goes by, new generations are identifying more with the U.S. culture, and eventually bilingualism should be more widely spread throughout PR.

The American influence that Carlos talks about is felt more strongly in the areas of the media and technology. When the oldest participants in this study were growing up, computers were still making their way into the home. Now, they are a normal part of people's lives since childhood. Ana, and at least seven other participants, mentioned technology as responsible for the incorporation of English words into Puerto Rican Spanish. Ana agrees with Carlos in that English penetration in Puerto Rican society is on the rise: 
The influence will increase, it increases more and more. If you notice how Puerto Rico was before, how it began, historically. Here, English was imposed, Americans tried to impose English, and force education in English, and people refused, and that's it. Now we find different idiosyncrasies and ideas. We live in a globalized world through the Internet. Yes, there are a lot of sites in Spanish, but the majority are in English and young people who have access to those sites know English and will know more English because they have access to that language, when before, they didn't have it. When we were growing up... OK, I'm talking about us, the MTV generation. We are not the YouTube generation, nor the Google generation, those people will know more English, and we may remain in the Commonwealth limbo, but the influence of English will continue on the rise.

La influencia va a aumentar, cada vez sigue aumentando. Si tú te fijas cómo era Puerto Rico, cómo empezó, históricamente. Aquí se impuso. Los americanos trataron de imponer el inglés y que se enseñara y se educara a la gente en inglés y la gente se rehusó a eso, punto. Ya ahora la idiosincrasia y la idea es diferente. Vivimos en un mundo globalizado con el Internet. Ciertamente hay un montón de sites en español, pero la mayoría es en inglés y la juventud que tiene acceso a esos sites, etc... dominan el inglés y lo van a dominar más por el acceso a ese idioma, que antes no lo tenían. Cuando nosotros nos criamos... ok, yo estoy hablando de nosotros, el MTV generation, pero no somos el YouTube generation, ni el Google generation, esta gente va a saber más inglés todavía y nos podremos quedar en el limbo del Estado Libre Asociado pero la influencia del inglés cada vez va a aumentar más. 
Ana makes reference to the history of English in Puerto Rico and emphasizes the contrast between past generations who rejected English and present generations who embrace English and are allowing it to penetrate more and more in the Island's linguistic scene. Bilingualization has been successful among the highest socioeconomic classes on the Island since the arrival of the U.S. Therefore, the biggest impact of technology, in terms of English learning, may be felt in other social classes because English is gaining ground in children's lives through video games and computers. Much of the research on bilingualism in Puerto Rico emphasizes the lack of English attainment of public school students (Clachar, 1996; Pousada, 1996; Schweers and Vélez, 1992; Torruellas, 1990). However, recently many children who go to public school are gaining access to computers and video games, and becoming curious about the language of these fun activities. This gives them an added motivation to learn the language. I have talked to several public school English teachers who confirm that technology has played a role in motivating their students to learn. However, we cannot be too quick to conclude that all Puerto Ricans are now more ready and willing to see English as a neutral code, and that this is translating into increased bilinguality. Considerable research remains to be conducted in order to ascertain if a change in attitudes toward English will eventually give way to an increase in bilinguality. At present, results of the "Puerto Rican tests" do not indicate high levels of bilinguality in students graduating from public high schools. ${ }^{18}$

Changing trends with regard to the penetration of English in the Puerto Rican context may also have an impact on both the proliferation and acceptability of codeswitching practices among bilinguals. One of the youngest participants, Diego (27), presently works at a law office, while studying to obtain his juris doctor. He observes that although it is clear that professional

\footnotetext{
18 “Resultados Pruebas Puertorriqueñas” 2002-2005. Department of Education.
} 
settings are not conducive to codeswitching, there are indications of change, and there are certain gray areas where English is being accepted more and more:

Little by little, in my experience, there has been a mixture, because I've seen people at work, in official dealings, who are constantly throwing in things in English, which is weird. I don't know, maybe there is a mixing process, a gray area. For example, I've had professors that do that in class. I had an evidence professor who, in every class, would say, "the law says this or that", and then he would say "whatever that means," and he would continue talking in Spanish. He would integrate (English), so I think today there is more acceptance than before. I see people like my grandmother scolding me and saying, you're not supposed to say this or that, and now that same word is more acceptable. It's generational.

Poco a poco en mi experiencia se ha ido mezclando eso, porque he visto gente en el trabajo en cosas oficiales que se pasan zumbando cosas en inglés, lo cual es raro. No sé a lo mejor hay un proceso de esa mescolanza, de un área gris. Por ejemplo he tenido profesores que hacen eso en las clases. Yo tenía un profesor de evidencia y en todas las clases decía "la ley dice tal o cual cosa”, y después decía: “whatever that means” y seguía hablando en español. Lo integraba, o sea que hay más aceptación creo hoy en día que antes. Veo gente como mi abuela regañándome y diciendo: eso se dice de tal forma y ahora esa forma es más aceptable. Es algo generacional.

Diego's observation supports the hypothesis of a generational change in terms of language use. Participants agree that the newer generations have more and more English influence. Virtually all participants made comments that point toward a process of linguistic change which includes an increased presence of English in everyday talk. Walter (37) mentions 
that those who do not know English are lagging behind when it comes to linguistic change. Adrián (31) says it is impossible to live in Puerto Rico and not be influenced by the English language. It will inevitably enter your daily vocabulary.

One interesting fact is that Adrián and Rey’s fathers are fully bilingual but never codeswitch. Both Adrián and Rey think this resistance to incorporate English is generational. The newer generations are more open to mixing languages because, in general, there is more openness to the incorporation of English in everyday life, a social phenomenon that is not restricted to Puerto Rico and has been documented in other parts of the world as well (Kachru, 1992; Romaine, 1996; Zuckermann, 2003).

A related topic brought up by participants in the present study who are parents of school age children is the decision of whether to enroll their children in all-English private schools or a Spanish private school with emphasis in English. Viviana (35) explains that many parents in her community face a difficult choice: "Should I enroll my child in an all-English school where I am sure he will learn good English, or opt for a Spanish speaking school?" Viviana opted for enrolling her six year old son in a school with a Spanish curriculum. She says that once her son reaches sixth grade she might transfer him to another school to reinforce his English. She makes it clear that she would do so only after his native language is well developed. Viviana does not believe that choosing an all-English school is a positive thing:

I noticed that the children of my friends who opted for all-English schools speak great English, but their Spanish is terrible. Terrible. They translate it. They are all between seven and ten years of age. At that age you know how to express yourself fairly well. And what happens is that you end up with very strange dynamics, because they speak English at home because obviously they hear it at school so they speak English with their 
siblings, and they play in English all the time. This is a phenomenon that you see more and more each day. It's happening in the upper middle socioeconomic classes. Me di cuenta de que mis amigas que habían optado por inglés nada más, sus hijos hablan muy bien inglés y un español fatal. Fatal, lo traducen. Tienen todos entre siete y diez años. Ya a esa edad tú te sabes expresar bastante bien. Y qué pasa, terminan unas dinámicas bien extrañas porque en las casas hablan inglés porque obviamente lo escuchan en la escuela, hablan con los hermanitos, juegan en inglés todo el tiempo. Es un fenómeno que se está dando cada vez más. Se está dando también en una clase socioeconómica media alta.

Viviana thinks it is great to know a second language, but Puerto Ricans should learn Spanish well, because it is their native language, and because it defines them as Puerto Ricans. If children learn English, that is well and good, but this should not happen at the expense of Spanish. Valeria (33), who works at an all-English elementary school in Guaynabo shares Viviana's concern about Puerto Rican children who do not learn Spanish well. She speaks sadly of children that enter first grade speaking Spanish and by the end of the year hardly speak it at all, and when they do, they have already developed a "strange foreign accent." All-English schools have existed for many years in Puerto Rico. However, these two mothers, bilinguals who grew up in "regular" private schools with Spanish speaking parents, had never before been exposed to an all-English culture in Puerto Rico. They find that the possibility of having children who grow up speaking only English on the Island is terrible and sad, and should be avoided. Both Valeria and Viviana recognize the value of English, but they are equally clear about the importance of Spanish. Even so, more and more parents are aware of the significance of giving their children the opportunity to learn English well. However, Valeria emphasizes that creating 
an imbalance that suggests that English is better than Spanish is problematic. She believes that one should not be viewed as more important than the other. Perhaps as a result of the increasing demand for English, new schools with this type of curriculum have opened recently. Valeria speaks of one such preschool:

If you want to see a very interesting preschool, there's the Parent Participatory Preschool. Teachers there don't even use one word in Spanish. Not one word. And you know, it's so interesting, how can it be that you don't speak Spanish to your three year old child, who you know is in the best moment to learn languages? To me that's ridiculous.

Si quieres algo pre-escolar bien interesante está el Parent Participatory Preschool. Allí no se les habla ni pajarito de español. Ni pajarito. Y tú sabes lo interesante que es que a tu hijo de tres años que tú sabes que está en el mejor momento de aprender idiomas tú no le hables español. Eso para mí es ridículo.

Valeria believes that not speaking Spanish to young children is ridiculous because, although times are changing and English seems to be gaining ground in the Puerto Rican context, the Spanish language has strong roots that are not easily replaceable. Informants in the present study are all bilingual, but their native language is still Spanish. They may codeswitch on a regular basis, but Spanish is the language in which most of them dream, pray, curse and love.

English may indeed be making its way into the Puerto Rican linguistic milieu. The effects of language contact on the Island are undeniable. This process is in part fueled by the influence of the media and technology, which paves the way, as in many modern societies, for the incorporation of English in daily life. The increased presence of English may have an impact on the motivation to learn it, and on ultimate bilingual attainment in Puerto Rico. All of the participants in the present study, without exception, expressed wanting their children to become 
bilingual and some would like them to be multilingual. Those who have children are already doing everything they can to make sure they learn English. Among the decisions they are making is having their children attend schools that will foster their bilinguality. One thing is certain; they will not leave their children's bilinguality to chance. The opportunities missed would be far too many.

After gaining a better understanding of the linguistic backgrounds of the bilinguals who participated in this study, there is considerable data to suggest that political and economic variables present in this context have had an impact on the availability, access to, and ultimate use of English. This language is an important form of cultural capital, more readily available to those of elite status and social privilege who have access to certain schools and certain social networks. English is also available to those who make conscious choices to invest in the language in order to reap the intellectual, professional, and economic benefits this language can bring. The linguistic practices of bilinguals, and in this case the possibility of alternating English and Spanish in conversation, can be interpreted in terms of speakers' appropriation of English as a symbolic resource. The next three Chapters, Seven, Eight and Nine, will concentrate on answering the study's research questions and presenting the most salient and interesting findings that resulted from the corpus of data. An analysis of codeswitching by Island Puerto Rican bilinguals will be achieved by correlating: (a) information about the macro-ideological template of the two languages used, (b) details about language alternation as documented in the recorded conversations and, c) data obtained from interviews with participants. 


\section{Chapter 7: English in Conversation}

The first research question addresses how English is being used by elite Island Puerto Rican bilinguals in informal group encounters. This chapter will highlight group tendencies and individual differences in English use. It will document language distribution in conversations, classify types of codeswitching, identify common discourse functions; and list and explain recurrent discourse topics in codeswitching examples. This chapter will also serve as a basis for discussing the relationship between language alternation and identity. Furthermore, the sociocultural linguistic analysis proposed here is not concerned with quantifying particular occurrences of English in conversation, but rather is focused on understanding "the effect of linguistic form on discourse practice and emergent social meanings” (Nilep, 2006, p. 17).

\section{Language Distribution}

A preliminary consideration is the distribution of the languages being mixed. In one of the early studies on Spanish/English codeswitching, Jacobson (1977) stated that the bilingual "who engages in codeswitching may achieve the mixing of the two languages by means of two different strategies: his language structure may be basically Spanish but contain English constituents, or it may be basically English with Spanish constituents inserted into it” (p. 233). In the present corpus of data, Spanish is the base or matrix language, with English constituents. This was expected, since Spanish is the native language of all speakers.

People in general find it difficult to report their own language usage in ways which are meaningful to the linguist. With regard to codeswitching, bilinguals are often not aware of which language they use at a particular time. Imagine having someone ask you to recall all the instances in which you used the past tense in your last conversation. Gumperz (1982) explained that asking 
speakers to recall codeswitching instances may be equally difficult. In the present study, speakers were not asked to recall specific instances of codeswitching, but were only expected to report on their general tendencies of English use. Evidence gathered in recorded conversations supported participants' perceptions. Speakers seemed aware of both how much English they themselves used, as well as how much English people in their family and social circle habitually use. This is not surprising since English, in this context, is not a neutral code. When speakers use this language in conversation, they inevitably draw on ideological associations. These associations are not evident to speakers at the moment of interaction, but their relevance was revealed once participants were asked to comment on them. The next chapter will discuss further the social interpretation of codeswitching.

Virtually all switches into English were not preceded by hesitation or pauses, and respected syntactical constraints of both languages. According to Poplack, (1980) this type of skilled codeswitching is evidence of a high level of bilingual competence (p. 231). It has already been established that all but three individuals (Walter, Jaime and Carlos) in the network of speakers under study have native -like control of English. However, there were differences in competencies and on levels of separation between the two languages. The topic of language processing in the bilingual brain lies beyond the scope of this research. However, the issue of language separation is of importance to the present study because it may have an impact on the distribution of codes in interaction, and also on codeswitching as a factor in defining these individuals' identities.

Participants were asked if they were able to speak solely in English or solely in Spanish, and if they found this difficult to achieve. Answers to this question can be divided into three categories: those who find it easy to block English words from their speech; those who have to 
pay close attention to their speech in order to avoid English; and those who find it difficult not to alternate languages, and need to put in a concentrated effort to speak solely in Spanish. Graciela expressed what it is like for her to be bilingual: "I find it hard to separate the two languages, especially when I have to speak solely in Spanish. I have to think about it more. I tend to want to say words in English, and to avoid it I have to think it through; I'm like... hmmn... that word was very difficult."

Based on the participant profiles discussed in the previous chapter, two factors could influence the degree of separation of the two languages: age of acquisition and frequency of exposure. María, for example, says she learned English in early childhood and finds it difficult to block this language altogether because it was such an integral part of her development. In Ana's case, both age of acquisition and degree of daily exposure to the language could influence her habitual use of English. Ana was born in the U.S. and had some exposure to English as a child. As an adult, she uses English constantly at work. She is a lawyer and many of the cases she handles are in English. Similarly, Valeria recently began working as a teacher at an all-English school. She uses English all day, every day. Valeria has even noticed a change in the frequency of her English use since she started working at this school: "When I speak Spanish, I speak Spanish, but I think now... My Spanish continues to be excellent, but I think now my mind has many more thoughts in English than before. Each day they are becoming more and more frequent."

One last topic regarding language distribution in codeswitching is the "amount" of English that is allowed or accepted as normal in interaction among this network of speakers. Lourdes was very emphatic about how much English is admissible in conversation: 
I know some people who make me nervous. They speak English, Spanish, English, Spanish. The sentence has five words and it goes: Spanish, English, Spanish, English, I've heard them do that. And I'm like, talk to me in Spanish, I understand English too. One thing is to have a word to kick it up, what does Emeril say?... Kick it up a notch, but I'm not going to speak to you in English and say: Oh, because yesterday I went to the supermarket. I'm not going to do that because it's not natural.

Yo conozco gente que a mí me pone nerviosa, que hablan en inglés, español, inglés, español. La oración tiene cinco palabras y va inglés español inglés español y las he oído. Y yo soy como que háblame español, yo entiendo inglés también. Una cosa es tú decir una palabra, pero no, eso a mí no me gusta. Una cosa es tener una palabrita que es por su kick it up, ¿como es que dice Emeril?... kick it up a notch, pero no es que te voy a hablar inglés y te voy a decir: Oh, because yersterday fui al supermercado. No voy a hacer eso porque es como que forzado.

Lourdes' opinion about how much English can be included in conversation is expected, given several contextual factors: First, Spanish is the society-wide accepted discourse mode in Puerto Rico. Therefore, including large amounts of English in conversation is bound to stir this type of reaction, even among those who habitually codeswitch. Second, Lourdes thinks that one should not use English for the sake of using it. She thinks that beginning a random sentence in English is not acceptable. At some level, Lourdes is aware of the pragmatic functions of codeswitching, where using English is not random; it is pragmatically and discursively motivated. Third, Lourdes was one of four participants who made observations about permissible amounts of English in conversation. Perhaps other speakers were less concerned about putting limits on their English usage because they themselves use much English in conversation. For 
example, Janet said that the amount of English Ana uses caught her by surprise, and is a bit too much. Ana was one of the respondents who expressed having difficulty separating the two languages. She codeswitches with regularity, but her codeswitching is no less pragmatically motivated. Alberto felt strongly about this topic:

If you have to, in order to get your message across, if you have to use an ENTIRE sentence in one language and an ENTIRE sentence in another, that is weird. People who do this thing where they take one entire sentence in English and then the other one in Spanish... That for me, I see it as a bit arrogant. Because I see it in a context where it is not necessary to have a complete sentence in English. But I could understand why some people feel more comfortable doing that. In fact, it's a stupid rule that I didn't even know I had, but I just realized I have it, of using words and phrases that are absolutely necessary.

Si tú tienes que, para llevar un mensaje, tienes que usar una oración ENTERA en un idioma y otra oración ENTERA en otro idioma, eso es weird. La gente que hace esa cuestión de coger una oración completa, ponerla en inglés y la otra en español, eso para mí, yo lo veo como un poquito arrogante, dentro de mí. Porque dentro del contexto de como yo lo veo, yo no veo que sea necesario decir la oración completa en inglés. Pero yo puedo entender por qué hay gente que lo haga porque se siente más cómoda haciéndolo. De hecho, es una regla estúpida que yo ni sabía que la tenía pero me acabo de dar cuenta que la tengo. Es usar las palabras y frases que sean absolutamente necesarias. Alberto does not know why he has a "stupid" rule against too much English. From the analyst's perspective, this comment is evidence of "critical language awareness" (Fairclough, 1992). The reason behind Alberto's rule becomes clear when we consider language conventions, 
and how linguistic practices are invested with power relations. Ideologies regarding language in Puerto Rico influence speakers' perceptions of permissible codes in interaction. In this case, Alberto is echoing a widespread ideology of English as the language of power and domination. Thus, if a speaker uses "too much" English, he or she is making a statement regarding those power relations. Codeswitching, as seen here, may or may not respond to a speaker's arrogance, as suggested by Alberto, but it certainly responds to the overall tendency to use English in each interaction. Indeed, codeswitching is sensitive to ideologies, beliefs and perceptions about language that are active in this context. Chapter Eight will further address the social interpretation of codeswitching.

\section{Classification of Switches}

The next step is to concentrate on the form codeswitching takes in conversation, that is, to examine the points in discourse where speakers mixed the two languages. A valid classification of switches was provided by Poplack (2000). The first type of switching is termed "emblematic" and includes tags, interjections, idiomatic expressions, and individual noun switches (e.g., Oh my God!, you know, and I mean). The second classification comprises the generalized use of intrasentential switching, which may represent an overall discourse mode. This type of switching occurs within the sentence boundary and must obey sentence-internal syntactic constraints. The third classification, intersentential switching, involves changes at the sentence boundary (p. 254).

Four types of switches, based on Poplack's classifications, were identified in the present corpus.

1) Single-word switches - Refer to lexical items which include adjectives, adverbs, and single and compound nouns, excluding proper names. In the following example, Ana and 
Manuel are talking about his new movie. One of the movie sets is Manuel's old high school. Ana asks him if it has changed much from the time he was a student there. In lines 04 and 05 below, Manuel uses the words 'face lift' and 'appeal' to refer to the improvements that would be made for filming. Line 11 is and example of intersentential codeswitching, which will be discussed next.

Example (1)

$01 \quad$ A: ¿No ha cambiado?

'It hasn't changed?'

02 M: Está más jodía, de hecho.

'It's worse, actually.'

$03 \quad$ A: ¿De verdad?

'Really?'

04 M: De hecho, yo fui con la persona de arte y va a haber que darle un face lift.

'Actually, I went with the art director and we're going to have to give it a face lift'

De hecho ese es parte del appeal, que vamos a poner árboles, vamos a pintar y 'In fact, that's part of the appeal, that we're planting trees, we're painting and'

$06 \quad$ arreglar y dejarla así.

'fixing it to leave it like that.'

07 A: De donación.

As a donation.

$08 \quad$ M: $\quad$ Eso en verano o si no sería empezarla en octubre con todas las

'That would be in the summer, if not, we would start in October with all the' 

'scenes that are not at the school, and then in November and December...'

10 A: Si te toca en diciembre que está todo el tiempo lloviendo If you have to do it in December, when it's raining all the time,

11 te chavaste. O sea, it would be very nasty. you're asking for it, I mean, it would be very nasty.

(2) Tag switches - Independent lexical items that may be placed anywhere in the sentence. Examples are: 'you know,' 'I mean,' 'whatever,' 'anyway' and 'Oh God.' In Example (2) Helena, Ana and Sandra talk about Helena's boyfriend, Pedro, and his sister. Pedro's sister seems to not like Helena. In line 04, Ana uses the word 'anyway.'

Example (2)

$01 \quad \mathrm{H}: \quad$ Yo no sé por qué a ella le molesta tanto que yo sea novia de Pedro. Digo, ella 'I don't know why it upsets her so much that I'm Pedro's girlfriend. I mean, she' tiene big issues to begin, o sea, ella es 'has big issues to begin, I mean, she has'

03 una persona de carácter bien difícil to begin with. 'a very difficult personality to begin with.'

04 A: Es igual que mi cuñada. Anyway...

'The same as my sister in law. Anyway...'

$05 \mathrm{H}$ : It makes for a really fun family reunion. 'It makes for a really fun family reunion.'

$06 \quad \mathrm{~S}: \quad$ ¿Ni siquiera hola?

'Not even hello?' 
$07 \quad$ H: $\quad$ Me saluda. Sí.

'She does say hi to me.'

(3) Intrasentential - Includes segments within a sentence that are larger than one constituent. According to Poplack (2000), "in order to produce this sort of switch, the speaker must also know enough about the grammar of each language, and the way they interact, to avoid ungrammatical utterances" (p. 247). An example of this type of switch can be seen in Example (3). Ana and Rey talk about a coffee shop that Ana likes. The coffee shop had to close because of an accident involving a diesel spill at the building where it was located. In line 01, Rey asks Ana if the coffee shop is a Starbucks, since the American chain had recently opened a store in downtown San Juan. In line 12, Ana switches to English halfway through a sentence to explain how the diesel accident happened.

Example (3)

$01 \quad \mathrm{R}: \quad$ ¿Es un Starbucks?

'Is it a Starbucks?'

02 A: No. ¡Qué Starbucks! Es un pequeño coffee shop. Starbucks

'No. What do you mean Starbucks! It's a small coffee shop. Starbucks'

03 es una cadena, esto es una boutique. Un coffee shop.

'is a chain, this is a boutique. A coffee shop.

04 De verdad, si tú eres cafetero, es el mejor café que hay. Traen

'Really, if you like coffee, it's the best coffee there is. They have'

$05 \quad$ unos granos brutales.

'great coffee beans.'

06 R: ¿Y qué es lo que pasa que está cerrado? 
'And why is it closed?'

07 A: Pues era en el edificio de TNY. Hace dos semanas o tres hubo un derrame de 'Well, it was in the TNY building. Two weeks ago there was a' diesel en el techo. Resulta que hay un transformador, porque los 'diesel spill on the roof. It so happens that there is a transformer, because they' transformadores los tienen en el techo y resulta que se había ido la luz varias 'keep the transformers on the roof and the electricity went off several times' veces y parece que en una, cuando volvió la luz, y no se dio cuenta que 'and it seems that when the electricity came back on, they didn't notice that' 11 la válvula, o qué sé yo qué, whatever... Y siguió tirando diesel 'the valve, or I don't know what, whatever... And it continued leaking diesel and it seeped through the whole building. Y entonces por las paredes... 'and it seeped through the whole building. And then through the walls...'

(4) Intersentential - Refers to one or more sentences that appear in an otherwise Spanish monolingual discourse, or in one speech turn. Poplack (2000) stated that these types of switches "require less knowledge of the grammar since they are freely distributable within discourse" (p. 242). However, intersentential codeswitching, as seen in Example (4) still reflects advanced communicative knowledge of the two codes. Here, Helena, Ana, and Sandra use both English and Spanish to discuss how Ana's wireless Internet system works.

Example (4)

$01 \mathrm{H}$ : No, porque cuando es inalámbrico tú no te conectas o desconectas. 'No, because when it is wireless you do not connect and disconnect.' 
03 A: I know... Sí, es cierto. It's always connected. Pues, anyway.

'I know... Yes, that's right. It's always connected. Then, anyway.

04 You have to block it. You have to call or do something and block it.

$05 \quad$ I did it with the...

06 S: They should block it for you.

07 A: Sí, pero, the way I did it was with the router people.

'Yes, but, the way I did it was with the router people.'

$08 \quad \mathrm{H}: \quad$ Es que a ellos no les conviene, es gratis.

'The thing is that it doesn't make sense for them, it's free.'

09 S: That's why they should do it. Van a perder negocio si no lo hacen.

'That's why they should do it. They're going to lose business if they don't do it.'

10 A: Pero eso depende del router y la cosa que tú compres yo creo.

'But that depends on the router and the thing you buy I think.'

$11 \mathrm{H}: \quad$ A míme lo van a instalar por cable... router.

'They're going to install it for me through cable... router.'

12 S: Para tener wireless.

'To have wireless.'

\section{Interference and Borrowing}

Apart from codeswitching, there are other linguistic phenomena that can arise from language contact situations, among them, interference and borrowing. Several codeswitched words in the recorded conversations can be considered "borderline alternations between L1 and L2" (Poplack, 2000 p. 238) because we cannot say for sure if they are borrowed English words, 
or words already integrated in the Puerto Rican Spanish dialect. For instance, the word 'wireless' in Example (4) in the previous section, could be classified as a single word codeswitch or as a borrowed word from English.

In part because of the negative connotations of the word interference, the term transfer has been adopted by many linguists to describe how structures of one language influence the structures of another. The study of transfer issues has often been associated with second language acquisition. Positive transfer happens when the knowledge of the L1 facilitates learning new material in the L2 and negative transfer occurs when knowledge of the L1 has a negative effect on the learning of the L2 (Romaine, 1995, p. 52). Romaine also cited Sharwood-Smith and Kellerman (1986, p. 1) who suggested the term crosslinguistic influence to more accurately describe cases where one language influences the other. Understanding variables that may foster or inhibit transfer processes is crucial in language contact situations. According to Morales (2000), in Puerto Rico, the influence of English in the Spanish vernacular has been documented in lexical additions, syntax, subject and infinitive clauses, prepositions, gerund constructions, and discourse. Much of this influence has been brought to the Island by Puerto Ricans who learn Spanish in the United States and in turn influence the dialect spoken on the Island. Some of the documented interference processes, mostly borrowings and prepositional calques, have affected large sectors of the population (p. 55).

A second linguistic phenomenon of importance to the present study is borrowing. The line that separates codeswitching and borrowing is not as clear as one would hope, and linguists have long debated the criteria that should be used to define each term. In general, those words that "belong" to language A but which have been integrated in language B are borrowings, while those that have not undergone this process of integration are codeswitched words. Some 
researchers argue for a strict division of the two, and others claim that these constructs are operationally indistinguishable. Poplack and Sankoff (1984) asserted that "there is no unequivocal way of deciding when a lexical item from one language, used during discourse in another language, whether by a single speaker or repeatedly by a community, should be considered a loanword" (p. 99).

One valid way of approaching the distinction between borrowed and codeswitched words, is to look at the degree of integration of words in the base language. Pfaff (1979) provided a series of questions to determine the status of an L2 word in an L1 utterance: a) Does the L1 have an equivalent?, b) If so, is it in use in the community?, c) Is the equivalent L1 term known to the individual speaker? Addressing these questions may seem like a straightforward solution, but definitive answers are difficult to obtain, since they entail extensive language studies in a community (p. 297). Another way of separating the two concepts looks at the degree of adaptation of linguistic items. Grosjean (1982) supported the distinction made by Haugen and Hasselmo: "a code-switch can be of any length (a word, phrase, or a sentence) that is a complete shift into the other language, whereas a borrowing is a word or short expression that is adapted phonologically and morphologically to the language being spoken" (p. 308). Examples are words such as lipstick, brown and weekend, to which Puerto Ricans have applied Spanish phonology and use as part of their everyday speech.

Myers-Scotton (1992) suggested that the solution to the borrowing/codeswitching dilemma lies in approaching it in terms of social content. She distinguished cultural borrowings from core borrowings. The first type, cultural borrowing, refers to words for new concepts or objects that are adopted by a language. It is predicted that speakers will use these words repeatedly because of the need to signify the same referent. They are also characterized by 
entering the lexicon abruptly. The second type, core borrowing, results from certain types of contact situations that may promote a desire to identify with the culture of another language, or some aspect of it. Core borrowings do not stem from need since the language incorporating the new words already has equivalent forms. Some core borrowings may enter a language when a prestigious person uses them and others follow (p. 29). Thus, she speculates that "core borrowed forms are first codeswitching forms: some codeswitching forms are ephemeral, but others are repeated until gradually they become borrowed forms" (p. 30).

\section{Borrowings in Puerto Rican Spanish}

One of the most intriguing aspects of this topic are the synchronic and diachronic processes that may result in borrowings. Poplack and Sankoff (1984) focused on the mechanisms by which an item goes from a foreign element to a nativized one. Their approach was to evaluate the degree to which processes of phonological, syntactic, lexical, and sociological integration of a foreign element occur independently or in unison. Poplack and Sankoff set out to examine over sixty-five hours of speech of New York Puerto Ricans. Before long, they realized they would not be able to measure the frequency or degree of integration of loanwords, since the occurrence of lexical items depends largely on the subject matter, and there was no guarantee that any two speakers would be talking about the same thing. Faced with this difficulty, they opted to elicit designations of concepts by presenting a randomized series of photographs and asking participants to name them. Poplack and Sankoff concluded that there is a relative homogeneity in a community with respect to loan word acceptance that suggests that borrowing is carried out on a community level, and is not a series of random accidents (p. 130).

Poplack and Sankoff also mentioned that it is commonly thought that bilinguals tend to use borrowings before monolinguals, who learn them from the former (p. 101). Furthermore, 
assimilation of new words is a diachronic process which, by definition, takes time. It may well be that, in this time period, "the borrowing process can pass through a phase where the Spanish designation is displaced by a number of competing English terms before any single one of the latter can predominate" (Poplack and Sankoff, 1984, p. 130). For the Spanish of Puerto Rico, a word such as 'wireless' that refers to new technologies, may become a loanword, or it may be that the equivalent word in Spanish, inalámbrico, will be the preferred one. Example (4) in the present study, presents evidence of the competition between 'wireless' and inalámbrico. In this segment of conversation, speakers use both the Spanish and English forms. Similarly, in November 2007, the faculty of the University of Puerto Rico at Río Piedras, received a letter from the administration informing them about the new "sistema wireless inalámbrico" in a new part of campus. The Spanish translation of "wireless system" is "sistema inalámbrico." This obvious error of redundancy also shows competition between the words 'wireless' and inalámbrico. As suggested by Poplack and Sankoff, in time, perhaps one of these words will predominate.

As evidenced in the previous example, computers and new technologies tend to be sources of linguistic borrowing. Nash (1970) made a useful classification of borrowed English words that are part of the everyday speech of Puerto Ricans. The first category includes international terms in science and technology. The second, English words that have Spanish equivalents such as: navy, overtime, anyway, building, easy, size, shopping center, freezer and truck. The third, cultural borrowings, many of them slangy expressions, such as $t$-shirt, hobby, hamburger, rush job, carriers, airmail and coffee break. The fourth category includes American merchandising, names of businesses, slogans and advertising. Nash explained that many Puerto Ricans employ English words because of ease of communication, but that the prestige factor, for 
some speakers, cannot be ignored. "A Puerto Rican buys a freezer rather than a congelador because that is the word he sees in the advertisements; he speaks of la high rather than la escuela superior because it is shorter; he can express a keener sense of disappointment with iQué fallo! than with the bookish ;Qué desengaño! And in every case, he knows that he will be immediately understood by his peers without the need of clarification, because this is their common language" (p. 230). More recently, López Morales (1998) cited a study carried out with the most cultivated sociolect of PR's metropolitan area which included twenty-one lexical fields. Results showed that the fields of media, clothing, and transportation have absorbed the most borrowings in Puerto Rico, while the church, agriculture, and animals did not show any English integration. Apart from linguistic studies, dictionaries are another useful source for documenting borrowed words in PR. Vaquero and Morales (2005) included many words of English origin (anglicismos) in the dictionary Tesoro Lexicográfico de Puerto Rico, published by the "Puerto Rican Academy of Language.” This language tesoro or 'treasure' consulted all the dictionaries, linguistic atlases and dialectology studies of Puerto Rican Spanish conducted over the last century. The eight-hundred page volume includes: crude anglicisms (anglicismos crudos) which conserve the original English spelling (team, beauty, background), hybrid words which are not clear in their lexical form (yunky, junkie), and those words that have been completely adapted (monchar, [to munch], alimonía, [alimony]).

Up to now, no dictionary has been devoted solely to borrowings in the Spanish of Puerto Rico. However, for the past few years, the "Puerto Rican Academy of Language" has been working on a Dictionary of Anglicisms. Maia Sherwood (2007) reported that the dictionary will include at least six types of anglicisms, which are found in the idiolect of the average speaker in Puerto Rico: 
1) anglicismos crudos [crude] - maintain the original English written form: 'air bag,' 'file,' 'refill,' 'gate' and 'foam;'

2) anglicismos adaptados [adapted] - have an English root but Spanish morphological ending: 'printear' [to print], 'dropearse' [to drop out], 'píchear' [to pitch], 'cáchear' [to catch];

3) anglicismos híbridos [hybrid] - consist of compound nouns or phrases that combine English and Spanish elements: 'guagua van' [bus van], 'cables de yompear' [jumping cables], 'esquema de corrupción' [corruption scheme];

4) neologismos [neologisms] - include words in English that, when adapted to Spanish, have evolved in ways that have not occurred in English. For example, 'bad trip' in English refers to a bad experience while using drugs, while in Spanish it means any negative experience. This word has even become an adjective 'badtripeado' to signify someone who is upset;

5) préstamos estructurales [structural borrowings] - refer to Spanish constructions that copy English syntax: 'tomar acción' [take action], 'al final del día' [at the end of the day] and 'fuera de servicio' [out of service]. (p. 36)

Bilinguals can be very creative, and the influence of one language on the other fuels this creativity. One example of an adapted anglicism that appeared in Carlos' interview for the present study was the word switchear. The interview was conducted in Spanish but when referring to codeswitching he constantly used the phrase: switchear los idiomas [to switch languages]. Carlos could have used the Spanish word alternar [to alternate] or 'mezclar' [to mix], but he chose to adapt the verb switch to Spanish morphology, a practice that can be observed among many Puerto Ricans. Other examples are janguear [to hang out], forwardear [to 
forward], printear [to print], and for those who know the linguistic term, codeswitchear [to codeswitch].

Johnstone (2002) discussed a Bakhtinian perspective on borrowing and codeswitching. This perspective is useful in interpreting the codeswitching data in the present study with PR bilinguals. Johnstone explores Bakhtin's idea of “appropriation.” Our words are always someone else's words, and there is always a gap between our intentions and the words we use. This gap is sometimes greater and sometimes smaller, but the goal is to make language one's own. As speakers learn a foreign language they must start "borrowing." They mimic words, structures, and ways of talking that belong to other people. Successful learners appropriate these borrowed blocks and make them their own. What starts as imitation becomes self-expression as bits and pieces of language are fitted into the person's own sense of meaning (p. 139). If we apply this viewpoint to codeswitching among Puerto Rican bilinguals, we see that many English words have become part of their self expression or normal way of communicating in informal contexts. However, we may not be able to establish with certainty which English words are integrated in the speech of this network of bilinguals, and which of those words are integrated into the Puerto Rican Spanish dialect as a whole. What we can say with some certainty is that the presence of codeswitching reveals speakers' appropriation of the English language. These speakers demonstrate high levels of appropriation of English, which manifests itself in their daily conversations. For these bilinguals, exposure to and appropriation of this second language is always potentially manifested in discourse; discourse which contains codeswitching instances and clearly depicts their culturally and linguistically heterogeneous experience.

Participants in the present study represent the average Puerto Rican in the sense that they make use of a certain amount of English loan words in their everyday interactions. However, 
they are different from the average Puerto Rican in that they habitually employ a second linguistic code. The following lists contain single word switches and borrowings that appeared in the recorded conversations. List (1) includes words that can be classified as borrowings. They appear in the Tesoro Lexicográfico de Puerto Rico (2005), and could be said to be integrated in the Puerto Rican Spanish dialect. Words in list (2), were not included in the Tesoro, but appeared in the present corpus. These words could be classified as "integrated in the speech of urban, well educated Puerto Rican bilinguals."

List (1): Borrowings

\begin{tabular}{l} 
anyway \\
background, bacon, beauty, blower, brain, bracket, break, brown, brownie, bumper, \\
\hline campus, cartridge, cartoon, cash, college, cool \\
\hline date \\
fast foods, full \\
\hline hard drive, heavy, hello, high school, hobby \\
\hline issue \\
\hline laundry, label, lighter, lip gloss, lipstick \\
\hline managers, manicure, mood \\
\hline nice \\
\hline online, out
\end{tabular}




\begin{tabular}{|l|}
\hline realtor, ready, relax \\
\hline sándwich, set, show, shower, size, slice \\
\hline tape, tour, trip \\
\hline valentine \\
\hline website, weekend \\
\hline zipper \\
\hline
\end{tabular}

\section{List (2): Single Word Switches}

\begin{tabular}{l}
\hline actually, again, annoying, appeal, approach, attention span, available, awkward \\
\hline backstage, backup, bead, blackmail, body suit, borderline, bracket, business \\
car seat, case, casting, cash flow, challenge, chunk, clear, close, conference room, \\
counselor, crappy, craving, crush, customer copy, customer service, cute \\
\hline deadline, deal, disgusting, dorm, dvd player \\
\hline e-mail, elf \\
fashion, financial aid, flat screen, fluent, forward, frame, freak, freelance, fun, funky \\
\hline gadget, gap \\
\hline handy, hard core, heavy, high chair, hint, honeymoon, hopefully, host, hot pants \\
\hline index card \\
\hline kit \\
\hline laid back, legal advisor, lifestyle, link, look, loser, loud
\end{tabular}


major, makeover, master bedroom, mat, maybe, media center, meeting

nasty, nerd, nervous breakdown, night light, nope

outcast

pad, peach, perfect, polite, predictable, primer, proper

random, reality show, receiver, request, rock climbing

shape, shit, season, secluded, second opinion, sitcom, skill, sliding door, sorry, speech, sporty, stage, stage fright, sweet

tax, therapy, time share, time sheet, timer, tip, toilet paper holder, tomboy, top secret, townhouse, trailer, trainer

unplugged

venue

waiter, waiting list, whatever, whatsoever, wireless, weird, workshop

Discourse Functions

Codeswitching instances can be classified in relation to their pragmatic aims (Gumperz, 1982). The purpose of this categorization in the present study is to show the pragmatic composition of the "clustering of linguistic sources" that characterizes the codeswitching style of this network of Puerto Rican bilinguals. Gumperz proposed a number of discourse functions that have been observed in different speech communities. He also tied the functions of codeswitching to Gricean theories of conversational implicature, which refer to the assumptions that the hearer must make in order to interpret messages. The crucial aspect of this comparison is that, in bilingual discourse, code usage conventions that are necessary to interpret implicatures are created within networks of interpersonal relationships. These conventions are subject to change, 
depending on factors such as power relationships and socio-ecological environments. This means, for example, that if someone overhears a conversation in which people are codeswitching, they might understand the words but not the communicative intent of the interlocutors. "The term implicature is used to refer to a sociolinguistic process by which communicative experience is retrieved to supply information not shared by listeners of different backgrounds" (p. 95-96). The bilingual professionals who participated in this study share similar backgrounds. They share a set of communicative norms and conventions that allow for meaningful communication within their social network. As evidenced by the speech samples collected for this study, codeswitching is, for most of them, part of their everyday conversational style.

The following five functions outlined by Gumperz (1982) were found in the present corpus. These functions are not intended to be exhaustive, and some were more frequent than others. Illustrative examples are provided for each one.

a) Quotations: Switching languages may distinguish a direct quotation or reported speech. Speakers are not always quoted in the language they originally used. In the following example, Leo, Graciela, Darío and Jacqueline are chatting after dinner at Graciela and Leo’s apartment in Guaynabo. Graciela is eight month's pregnant. In line 02 Leo talks about his boss' concern for his wife's well-being and quotes him in English.

Example (5)

01 L: A míme da risa porque el jefe lo tengo aquí, todos los días, 'It's funny because my boss is telling me everyday,

02 how's your wife doing? ¿Está todo bien? Porque yo le dije, después de 'how's your wife doing? Is everything ok? Because I told him that' 
'after March first I will not travel any more and I really didn't travel this week.

04 Así es que de aquí ahora no viajo más. Y me pregunta, ¿qué necesitas?,

'So from now on, I will not travel anymore. And he asks, what do you need?,

05 ¿qué puedo hacer por ti?

'what can I do for you?'

06 D: ¿Pero él tiene hijos?

'But does he have any children?'

07 L: Sí, una hija de tres o cuatro años.

'Yes, a three or four-year-old daughter.'

b) Reiteration: An utterance in one language that is repeated in another. It is often used to clarify what is being said, or to amplify or emphasize a message. In the following example, Ana and Alberto are discussing favorite movies. Ana tells Alberto about the best comedy of all time, and in line 03, reiterates how good it is by using English. In line 05, Alberto corrects her because she changed the title of the movie. On her next turn, Ana admits her mistake.

Example (6)

$01 \quad$ A: ¿Cuál? ¿La uno, la dos?

'Which one? Number one, number two?'

02 A: Ah, mentira... No, no, no, la mejor película de todos los tiempos es una

'Ah, that's not it. No, no, no, the best movie of all time is one' que se llamaba Dirty Rotten Stinking Rich. Estaba brutal. It was really good! 'that was called Dirty Rotten Stinking Rich. It was great. It was really good!' Con Leslie Nielsen. Que se hacía el paralítico... 
'With Leslie Nielsen. Who played a paralytic...'

05 A: $\quad$ Esa es Dirty Rotten Scoundrels.

'That one's Dirty Rotten Scoundrels.'

c) Message qualification: The speaker will say something in one language and then qualify or further explain an idea or concept. In Example (7) Alberto and Manuel are discussing the movie that Manuel is directing. Both speakers use English to explain their ideas further. In line 01 Alberto mentions several things that Manuel could be doing to promote his movie. He starts his turn in Spanish and ends it in English. Alberto talks about the 'story board,' a term commonly used in the advertising/movie business. In lines 03-04 Manuel further explains the concept of a 'trailer.' In line 05, Alberto asks if the trailer was in English or Spanish to have a better sense of the intended audience.

Example (7)

$01 \quad$ A: ¿ ¿Tú piensas hacer algo, algunas cosas en video alante, un story board? 'Do you plan to do something, video things beforehand, a story board?'

$02 \mathrm{M}$ : Lo primero que hice fue un mood piece para los inversionistas, con clips de 'The first thing I did was a mood piece for investors, with clips of' otras películas hice como un trailer de cómo sería la película. An idea of 'other movies I did like a trailer of what the movie would be like. An idea of'

$04 \quad$ what it's about.

'what it's about.'

$05 \quad$ A: ¿En inglés?

'In English?'

06 M: $\quad$ No, porque son clips y música y son imágenes. Es como un video musical. 
'No, because there are clips and music and it's all images. It's like a music video.' d) Interjections: These are equivalent to Poplack's tag switches. They mark an interjection or serve as sentence fillers. The following example was taken from a one hour conversation between Marla and Diego that took place at Marla's home in San Juan. One of the topics of conversation was the upcoming 2008 elections on the Island and in the U.S. Marla tells Diego that, while she was away at college in the U.S., she did not vote in the Puerto Rican elections nor in the U.S elections. In line 07, Marla uses the sentence filler 'whatever,' which was used fourteen times in the course of the conversation, mostly by her.

Example (8)

$01 \quad$ M: Yo siempre viví en los dorms de la universidad y los dorms no los contaban como 'I always lived at the university dorms and the dorms are not considered a residencia. Los contaban como algo temporero por ser 'residence. They considered them something temporary because I was a' estudiante, o sea que a menos que yo no viviera en un apartamento off campus 'student, so unless I lived in an apartment off campus'

$04 \quad$ no podía ser residente. 'I couldn't be a resident.'

05 D: Sí, verdad, porque yo voté pa' presidente allá pero era cuando 'Yes, that's right, because I voted for President there, but that was when I' 06 ya vivía allá. Poco bien que hizo pero por lo menos traté. 'already lived there. It did little good, but at least I tried.'

07 M: Sí, whatever. Fíjate, yo nunca he votado. Tengo la tarjeta ahí pero... 'Yes, whatever. You know, I've never voted. I have the card there but...' 
e) Personalization vs. objectivization: Different languages may be used to establish speaker involvement with what is being said. For example, the speaker may mark a distinction between his personal opinion and a generally known fact. In Example (9) Ana, Laura, and Alberto are discussing their favorite movies. In line 09, Ana attempts to dismiss one particular movie she has not seen. Instead of just giving her his opinion about the movie, in line 12, Alberto uses an old saying in English that means "don't judge something until you give it a chance."

Example (9)

01 A: La película más tripeosa ${ }^{19}$ en esa tónica anormal fue There's something about Mary.

'The coolest movie of that weird genre was There's something about Mary.'

02 L: $\quad$ Pues, pues es algo así...

'Well, it's something like that, yeah ...'

03 A: No, pero Dumb and Dumber's too much. Y fijate

'Yeah, but Dumb and Dumber's too much. And you know

$04 \quad$ hubo otra, ¿cómo se llamaba?

'there was this other one. What was it called?'

05 L: Que era con... Tommy Boy no es tan out there como Dumb and Dumber.

'That was with (...) Tommy Boy isn't as out there as Dumb and Dumber.'

06 A: Pero, ¿cómo se llamaba esta otra? Tú tienes que saber, que era con Cameron 'But what was that other one called? You have to know, the one with Cameron' Díaz y Christina Applegate. Esa estuvo buena también.

\footnotetext{
19 The word "tripeosa" comes from the English word "trip", used by young people to refer to something "funny" or "cool." It combines the English noun "trip" with Spanish adjective suffix "-osa" = herm-osa (beautiful).
} 
'Díaz and Christina Applegate. That one was good too.'

08 A: Tommy Boy es la típica comedia física.

'Tommy boy is the typical physical comedy.'

$09 \quad$ A: $\quad$ Mira, I'm sorry. Yo vi...

'Listen, I'm sorry, I saw (...)'

10 A: ¿Tú la viste?

'You saw it?'

11 A: No.

'No.'

12 A: Entonces, don't knock it until you try it.

'Then, don't knock it until you try it.'

Speakers who adopt a codeswitching style often have no awareness of the way they use their languages, because their main concern is the communicative effect of what they are saying. Since speakers often have no words of their own to describe codeswitching practices, a list of functions is a tool to start discussing the relevant characteristics of this phenomenon (Gumperz, 1982, p. 61). When asked why they codeswitch, many respondents say: "I just do.” Not all codeswitching instances found in the conversations can be classified according to the parameters presented up to now. After studying codeswitching among Puerto Rican bilinguals in New York, Zentella (1997) concluded that not every switch can be identified with a particular function, and every change in communicative function is not accomplished by a shift in language (p. 99).

Discourse functions active in the conversations in the present study also respond to the characteristics of conversational style between friends. It is common for such conversations to include language patterns that do not exist among strangers. People who regularly interact with 
each other develop a special kind of language, one that is distinct and may include playful routines, irony, and allusion and reference to familiar jokes (Tannen, 1984). One example found in the recorded conversations, is the frequent use of legal jargon by Ana and Rey. In Example (10) Rey, Ana, Janet and I are having coffee at Starbucks. Janet and I hardly speak because Rey and Ana tend to dominate the conversation. They both admit they love to talk. In line 01, Ray uses the English expression of legal origin "I rest my case," to reiterate that he did not have to present any more arguments to prove the point that Ana talks more than he does. Ana had asked him a question five minutes earlier and had not allowed him to answer it.

Example (10)

01 R: Mi único punto es que I rest my case, porque a mí me hicieron una 'I'm only going to say that I rest my case, because somebody asked me a pregunta y yo todavía no he podido contestarla. 'question and I still haven't been able to respond.'

03 A: ¡Ay, qué embustero!, ¿Qué petaca eres! 'You're such a liar!, You're so bad!

Responses to the questionnaire designed for the present study suggest that, although not all participants codeswitch regularly, codeswitching is part of the accepted ingroup speech style of these bilinguals. In informal encounters, any member of the group may use English words and phrases without hesitation, since all of them share codeswitching conventions that allow conversation to run smoothly. No one questions the use of English as a means of conveying pragmatic intent. In the present data set, only Carlos and Jaime did not alternate languages. Nevertheless, they appear to have passive participation in the codeswitching style used in their social and professional circle. Diego said: 'I'm very used to it, I don't mind if someone says a 
word in English. Communication might be disrupted if someone used English words I have never heard, but that never happens in casual conversations because I'm familiar with the words used." In the present study, the mere use of English in an otherwise Spanish dominant interaction is presupposed as an acceptable discourse strategy. Crucially, the predictability of these presuppositions relates to shared cultural experiences and similarity of interactive styles.

\section{Discourse Topics}

In bilingual settings various factors are involved in determining what language is used in interaction, such as group membership, situation, and topic (Appel and Muyksen, 1987, p. 23). With regard to discourse topics that can instantiate codeswitching, Hudson (1996) noted that codeswitching in conversation generally takes place more or less randomly as far as subjectmatter is concerned (p. 54). This statement was partially confirmed by the present study. Upon close scrutiny of the recorded conversations, it was found that many of the switches into English were primarily stylistically motivated, and did not have a direct relationship with the topic being discussed. However, many other switches were prompted by the topic at hand. This section discusses four topics that appeared in more than one conversation and prompted codeswitching instances: a) Idiomatic expressions, b) U.S. Culture, c) U.S. Movies and TV Shows, d) Business and Technology. Each topic includes excerpts from the recorded conversations. Discussions are also complemented by participants' responses to the questionnaire.

\section{Idiomatic Expressions}

Conversations in the present study carry a particular history. Each utterance reflects the historical processes that are at play on the Island. These conversations have an inherent historicity, one that evidences more than one hundred years of language contact between English 
and Spanish. Codeswitching is just one of the many manifestations of this particular history. For codeswitching to constitute a valid speaking style among these twenty-seven bilinguals, they must have the ability to collectively and individually interpret and evoke "prior texts or lingual memories" (Becker, 1994, p. 167). Each situated use of English, in an otherwise Spanish monolingual discourse, becomes and intertextual link that binds these speakers into a particular social group. This is what Becker (1994) called a "shared repertoire of prior texts" (p. 165). Speakers draw from shared languages (texts). This sharing of linguistic resources is not random. It is dependent on historical realities that surround these speakers, and is at the heart of their identity work.

Bilinguals who codeswitch often report using a certain language at a certain point because "it sounds right," "because only that phrase in English can say what I want to say," or "because it's the right word." This experience relates to what Becker (1994) expressed about the impossibility of translating a story from English to Malay. He could not translate the expression "That reminds me of a story," because this phrase had no idiomatic equivalent in Malay. To be fluent in a language means not only saying things in pre-patterned chunks, but also being able to use them in culturally appropriate ways. This is precisely what speakers in the present study referred to when they said that an English idiomatic expression was "better" than one in Spanish. When facing untranslatability, they simply used the English expression. They could do so because speakers in their social network share a repertoire of prior texts which can be readily evoked in informal interactions.

Auer (1998) analyzed informal conversations among a group of Spanish-German bilingual speakers of South American origin in Hamburg. Conversations were basically in Spanish, but speakers repeatedly used German words. In one conversation, they used the words 
flur 'corridor' and Nichtraucher 'no smoking'. Auer explained that background information not explicated in this conversation reveals that smoking in German society had been a topic in this group of speakers: "On the basis of this background information, it is possible to understand that the insertion establishes a link between this episode and previous ones in the same group; that is, it works "intertextually"' (p. 7). To recognize these intertextual links, it is important to know the "historicity" that accompanies each word or phrase. Participants in the present study have not only a purely grammatical understanding of English, they are also able to use English words and phrases in a new context, in order to make intertextual connections in meaningful ways for this group of speakers. Furthermore, this type of intertextual work contributes to identity creation. The extent to which a group of people can find meaning in intertextual relationships determines the potential for the formation of a community/culture.

The following ten idiomatic expressions found in the present corpus of data are part of the "shared repertoire of prior texts" mentioned by Becker (1994). They are evidence of a common understanding and appropriation of the English language. The use of these expressions in meaningful ways shows participants' true appropriation of their second language. The following list contains intersentential and intrasentiential codeswitching:

1) Alberto: Where there's a will, there's a way.

2) Graciela: Muy bien. Así es la cosa. Right on track.

'Very well. That's the way to do it. Right on track.

3) Darío: Back in the day, era algo normal.

'Back in the day, it was something normal.'

4) Ana: Tú haces todo lo que se supone, by the book.

'You do everything as it should be, by the book.' 
5) Lucas: $\quad$ Tú sabes como es, heard it through the grapevine.

'You know how it is, heard it through the grapevine'

6) Rey: $\quad$ El segundo año nos querían cobrar an arm and a leg.

'The second year they wanted to charge us an arm and a leg.'

7) Rafael: $\quad$ Alquilamos dos películas y las vimos en casa las dos back to back.

'We rented two movies and watched them at home back to back.'

8) Juan: Es como que la lista de things to do before you kick the bucket.

'It's like the list of things to do before you kick the bucket.'

9) Manuel: $\quad$ Yo hice un examen así como que idiot proof y no funcionó.

'I made an idiot proof test and it didn't work.'

10) Juliana: _ ¿Eso todavía es top secret, verdad?

'That is still top secret, right?'

Many have tried to answer the 'why' question behind codeswitching. For instance, Li and Tse (2002) explored the linguistic motivations for codeswitching among Hong Kong Chinese /Cantonese and English bilinguals. They mentioned pressure of biculturalism and acculturation, pressure to accommodate to the speaking style of members in their social group, idiomatic expressions, and the principle of economy, as possible motivations for codeswitching (p. 182). Li and Tse argued that "code choice is largely a function of, and highly sensitive to, the sociolinguistic variables in a given situation-specific interaction type" (p. 180). The macro, sociocultural processes behind speakers' ability to alternate languages has proved crucial to understanding codeswitching. There are processes of acculturation and biculturalism that result from sustained language contact, and manifest themselves in the speech of bilinguals. The shared 
idiomatic expressions mentioned above result from sociohistorical processes that are at the heart of mixing languages.

\section{U.S. Culture}

Codeswitching, as seen is this dissertation, is evidence of how Puerto Rican bilinguals employ the linguistic/cultural tools they have available, and in the process create a speaking style that may be associated with social identities. Cultural tools may also be defined as "carriers of social, cultural, and historical formations that amplify certain social actions and limit others" (Norris \& Jones, 2005, p. 49). The fact that the bilinguals in this study have appropriated cultural meanings which pertain to the U.S. Discourse is a reflection of the political relationship between Puerto Rico and the United States that has been in effect since 1898: "Cultural tools fundamentally shape what we say and think and these cultural tools always reflect the sociocultural setting in which we live and act. However, such cultural tools should not be taken as mechanistically determining consumption, and hence any complete account needs to examine how they are taken up, resisted, or otherwise consumed, as well as how they are produced" (Wertsch, 1997, p. 470). This section provides several examples of how bilinguals in this study, take up, and consume U.S. cultural tools.

Experiments in bilingual literature "point toward biculturalism as a necessary aspect of communicatively competent bilingualism" (Agar, 1991, p. 168). Therefore, many codeswitching instances in the recorded conversations may be an indication of the extent to which speakers have assimilated U.S. cultural aspects. They not only speak American English, they have also internalized many aspects of U.S. culture, which they feel may be better expressed in English. This takes us back to Myers-Scotton's (1992) discussion of core borrowings, which result from the desire to identify with the culture of another language. It may be that words and concepts 
found in the conversations pertaining to the American Discourse have already become an integral part of this particular social network's linguistic repertoire. Frequent exposure to cultural imports that employ English can also lead to habitual use of this language. Respondents are in constant contact with English from many sources, which include entertainment, education, and work.

It must be noted that the bicultural experience of bilinguals in general does not automatically give way to codeswitching. Although "bilingualism can be said to be reflective of complex cultural and linguistic reality, it need not be manifested in the acceptance of overt practice of codeswitching" (Toribio, 2002, p. 109). The importance of being open to the culture that is inevitably embedded in language cannot be underestimated when it comes to codeswitching. Toribio (2002) evaluated the linguistic attitudes and attributes that characterize and delimit codeswitching practices among Spanish-English bilinguals in the U.S. One participant in Toribio's study, Federico, was a bilingual with a high degree of competence in his two languages, but he seldom codeswitched. When, as part of the study, he was asked to complete the task of producing a codeswitched narrative, he failed. Other participants, who habitually codeswitch, were able to successfully complete this task and perform structurally appropriate switches. Toribio concluded that competence in two languages, while being a prerequisite for codeswitching, is not enough to guarantee successful performance. Membership in a community in which codeswitching is regularly practiced may also be required.

"Codeswitching requires social knowledge that is culturally specific and acquired only through contextualized practice" (p. 103). Although Federico possessed the requisite bilingual capacity, he did not posses the culturally relevant disposition to welcome English and Spanish into one cohesive context. These two languages maintained "an antithetical relationship circumscribing 
distinct worlds" (p. 104). This restricted relationship revealed his sociolinguistic reality, where the two languages represent the conflict between the Latino and U.S. identities. Federico also claimed that mixing English and Spanish did not reflect who he was. His decision to not codeswitch was symptomatic of a linguistic and cultural ambivalence that he did not espouse or tolerate. Thus, differing attitudes toward the practice of codeswitching and its role in establishing sociocultural identity may influence its quantity and quality.

There were many occasions in the recorded conversations in which speakers discussed topics related to the U.S.: 1) Several general discussions of U.S. politics, 2) Many references to favorite American movies, 3) Mention of friends and family now living in the U.S., 4) U.S.owned cellular phone companies on the Island, 5) Better living conditions in the U.S., and 6) PR's political relationship with the U.S. Most of the informants recognize that the influence of U.S. culture is a factor that contributes to the presence of English on the Island, and that they know the language because they were exposed to it from an early age. The following examples reveal how reference to U.S. culture prompted switching into English.

Overall familiarity with U.S. current events and their relevance to Puerto Ricans' daily lives is evident in the conversations. In Example (11) Leo tells Darío about an experience he had checking in at the San Juan airport. In line 07 Graciela, his wife, uses English to comment that his travel problems happened right after the events of September 11, 2001, in New York City. Example (11)

$01 \quad$ L: Hubo como dos años que yo no podía hacer online check-in. 'There were a couple of years that I could not do online check-in.' 02 Tenía que hacer check-in allí. 'I had to check-in there.' 
03 D: ¿Qué?

'What?'

04 L: Porque no me dejaba. Me decía, "sorry, you have to show your driver's license" 'Because it wouldn't let me. It would say, "sorry, you have to show your driver's license",

05 D: ¿Y después averiguaste qué era eso?

'And did you find out later why that was happening?'

06 L: Yo después pregunté y les dije, mira yo viajo todas las semanas.

'I then asked and told them, listen I travel every week.'

07 G: $\quad$ Eso fue right after nine eleven.

'That was right after nine eleven.'

08 L: Yo soy executive traveler, lo que pasa es que, cuando pasa eso, 'I'm an executive traveler, what happens is, they told me dijeron que usara mis dos nombres para que no pasara eso. 'me to use my two last names to prevent that from happening.'

Another factor that contributes to the predominance of English on the Island is its presence in popular culture; its influence is felt in movies, music, cable TV, large chain stores, and mass consumer items, to name a few (Schweers and Vélez, 1992). Major stores like JC Penney, Kmart, Macy's, Marshall's, and Walgreens, among others, make great profits on the Island. There are also many fast-food chains like Burger King, Kentucky Fried Chicken, McDonald's, and Wendy's, throughout the Island. Starbucks arrived in Puerto Rico in 2002, and by 2008 it had about 22 stores. This coffee store was referenced in two of the conversations. In the following example, Jacqueline and Leo discuss the difficulties of familiarizing themselves 
with the "Starbucks jargon." Like many bilinguals in their social network, they needed to add the Starbucks vocabulary to their codeswitching idiolects. For Jacqueline, ordering at Starbucks was a bit confusing, perhaps because 'grande', means 'big' in Spanish, and this is actually the smallest cup size. So, when Spanish speakers order a 'grande latte' for the first time, they might have a hard time remembering the fact that it is actually a 'small latte.'

Example (12)

$01 \quad$ J: $\quad$ Yo no tomo café allí casi nunca. Y un día fui a pedir algo para Jorge en el 'I hardly ever drink coffee there. And one day I went to get something for Jorge'

02 Starbucks alli de Condado. Yo no podía, me dio como un estrés, tuve que 'at the Starbucks there at Condado. I couldn't, I was stressed out, I had to'

$03 \quad$ llamar a Teresa de nuevo, ¿cómo era? Es de los fríos o sea que me 'call Teresa again, how was it again? It was one of the cold ones so I got'

04 confundí, entre el tamaño y después se me olvida si es grande, tall o qué. 'confused, I had to remember the size and I forgot if it was grande, tall or what'

$05 \quad$ L: Venti.

'Venti.'

06 J: Yo lo que pido es chocolate.

'I always order hot chocolate.'

$07 \quad$ D: $\quad Y$ no puedes decir cold, tienes que decir... tiene un nombre como... 'And you can't say cold, you have to say... it has a name like...'

$08 \quad$ on the rocks o algo así.

'on the rocks or something like that.'

$09 \quad \mathrm{~J}: \quad$ Ice algo. 
'Ice something.'

10 L: $\quad$ Ice frappuccino.

'Ice frappuccino.'

11 J: Sí, era algo así ice frapuchino latte no sé qué,

'Yes, it was something like ice frapuchino latte and I don't know what else,

12 mocha era algo con mocha.

'mocha it was something with mocha.'

13 D: Yo gracias a Dios no tomo café.

'Thank God I don’t drink coffee.'

There are many cultural differences between the United States and Puerto Rico. In several conversations, speakers revealed being aware of such differences. In Chapter Nine I will further discuss the issue of biculturalism for participants. For now, I will present two examples of speaker awareness of cultural differences which prompted codeswitching instances. In Example (13) Graciela and Leo talk about the differences in names in the two cultures. In Puerto Rico, it is customary to use two last names, the father's last name first, and then the mother's. In line 01, Graciela says that when she moved to the States she had to stop using her mother's last name to avoid problems. Leo then talks about a news article he read in USA Today which referred to Puerto Rico's governor as Governor Vilá. Vilá is actually his second last name. In line 06, Graciela notes that the author of the article must have read Aníbal Acevedo Vilá, and assumed that Acevedo was his middle name, when in fact it was his last name.

Example (13)

01 G: Yo cuando me fui para allá tuve que poner Graciela Rivera y más na’.

'When I went abroad I had to write Graciela Rivera and that's it.' 
02 L: Hay una sección en el USA Today que sale una noticia bien pequeña de cada 'There's a section in USA Today with daily news about each state.' estado. Y había una sección de Puerto Rico y decía Governor Vilá. Y no es 'And there was a section on Puerto Rico and it said Governor Vilá. And it's not' Governor Vilá, es Governor Acevedo, pero como siempre, cogen el último 'Governor Vilá it's Governor Acevedo, but, as always, they take the last' nombre, pues se creen que Vilá es el apellido. 'name, because they think Vilá is the last name.'

06 G: Se creen que es un middle name. Como me hacían a mí, me ponían.... 'They think it's a middle name. Like they did with me, they would put...' The experience of having lived in the United States may prompt speakers to compare customs, standards of living, and government policies. In Example (14) Laura and Manuel are driving in Manuel's car after having dinner with friends. Laura notices the bad state of some roads in Puerto Rico and compares the Island's situation with that of Fort Lauderdale, Florida, a place she visited often when her husband, Alberto, lived there. Manuel tries to convince her that there are bad roads and bad places in the U.S. too, since he lived in New York and California for seven years, and visited several other states as well. In lines 07 and 08 Laura switches languages in what can be classified as intrasentential codeswitching:

Example (14)

$01 \quad \mathrm{~L}: \quad$ Ay, yo no sé, aquí no le dan mantenimiento a nada. Todo es tan feo.

'Well, I don't know, here they don't upkeep anything. Everything's so ugly.'

02 M: Pero por ejemplo, si el servicio del gobierno es una mierda, el servicio del 'But, for example, if government service is terrible, government services' 
gobierno es una mierda en todo Estados Unidos.

'are also terrible in the whole of the United States.'

04 L. Sí pero, en Estados Unidos también hay corrupción igual, pero los sistemas 'Yes, you also find corruption, but in the U.S., but basic systems' básicos siempre siguen funcionando. Siguen recortando el landscaping 'always continue to work. They keep taking care of the landscaping.' en la carretera, las aceras también, los rotos en la carretera no existen. 'on the roads, and the sidewalks too, and there are no potholes on the roads.' Como que hay corrupción y eso, but at least la calidad de vida, 'It seems there is corruption and such, but at least the quality of life' no se afecta tanto porque más abajo people are doing their work.' 'is not too affected because at the basic level people are doing their work.' Y aquí cada obra que hacen gastan yo no sé cuantos millones.

'And here they spend I don't know how many millions on each project.'

The following two examples present instances of cultural appropriation. In the first example, the concept of the 'tooth fairy' has a cultural equivalent in Puerto Rico. In the second example, speakers mention 'house warming', a tradition that is not present in the Puerto Rican cultural milieu, but, according to the evidence in this study, is being adopted by some social networks.

While not an exclusive American myth, the tooth fairy is part of American folklore mythology. The fairy brings children a gift (often money) whenever they lose a tooth. Children typically leave the tooth under their pillow for the fairy to take while they sleep. This myth has a cultural equivalent in Puerto Rico: "el ratoncito" [the little mouse]. For Puerto Rican children, a 
little mouse comes into their rooms at night, takes the tooth from under their pillow and leaves the money. In Example (15), Manuel and Ana are discussing gay marriage, a topic that was hotly debated in U.S. media at the time of the recording. Ana mentions that some people think that because they do not believe in gay marriage, it should not exist. Manuel compares this situation with the tooth fairy, namely, if you do not believe in it, it does not exist and vice versa. Interestingly, he did not mention the little mouse, which, in theory, should be a more familiar reference to a Puerto Rican. Manuel's familiarity and internalization with the U.S. culture is significant, but he still maintains an integral Puerto Rican identity, an issue that will be further addressed in Chapter Nine.

Example (15)

01 A: Es que le quieren imponer... Esa es la cuestión, que no tienen tolerancia 'It's that they want to impose their... The thing is that they are not tolerant' y le quieren imponer sus ideologías a los demás. "Yo no creo en los gay, 'and they want to impose their ideologies on others: "I don't believe in gays,' ni en el matrimonio gay, así que ustedes no se pueden casar”. Mira, por favor. 'and in gay marriage, so then you can't get married." Oh, please.'

04 M: Es como el tooth fairy. 'It's like the tooth fairy.'

In the second and last example of this section, Manuel talks to Laura and Ana about a woman he ran into at a friend's "housewarming" party. Although Puerto Ricans sometimes invite their friends and family over when they move to a new home, this is not a traditional celebration, as it is in the U.S. and other countries. Manuel uses the term 'housewarming' in line 06, and his 
interlocutors appear to be familiar with the concept. Also, in line 04 he clarifies that the t-shirt he was wearing said "Evil" instead of the popular jean's brand "Levi's."

Example (16)

$01 \quad$ M: $\quad$ Y yo tenía una camisa que decía evil.

'And I had a t-shirt that said evil.'

$02 \quad \mathrm{~L}: \quad$ ¿Kneivel?

'Kneivel?'

03 A: Kneivel. Just kidding.

'Kneivel. Just kidding.'

$04 \quad$ M: En vez de Levi's Evil.

'Instead of saying Levi's Evil.'

05 Ella estuvo chavando con "evil man" toda la noche. Hablamos

'She kept giving me a hard time calling me "evil man" all night. We talked'

$06 \quad$ un ratito pero nada y después me la encontré en un housewarming

'for a while and then nothing, and then I ran into her at the housewarming'

07 de alguien que yo conozco...

'party of someone I know...'

08 A: Pero llegó aquel día, que tú estabas preocupado que no iba a llegar.

'But she showed up that day, when you were worried about her not showing up.'

\section{U.S. Movies and TV Shows}

In a discussion about linguistic change from a social perspective, Romaine (1996) mentioned that the word nörd (from American English nerd) was being used by Swiss youths to 
refer to someone who is dumb or stupid. She and her colleagues concluded that the word must have crossed the Atlantic and entered Switzerland through the movie Revenge of the Nerds. Another reason given was the young people who visit the United States and return, bringing with them such terms. Romaine stated that, without a doubt, the influence of American pop culture over the youths of many parts of the world has paved the way for the introduction of many new anglicisms in other languages (p. 163). The possibilities for this type of linguistic change are significant, since most people are exposed to the media, and therefore to linguistic norms outside their communities. If this observation was true in 1996, it is even more noteworthy now, more than ten years later. Technological advances and the fast proliferation of Internet access have contributed to this process of linguistic exchange.

This phenomenon was also observed by Jorgensen (2005), who analyzed the codeswitching behavior of Turkish-Danish bilingual grade school students, who not only use their L1 and L2 in interaction, but also English, French, and German. He noted that some of the uses of English and German are in fact routines that are not independently constructed utterances. He also observed that these routines may have originated outside their school experience from TV commercials and other advertisements that are often entirely in English in Denmark. Alberto, in the present study, is convinced that movies and television are responsible for the incorporation of English words into his vocabulary:

This codeswitching that one does is mostly because of things that one has learned in movies and such. It's completely that, because, how else could you absorb a phrase and say, that sounds better to me that way? Because you have heard it somewhere. Because you're absorbing it from a movie, you see it in "Friends." And ways of saying things, it's 
like... They stick to you and I'm sure that if you took a Puerto Rican with all the same characteristics as I, and he didn't watch television, he wouldn't speak the same way. Este codeswitching que uno hace es más por cosas que uno ha aprendido en películas y cosas. Es completamente eso, porque ¿de qué otra manera tú puedes absorber una frase y decir, esto me suena mejor de esa manera? Porque lo has oído en algún lado. Porque lo estás absorbiendo de una película, o lo ves en "Friends”. Y maneras de decir las cosas y es como, pues... Se te pegan y yo estoy seguro que tú coges a un puertorriqueño con todas las otras mismas cosas que yo tengo y si no tiene televisión, no hablaría igual. Alberto's conclusion that television is solely responsible for bilinguals' appropriation of English is not entirely accurate, since many other factors contributed to his acquired bilinguality. However, the media is a significant source of second language input for this network of speakers. In his comment, Alberto also inadvertently refers to the identity work accomplished by the incorporation of English words. He specifically distinguishes himself from other Puerto Ricans who do not have the same exposure to English through television.

To illustrate the use of the routines mentioned by Jorgensen (2005) that may originate from exposure to the media, let us turn to Example (17). Jacqueline is trying to get her daughter Marie to drink her milk, but is finding it difficult because the child is too interested in what is going on around her. Darío, uses a phrase taken from a popular TV commercial about the importance of drinking milk, to emphasize that his daughter should not want to socialize because she already has what's important to her: milk.

Example (17)

$01 \quad \mathrm{~J}: \quad$ Está peleando porque hay acción aquí y ella no quiere

'She's fighting because there's too much going on here and she doesn't want to' 
perderse nada. Pero está tomando. Ya... ya...

'miss anything. But she's drinking. There... there...'

03 L: Ella quiere socializar.

'She wants to socialize.'

04 D: You've got milk. Tiene leche.

'You've got milk. She has milk.'

Movie theaters in Puerto Rico show mostly American movies with subtitles in Spanish. Participants in this study go to the movies on a regular basis, and also regularly rent movies to watch at home. Local television channels often show dubbed American movies. However, two respondents in this study said that they cannot stand watching dubbed movies. Juliana mentions that when she watches rented movies with her husband's family she cannot stand it when they change the language options to Spanish. When it comes to movies, participants in this study watch them just like American audiences. Unlike audiences in Spain, for example, where movies are usually dubbed, these speakers are accustomed to consuming American movies exactly as they are originated, and this includes the English language.

It is not surprising that movies were a common topic in the recorded conversations for the present study. In several conversations, speakers discussed movies they had watched or wanted to watch. Example (18) illustrates how this topic of conversation often gave way to codeswitching. Lucas, Juan, Rafael, and Sara recorded a one and half hour conversation while having lunch at a restaurant in San Juan. While Lucas, Juan, and Rafael are friends and have the same linguistic practices, Sara is older than they are, and does not share their linguistic background. (She was not included in this study, but was kind enough to put me in contact with the other three speakers, whom she worked with and knew were avid codeswitchers.) I was not 
present in this conversation, but relied on Sara to arrange the recording of a conversation during a typical lunch meeting. Sara is bilingual, but as we will see in Example (18), she did not appear to know the meaning of the familiar English phrase "kick the bucket." The other three bilinguals did know the meaning of this phrase. The movie discussed is called The Bucket List.

Example (18)

01 J: $\quad$ Mi esposa fue a like a... En el trabajo hicieron como un morale event 'My wife went to like a... At work they did like a morale event'

$02 \quad$ o algo y los fueron a llevar a ver The Bucket List 'or something of the sort and they saw The Bucket List'

03 L: $\quad$ Ah, The Bucket List, me dicen que es buena.

'Oh, The Bucket List, they tell me it's good.'

04 J: Fueron a ver The Bucket List.

'They went to see The Bucket List'

05 S: ¿Qué aprendieron de la película? Hay que verla.

'What did they learn from the movie? We have to see it.

06 J: Dicen que it's a nice story, pero es de los niños, que van, están terminally ill, 'They say it's a nice story, but it's about kids, that go, that are terminally ill,' se van a morir y uno es millonario y hace una lista de 'they're going to die, and one of them is a millionaire and does a list of' qué cosas quieren hacer. Entonces, pues se llama Bucket List, porque 'things that they want to do. Then it's called Bucket List, because, you kick the bucket, es como que la lista de things to do before you 'you kick the bucket, it's like a list of things to do before you' 
11 L: $\quad$ Olvídate de eso.

'Forget about it.'

12 S: ¿Kick the bucket es morirse?

'Kick the bucket means dying?'

Despite the availability of local channels in Spanish, only two participants in this study mentioned watching television in this language. All others, watch many of the same TV shows as American audiences. As we saw in the participants' descriptions, most of them have been doing so since they were children. Jacqueline and Lourdes commented on the noticeable difference between their English proficiency and that of the other kids at school, who did not watch cable TV. It is not surprising that the majority of respondents mentioned television as a significant factor in their learning of English. First, virtually all of them have been exposed to television shows in English their whole lives. They figure that regularity of exposure must have had an impact on their English attainment. Second, in the context of Puerto Rico, as they were growing up, these bilinguals had limited opportunities to be exposed to spoken English. Television became a source of information about everyday language use. Several of them did have English speaking relatives or friends, traveled to the United States occasionally, or, in the case of Rey, his father made it a point for him to speak his second language. But apart from these factors, opportunities to speak English are scarce on the Island. Also, some of them mentioned that their school experience with the language was often limited to grammar lessons, with little or no oral practice. Thus, they recognize television as their only exposure to colloquial English as they were growing up. 
Furthermore, constant and early exposure to English through movies and television influenced their understanding of English, not as a decontextualized foreign language, but as a language invested with American cultural idiosyncrasies. When asked why she codeswitched, Janet mentioned that she has assimilated many "slang" expressions from being exposed to movies and television in English, and then uses them in her daily life. Leo responded similarly to this question: "Since I watch so much television in English, I learn English phrases, like 'day to day.' That's what I would say. I learned it from television. I think I've never heard that in Spanish. I guess it would be 'día a día’, or I don’t know...”

In Example (19) Alberto talks to Ana about a person in New York who was supposedly spreading a new strain of the AIDS virus. Two things stand out from this excerpt. First, it evidences participants' familiarity with U.S. news channels and knowledge of current events. Second, we see how the word "strain" is being adopted by speakers. The equivalent in Spanish, 'cepa,' does not appear in the exchange. It appears that the English word 'strain' has already been appropriated by this group of speakers.

Example (19)

01 A: Mira oíste del tipo ese, le estaba diciendo a Laura, 'Listen, did you hear about that guy, I was telling Laura about it,' el tipo ese en Nueva York que lo están buscando, un tipo que está regando Sida. 'The guy from New York that they are looking for, the guy is spreading AIDS.' Es un strain nuevo que hay que en dos semanas...

'It's a new strain that in two weeks...'

04 A: Yo sé que hay un strain nuevo pero... 'I know there's a new strain but...' 
05 A: En dos semanas te deso, y no está respondiendo a ningún medicamento.

'In two weeks it does its harm, and it's not responding to any drug.'

'Then they identified this guy that has spread it to more than a hundred people.'

07 A: Yél es portador y no le pasa nada, obviamente.

'And he's a carrier and nothing happens to him, obviously.'

08 A: Y yo lo han conseguido. Estaban hablando de eso, lo oí por CBS News.

'And they haven't found him. They were talking about that, I heard it on CBS

News.'

In a conversation between Alejandro, Lourdes, Manuel, and I while having dinner, approximately thirty minutes (of a total of ninety minutes) were dedicated to talking about television shows and movies. I made it a point not to steer the conversation in any direction, but instead, went along with the topics proposed by the other the three participants. This topic probably gave them a lot to speak about because they all love movies and watching television. Also, whenever Manuel, a film maker, is in a conversation, there is always talk about movies. He always provides movie reviews and tells stories about Hollywood movie actors he has interviewed. Examples (20) and (21) were taken from this conversation. In the first one, Manuel complains about his wife always watching television before bed and leaving the TV on while reality shows are on. In the second example, Manuel and Lourdes talk about problems with broadcasting of U.S. networks in Puerto Rico. The words 'reality show,' 'thriller,' 'season,' and 'season premiere' appear to also be incorporated into elite bilinguals' vocabulary. These words were also found in other recorded conversations with the same referents. 
Example (20)

$01 \quad$ M: A mí me da cosa que ella siempre deja el televisor puesto en Bravo.

'It bothers me a bit that she always leaves the television on Bravo.'

02 Entonces me quedo dormido con el televisor prendido y la lámpara prendida.

'Then I fall asleep with the television on and the lamp on.'

$03 \quad Y$ de momento me levanto y hay una gritería y es un reality show de Bravo.

'And suddenly I wake up and there's shouting and it's from a Bravo reality show.'

$04 \quad$ Y eso me da pesadillas. Olvídate de ver un thriller a las diez de la noche.

'And that gives me nightmares. Forget about watching a thriller at ten at night.'

05 A: A mínunca me dan pesadillas así.

'I never get nightmares like that.'

Example (21)

$01 \quad$ A: ¿Tú lo bajas por itunes?

'Do you download it from itunes?

02 M: $\quad$ Lo que pasa es que el streamline de ABC, yo así lo tengo en la computadora y 'What happens is that the ABC streamline, I can keep it in the computer and'

03 lo puedo ver cuando quiera.

'I can see it whenever I want.'

04 L: Pero ellos lo cortan. Me acuerdo para Desperate Housewives, me acuerdo que 'But they cut it. I remember that with Desperate Housewives, I remember' lo cortaban. A veces había empezado y ellos tenían anuncios.

'they would cut it. Sometimes it had already started and they had commercials.' 
06 M: No respetaban los breaks comerciales de Estados Unidos. En el season finale de 'They did not respect the U.S. commercial breaks. In the season finale of' Desperate Housewives del season antepasado hubo escenas

'Desperate Housewives of the season before last, there were scenes'

08 que aquí no se vieron. Había cosas que como que no se entendían. 'that were not seen here. There were things you couldn't understand.'

\section{Business and Technology}

The English voice of technology is present in many instances in the present study. In his study of biculturalism and bilingualism in Hong Kong, Li (1996) identified several domains in which code mixing was widespread among Hong Kong speakers of Chinese and English. These are instances which may trigger codeswitching because of culture or field-specific vocabulary in the guest language (in Li's case it was also English). One of Li's informants said: "I cannot carry a conversation involving the use of technical terms in Chinese, much less explain these terms themselves" (p. 47). Li concluded that no other domain was more dominated by English terminology than the "computer discourse." This does not mean that there were no equivalent terms in Chinese, but that speakers in his study learned these terms in English first. The result is that, usually, they are cognitively retrieved in the language in which they were first introduced. Speakers in the present study also revealed having appropriated many technological terms in English.

Another source of vocabulary in English is the business world. The exact role of English in Puerto Rican business is subject to scrutiny. Uber (2000) provided an excellent description of the situation: "Puerto Rico represents a unique bilingual market, where written documents, technical terminology, and product names may be in English, but spoken business dealings are 
generally conducted in Spanish" (p. 130). This statement was partially confirmed by the present study, since several participants confirmed that they conduct business in Spanish, but they constantly use codeswitched words in English. Despite the predominance of Spanish use in everyday commercial contexts on the island, few would deny that high level management positions in certain industries, such as banking, law, and technology are most likely to be held by bilinguals. It is highly probable that individuals in these positions will have direct contact with English-dominant individuals, companies, or institutions (from the United States) which have a direct bearing on the success and maintenance of their industry. The balanced bilinguality required in these fields, and the widespread acceptability of many technological and business terms in English, provide fertile ground for the practice of codeswitching.

A common practice in Puerto Rico is using English names for businesses. In Example (22) Graciela talks about the many businesses that use 'Rodríguez', her husband, Leo's last name. Most of the business names she mentions are in English:

Example (22)

01 G: Hay Rodríguez Aluminum, Rodríguez Auto, Rodríguez Air Conditioning. ‘There’s Rodríguez Aluminum, Rodríguez Auto, Rodríguez Air Conditioning.'

02 D: Aquí hay una familia bien entrepreneur.

'Here we have an enerpreneur family.'

03 L: Cogiendo la curva de San Patricio pusieron un letrero nuevo Rodríguez 'When you take the San Patricio turn they put up a new sign, Rodríguez

$04 \quad$ all aluminum.

05 G: All aluminum. Ese sí. 
'All aluminum. That one's great.'

The following two examples show the incorporation of technological terms in the everyday speech of speakers. There are Spanish equivalents for words like 'online,' 'random,' 'upgrade' and 'headset,' but speakers seem to be more comfortable using English terms. Alberto, Ana and Carlos appear in the following examples:

Example (23)

01 A: Nosotros tenemos un juego que vino con el Xbox, que es Tetris.

'We have a game that came with the Xbox, which is Tetris.'

02 A: Ah, ese está bien nice, I love it.

'Ah, that one's nice, I love it.'

03 A: $\quad Y$ ese se puede jugar online, y juegan cuatro personas, tú, otra

'And you can play that one online, and there are four players, you, another'

$04 \quad$ persona y dos más en Internet.

'person and two other ones from the Internet.'

Example (24)

01 A: Pero lo nítido es jugar por Internet con otra gente.

'But the neat thing is to play over the Internet with other people.'

02 A: Te dan el upgrade, no lo tienes que comprar.

'They give you the upgrade, you don't have to buy it.'

03 A: Entonces la gente habla. Oyes la gente hablándose el uno al otro.

'Then people talk. You hear people talking to each other.'

04 Hay una cosa ahí, que tú pones un juego random ahí, lo pones. 
'There's this thing, where you select a random game, you select it.' Y tú oyes gente de Francia...

'And you hear people from France...'

$06 \quad \mathrm{C}: \quad$ ¿De verdad?

'Really?'

07 A: Sí, y alemanes, de todo hablando por ahí. Yo no tengo el headset, 'Yeah, and Germans, everyone talks. I don't have the headset,' yo no soy tan fiebrú. Se oye por el televisor. Y tú compites con esa gente.

'I'm not that into it. I can hear it through the television. And you compete with these people.'

Examining common discourse topics is relevant for the present analysis because it sheds light on the potential identities resulting from interaction: "Social identities are made manifest through talk, not just through the actual language or 'code,' but also through content and context" (Sebba and Wootton, 1998, p. 284). Speakers are in close contact with many cultural aspects of the United States, which is manifested in their everyday use of language. The content of their conversations, prompted by their familiarity with U.S. culture and cultural imports, can be added to the host of sociolinguistic variables active in this context, to which codeswitching responds.

Close contact between Puerto Rico and the United States, and between English and Spanish, manifests itself in the linguistic practices of these speakers, and says much about their personal and social identities. In terms of personal identity, if English were eliminated from these conversations, there would be a communication breakdown of some kind among speakers. Codeswitching has not only become a central communicative style, but also a fundamental part 
of who they are as individuals. Also, the ability to deploy idiomatic expressions with ease, talk about U.S. current events, demonstrate familiarity with cultural imports such as movies and television shows, and being able to remain up to date with technological advances, all contribute to creating their personas, and inevitably generate a rapport among this network of speakers. There exists a certain pressure to accommodate to the codeswitching style of others. In this process of adaptation, integration, and appropriation of English, identities are created and maintained. 


\section{Chapter 8: Codeswitching Style}

The second research question is: What constitutes speakers' codeswitching style and how is it interactionally negotiated? The question relies on the assumption that speakers regulate group membership (i.e., multiple identities) through particular patterns or styles of linguistic behavior. It also presupposes that there are common patterns, as well as differences, between participants in terms of how they negotiate and deploy their linguistic resources in interaction. This chapter provides a window into the process of code negotiation which takes place in the creation of speakers' codeswitching style. It will further discuss the language ideologies that are relevant for this group of bilinguals. Understanding speakers' perceptions of these ideological constructs is necessary for interpreting the construction of a codeswitching style. The chapter ends with a discussion of the social interpretation of codeswitching, which will lead to the last chapter of this dissertation, which focuses on identity.

There are three interrelated concepts that are crucial in the present analysis of style. The first one is style as practice: "Style (like languages) is not a thing but a practice. It is the activity in which people create social meaning, as style is the visible manifestation of social meaning" (Eckert, 2004, p. 43). When speakers negotiate a codeswitching style in interaction, they are not only engaging in a pragmatically and referentially meaningful activity, they are also creating social meaning. The second premise is that style is not created by individual instances of code alternation, but by the overall deployment of codes in linguistic practice: "The sociolinguistic analysis of style claims, then, that the social meaning of linguistic heterogeneity does not actually reside in individual linguistic features but rather in constellations of such features, which are interpreted together" (Auer, 2007, p. 12). Thirdly, and most importantly, the social meaning of the practice of codeswitching can be found in the creation of categories that may be 
recognized by individuals and are socially interpreted: "There is social knowledge involved about how to relate constellations of features to social groups, milieus, life-worlds, etc." (Auer, 2005, p. 13). Furthermore, the practice of codeswitching in Puerto Rico may be related to social groups and identities, since this practice is embedded in a more general style, including leisure activities, and other distinguishing features.

\section{Overview of Code Negotiation}

The most common and regular type of codeswitching occurs in societies characterized by diglossia, where society itself determines the use of different varieties according to social occasions, participants and topics (De Fina, 1989, p. 109). In this sense, the codes to be used are mainly contextually prescribed. However, the type of codeswitching observed in the present corpus of data is one best defined as a stylistic device. It is also clear that participants do not belong to a Puerto Rican bilingual community like the one studied by Poplack (1980) and Zentella (1997) in New York, where codeswitching is the accepted community-wide discourse mode. Most Island Puerto Ricans do not codeswitch, but in spite of this, most participants in the present study affirm that codeswitching is an integral part of their linguistic repertoire, and they employ it in their normal, everyday interactions. Although this behavior strays from the community-wide accepted discourse mode, it is allowed and (for the most part) embraced by their social network: “The speakers' total repertoire is fully exploited in those bilingual settings where the speaker can call on the resources from each of the available codes and on the strategies of switching among them" (Lavendera, 1978, p. 391).

Like monolinguals, bilinguals choose among different varieties or registers of language and styles, but for the latter, the situation is far more complex, since they have two codes from which to choose. Still, the concept of "choosing" does not accurately describe what goes on 
when speakers engage in the practice of a codeswitching style. The two codes, as manifested in speakers' linguistic behavior, are integrated in such a way that using them in interaction becomes part of their overall lifestyle. Auer (2005) mentioned Turkish/German examples of codeswitching among two cousins in Germany and commented that they had integrated Turkish into their everyday life, and used it both among themselves and with Turkish friends "without such a sense of interpretive richness and certainly not as trespassers into foreign linguistic territory" (p. 409). This notion was confirmed in the present study. Laura, for example, says that she does not stop to wonder which language she will use next: "I say it in the language that best expresses what I want to say."

Participant interviews also confirmed that there is a connection between interlocutors' perception of the communication situations they encounter, and the language they allow in interaction. Most participants expressed that they decide whether to allow codeswitching to take place or block it altogether. They consider the linguistic capabilities of the interlocutors, the context and the situation, and accommodate their speech accordingly. This is consistent with Jacobson's (1977) findings in which speakers' appraisal of the situation and interlocutors would determine the appropriateness of mixing Spanish and English. There are contexts that are better suited for a certain language variety, be it the home, peer group, school, or employment. Codeswitching then assumes a function equivalent to that of any other regional or social variety (p. 235). The use of codeswitching is parallel to monolingual use of different registers or styles within the same language, which accommodates to different speech situations.

Manuel, for example, is a film professor and movie critic for a local newspaper. He interviews Hollywood actors in English, but translates the interviews into Spanish for publishing in a local newspaper on the Island. In his role as a professor, he codeswitches occasionally, but 
he tries to avoid it. Likewise, when he appears on television, on a weekly basis, he makes it a point not to codeswitch. In fact, virtually all informants explained that codeswitching is unacceptable in professional situations. Manuel said "speaking only Spanish or only English reflects professional skills that will give me an advantage over other people." However, the informal, ingroup nature of codeswitching makes it acceptable amongst co-workers. Ana, who used to work in advertising and is now a lawyer, said: "At work I codeswitched all the time because everyone was fluent in English. This language was part of our work, we used it to brainstorm. Now, at the firm, we do it also in our everyday speech because we are all bilinguals." Helena and Sandra are also lawyers. At work, with their peers, they mix languages. Before the Federal Court, they express themselves only in English, and before a local court, they do so solely in Spanish. Eckert (2004) explained that "the selection of variables for making stylistic moves is based, then, in the speaker's interpretation of the meaning potential of available resources" (p. 43). When speakers choose to block English altogether, as in professional situations, they are interpreting the meaning potential of their available linguistic resources and then act accordingly.

One final observation pertaining to code negotiation, is that codeswitching must not be confused with gaps in knowledge in the two codes. Lipsky (1980) concluded that sufficient evidence has been found to indicate that speakers who codeswitch do not do so because they do not know the appropriate words in each language (p. 36). Code alternation is rarely motivated by language deficiencies, since in the case of balanced bilinguals, information can often be equally expressed in either language. Thus, at some level, bilinguals are aware of alternative communicative resources which can be used for different purposes, one of which may be as simple as adding subtlety to what is said. When participants say that English expressions are 
"better," they are referring to the semantic and/or pragmatic aspects of communication. In many cases, they could convey exactly the same semantic meaning with Spanish words, but their choice of language and the difference they notice is a pragmatic one, at the discourse level. In other cases, speakers use words in English because they can "successfully convey the intended meaning" (Li and Tse, 2002, p. 171). Most participants in the present study expressed that one of the reasons they codeswitch is because English words are "better suited" to deliver their message. Laura said: "I codeswitch mostly when the expression in English for what I want to say is more accurate than the expression in Spanish, or sometimes simply because I like the sound of the English expression better." Sandra echoes this sentiment: "Sometimes using English or Spanish helps me communicate better."

When we consider why bilinguals codeswitch, it may just be a matter of taking advantage of what is available in their linguistic repertoire. As we saw in Blommaert's (1992) study on Campus Kiswahili, codeswitching may become a sociolect shared by members of a social network. He asserted that this mixture of codes is stylistically motivated and not a result of speech economy or untranslatability (p. 62). In a similar vein, Lavendera (1978) wrote that, for Chicano and Puerto Rican bilingual speakers in the U.S., a fully developed communicative performance is not possible in each of the codes, especially when it comes to social and stylistic meanings. "Neither their variety of English nor their variety of Spanish will offer them all the stylistic and social variation available to monolingual speakers of either code" (p. 405). This characterization of codeswitching has important implications for the present study. It seems that the full range of stylistic meaning among this network of speakers is only accomplished by incorporating English in an otherwise Spanish monolingual discourse. Lavendera also suggested that speakers will prefer those communicative situations in which their whole linguistic 
repertoire is appropriate (p. 405). This assumption was confirmed in the present study.

Respondents, for the most part, reported feeling comfortable in situations where they could codeswitch freely, without having to worry about which language was appropriate.

\section{Individual and Group Characteristics}

Codeswitching has both individual and group functions and motivations. For instance, it could be dependent on individual factors such as personality. When describing the linguistic situation in Alsace, Gardner-Chloros (1991) mentioned that in one of the conversations she analyzed, Mr. Eder, who loved chatting and telling stories, had far more opportunities to switch languages than someone less talkative (p. 184). She concluded that individual differences do have a noticeable impact on codeswitching practices. In the present corpus, Ana and Rey, the two participants who codeswitched the most, define themselves as very communicative people. In the recorded conversations, they were often willing to offer more information about their thoughts and opinions than other participants.

The interviews conducted with each participant revealed metalinguistic awareness regarding the reasons behind codeswitching. The following are some of the comments made by participants as to why they codeswitch:

1) Ease of expression.

2) Codeswitching is normal among peers, family or co-workers.

3) It is more "natural" to use English words.

4) Some terms have no satisfactory translation into Spanish.

5) Codeswitching is a signal of group membership.

6) Alternating English and Spanish is a habit.

7) It is hard to speak only Spanish. 
8) Being too lazy to look for the Spanish equivalent of English words.

9) Being relaxed and not being judged prompts the use of English.

10) There are things that can only be expressed in either language.

Within a linguistic community, there is no single set of norms that dictate exactly when and how to codeswitch. Members of the same family, or people with the same educational and social background, may show different preferences for language usage. Furthermore, even the most careful scrutiny of speech patterns in a group of speakers usually reveals no consistent behavior in terms of codeswitching. This refers not only to the frequency of switches, but also to the form they take within the sentence, or even how many words should be said in each language (Lipski, 1980, p. 38). Therefore, the corpus of data in the present study is suggestive of individual and group patterns of codeswitching, rather than conclusive.

Table 2 shows degrees of codeswitching frequency, as determined by overall codeswitching tendencies gathered from recorded conversations. 
Table 2: Codeswitching Tendencies in informal group encounters.

\begin{tabular}{|l|l|l|l|l|}
\hline Name & All the time & $\begin{array}{l}\text { Most of the } \\
\text { time }\end{array}$ & Sometimes & $\begin{array}{l}\text { Hardly } \\
\text { ever }\end{array}$ \\
\hline Darío & & & & \\
\hline Jacqueline & & & & \\
\hline Leo & & & & \\
\hline Lucas & & & & \\
\hline Rey & & & & \\
\hline Graciela & & & & \\
\hline Diego & & & & \\
\hline Marla & & & & \\
\hline Helena & & & & \\
\hline Sandra & & & & \\
\hline María & & & & \\
\hline Juan & & & & \\
\hline Alejandro & & & & \\
\hline Rafael & & & & \\
\hline Juliana & & & & \\
\hline Valeria & & & & \\
\hline Viviana & & & & \\
\hline Jaime & & & & \\
\hline Walter & & & & \\
\hline Janet & & & & \\
\hline Laura & & & & \\
\hline Adrián & & & & \\
\hline Ana & & & & \\
\hline Manuel & & & & \\
\hline Alberto & & & & \\
\hline Lourdes & & & & \\
\hline Carlos & & & & \\
\hline
\end{tabular}

More than one participant in this study made reference to the "contagious" nature of codeswitching. Valeria, for example, could pinpoint those groups in which she codeswitches and those in which she does not. Mostly, she alternates languages in relaxed atmospheres with friends and coworkers: 
I think that inevitably, the English part of me relaxes and comes out, because many little doors open. I think that a person has some sort of files, and I can then open as many files as I want... The same thing happens when I use codeswitching and when I curse. In my group of friends I feel comfortable and I curse and speak English... There is no judgment, no criteria, the standards are low.

Yo creo que es que inevitablemente, mi parte de inglés se relaja y sale, porque se abren muchas puertecitas. Yo creo que uno tiene como unos files y puedo abrir los files que me de la gana... Igualmente me pasa cuando hago el codeswitching y cuando digo malas palabras. En mi grupo de amistades, yo me siento cómoda y hablo malo y hablo en inglés... No hay juicios, no hay criterios, los estándares son bajos.

Notice the use of the word 'inevitable' by Valeria. English is so integrated in her in-group speech style with friends that she feels compelled to use it in interaction. She emphasizes that codeswitching is allowed in contexts where standards are low. The standard, in this case, would be speaking solely Spanish. In informal in-group interactions, this standard is not enforced, and she is able to use her two languages freely. However, in the three hour recorded conversation in which Valeria participated, she generally restricted her use of English to single word switches. A possible reason for the limited integration of English in her idiolect is that she has assimilated ideologies regarding the purity and correctness of Spanish. Valeria prides herself on "still" having great Spanish, which reveals that she sees codeswitching as an intrusion into her otherwise "correct" Spanish. Example (25) illustrates Valeria's use of codeswitching. She talks about her four-year-old daughter's schedule at school, and comments on the way she pronounces the word 'scrapbooking': 
Example (25)

$01 \quad$ V: $\quad$ Ella está en la escuelita hasta las dos. Los lunes ella coge teatro, los martes 'She's at school until two o'clock. On Mondays she takes theater, Tuesdays,' yoga, los miércoles coge clases de scrapbooking, scrapookin, como ella le dice. 'yoga, Wednesdays she takes scrapbooking clases, scrapookin, like she says:' "Mami, hoy no hicimos scrapookin."

'Mommy, today we didn't do scrapookin.'

Valeria's speech style is characterized by single word switches, while Rey and Ana constantly engage in intrasentential and intersentential codeswitching. In fact, sometimes they use so much English that at some points of the conversation there can be doubts as to what the matrix language is, Spanish or English. In Example (26) Ana and Rey talk about his political views. Ana makes reference to 2008's Presidential candidate John McCain in her attempt to figure out how liberal or conservative Rey actually is.

Example (26)

01 A: Ah Dios mío, ¿tú eres republicano? Oh my God!, qué vomito, perdona. 'Oh my God, you're a Republican? Oh my God!, disgusting, I'm sorry.'

02 R: $\quad$ Toda la vida he sido republicano.

'All my life I've been a Republican.'

$03 \quad$ A: Uh, that's bad, that's very, very bad.

04 R: Lo que pasa es que yo soy un in between. 'The thing is I'm an in between.'

05 A: That's terrible. 
06 R: No, no, no, no, me explico, yo soy un in between.

'No, no, no, no, let me explain myself, I'm an in between.

07 A: Leftist o rightist? ¿Qué serías? ¿Cómo McCain?

'Leftist or rightist? You would be like McCain?'

08 R: $\quad$ No, no, no, lo que pasa es que yo no soy un left wing rightist,

'No, no, no, what happens is that I'm not a left wing rightist.'

$09 \quad$ pero soy mucho mas right que left.

'but I'm much more right than left.'

10 A: Ok, abortion.

11 R: Pero, pero, by far.

'But, but, by far.'

12 A: Pero entonces pérate, pérate, que este es el tipo de cosas que yo no había

'But then wait, wait, this is the type of thing that I hadn't'

13 descubierto de ti, abortion rights?

'discovered about you, abortion rights?'

$14 \quad$ R: What about that?

15 A: Pro life or pro, whatever... pro choice?

16 R: Pro choice.

17 A: Está McCain like.

'He's McCain like.

$18 \quad$ R: $\quad$ McCain like?

19 A: Bueno, pero por eso es que los fundamentalistas estos no lo quieren porque

'Well, but that's why these fundamentalists don't want him because' 
supuestamente es un poquito más liberal. Déjame ver. Qué más, gay rights, 'supposedly he's a bit more liberal. Let me see. What else, gay rights,'

$21 \quad$ R: What about it?

22 A: Pro choice or?

23 R: They have all the rights in the world.

24 A: They don't have all the rights in world.

25 R: They should.

26 A: They should, oh ok, they should. Ok, but they don't, oh ok, they should.

27 ¿Estás en contra de la 99? ¿Vas a ir a votar en contra de la 99?

'Are you against the 99 ? Will you go vote against the 99?'

$28 \quad$ R; $\quad$ Yeah right!

29 A: Yeah right, ¿qué? ¿Vas a votar por una enmienda constitucional

'What do you mean, yeah right, Are you voting for a constitutional'

$30 \quad$ a favor de que prohíban el matrimonio entre gays?

'amendment in favor of prohibiting gay marriage?'

$31 \quad$ R: $\quad$ No, I simply won't vote.

Another common characteristic of the codeswitching style of participants is the frequent use of tag switches such as "thanks," "I’m sorry" and "anyway." These stereotypic and pragmatically appropriate elements contribute to the cohesive nature of this network's speaking style. Rampton (1999a) explained that "within single stretches of speech, stereotypic elements from elsewhere mingle with habitual speech patterns, and in the process they generate symbolically condensed dialogues between self and other" (p. 422). Rampton called these stereotypic elements, such as thanks and apologies, "interpersonal rituals in friendly 
interactions" (p. 487). He characterized these insertions in discourse as unspectacular and pragmatically appropriate. They tend to occur in small group talk that is not officially approved. Similarly, in his 1999b study, Rampton analyzed the talk of a multiethnic tutor group of teenagers in an inner London school. He observed how adolescents used German outside their classes in small group peer interactions. He found ritually pregnant moments where German was used, and concluded that it was a resource for identity construction available for students (p. 499). Using words in another language contributed to nourishing, performing, and ratifying their group German. The codeswitching style of the participants in the present study also served to nourish, perform, and ratify individual preferences and group values, which ultimately contribute to the construction of identities.

\section{Language Ideologies}

At first glance, some may think that it is only natural for bilinguals to mix languages when they speak. What could be wrong with that? As long as both speakers are bilingual and the two codes can be understood, there seems to be no problem. Communication would be as potentially successful as with monolingual exchanges, and that would be the end of the story. However, there are many variables that may influence a bilingual speaker's choice of a particular language or style from their communicative repertoire. One of these variables is the ideological impressions they have of the languages they speak and their views on mixing them, which are in turn influenced by macro social ideological conceptions of language.

Ideology invests language, and certain linguistic styles may be ideologically invested. (Fairclough, 1992). In the case of codeswitching, we must consider ideological associations tied to each language, because these associations are also there when codes are deployed in interaction. Before discussing specific ideological constructs in the context of Puerto Rico, and 
how they relate to the codeswitching style of participants, let us review some basic converging dimensions between language and ideology (Kroskrity, 2004):

1) Language ideologies represent the perception of language and discourse that is constructed through the interest of a specific social or cultural group. A speaker's perception of what is "true" or "aesthetically pleasing" about language and discourse is grounded in social experience and often demonstrably tied to political-economic interests. (p. 501)

2) Language ideologies are profitably conceived as multiple because of the plurality of meaningful social divisions (class, gender, clan, elites, generations, and so on) within sociocultural groups that have the potential to produce divergent perspectives expressed as indices of group memberships. Language ideologies are thus grounded on social experience. (p. 503)

3) Speakers may display varying degrees of awareness of local language ideologies. While ideologies may be explicitly articulated by speakers, researchers also recognize ideologies of practice that must be read from actual usage (p. 505).

4) Speakers' language ideologies mediate between social structures and forms of talk. Linguistic and discursive forms are indexically tied to features of their sociocultural experience. (p. 507)

5) Language ideologies are productively used in the creation and representation of various social and cultural identities (e.g., nationality, ethnicity). Language, especially shared language, has long served as the key to naturalizing the boundaries of social groups. (p. 509) 
Whenever two languages are in contact, one is usually considered more prestigious than the other (Grosjean, 1982, p. 120). However, in the case of PR, it is difficult to pinpoint one language as more prestigious. The precise relationship between Spanish and English in PR in terms of the "dominant" language is difficult to unravel. English is both a language of prestige, power, and economic advancement, and the language of the United States. However, in terms of ideology, English may assume the role of an "alien" tongue that threatens to pollute Spanish, the language associated with a highly valued Puerto Rican identity. This negative connotation stems from historical events, and political-economic interests between PR and the U.S.

Spanish is not necessarily less powerful and prestigious than English in the PR context. It is the language of culture, literary tradition, solidarity, and Puerto Ricanness. As the present research was being completed, Puerto Rico's Spanish Language Academy celebrated its fiftieth anniversary. There are several generations of Puerto Rican writers whose main tool of expression is Spanish, and many Puerto Ricans affirm that Spanish is an integral part of their ethnicity. Furthermore, the widespread use of codeswitching among Puerto Rican communities in the U.S. confirms positive views toward Spanish. In this situation of displacement, Spanish could have been easily completely substituted by English. Puerto Ricans in the U.S. continue to hold on to Spanish, often in the form of codeswitching, while on the Island there are widespread protective attitudes toward Spanish against English influence. Therefore, for Puerto Ricans, both in the U.S. and on the Island, Spanish is a crucial criterion for group membership, which confirms its importance.

In Puerto Rico, English stands beside Spanish as a marker of prestige and is an important requisite for upward social mobility. Clachar (1997) conducted a study on attitudes toward English and Spanish on the Island, and concluded that "there seem to be conflicting tendencies 
given the perceived instrumentality of learning English, on one hand, and the desire to retain the valued ethnic tongue, on the other" (p. 94). If language is seen as a symbol of social mobility, the development of favorable attitudes toward learning it and using it are expected. Based on their studies of language acquisition in North America, Gardner \& Lambert (1972) found that "factors of attitudinal and motivational sort play very important roles in the acquisition of a second or foreign language" (p. 134). They maintained that attitudes are a stable personal characteristic which may influence one's progress in mastering a foreign language.

Participants in the present study have had different degrees of exposure to English. But what is common to all of them is that, in a way they have challenged ideological prescriptions against English. In more or less propitious circumstances they strived to learn English and be fluent in it. It is not enough to be exposed to a language; the motivation to learn it is crucial. A thorough analysis of their linguistic backgrounds revealed that class and socioeconomic expectations influenced their ideological conceptions of English. Their social experience allowed speakers to internalize the ideological advantages of English. This, in turn, influenced their motivations and attitudes toward learning it and, ultimately, their high levels of bilingualism. Speakers' competence in English and Spanish has resulted in the potential to codeswitch, and in its adoption as a legitimate communicative style in day-to-day interactions with friends.

Fairclough (1992) emphasized that we should not assume that people are aware of the ideological dimensions of their own practice. Ideologies may become so naturalized and automatic that it becomes difficult to pinpoint possible ideological investments. Practices may be interpreted as resistant or contributing to ideological change, but speakers are not always aware in detail of this ideological import (p. 90). Participants in the present study were asked to comment on ideological perceptions of the languages they speak, and the relationship between 
them and the practice of codeswitching. The goal was to better understand how these ideological perceptions may or may not influence their use of language. Speakers' perceptions are important because codeswitching is much more than an automatic response to social structural factors:

The practice of codeswitching is mediated by speakers' own understanding of their position in that structure (Gal, 1987). It is ultimately not any objective positioning or value of a language, but rather speakers' ideological interpretation of and response to that value, that are mobilized in codeswitching. Because of this, codeswitching and related translingual phenomena provide a window on social and political consciousness, as both Hill (1985) and Gal (1987) have argued (Woolard, 2004, p. 82).

In this chapter, speakers' ideological interpretations were divided into three categories based on the information gathered from recorded interviews with each participant: 1) English and Spanish: Participants in this category are comfortable with codeswitching in everyday talk, and show no reservations about its effect on their Spanish; 2) English and Spanish with reservations: Participants show some reservations about how codeswitching may affect their Spanish; 3) Spanish Only: Participants in this category have purist tendencies, and seem to be convinced of the negative effects of codeswitching. They are concerned because codeswitching has become so natural and automatic in interaction that they find it difficult to separate their two languages.

\section{English and Spanish}

Speakers in this first category show neutral or positive evaluations of codeswitching. They are comfortable with using English and Spanish in everyday talk, and show no reservations about how English may be affecting their native language. Gumperz (1982) stated that, when discussing codeswitching with bilinguals, they demonstrate widely differing attitudes, from 
negative evaluations that see it as bad manners and an uncertain control of two grammars, to positive ones that regard it as a legitimate style of informal talk. This statement was confirmed by the opinions expressed by participants in the present study.

In Pousada's 2000 study of Puerto Rican bilinguals, all of the respondents admitted to mixing or codeswitching at least on occasion, and the great majority reported that they did it daily. Three of them felt codeswitching was negative and stated that they tried to avoid it, but the majority felt that it was natural, comfortable, and even fun. They also mentioned that, in certain social situations, it was inappropriate and should be avoided (p. 111). These findings where confirmed by the present study. When asked if they thought mixing languages was something bad, some respondents said they didn't think it was negative, but emphasized that codeswitching is "situational." In professional situations it was best to avoid it because it could be seen as unprofessional. Many other respondents opted to classify codeswitching as something neutral. Rey, for example, thinks that codeswitching is useful in business dealings because he can get his point across easily. He emphasizes the neutral character of mixing languages:

MPC: $\quad$ Do you see codeswitching as something positive or negative about yourself? Rey: $\quad$ Neither, I don't think its good or bad, it is.

"Ni uno ni la otra, no creo que sea bueno ni malo, simplemente it is.",20

Speakers' linguistic outlook is influenced by widespread impressions about language (stereotypes), and by specific social circumstances. Heller (1988) believed that codeswitching is a popular research topic because it "violates a strong expectation that only one language will be used at any given time. It is seen as something to be explained, whereas the use of one language is considered normal" (p. 1). There seems to be a strong tendency for many cultures, such as the

\footnotetext{
${ }^{20}$ In all the quotes taken from participant interviews that will appear in this Chapter, words that were originally said in English by participants will appear in bold.
} 
American and the Puerto Rican, to adopt criteria for "speaking well" that necessarily include putting boundaries between languages. Not only are there global tendencies for the separation of languages, but there are local authorities (teachers, professors, intellectuals, institutions) that emphasize the "correctness" of language. As mentioned previously in this dissertation, the presence of English in Puerto Rico has come to index the "corruption" of Spanish. "Such imposed indexical ties may create ideological expectations among speakers and hence affect linguistic practice" (Bucholtz and Hall, 2005, p. 596). Two participants in this study made reference to their initial adherence to ideologies of language correctness, and subsequent acceptance of codeswitching as a legitimate practice. They mention childhood teachers as the source of this initial worry about "correctness." For instance, Alberto reports that he used to have a negative view of mixing languages, a view fostered by school authorities. However, this view has changed. He now believes that codeswitching is part of who he is, and there is nothing he can do about it:

MPC: $\quad$ Do you think mixing languages is wrong?

Alberto: $\quad$ Nope! Before, I did, but I think I don't anymore.

MPC: $\quad$ And why did you think so before, and don't anymore?

Alberto: Because before, when you're at school they say to you: No! Spanish is Spanish! But now I realize that that's the way I am. What can I do about it?

I probed a bit further to find out just how comfortable Alberto was with renouncing notions of language correctness:

MPC: Do you think codeswitching is affecting or enriching your Spanish?

Alberto: I'm certain it is not enriching Spanish. Because I'm replacing it with something else. I would say that it's affecting it, because I'm not practicing it as I should. 
For example, what I just told you. I said "everyday life" (in English) instead of "diario vivir." If I'm not using "diario vivir," then it's being affected.

MPC: $\quad$ And this worries you?

Alberto: $\quad$ Not at all. As long as I remember that that's how you say it in Spanish.

Protecting Spanish from English influence is a controversial issue among participants.

Some are torn between their allegiance to Spanish, and the inevitable incorporation of English in their daily lives. Janet, for example, was surprisingly aware of the role of imposed ideological conceptions of language correctness, and their relationship with individual choices for communication. The last part of the questionnaire designed for this dissertation addressed some of the main ideological Discourses related to languages in Puerto Rico. Participants were asked to comment on each ideological statement. Janet's reaction to the following statement about the need to protect Spanish from English influence revealed that she resists prescriptive ideologies of language protection.

MPC: $\quad$ The purity of Spanish must be protected from English influence.

Janet: Really? Am I supposed to tell you what immediately comes to mind?

MPC: $\quad$ Yes. Why?

Janet: That's what's interesting. What you just said is the first thing that comes to mind, but the truth is that I agree with it because that's what Spanish teachers wanted you to believe. Not because it is necessarily your ideal, or something very important to you at a personal level.

MPC: $\quad$ So, it would be an initial "yes" and then a "no"?

Janet: $\quad$ My second reaction would be indifference. It's like what I told you earlier. As long as you can communicate... Because for me the idea of a language is the fact 
that you are able to communicate with someone. If you can communicate using codeswitching, so be it. But if it's going to be the reason why you are not able to communicate with the other person, then there's a problem.

Janet appears to have a very open perspective on codeswitching: "If you can communicate using codeswitching, so be it." ["Si tú puedes comunicarte haciendo codeswitching, so be it."] She thinks languages should evolve, and English influence, in a way, has made the Puerto Rican dialect evolve. Walter expresses similar opinions about codeswitching. He also seems to be indifferent to the influence of English on the Spanish of Puerto Rico. What is more, incorrect use of Spanish itself worries him more than the inclusion of English:

MPC: $\quad$ Do you think codeswitching is affecting or enriching your Spanish?

Walter: I think it affects Spanish, but I don't mind.

MPC: $\quad$ Why don't you mind?

Walter: Just because. Because I don't depend on anybody to... I'm not worried about that, about what others think, it would be worse if I said something uneducated, if I said a word in Spanish incorrectly, that would traumatize me more than saying it in English. Because it's like a social status. Do you agree with me? Do you think Spanish is being screwed up?

Walter has a positive view of English and of codeswitching. He is aware of English as a status marker, and does not mind including it in conversations. Likewise, he is not worried about what any authority may say about English and its relationship to Spanish. Although he initially says that he is not concerned about what others think, he later reveals that he $i s$ concerned about his immediate social circle, and what they may think of his use of languages. Walter thinks that 
if he makes mistakes in Spanish people will think less of him, and think he is not intelligent. But this would not happen if he speaks English. On the contrary, English is "cool," so blocking it from his speech would be counterproductive for the identity he has created for himself as an urban, elite bilingual. (This process of identity creation will be further discussed in the next chapter.) Alejandro also has positive views on codeswitching. In the following excerpt he reflects on what actually constitutes "the Spanish of Puerto Rico," and talks about English influence and the role of language authorities:

MPC: $\quad$ English enriches the Spanish of Puerto Rico.

Alejandro: I don't think so. I don't think knowing new terms affects the Spanish of Puerto Rico, but probably in other countries they don't say “housewarming," or they have another term for that. Maybe that concept is not in the Spanish Royal Academy Dictionary. Spanish varies a lot in different countries, and who decides if words are approved or not?

In this excerpt, Alejandro refers to the incorporation of cultural borrowings, words that are needed to signify concepts that did not previously exist in his Spanish dialect. Alejandro is curious about the process of incorporation of anglicisms into the Spanish of Puerto Rico. He wants to know who decides which words become part of a language and which do not. Ultimately, the incorporation of new words into a language is a normal outcome of language contact. Despite the inclusion of borrowed English words, and worries about the contrary, Spanish continues to be the majority language in Puerto Rico. Laura recognizes this truth as the main reason why she is not worried about codeswitching and about English influence on Puerto Rican Spanish:

MPC: $\quad$ So you are not concerned about losing your Spanish, you're clear in that it's not 
being affected by codeswitching?

Laura: $\quad$ No, no, no.

MPC: $\quad$ But do you think that for some people this could be the case; that they use so much English that their Spanish is affected?

Laura: I think that could happen to them if they lived in a country where Spanish is not spoken. Because, if you stop practicing it, you stop speaking the language and you do lose it, but if you're living in Puerto Rico, where the language is Spanish, and it's all around you, then it's impossible to lose it. It's the official language and it's impossible to lose it. We are doing codeswitching, we are mixing languages, but there are still two languages.

Although research has shown that negative attitudes toward codeswitching are very common, this was not confirmed in the present study (Acosta-Belén, 1975; Chana and Romaine, 1984; Grosjean, 1982; Jacobson, 1977; Lawson and Sachdev, 2000; Pandit, 1986; Swigart, 1992; Toribio, 2002, 2004). Eight participants opted for classifying codeswitching as "neutral." Eight others said they viewed alternating languages as something positive, and five more viewed the practice as positive but had some reservations. (Three of these made it clear that in some situations, mainly professional contexts, it is not appropriate.) Six participants expressed a strictly negative evaluation of mixing languages. Overall, the majority of participants did not show an overwhelming negative perception of codeswitching. The following section includes participants who have positive opinions about codeswitching, up to a point. They expressed concerns about how language alternation may be affecting the Spanish of Puerto Rico. 


\section{English and Spanish with Reservations}

Participants in this category do not readily embrace codeswitching as a legitimate form of communication. They are torn between recognizing the ease of expression codeswitching provides, and their worries about the effects of English on Puerto Rican Spanish.

In Dakar, the capital city of Senegal, Swigart (1992) found the following language contact situation: Wolof is the language learned at home and used in everyday communication, and French is the official language. Most people in Dakar can communicate in Wolof, but there are many who do not speak French. Codeswitching between Wolof and French is very common among educated, urban bilinguals. Swigart explained that there are complicated and often contradictory attitudes surrounding codeswitching use (p. 84). In her study, there was a marked discrepancy between how speakers thought they should speak and how they did speak. Many bilinguals viewed codeswitching as something negative, even though it occupied a central position in their speech repertoire. She concluded that "mixed codes are typically considered by members of bilingual speech communities, including their habitual users, to be deteriorated forms of local languages, evidence of the loss of cultural integrity and/or proof of lack of linguistic competence in any language" (p. 97).

The context of the present study shows similarities to the one carried out by Swigart in Senegal. There is one language that is indispensible for conducting most everyday activities and a second language that is needed for certain domains, and associated with the educated elite. The negative evaluations of codeswitching presented by Swigart were echoed by participants in the present study. The following five participants are concerned about the negative consequences of codeswitching, but still show some acceptance of language alternation as a valid element of their communicative repertoire. 
Ana, for example, does not express an outright negative view of codeswitching, and at some point describes it as "part of who I am." However, her responses to the questionnaire show some ambivalence and reservations about this practice. Ana says that she has accepted that codeswitching is how she expresses herself most of the time, but she is genuinely worried about not being able to speak correct Spanish nor correct English. Codeswitching means that she is not being "faithful" to either language. Ana says it is somewhat stupid and ridiculous not to be able to speak her native language correctly, and to have to constantly add words and phrases in English: "It's ridiculous, but I do it." The following was Ana's reaction to a statement regarding the purity of Spanish:

MPC: $\quad$ The purity of Spanish should be protected from English.

Ana: $\quad$ Oh my God, that's very difficult to answer. I don't agree with that. I partially agree, I should say, because you obviously need to protect language. But the thing is that there is no such thing as purism.

MPC: $\quad$ Purism does exist for some people... but do you agree with it?

Ana: $\quad$ No, because languages enrich one another. I mean, English has many, many words in French, "touché."

MPC: $\quad$ But you said you were worried about Spanish incorporating words like 'parking'...

Ana: Well, again, it's not that I'm a purist, but I think that if there's an appropriate word in Spanish, I should use the word in Spanish. If it doesn't exist, like the one we were talking about before, "punchline"... Again, maybe it exists, but if the word does not exist, why wouldn't you enrich Spanish with a word like "punchline." It's the same as "fax." 
Ana states that it is "obvious" that languages need to be protected, but does not consider herself a purist. This reveals that she is fairly aware of normal processes of language change, but, at the same time, is not willing to compromise her native language. To Ana, codeswitching is an inevitable but ridiculous practice. Because it threatens the value she places on Spanish; codeswitching stirs negative feelings in her. However, constantly engaging in codeswitching practices also leads Ana to resist purist conceptions of language. In her interview, Ana criticized a co-worker who was constantly correcting everyone in their use of "proper Spanish." He even went as far as correcting e-mails in which people mixed the two languages. This went on until the president of the company told him to stop giving employees grammar lessons.

Diego agrees with Ana to some extent. He thinks that it is not always necessary to have protective attitudes toward languages, but if circumstances call for it, then those attitudes are needed. He thinks that what usually happens in Puerto Rico is that words in Spanish are replaced by those in English, but that this process rarely occurs to fill a void in Spanish. He fears the "weird mixture" of languages that may result on the eventual disappearance of Spanish, if English influence continues as strong as it is today.

MPC: $\quad$ Do you think mixing languages is wrong?

Diego: $\quad$ Yes, because it can go to an extreme. I obviously do it, so it's not that horrible. There's so much cultural influence here that it's ok, but it could reach an extreme and become a total mixture, incomprehensible for one or the other. Since I do it, it's not bad, but I see the dangers it can bring.

Diego's initial evaluation of codeswitching is negative. He then figures that if he does it, it must not be such a bad thing. He admits that, in some formal contexts, it is definitely wrong and inappropriate, but that in informal interactions with friends it is acceptable and even fun. He 
insists that codeswitching for him happens in contexts where others freely do it, and it is an accepted form of communication. However, Diego says that there is always that worry: that the more natural codeswitching becomes, the less he uses solely Spanish, and the weaker it becomes.

Graciela agrees with Diego in that codeswitching becomes acceptable in contexts where others do it as well. However, this in-group character of codeswitching does not take away from the fact that she is saddened by its effect on her two languages. She recalls that her Spanish was perfect when she graduated from high school. Then she went to college in the U.S. and English was a bit difficult for her. Then she came back to Puerto Rico, and now Spanish was the source of trouble. She says that when she came back to the Island, Spanish words would just not be "there" when she tried to use them. She managed to regain her Spanish up to a point, but now English is the one suffering because she does not practice it as much as she did in Boston. Graciela is then left with what she calls a "mess." She says the following about codeswitching: MPC: $\quad$ Do you think mixing languages is wrong?

Graciela: It's not that it's wrong, there's no absolute rule, but it's a mess. What happens is that I know so many people that do the same thing, that I continue to do it and I don't feel out of place. But, really, one should be able to... listen to me, I was going to say "stick to one language," in English. One should be able to speak in only one language.

Similarly, Helena would prefer not to codeswitch because she feels that you "lose when you can't speak only one language." This comment stems from the fact that, like Graciela, it's hard for her to speak only Spanish. Helena says that if she is forced to speak only Spanish, she sometimes has to stop and think of the right words. Many participants also admitted that 
speaking solely in Spanish involves a conscious effort because their natural tendency is to mix the languages.

These four participants, Ana, Diego, Graciela, and Helena, are genuinely worried about the "purity" and "correctness" of their Spanish. Ideologies that reject speaking more than one language at a time are very present in their minds. The last participant in this category, Valeria, recently began to teach at an all-English school and has noticed an increase of the amount of English present in her idiolect. She says she is worried about this new tendency to think in English. It is OK, she states, for one to include some English in everyday conversations, but when the vernacular is being affected, then there is a big problem, because "that's your language":

MPC: $\quad$ Do you think mixing languages is wrong?

Valeria: No, I don't think it's wrong. I think it would be wrong if I lost my vernacular. Losing your vernacular is what's wrong. But as long as I can write Spanish correctly and communicate with someone who can only speak Spanish, then there is no problem. It would be bad if the influence of one language would make me lose the other or made the other dysfunctional.

Linguists in general are aware that speaking of a "good" or a "bad" language, dialect or speech style is unfounded, and resisting language contact phenomena like codeswitching is going against the natural tendencies of human language, which is a constant state of change and variation. As Edwards (1999) aptly put it: “The variation found in speech-evaluation studies reflects social perceptions of the speakers of given varieties and has nothing to say about any intrinsic qualities, logical or aesthetic, of the language or dialect itself" (p. 102). Edwards stressed that these perceptions do not occur randomly but rather serve as a window to view social 
structures. When a speaker uses or listens to a language, he or she perceives it according to the attitudes, prejudices, ideologies, or stereotypes about the relevant speech community. Therefore, although participants in this dissertation may accept codeswitching as a legitimate practice in everyday conversation, some still express reservations about its effect on their vernacular. These concerns stem from the presence of prevalent ideologies that promote the preservation of Spanish, and the prevention of the "intrusion" of English, in speakers' sociocultural experience.

\section{Spanish Only}

Participants in this category express certainty about the negative aspects of codeswitching. Six speakers expressed negative views of language alternation. Their three main concerns were: 1) It reveals language deficiency, 2) It paves the way for language loss, and 3) It is wrong, because one should speak one language or the other, not both.

Lawson \& Sachdev (2000) reported that attitudinal dimensions of codeswitching are a relatively neglected area in research since most studies have focused on purely grammatical issues, have examined codeswitching as a language acquisition strategy, or have looked at it as a language contact phenomenon (p. 1344). Overall, the findings of codeswitching studies reveal a negative attitude toward it. Similarly, in his discussion on codeswitching, Grosjean (1982) said that monolinguals have long had a negative attitude toward codeswitching and that many bilinguals adopt this view, at least, overtly (p. 147). One consequence of this is that some bilinguals never switch, while others restrict it to situations where they know that it will not be stigmatized. Viviana, Adrián, Darío, and Leo belong to the second group. They think codeswitching is wrong, but practice it with regularity with friends, family and even co-workers.

Acosta-Belén (1975) mentioned widespread negative attitudes toward codeswitching in the United States. Speakers of a nondefined mixture of Spanish and English in Hispanic 
communities in the U.S. are judged as "deficient," "sloppy" and are often labeled as "verbally deprived," "alingual," or "deficient bilinguals," because they supposedly cannot speak either language well (p. 151). In the present study, speakers expressed their ideas about what codeswitching reveals in terms of proficiency or deficiency in language. Diego thinks you can codeswitch for both reasons, deficiency and proficiency, and the latter means that the speaker knows both languages well enough to alternate them. Laura and Darío think codeswitching into English is about being lazy, about taking the easy way out, and not having to think over how to say something in Spanish. Janet and Viviana took another approach to the issue, and said that it was not a matter of proficiency or deficiency but of having both languages "present" in conversation. At least seven participants thought it was a sign of knowing both languages well.

The problem with associating codeswitching with language deficiency is that participants in general have a high esteem for their Spanish language and worry about their native language skills. Some speakers, like the ones mentioned in previous sections, are able to dismiss these worries, but others continue to be genuinely worried about losing Spanish. This concern is not unfounded. Resnick (1993) confirmed that many Puerto Ricans fear the spread of English on the Island because they are responding to fundamental principles in the sociology of language. Language spread may lead to language shift, and language shift may lead to language loss (p. 269). This may be precisely why speakers like Darío, in the present sample, display negative attitudes toward codeswitching.

Darío: $\quad$ Yes. There comes a point when you lose... You lose your languages.

MPC: $\quad$ So, that's what you're worried about?

Darío: $\quad$ There are times when you're talking and the word in Spanish just doesn't come. You truly don't know it. 
MPC: $\quad$ Do you think there's a possibility that you know the word, but at that moment it didn't come to mind?

Darío: I think you lose it. If you start substituting the same word over and over and over again, you lose it. You don't practice it, you don't put it to use, you don't remember it.

Darío went on to say that, not only are Puerto Ricans losing Spanish, but that they might be creating a new language. He has travelled extensively to Trinidad, Curaçao, and other places in the Caribbean, and has come across dialects which are the product of creolization processes. I tried to explain to him that the circumstances behind the creation of these dialects is different from the one found in Puerto Rico, but his fear of language shift appears to be deeply seated. Darío fears the loss of lexical skills and a massive relexification of Puerto Rican Spanish, where words from a dominant language replace words of the minority language (Appel and Muysken, 1987, p. 42). Despite his fears, neither Darío, nor any of the other participants in this study foresee English replacing Spanish anytime soon. Vélez (2000) confirmed that "neither societal bilingualism nor language shift appears to be at hand. In this sense the island is a true languagemaintenance success story" (p. 19).

There are two situations in Darío's linguistic background that shed light on important issues that pertain to Puerto Rican bilingualism and language ideologies. When Darío arrived at Florida Tech to continue his college education, he immediately noticed that some of his Puerto Rican friends spoke neither English nor Spanish: "What they did was a horrible codeswitching and they could not express themselves in either language. I thought that was frustrating because they didn't have any other language, just those two." It turns out that his friends were, as Darío 
described them, "nuyoricans."21 They were Puerto Ricans who were raised in New York City and who, according to Darío, tried to speak Spanish and were not able to do so. Darío felt it was sad that they had "lost" their Spanish. Darío's first-hand experience of the possibility of language loss made him aware of possible dangers in his own environment. What Darío failed to consider was that the migratory context of New York Puerto Ricans is different from the one on the Island, where Spanish continues to be the dominant and preferred language in all domains.

Another situation that helped fuel Darío's worries was that in Florida he would speak Spanish with people from Venezuela, Colombia, Costa Rica, etc. and they would make fun of him because of his Puerto Rican pronunciation, and his constant use of English interspersed with Spanish:

Darío: $\quad$ You would speak in front of Venezuelans or Colombians and they would laugh at you because there where many situations where you would not be able to speak solely in Spanish. There are many English words that we use in our daily lives; we have substituted Spanish words by English ones.

MPC: $\quad$ And you think this is already happening too much in PR?

Darío: I would begin to worry. I have learned that it is not such a threat, but it's still negative, it's sad. The way I visualize Puerto Rico's future is that suddenly it's going to be so common, it's going to be common knowledge that in Puerto Rico what we speak is some sort of codeswitching.

Despite all Darío's concerns, he still codeswitches considerably with family and friends. I asked him if he was constantly trying to suppress his English and he said that he has "learned to cope with it" and does not see codeswitching as something completely negative. It has negative

\footnotetext{
${ }^{21}$ New York Puerto Ricans who return to the Island came to be known as 'Nuyorican.' The term can be used descriptively as well as pejoratively to denote a new breed of Puerto Rican (Haiman, 1993, p. 49).
} 
implications, but he has better things to worry about than editing himself on a daily basis. Still, his negative views on codeswitching seem to predominate, and he would still prefer to be able to speak one language without the help of the other. Darío's experience also emphasizes the social aspect of codeswitching. Darío does not control his surroundings, the linguistic practices of his friends and family. In his social network, English is very present in the form of codeswitching. The in-group character of codeswitching is important in explaining its presence in interaction, in spite of possible negative associations: "Despite the negative prestige attached to many varieties, they persist over long periods of time, partly because they serve important functions as markers of in-group identity" (Chana and Romaine, 1984, p. 451).

The effects of codeswitching as part of a continuum that opens a door to the integration of many more English words into Puerto Rican Spanish may seem the worst nightmare of those who subscribe to purist views of language. A comparable linguistic situation was described by Pandit (1986), who studied the codeswitching by urban educated speakers of Hindi who have learnt English through formal education. She cited a newspaper article by Mullick (1980) that evidenced adverse reactions to it: "The purists brand it as 'linguistic pollution' which they think is 'funny' as well as 'tragic.' Some fear that Hindi is being invaded and swamped by a host of English words and expressions which is stifling its native character" (p. 19). Leo shares this view of codeswitching as something sad.

MPC: $\quad$ Do you think mixing languages is wrong?

Leo: $\quad$ That's tricky. I think that, yes, it is wrong. But, I do it anyway. Particularly, saying that I can speak English better than Spanish is like dismissing my first language. The one I learned and grew up speaking. I don't know, it's kind of sad. MPC: $\quad$ Not speaking solely Spanish? 
Leo: It worries me. I feel that I'm always losing something, I feel less intelligent if I can't speak Spanish. It's frustrating that my first language...

MPC: $\quad$ You can't speak Spanish?

Leo: $\quad$ Yes, yes. I'm fluent in both. But sometimes I feel that I can't, that I'm more fluent in English than Spanish.

Despite the concern of some participants in the present study about their inability to speak "correct" Spanish, it cannot be said that acceptance and integration of the English language into their everyday lives has significantly undermined their Spanish. Furthermore, it is very difficult to pinpoint what constitutes the amount of interference in any one speaker. "In the majority of cases mixing languages is highly idiosyncratic and variable from speaker to speaker, and also within the same idiolect during different communicative situations. Therefore, charges that bilingualism hampers language differentiation must be tempered with caution" (Lipsky, 1980, p. 33). What can be said for certain is that, in the Puerto Rican context, subscribing to purist ideologies that privilege Spanish over English faces complex obstacles: "For Puerto Ricans, language and history are ever intertwined in a dance, as the ideologies and practices of colonization have historically pressed onward for a "purity" of speech that remains both senseless and unrealistic given the forces at work in shaping Puerto Rican life" (Vidal-Ortiz, 2004, p. 256). Participants in the present study who have negative views of codeswitching subscribe to the idea that this practice is a reflection of those forces that challenge linguistic purity. Adrián insists on the imperative of speaking only one language at a time.

MPC: Do you think mixing languages is wrong? 
Adrián: I think that it's not correct. One should force oneself to speak one language and if you switch to the other language, you should do it in full. There you go, I just said a word in English!

In Puerto Rico, worries about the corruption of Spanish because of English penetration are widespread. Although Viviana codeswitches with regularity, she also thinks it is wrong: In the following excerpt of her interview, she makes reference to a 1995 television advertising campaign commissioned by the Communications Department of the University of the Sacred Heart in San Juan, PR. The campaign was titled Idioma defectuoso, pensamiento defectuso [Flawed language, flawed thinking]. (See Appendix C) The television commercial featured many Puerto Rican celebrities speaking about the correct the use of anglicisms: "No digas 'size', di 'talla' o 'tamaño'”. [Don’t say 'size,' say 'talla' or 'tamaño']. Hispanicity ideologies, like the one promoted by this campaign, have gained widespread acceptance on the Island, which translates into resistance to the penetration of English into the linguistic landscape.

MPC: $\quad$ Do you think mixing languages is wrong?

Viviana: Yes, because like the campaign says "Flawed language, flawed thinking" and being someone that writes for a living, I should make a conscious effort to speak either English or Spanish.

MPC: $\quad$ So, although you practice codeswitching you don't approve of it?

Viviana: $\quad$ No. And I would try, for example, for my kids not to do it. I mean, correct them so that they learn things correctly. But bad habits are always there.

As evidenced in the present study, even Puerto Ricans who are fully bilingual and who have made English a part of their daily lives appear to be greatly influenced by purist ideologies. This chapter has highlighted the links between ideologies and communicative practice. As 
Woolard (2004) reminded us, codeswitching does not reveal objective positionings but rather speakers' ideological interpretation and responses to the value of languages (p. 82). Speakers' views about the relationship between English and Spanish and about their use in daily interaction are often conflictive. Their codeswitching style contributes to maintaining prevalent ideologies, and also challenges them.

\section{Social Interpretation of Codeswitching}

Ideological conceptions of Spanish and English in Puerto Rico are inevitably present in the linguistic practices of bilinguals in the present study. Codeswitching is both a reflection of dominant ideologies and relations of power between two languages, and an agent of change that challenges dominant linguistic expectations and conventions.

As noted in Chapter Seven, the bilinguals who participated in the present study do not appear to have in mind the indexical associations of each language in interaction. In everyday conversations, speakers are not aware of the potential metaphorical meaning of individual instances of codeswitching. When questioned about why they codeswitch, most of them expressed that mixing languages was a habitual way of expressing themselves in informal group encounters. However, in the interviews conducted for the present study, speakers were asked to deconstruct the social meaning of the way they use their languages. They were asked about their interpretation of this style, and how they thought it could be interpreted by those around them. These individual and social interpretations are important because they open a window into the "kinds of people" that codeswitch. This issue is at the heart of one of the principal aims of this study: identity creation. Although participants do not have these ideological interpretations in mind while interacting with family and friends, they do affect their linguistic practices. Alberto said the following about codeswitching: 
I do it with a lot of people but sometimes I don't do it... Sometimes I try to be more conscious of not doing it when I talk to someone I don't know well. If I'm making a presentation in front of a client, I catch myself stopping myself when I am about to use a word (in English), and I try to translate it into Spanish for fear that they don't understand me. It's possible that I do this also because I don't want to sound pompous. Like arrogant. I try not to project that, so I try not to...

Lo hago con mucha gente, y a veces me cohíbo cuando... A veces trato de ser consciente cuando hablo con una persona que no tengo confianza o algo, de no hacer eso. Si estoy haciendo una presentación a un cliente, me veo a veces yo mismo frenándome cuando voy a usar una palabrita, trato de traducirla al español, por miedo a que no la entiendan. Inclusive, podría ser también hasta hacerlo para no sonar pompous. Como arrogante. No me gusta proyectar eso y yo trato de no...

Alberto's comment is evidence of a "critical awareness" about what codeswitching can reveal in terms of the indexical ties between English and specific types of personae. He associates using English with appearing "pompous." Alberto went on to explain that when you codeswitch you are automatically setting yourself apart from the people who do not do it or are not able to do it, and that it is a status signal: "English is the cool language," he says. He also mentions that there seems to be a limit on how much English you can include in your conversations. If you use too much English, it is a clear sign that: "You think you're better than others because you can speak English." Virtually all other participants agreed with Alberto that speaking too much English can make you seem arrogant and snobbish.

To explain the indexical association between English and "arrogance," we must go back to the historicity of English in Puerto Rico and review the concepts of critical language 
awareness, linguistic market, and elite closure. The imposition of English after PR was ceded to the United States in 1898 made an initial mark in the consciousness of Puerto Ricans. English was the language of the more powerful nation to which the Island was ceded. In the Puerto Rican linguistic market, the language associated with power, social mobility, and advancement is English. Speakers are in some way aware that language is invested with power relations. Crucially, English has become a commodity more easily available to speakers of an elite who have access to the "right" level of education and the "right" social networks. One important aspect of the social interpretation of speaking styles is that "linguistic choices index such things as attitudes, stances, and activities that in turn are associated with social categories" (Eckert, 2004, p. 47).

Codeswitching among bilinguals represented in the present study indexes a "superior" social category and, in turn, it indexes certain attitudes and stances toward this social category. The case of Adrián is also an excellent illustration of this indexical association. Adrián grew up in a lower-middle class family. Adrián speculates that he learned English not only in school, but also from contact with English speaking people outside his immediate social circle, since his family lived close to one of San Juan's elite English-speaking schools. Adrián's socioeconomic background was different from that of his English speaking childhood friends, and their linguistic practices revealed this. In the following excerpt, Adrián talks about his childhood. Although he was bilingual, he did not see the need to speak English with his friends. He found it strange and pretentious whenever they used English. Later he reveals how he changed this initially prejudiced view of his friends.

Look at those background differences, I come from one society and they belong to a different class, and the way I saw them, when they spoke English; I thought: "Look, I 
speak English, but I don't need to speak it all the time." I speak it if I need to speak it. And then, sometimes I saw that, although they were Puerto Rican, they spoke English amongst themselves. Maybe I sometimes thought: "Damn, they're so stuck up, what is this about?" Yeah, I saw this and said to myself: "What's wrong with them?"As time went by I was able see the broader picture...

Mira esas diferencias de background, que yo vengo de esta sociedad y ellos son de esta otra clase, y yo veía a esta gente, cuando hablaban inglés; yo estaba: "Mira, yo hablo inglés, pero no tengo que estar hablándolo". Yo lo hablo si lo necesito hablar. Y entonces, algunas veces yo los veía a ellos, que entre ellos mismos, son puertorriqueños, pero ellos hablaban inglés. Quizás yo algunas veces decía como: "Diablo, pero que come mierda, pero qué es esta cosa?" Pero sí, lo observaba y yo decía como que por dentro, “Qué les pasa?” A medida que pasa el tiempo, yo puedo ver otros aspectos un poquito más amplios...

In Adrián's world if Puerto Ricans spoke Spanish, and the kids he played with were Puerto Rican, then why did they need to speak English? He says that it irritated him a bit. Who did they think they were? The way they talked was so conceited! Even as a child, Adrián was not able to see English as a neutral language. He could not consider the possibility that they were speaking English simply because they were bilingual, and they were using the language they knew and were accustomed to using in school with their classmates. He saw their use of English as a way of flaunting their knowledge of the language associated with power in Puerto Rico. Adrián continues:

I used to think: "I know you speak English, but we all speak Spanish here, why can't we speak Spanish and that's it?" And then I think that maybe I didn't see the bigger picture 
back then, that they studied at a school that was 100\% English, except for Spanish class. And that they were used to speaking English amongst themselves. I realized this later on, not back then. My judgment was a bit more ignorant.

Y yo pensaba, yo sé que tú hablas inglés, pero aquí todos hablamos español, ¿por qué no nos ponemos a hablar en español y ya? Y entonces como que quizá, yo no veía el campo más amplio de que ellos estudiaban en una escuela que era cien por ciento en inglés, excepto la clase de español. Y que están acostumbrados a hablar en inglés entre ellos. Eso lo vengo a entender yo después, no desde entonces. El juicio de uno es un poquito más ignorante.

Evidently, as time went on there was a change in Adrian's outlook. He was able to move beyond established linguistic conventions, and conceptualize English as a valid form of communication for those children. He realized they could not help using English because it was an integral part of their upbringing. However, there is a related scenario that was mentioned more than once by participants in the present study: What happens when a Puerto Rican who does not have an English-only background decides to use "too much" English? Rey, for example, alternates between English and Spanish daily and frequently with virtually everyone in his social circle. When asked about how others could interpret his codeswitching behavior, he said that he was sure that many people would think that he was very arrogant. He said that he figures they would feel the same way he, himself, would feel if someone started speaking English to him: Rey: If that person knows the same Spanish as I, then there's no reason for him to speak to me $100 \%$ in English.

MPC: $\quad$ Why? That person is simply using another language.

Rey: $\quad$ Because we're in Puerto Rico. 
MPC: $\quad$ So you can't use either language here?

Rey: $\quad$ You can, of course you can, but my language is Spanish, English is my second language.

MPC: $\quad$ So, summarizing what you said a while back, you're a snob if you use your second language?

Rey: Because that's not something you do in Puerto Rico, and doing it implies that maybe that person doesn't speak Spanish because he feels more comfortable speaking English. But if that's not the case, and you have a person who speaks perfect Spanish and you know he speaks perfect Spanish, and that person speaks to you in English, that seems pretentious. It's not nice at all, because, why would you speak to me in English, if you speak Spanish?

Although codeswitching is completely acceptable for Rey, he draws the line when it comes to communicating solely in English in the Puerto Rican context. He seems clear about the inappropriateness of English as a language of everyday communication on the Island. Likewise, he is certain that the more English you use, the more arrogant you become. Manuel goes a step further in explaining why this is so:

The problem here is that everything that comes from outside is better than what's from here. And the English speaking person may not be an elite, he could be from a trailer park in Wyoming. But people hear someone speaking English and they're going to think that if he's not from here, he's superior. It's a type of inferiority complex that we have on a cultural level.

Es que aquí se asocia que todo lo que es de afuera es mejor que lo de aquí. Y el que habla inglés puede que no sea necesariamente elite, puede ser de un trailer park en 
Wyoming. Pero la gente escucha a alguien hablando inglés y va a pensar, si es de afuera, pues es superior. Es un tipo de complejo de inferioridad que tenemos a nivel cultural.

Manuel describes the inherently ideological processes that invest language, and result from historical and cultural circumstances. In the context of Puerto Rico, the use of the English language can be associated with "superiority." ${ }^{22}$ Therefore, those who codeswitch are vulnerable to being perceived as people who use English on purpose, to seem better than others. However, the experience of most bilinguals in the present study is that they use English simply because it is a natural part of who they are. It is a comfortable form of expression that does not carry any immediate metaphorical meaning in interaction. Graciela recounts her experience with language when she came back to Puerto Rico after finishing her Master's degree at MIT. Shortly after returning to the Island, she began working at a bank with people of different backgrounds and language abilities:

There were people who practiced this codeswitching mess and others that maybe studied in Puerto Rico their whole lives and were not familiar with English. They did not codeswitch because they did not know English well. They never studied it well at school either. And when I talked, they thought: "Why does she have to speak so much English?" They didn't like me that much. They thought: "This person thinks she's a gringa?, What's the deal with speaking English?, I don't see the need to speak English." I never thought of (codeswitching) that way until I met many Puerto Ricans who think that way. Some people think I do it because I think I'm better than anyone else. But I don't do it because of that, I simply can't help it, I just speak that way.

\footnotetext{
${ }^{22}$ The use of English on the Island can also be associated with Puerto Ricans whose families are forced or chose to leave the Island for economic reasons, live in the U.S. for some time, and then return to the Island.
} 
Había gente que hacía este revolú de codeswitching y otros que a lo mejor habían estudiado aquí toda su vida y no estaban tan familiarizados con el inglés. No hacían codeswitching porque no conocen bien el inglés. Nunca lo estudiaron bien en su escuela ni nada. Y cuando yo hablaba era como que: “¿Ay, y ésta, por qué tiene que estar hablando tanto inglés?" Como que les caí un poco mal. Era como: "Ésta se cree gringa. ¿Cuál es la cosa con el inglés? ¿Porqué hay que estar hablando inglés?” Y no era mi perspectiva hasta que conocí mucha gente de aquí de Puerto Rico que pensaban así. Hay un grupo de gente que piensan que es por guille. Yo no lo hago por guille, es que sinceramente, me sale.

Graciela mentions three key pieces of this linguistic puzzle. First, Puerto Ricans in general do not see the need to use English in their everyday lives. Second, she mentions the association between speaking English and being a "gringa." (The term "gringo" or "gringa" is used commonly in Puerto Rico to refer to Americans.) And third, codeswitching is a natural part of Graciela's life. She employs this language with local interactional purposes in mind, and not because she is putting on a "show of superiority." María echoes this sentiment when she speculates about how others see codeswitching:

They probably see it as something pretty unbearable, snobbish, pretentious, a little obnoxious, arrogant, maybe, you know. I think it's simply the way I express myself sometimes, not always, but it's pretty present in my life. It's not a persona that you put $\boldsymbol{o n}$. It's not because I want to be cool, absolutely not. In fact, I think a friend of mine mentioned something like that once. She said that she often feels that people who codeswitch do it to show off, to say, I studied in the States and I kick ass. That may be true in some social circles, but not for me. 
Probablemente lo ven bastante insoportable, snobbish, pretentious, a little obnoxious, arrogant, maybe, you know. Yo creo que simplemente es la manera en que me expreso algunas veces y no es siempre, pero está bastante presente en mi vida. No es una persona que you put on. No es porque quiero ser cool, absolutely not. De hecho, me parece que una compañera mencionó algo. Dijo que muchas veces ella sentía que las personas hacían eso como que to show off. Estudié afuera y soy la más jodona, eso se da en ciertos círculos quizás, pero no para mí.

María leaves the door open to the possibility of English being used "on purpose" to seem superior, but clarifies that this is not her case. On the one hand, the present network of bilingual speakers is aware that using too much English can be considered snobbish, but on the other hand, with close friends and family, forced avoidance of English can be considered contrived and strange. The codeswitching style of these bilinguals presents the juxtaposition of complementary and oftentimes disagreeing voices. When they codeswitch, they strike a balance between the centripetal (unifying) and centrifugal (differentiating) forces in their linguistic scene. English seems to be a unifying and cohesive resource for communication among peers, but it also serves as a differentiating factor. Codeswitching, as a communicative style, differentiates them from other Puerto Ricans and signals their group identity: urban, educated, middle/upper class bilinguals. To close this chapter I will present two examples taken from local a newspaper that confirm participant's perceptions of their codeswitching practice.

Most of the participants in this study live in San Juan or Guaynabo, a town is located next to San Juan, which boasts the highest per capita income on the Island. The term "Guaynabito" has recently been coined to refer to the stereotype of the high-class, bilingual native of 
Guaynabo, who is known to codeswitch on occasion. On April 8, 2007, Marcos Pérez Ramírez ${ }^{23}$ published a column titled "Guaynabitos" in El Nuevo Día newspaper. It made reference to the codeswitching behavior of high-class Puerto Rican young men and women. He explicitly describes their tendency to mix languages in conversation. (See Appendix B for original version in Spanish. The words in bold appeared originally in English.)

The first time I heard this neogentilicio ${ }^{24}$ it was from an ex-friend who decided to exchange our friendship for the cynicism and bitterness that consume him. It so happens that where San Juan and Guaynabo meet, there is a gas station where, seemingly well-todo young people gather to have a drink and talk, always under the watchful eyes of their European cars. I was there because I needed gas for my car, and ran into the phenomenon.

There were approximately fifty of them. They spoke Spanish, sprinkling their observations here and there with an American collegiate English adorned by an argot that begins each sentence with "It's like... [fill in the blank]... like..." Geez!, I thought, these gatherings have such high metaphorical undertones!, so I moved a bit closer to listen, morbidly fascinated by the scene. Although I'm fluent in el dificil ${ }^{25}$ I confess their change of register - Spanish, English, back and forward - made me lose track of the conversation...

Who's playing that reggae roots which is now making them move their hips? A faint smell of burning rope ${ }^{26}$ makes me catch the drift. I was already wondering why they

\footnotetext{
${ }^{23}$ Marcos Pérez Ramírez is a writer and newspaper reporter. He was born in Cuba from Puerto Rican parents. He completed a B.A. in Hispanic Studies at the University of Puerto Rico and an M.A. in Latin American Studies at the University of Maryland at College Park, MA.

${ }^{24}$ Neogentilico - new way of naming the inhabitants of a place, town or country.

25 "el difícil" - [the difficult one] Phrase used by Puerto Ricans to refer to English.

${ }^{26}$ Reference to the smell of marihuana.
} 
don't party in their houses, probably spacious, with luscious gardens and warm pools. What's more, if they live in Garden Hills ${ }^{27}$, they would only have to cross the street to take the party home. But I then remembered the words of Lavoe ${ }^{28}$ when in one of his songs, Rey de la puntualidad, confessed to "doing back there what they don't let me do here." Something similar is going on here. This is "safe." We're in San Juan, but not in the depths of my city infested by $\operatorname{cacos}{ }^{29}$ who have no problem robbing rich kids. It's like, better, it's like, uff, thank God!

Pérez Ramírez makes reference to the Guaynabito's tendency to codeswitch.

Throughout the column, he highlights the in-group character of the way they use their languages. He describes their English as an "American collegiate English," which emphasizes the exclusiveness of their bilinguality, since not all Puerto Rican's have the opportunity to study in the U.S. His characterization of the Guaynabitos also includes references to their material means (European cars and big houses in Garden Hills). This observation confirms the association between bilingualism and elite networks in Puerto Rico. Pérez Ramírez says that the practice of codeswitching was confusing for him, although he admits to mastering the English language or "el difícil." This fact underlines the in-group nature of codeswitching. He is not part of this network, and does not communicate like them, despite his bilinguality. What is more, Pérez Ramírez seems intent on differentiating himself from this group of rich kids. He knows English, but he does not codeswitch. He can freely roam the streets of San Juan, which he calls "my city," while the Guaynabitos have to stay close to their mansions for fear of being robbed. He is the one in tune with Puerto Rican culture and can cite famous salsa lyrics, while they listen to

\footnotetext{
27 "Garden Hills" is one of the most expensive housing developments in Guaynabo.

${ }^{28}$ Héctor Lavoe was a very famous Puerto Rican salsa singer in the seventies and eighties.

${ }^{29}$ Cacos - popular name for drug addicts.
} 
reggae. In sum, Pérez Ramírez is different from them in many ways. His tone suggests that he wants to convey that it is he who is in a superior position in Puerto Rico, not the ones with wealth and a better grasp of English. The "Guaynabitos," with their strange way of communicating, are the foreigners in "his" city. Let them continue partying in two languages, and in their safe neighborhoods, nice houses and warm pools, while the rest of Puerto Rico goes about its business.

Another newspaper column titled Guaynabo City Blues by Puerto Rican writer Edgardo Rodríguez Juliá, uses irony and crude humor to tell the story of Guaynabo. Rodríguez Juliá (El Nuevo Día, 2008) describes how the rich Garden Hills community exists in close proximity to a "barriada" or low-income community called "La Playita." He begins his column by saying that in the midst of Guaynabo's opulence there was a "barriada" whose bars were frequented by many who transcended class lines for their love of beer and a good time. Rodriguez Juliá then talks about high-class Guaynabo women, and characterize them as blonde, arrogant, and bilingual.

Guaynabo is like that; when you least expect it, the "cafetín" 30 " culture is close by to blonde Guaynabeñas, ${ }^{31}$ who, in two languages, or arrogant Spanglish, fight over the damn parking spots at Garden Hills Plaza, or over where you can find the best risotto. There we are, so close to the Garden Hills entrance, which, since the fifties, has always been an emblem of high society...

Guaynabo tiene esto; cuando menos te lo imaginas, la cultura del cafetín está a pocos metros de las disputas de las guaynabeñas rubias, a dos lenguas o arrogante Spanglish, sobre los malditos estacionamientos de Garden Hills Plaza, o dónde se consigue el mejor

\footnotetext{
${ }^{30}$ In Pueto Rico, a "cafetín" is a small bar that usually sells liquor and cigarettes.

31 "Guaynabeña" means from Guaynabo. The suffix "eña" refers to the country or town where one is from.
} 
risotto. Ahí, tan cerquita como estamos de ese emblema de la high society de los años cincuenta que siempre fue la entrada a Garden Hills...

Rodríguez Juliá specifically refers to Guaynabo residents' habit of mixing Spanish and English as 'arrogant Spanglish.' It is common for nonlingusits to confuse codeswitching with 'Spanglish.' Nash (1970) described Spanglish as “a gradual relexification of Puerto Rican Spanish through borrowings, adaptations, and innovations of the kind observable in any language" (p. 230). She made it clear that Spanglish forms part of a continuum of use that reflects the influence of English in the Puerto Rican dialect. What Rodríguez Juliá observed in Guaynabo was in fact codeswitching. The normal use of borrowings would not have seemed arrogant to him, since it is considered a normal part of the Spanish of Puerto Rico.

Eckert (2004) reminds us that "language does not work on its own and no linguistic variant works on its own. Language is part of a broader semiotic system that includes such things as clothing, territory, musical taste, activities, and stances" (p. 47). In his column, Rodríguez Juliá explicitly addresses many aspects of a semiotic system that includes language alternation. The women at the prestigious "Garden Hills Plaza" shopping center are blonde. Only a small percentage of Puerto Ricans are naturally blonde. Reference to this hair color makes the local reader think of these women as different or foreign. Their use of English also distinguishes them from other "true" Puerto Ricans. Rodríguez Juliá also mentions their territory. These blonde women are the ones that most frequent "Garden Hills Plaza," and thus fight to defend their right to park and shop there. They happen to do that fighting in two languages, which reinforces the association between the way they speak and their arrogance. Rodríguez Juliá groups all these blonde "housewives on their way to the Power House Gym" into one category, which includes the way they look, the way they carry themselves, and the way they talk. In this example, the 
prototypical "high class" lifestyle, often regarded as superficial and arrogant, is clearly associated with mixing languages.

These two columns capture how language can be an integral component of the formation of social dynamics and categorizations. In these examples "each language reflects, in its particular unsystematic clustering and clumping, the contingent historical and social forces that have made it" (Morson \& Emerson, 1990, p. 141). Codeswitching among the speakers represented in this study reflects the influence of the historical and social forces that have made a mark on the Spanish of Puerto Rico over the past century. These bilingual speakers respond, albeit unconsciously, to inner dialogues between the different ideologies which are tied to each of their languages. Furthermore, their codeswitching style has implications for social identity formation in the Puerto Rican context. 


\section{Chapter 9: Codeswitching and Identity}

Languages in contact cannot exist without influencing one another. As bilinguals appropriate their linguistic resources and deploy them in interaction, significant connections are made between languages, between ideologies, between Discourses, and, in this way, new meanings are created, new ways of being in the world, new identities. Codeswitching is inherently heterogeneous and creative. What on the surface may appear as a random mixture of codes, is in essence the product of speakers' mediation of linguistic, ethnic, and social boundaries. In this process, they adopt multiple identities.

The Puerto Rican bilinguals who are the focus of the present study, are part of a social network with access to linguistic resources that are out of reach for the majority of the Island's population. The "intrusive" language (English) is mostly learned through the school system rather than through direct contact with speakers. Usually, this results in bilingualism for the educated class, which is indeed the case in Puerto Rico (Vélez, 2000, p. 19). This particular situation makes the Island an ideal context for the study of codeswitching, and what it means for the construction of social identity. This context holds great potential for examining the creation of speech styles that reveal important sociocultural processes. As speakers employ their speaking styles and identities, they also contribute to significant linguistic and cultural changes.

The third research question addresses how codeswitching is linked to participants' identities. This chapter is divided into two main sections. The first section presents the process of arriving at relevant identity categories ${ }^{32}$, and focuses on the mechanisms of group identity formation. The second section illustrates the process of identity construction, concentrating on the following identity categories: 1) Elite, 2) American, 3) Puerto Rican, and 4) Bicultural.

\footnotetext{
${ }^{32}$ Categories, in this dissertation, are not viewed as static constructs, but as changeable and potentially heterogeneous.
} 


\section{Identity Formation}

Discussions in previous chapters, of studies which have addressed the relationship between codeswitching and identity, suggest that identity categories cannot be readily ascribed to the languages used by speakers in the present study. The first issue to be addressed is how to arrive at identity categories that may be relevant in the interactions to be analyzed. Antaki and Widdicombe (1998) argued that there are two ways to approach this issue. The first follows Sacks (1972) and relies on the cultural familiarity of the analyst with the participants. The second follows Schegloff (1991) and abides only by what is patent in the development of the interaction. Yet a third approach, which will be adopted here, is to work with the categories that result from the cultural competence of the analyst as a starting point, and then see how those categories are relevant to the participants. Identity categories will be considered meaningful to participants to the extent that they respond to who they are (as members of a distinct group of individuals), and how they think of themselves. The proposed analysis rests on the premise that in employing a codeswitching style, speakers use their linguistic resources to project, shape and re-shape multiple identities.

In determining the categories that could be ascribed to participants in relation to their codeswitching practices, it was not assumed that speakers had such identities in mind when they interacted with other bilinguals. Stroud (1992) was one of the first researchers to question sociolinguistic work on codeswitching which takes for granted that a speaker intends something with each of his or her switches (e.g. allusions to 'us' or 'them'), and that 'this intention is encoded in the switch, and can be inferred by the interactants" (p. 133). Stroud insisted that when speakers codeswitch, they are not necessarily evoking and laying claims to obligations and identities associated with each language. He contended that meaning is negotiated, and is not 
found in every switch. The problem lies in assuming the speaker's meanings and intentions. It is then necessary to ascertain the possible, permissible, and apprehendable meanings for speakers in each community we examine. De Fina (2007), for instance, studied the mechanisms of identification of members of an Italian-American card game club in the U.S., and found that language mixing was used as a central element in conveying this group's distinctive style. However, she emphasized that "language choice or switching do not mechanically correlate with identity work" (p. 65).

The current study approaches identity as something emergent, which people do and is embedded in social activity and not something that can be determined a priori (Antaki \& Widdicombe, 1998). However, emphasis on bilinguals' construction of identities which emerges through habitual patterns of interaction still takes into consideration each language's indexical associations and established social categories. "Of course, the property of emergence does not exclude the possibility that resources for identity work in any given interaction may derive from resources developed in earlier interactions (that is, they may draw on 'structure' such as ideology, the linguistic system, or the relation between the two)" (Bucholtz and Hall, 2005, p. 588). Thus, the social meaning of codeswitching emerges in interaction, but also relies on the greater social and metaphorical meanings tied to the languages used, in this case Spanish and English.

Communicative styles may signal distinct affiliations and social categories. Through their codeswitching style, participants in this study contributed to the creation of multiple, flexible identities. Auer (2007) explained that through their linguistic practices individuals become actors who -within certain limits- choose their affiliations and express them symbolically through language (p. 4). Still, the reality of most participants in the present investigation is that they do 
not straightforwardly "choose" their languages in interaction. Instead, the concept of habitus (Bourdieu) best explains what takes place for these speakers. They have appropriated English and Spanish in their habitus or habitual patterns of interaction. Codeswitching, as displayed by this network of speakers, is not a product of fixed intentionality, but of habitual action. The main goal of the present analysis is not to analyze instances in which speakers consciously make use of one language versus the other, but to interpret the potential overall meaning of the practice of codeswitching in terms of personal and social identities. It is the constant iteration of such practices that cumulatively produces each individual's identity (Bucholtz and Hall, 2005, p. 590).

Le Page and Tabouret-Keller (1985) gave an example of a woman in Belize who switched between Spanish, Creole, and English in the same interaction. The authors claimed this behavior could point toward this woman's capacity for more Spanish-like, more Creole-like, more English-like, or more American-like behavior. The woman could shift her identity according to her company, and she and her friends varied from one another to the degree in which they were prepared to shift in a particular direction, and make known their political and cultural identity. The authors explained that this woman engaged in 'acts of identity' in which people reveal both their personal identity and their search for social roles (1985, p. 14).

However, as we speak of "acts of identity" we must not assume that instances of codeswitching must constitute an agentive attempt to index a particular identity category. Bailey (2007) studied language alternation as a source of identity negotiations among Dominican American bilinguals in the U.S. He found that the majority of the recorded code switches among "Dominican American high school students did not involve any evident metaphorical negotiations of identity or highlight indexical meanings of one code or another" (p. 34). Codeswitching, in that context, was evidence of how speakers may embrace multiple social and 
linguistic worlds. They displayed the seamless integration of cultural worlds through their habitual language alternation. Bailey explained that codeswitching in conversation was not activated to highlight any social or metaphorical meaning related to conventional associations of Spanish and English. Speakers in his study were not discursively conscious of why they codeswitched at any given moment. They were not aware of codeswitching as constitutive of a distinctive style, and they were not mindful of how their languages could be metaphorically loaded. However, this is not the same as "arguing that such codeswitching has no meanings or implications for social identities. One must distinguish between local functions of particular codes switches and the more global sociopolitical functions of codeswitching as a discourse mode" (p. 35). The frequent codeswitching found among the network of Island Puerto Rican bilinguals which is the focus of the present study also has consequences and implications for identity formation on the Island.

This chapter will focus on codeswitching as a resource for constructing social meaning, specifically its ability to signal membership in a certain group or network of speakers. The following sections will address how co-membership in such social group is created, and then will present several identity-relevant categories. Bucholtz and Hall (2005) wrote: "From the perspective of the analyst, it is not a matter of choosing one dimension of identity over the others, but of considering multiple facets in order to achieve a more complete understanding of how identity works" (p. 593). Following this recommendation, the following discussion addresses the relationship between codeswitching and the following categories: 'elite,' 'American,' 'Puerto Rican,' and 'bicultural.' 


\section{Group Identities}

The present study is concerned with discovering possible social formations, groups, categories, and activity types (Irvine, 2001, p. 22), which are potentially indexed by the codeswitching practice of PR bilinguals. There is no doubt that the Puerto Rican bilinguals represented in this paper distinguish themselves from the "average" Island Puerto Rican in many ways. They belong to a certain socioeconomic level, and have internalized the idea of English as a symbolic resource, a form of cultural capital (Bourdieu, 1991). The social practice of codeswitching entails specific identities, afforded and constrained by the cultural tools they have appropriated.

An important aspect of identity is its relational nature. "Identity is inherently relational, and will always be partial, produced through contextually situated and ideologically informed configurations of self and other" (Bucholtz and Hall, 2005, p. 606). Identities only acquire meaning when individuals, in relating with other social actors, form groups, which in turn create social boundaries. Codeswitching has great implications for group membership, since language plays an undeniable role in shaping group identity. When asked about his views on codeswitching, Darío made an observation that confirms the cohesive nature and group character of this practice:

Obviously, you can't codeswitch with everybody. There are people who do not speak English. The fact that you can do it with someone creates a type of bonding, because you're telling that person indirectly: "Listen, we're both in the same place. You and I understand each other. We're similar and have the same background, and we can express ourselves this way, and we will understand each other." 
Obviamente, tú no puedes hacer codeswitching con todo el mundo. Hay gente que no sabe inglés. Y el hecho de que lo puedas hacer con alguien, es un tipo de bonding, porque tú le estás diciendo indirectamente, "Mira, tú y yo estamos en el mismo lugar. Tú y yo nos entendemos. Los dos somos iguales y tenemos el mismo background y nos podemos expresar así y nos vamos a entender".

Darío's words make reference to the concepts of adequation and authentication in identity creation. Codeswitching becomes an adequate and appropriate form of communication only when certain "kinds" of people come together. The social backgrounds and linguistic abilities that speakers have in common are emphasized, and "bond" speakers together. This supports the creation of a common identity. Notice that Darío does not refer to codeswitching as a necessary aspect of interaction. He emphasizes that the possibility of successfully engaging in the practice of codeswitching is enough to characterize speakers as sufficiently similar. When asked about the people with whom she codeswitches, María said:

I think it also depends, with my friends, they do the same thing I do, they communicate similarly. They're in that constant switching back and forth. It's a product of the way we grew up, studying at Saint John's (School), living in Puerto Rico...

Creo que también depende, con mis amigas, ellas hacen lo mismo que yo, se comunican de la misma manera. Están en ese constant switching back and forth. Es un producto de esa crianza, de estudiar en Saint Johns, vivir en Puerto Rico...

María mentions that a similar upbringing has an impact on linguistic practice. Young children, teenagers, and adults adopt language varieties that contribute to determining who belongs and who doesn't belong to a group of friends, a community, an ethnicity, a race, a social class, or even a nationality. Furthermore, codeswitching can serve to shape group identity even if 
people view it as something negative. Chana and Romaine (1984) summarized why codeswitching persists in certain communities: "Despite the negative prestige attached to many varieties, they persist over long periods of time, partly because they serve important functions as markers of in-group identity" (p. 451). Diego also talks about the in-group aspects of codeswitching;

I don't judge it. I'm kind of neutral. It's something that is there and that's how it happens. I avoid it in certain situations, but it's not a mortal sin. The important thing here is its general acceptance. If I were the only one that did it, then obviously, it would be a problem, but here everybody does it so... In my environment, what I do is nothing out of the ordinary, so I don't see it as something negative. I did see it as something negative when I went to Spain to study. They don't use English at all there, and when I realized I couldn't say some things in Spanish, I saw it as something very negative, in that context. No sé, no lo juzgo. Soy medio neutro. Es algo que está ahí y así es que pasa. Busco evitarlo en ciertas situaciones, pero tampoco es como un pecado mortal. Pero el elemento importante es la aceptación general que tiene. Si fueses el único, pues obviamente sería un problema, pero aquí en la sociedad todo el mundo lo hace, así que... En mi entorno no es nada fuera de lo común lo que yo hago, así que no lo veo como negativo. Me pasó que yo mismo lo veía como algo negativo cuando fui a España a estudiar. Allí no usaban el inglés para nada básicamente. Entonces yo al ver que no sabía decir algo en español lo veía como algo bien negativo en aquel contexto. When Diego says that "everybody" around him codeswitches, he is referring to everybody in his social circle. His linguistic behavior is a normal part of his life in the context of his immediate social grouping in Puerto Rico. However, when he moved to Spain, Diego 
resented the constant presence of English in his idiolect. In Puerto Rico, it was a source of adequation and authentication, while in Spain it became a source of distinction and denaturalization. The way he used his two languages was not appropriate because it violated the ideological expectation of using "only Spanish" in everyday communication. In Spain, he viewed codeswitching as a negative practice because it activated his identity as a foreigner, an identity which he did not want to portray. Something similar happened to Juliana in the context of Puerto Rico. She works at an American-owned company which hires people from several Latin American countries, such as Venezuela, Argentina, and Uruguay. While these individuals studied English and most of them have to master this language in order to work for the company, they are not used to mixing English and Spanish in conversation. Juliana talks about an experience she had with her Venezuelan boss:

More than the fact that they don't understand English is that they... (It happens with Argentinians, Uruguayans, etc...) They all start at the company with the mentality that if you're going to speak Spanish, you should speak solely Spanish. And if you speak English, you should speak only English. They don't use this mixture. When I communicate, I use some terminology in English, for example, readings. I would ask my boss: "Are the readings here? Are the top-liners here?" And in doing so, I would lose her. She wouldn't get what I was saying. It was difficult for her to follow what I was saying. That happens to all of them when they get here. Then they become Boricuas (Puerto Ricans).

Más que el hecho de que no entienden inglés, es que ellos... Me pasa con argentinos, uruguayos, etc... Todos ellos vienen con una mentalidad de que, si voy a hablar español, hablo español. Si voy a estar hablando inglés, hablo inglés. No usan esa mezcla. 
Entonces pasa que cuando yo hablo uso terminología en inglés, por ejemplo, los readings. Entonces yo le decía: “¿Ya llegaron los readings? ¿Ya llegaron los topliners?”. Entonces la perdía, como que no entendía y le daba trabajo. Y eso les pasa a todos ellos cuando llegan. Ya después se ponen boricuas.

Juliana made it clear that the problem was not that her coworkers did not know English or the terminology used in their industry. The problem was in alternating languages. One co-worker explicitly told her that inserting words in English when speaking Spanish was definitely confusing, and that her message was not getting across. Juliana thinks that, for the Puerto Ricans she works with, English is much more natural, and codeswitching is a normal practice. In contrast, when her Latin American coworkers hear codeswitching, they have to stop, think of the meaning of the word in English, and then continue the conversation. However, over time, they do get used to the switching and can follow it better. Juliana's last words in this excerpt were "they become Boricuas (Puerto Ricans).” In other words, by modifying their linguistic practices they eventually "belong" to the group of Puerto Ricans who incorporate English in their daily lives.

The issue of "belonging" to a group is significant for identity creation. "Each individual creates for himself the patterns of his linguistic behavior so as to resemble those of the group or groups with which from time to time he wishes to be identified, or so as to be unlike those from whom he wishes to be distinguished" (Le Page and Tabouret Keller, 1985, p. 181). Speakers choose groups with which they want to identify, and express this choice symbolically through language. However, an individual's ability to get into focus with those with whom he or she wishes to identify is constrained, up to a point. According to Le Page and Tabouret-Keller (1985) 
one can only behave according to the behavioral patterns of groups with which one finds it desirable to be identified, to the extent that:

a) one can identify with groups,

b) one has both adequate access to the groups and the ability to analyze the behavioral patterns,

c) the motivation for joining the group is sufficiently powerful, and is either reinforced or lessened by feedback from the group,

d) one has the ability to modify our behavior. (p. 115)

In the present study, Walter is an example of someone who tries to adopt a codeswitching style, mainly because he identifies with the elite group that engages in it. Alternating languages is not an intrinsic part of Walter's idiolect. In contrast to other participants for whom codeswitching is a natural and almost necessary part of communicating, in the recorded conversations, Walter's codeswitching was limited to sporadic single word switches. His proficiency in English appears not to prompt a seamless alternation between his two languages. However, Walter revealed in his interview that he makes it a point to include English in conversation. He relates codeswitching to an "elite" form of communication, which is positive and desirable. It is clear that he wants to be associated with "elite" bilingual people who codeswitch, and by using English, he claims membership in this group. Following LePage and Tabouret-Keller (1985), in order to be considered a member of this codeswitching group Walter needed to: identify himself with the "kinds" of people who codeswitch; gain access to the group by becoming bilingual, have the motivation to belong to this group, and finally, have the ability to modify his behavior. Ultimately, he felt that if he could "speak" like them, he could "be" like them. 
The identity work accomplished by Walter relies on the processes of adequation and distinction. Walter uses codeswitching to identify himself with bilingual, elite Puerto Ricans. His sporadic use of English is enough to align himself with the group who legitimately masters this language. At the same time, his use of English distances him from members of his family or people who are not fluent in English. Walter prides himself on his ability to learn new English words and phrases, and successfully use them in conversation with other bilinguals. In the following excerpt of his interview, he comments on someone's "exaggerated" use of English. Words in bold were originally said in English. Notice that Walter's English includes a few ungrammatical instances.

Walter: $\quad$ And I see people like that and it sometimes sounds ridiculous. I was in a store at Plaza las Americas and this guy spoke English (to the salesperson)! This bag's waterproof? But, what you really mean waterproof. What?”

MPC: $\quad$ Was he Puerto Rican?

Walter: $\quad$ He was Puerto Rican.

MPC: $\quad$ How could you tell?'

Walter: Well, because of his accent. The other one seemed Nuyorican, the one at the store. The other one knew better English. But this guy was a jíbaro, ${ }^{33}$ he wasn't even from the metro area. He seemed to be from Ponce. ${ }^{34}$ I don't really know, because I had never seen him before, but the way he was dressed made it clear that he's not from Condado, ${ }^{35}$ so as to be speaking English at Plaza with the guy who works at the store. He was looking for a bag. He asked whether the bag was

\footnotetext{
33 "Jíbaro" is the word used in Puerto Rico for someone who lives in rural areas and is usually uneducated.

${ }^{34}$ Ponce is the second largest city in Puerto Rico. It is located in the south of the Island. It takes approximately an hour and a half to drive from San Juan to Ponce.

${ }^{35} \mathrm{El}$ Condado is a middle to upper class community and tourist area close to the historic district of Old San Juan.
} 
waterproof, and he said: "For example, if I'm in a bicycle, running a bicycle from San Juan to Ponce." That's why I think he's from Ponce. "And it's really raining... you think, when I get to Ponce, I gonna be.... the... my clothing inside the bags, eh, they gonna be wet? And I said to him: "Man, if you ride a bike from San Juan to Ponce, you're simply incredible, you hear me?... So if you stick it in. (English) If you force it too much, then it's like... And, speaking English there at the store... How ridiculous. Yes, I think it's ridiculous.

MPC: Why is that?

Walter: Yeah, because there's no need. Because sometimes there are phrases that are cool, because you integrate them, and it sounds cool when you include them because I think you can better express what you mean, the message you want to get across to the other person, better than saying it in Spanish. But speaking in English all the time... Either we speak English or we speak Spanish.

According to Walter, using too much English in conversation is simply ridiculous. He thinks that by attempting to communicate solely in English in the Puerto Rican context, the man at the mall made an unsuccessful (and ridiculous) attempt to align himself with the "cool" English-speaking people. The process of authorization and illegitimation in the formation of identities is evident here. What comes into question is how appropriate or legitimate it is for a Spanish-speaking Puerto Rican to speak English in the context of a casual interaction at a store. Walter's words point toward a strong essentialist assumption that some "kinds" of Puerto Rican are not "allowed" to speak English. Strong ideological structures regarding the appropriateness of speaking English in Puerto Rico prevent Walter from accepting the possibility of English being used in this context. Walter takes into account, be it unconsciously, the prevailing 
ideologies regarding language on the Island to authorize or illegitimize the man's use of English. For Walter, only those who were born and raised in New York (Nuyoricans), or those who live in Condado, an affluent sector of San Juan, are allowed claims to this "English speaking" identity. Furthermore, in his daily life, Walter also chooses to circumvent prevalent Spanish-only ideologies in the Puerto Rican context and legitimize the use of English (also to a certain extent) among elite bilinguals. This excerpt of Walter's interview also highlights several features that helped forge the identity of the man at the mall: His accent in English displayed his Puerto Rican identity. His clothes identified him as someone who does not follow the trends of "Condado," the chic area of San Juan. And, although he was bilingual, his exaggerated use of English was not in line with elite groups that customarily engage in codeswitching.

Auer (2007) explained that there are several ways in which lexical choices can come to index the speakers' identity in a given context and community of practice: 1) the person may use lexical items innocently without knowing their identity-rich potential; 2) the person may use lexical items 'metaphorically', in order to invoke a specific 'voice' associated with the language in question; and 3) the person may role-play and pretend to belong to a specific group. Walter's experience with the man at the mall was an example of the third case. The man's codeswitching was 'fake' and that is partly why Walter thought it was ridiculous. In contrast, the man at the store who appeared to be from New York was legitimately using English. Walter's bilingual friends also use English legitimately, and they can do so because they have made English an intrinsic part of their life-style. Including some English in conversation is part of the clustering of linguistic and nonlinguistic elements that make up their group identity.

For participants in this study, the appropriation of English allows for the ongoing use of a distinctive style that signals personal as well as group identity. There will always be categories 
(e.g. personal, social, ethnic) that circulate within ongoing discourse. Categories imply linguistic features. For example, in order to be included in the category of "Puerto Rican" it may be necessary to display certain linguistic patterns such as: speak Spanish or know the lyrics to popular traditional songs. Moreover, conventional associations between language use and certain categories are not fixed. This study sought to ascertain how speakers may categorize themselves, and to identify the linguistic features that accompany such categorizations.

\section{On Being an Elite Group}

Chapter Two discussed the widespread awareness among Puerto Rico’s higher social classes of the need to learn English as the means to maintaining their privileged status and achieve professional success. Similarly, Chapter Six established a link between elite private schools and proficiency in English in Puerto Rico. As a general rule, the more expensive the school, the more emphasis is placed on learning English. Thus, on the Island, there is a link between socioeconomic status and language attainment. When I discussed this scenario with Valeria, she emphasized that being bilingual should not depend on spending money:

Private schools, I'm talking about the schools, not my opinion, have made society think that bilingualism is something expensive. That for you to have access to a bilingual environment you have to pay for it.

Las escuelas privadas, estoy hablando de las escuelas, no mi opinión, le han hecho ver a la sociedad, que el bilingüismo es algo costoso. Que para tú tener acceso a un entorno bilingüe tienes que pagar por ello.

Children in many countries successfully acquire their second language at school.

However, this is not the case in Puerto Rico. Most public school children do not become bilingual, so parents find themselves actually paying for bilinguality by sending their children to 
private schools. Valeria thinks that private schools are to blame for this situation. But these schools are only a reflection of the fact that, in Puerto Rico, literacy and bilinguality are, for the most part, expensive.

To the extent that the participants in this study attended public or private schools, they also share in this reality. English as cultural capital is not equally available to all Puerto Ricans. All of them, either as children or as adults, invested in the learning of English. Some of them had the support of their families, others of their school system, and still others had to make a conscious decision to invest in their language skills. Regardless of the circumstances in which they learned their second language, by the time this study was carried out, they occupied an educational and economically privileged position in Puerto Rican society. Their bilinguality, as a commodity, conveys social meaning. Similarly, the practice of codeswitching serves to construct their identities, and, in this case, characterizes them as an elite group. From the perspective of the analyst, there is a straightforward link between language and an elite identity for Island Puerto Rican bilinguals. However, what becomes paramount in this analysis is how participants position themselves in relation to this and other social groupings, based on their linguistic practices. The questionnaire prepared for this dissertation included the following question: "In Puerto Rico, is codeswitching linked to belonging to a social elite?" Darío answers:

Yes, it is associated with an elite, with someone who could study abroad, that had money, that travels to the U.S. a lot, someone whose education was expensive, who lived in the U.S. When you codeswitch you are saying: "I know English, I lived abroad." You are letting the other person know that you have a background in English. Sí, se asocia con una élite, con alguien que pudo estudiar fuera, que tuvo chavos, que viaja a Estados Unidos mucho, alguien para quien la educación ha sido cara, que vivió 
en Estados Unidos. Tú, al hacer codeswitching, estás diciendo, yo sé inglés, estuve fuera, estás dejándole saber a la otra persona que tienes este background en inglés.

Darío observes that when a person uses English and Spanish in conversation, he or she displays membership in a category that includes several distinguishing features: the opportunity to travel to, live in, or study in the U.S.; a privileged socioeconomic position; and an expensive education. All of these characteristics index membership in an "elite" category. Swigart (1992) explained that urban balanced bilinguals in Dakar, the capital city of Senegal, use Wolof and French more often in a fluid and unmarked kind of codeswitching than separately. This has resulted in what might be described as a third code, Urban Wolof, which occupies a central position in the speech repertoire of these bilinguals, and is used primarily in informal contexts. Swigart affirmed that this type of "in group" phenomenon among educated urban dwellers has also been attested to by Myers-Scotton in African capital cities, and is thought to encode a dual identity; the speaker is both African and a member of an educated elite. There are many conditions that must be met for the development of the type of "urban code" described by Swigart. We may be far from being able to posit that there is such an established "urban code" in San Juan, but Swigart established an important characteristic of this type of codeswitching, which may be correlated to the results found in the present study: its association with the elite.

The concept of "distinctiveness" is relevant when discussing any identity category. Many participants in the present study explicitly address how linguistic practice may lead to differentiation. Walter, for example, does not think that codeswitching is tied only to being better off financially, he believes it is a matter of social status. Walter does not know where codeswitching comes from, but he is sure that his friends who do not belong to a certain privileged social status, do not codeswitch. Janet also highlights the differentiating aspects of 
codeswitching. When I asked her if she thought codeswitching had anything to do with belonging to a social elite, she said that it did, and that proof of this was that if she had stayed in public school her knowledge of English would have been limited, and she would not have made it such a ubiquitous part of her life:

I think this is so, precisely because of what I was commenting about the change I made from public to private school. I'm ninety-eight percent sure that if I had remained in public school, my codeswitching would probably be nonexistent. It would be incredibly limited or would not be there at all. I would not have had English so present, because I didn't need it, so... You immediately relate "private school" with people who are different. And in that sense I think that, yes, you could relate codeswitching with an elite. And many times it has to do with people who, for example, go study in the United States, because the majority of lower-class people are not the ones who go study in the United States, because it's really expensive. So, these things tell you something. Sí. Pienso que sí, precisamente por lo que te comentaba del cambio mío de escuela pública a colegio. Estoy como un noventa y ocho por ciento segura, de que si yo me hubiera mantenido en escuela pública, posiblemente mi codeswitching sería básicamente nulo. Sería exageradamente limitado o ninguno. Porque no lo iba a tener muy presente el inglés, porque no lo necesitaba, así que pues... Inmediatamente tú asocias "colegio" con personas diferentes. Y entonces pues, por esa parte, yo entiendo que sí, que pudieras asociar el codeswitching con una elite. Y muchas veces, pues, es también en el caso de muchos que he sabido que, por ejemplo, se fueron a estudiar a Estados Unidos, pues la mayoría de la gente de clase baja, tú no ves que son de los que se van a estudiar a Estados Unidos, porque es realmente costoso. So, por esos aspectos se puede saber. 
Language use can reveal differences between groups, and these differences have social connotations. As discussed in the previous chapter, codeswitching may be tied to an elite, but also with the arrogance and snobbishness that is often times associated with these privileged social groups. Li and Tse (2002) found that for many of the educated bilingual Chinese Hongkongers in their study English would pop out of their mouth unintentionally. Some people around them would interpret this as showing off although it was completely unintended. The authors explained that this was an illustration of "an interesting social dilemma between on the one hand, a tendency for educated Chinese Hongkongers to sprinkle English expressions of various lengths onto their Cantonese, and on the other hand, latent hostility towards this common everyday language use pattern which is pejoratively labeled "mixed code" (cf. Gibbons, 1987)" (p. 178).

Juliana, in the present study, explains that when a person alternates languages, he or she is sending a message, and that message may be interpreted as one of superiority. Juliana adds that those who do not practice codeswitching themselves may think that people who codeswitch are alternating languages on purpose to "seem superior."

They think that it is synonymous with a higher social strata, a higher socioeconomic level. They think you are doing it to boast your status. It's as if you entered a room and said: "This is my Louis Vuitton bag, look at it, here it is. This is the way I talk." We are making a separation, you belong to this group, and I belong to this other one.

Piensan que eso es sinónimo de una estrato social más alto, un nivel económico más alto. Como que tú me lo estás echando en cara. Es como que tú llegas: "Esta es mi cartera Louis Vuitton, mírala, aquí está. Esta es la forma en que yo hablo”. Estamos haciendo aquí una separación, tú eres de este bando y yo soy de éste. 
A parallel can be drawn between codeswitching, as explained by Juliana, and the distinction made by Gumperz about code appropriateness. Gumperz (1982) referred to a "they" code associated with out-group relations, and a "we" code associated with in-group activities. In the present corpus, the "we" code would be "Spanish with the possibility of incorporating English words and phrases," while the "they" code would be "Spanish with no English words." The "we" code that Juliana talked about, which includes codeswitching instances, serves as an identity marker. Among the distinguishing features of this identity are a high socio-economic status and closer cultural ties with the United States. Another related phenomenon occurs when speakers try to purposely adopt the "we" code associated with a social elite. Jacqueline talks about such people:

You hear some people using phrases (in English) but they don't say them right, or they don't pronounce them right. They say them because they hear them from other people. I have friends like that. I've heard them say phrases in English and you know that they say them because they have heard them, but maybe they don't even know what they mean or how to pronounce them correctly because...

Hay gente que tú los oyes diciendo las frases, pero no lo dicen bien, o no lo pronuncian bien. Lo dicen porque lo escuchan de otra persona. Yo tengo amigas así, que las he escuchado decir frases en inglés y tú sabes que no... Ellas las dicen porque las han escuchado, pero quizás no saben ni lo que quieren decir o ni cómo se pronuncian correctamente, porque...

Jacqueline noticed that people in Puerto Rico who are not necessarily bilingual sometimes adopt English words or phrases simply because they hear them often enough, or perhaps because they want to be associated with a higher socioeconomic class, or a more 
educated group. Although it has been demonstrated that many linguistic changes come from the lower social classes, Jacqueline's experience suggests that elite groups can become leaders and trend-setters with the potential of influencing the language dynamics in their immediate social circle and beyond. Leo also commented on this phenomenon. He recognizes that, traditionally, in Puerto Rico English has been reserved to the elite, but as time goes by, this is very likely to change:

Maybe in other times, because now, I think in television shows, and I watch very little local TV, I've noticed that they are using a bit of English. Also, people hear this and they repeat it. Obviously, if it's something related to the elite, then others imitate it, to feel that that they belong to the elite. It's a fashion thing. It's like fashion, something fashionable comes along and others imitate it.

A lo mejor antes, porque también ahora yo creo que la televisión, de lo poquito que yo veo de televisión local, también ha comenzado a incluir un poco de inglés. Obviamente, si es algo elite, entonces los demás lo imitan, para creerse que son elite. Es el fashion. Salen todas estas cosas fashionable y todos los demás lo imitan.

While conducting research for this dissertation, a new TV sitcom called Elena Santos began showing in Puerto Rico's government-sponsored channel. The show's protagonist was a young woman who belonged to a rich family from Ponce, a town south of San Juan. She moved to San Juan to find her own path in life, and found a job at a magazine called "San Juan Living." This show caught my attention because of its constant use of single-word switches into English, and occasional intersentential codeswitching. Fullana Acosta reported that thanks to this sitcom at last the Puerto Rican public would "see in the small screen a comedy, filmed like a U.S. sitcom, which would present everyday characters that reflect our society, and would address 
topics, such as sexuality, that pertain to the country's realities" ("Primera Hora" Newspaper, 2008). It is notable that a show that is modeled after U.S. television formulas, and includes frequent codeswitching is thought to reveal Puerto Rican realities. This show supports Leo's observation about the increased presence of English on the Island. This show is a reflection of the cultural and linguistic contact that has been present in the Puerto Rican context for more than a century. In addition, the show's premise is a desire to be modern, and it appeals to young people. The use of English and its dynamic format are probably thought to contribute to achieving this goal.

It is important to mention that codeswitching on the Island is not only associated with a socioeconomic elite. The use of English in everyday conversations may be common among elite Puerto Ricans with backgrounds similar to the ones represented in the present study. However, codeswitching may also be associated with the 'nuyorican,' a Puerto Rican who, from the 1930's to the 1950's, left Puerto Rico and went to New York and other States, mainly in search of better financial opportunities. These Puerto Ricans left and continue leaving the Island and sometimes return, bringing with them codeswitching patterns of communication. Several participants expressed being aware of the association between codeswitching and New York Puerto Ricans. Diego said that codeswitching:

could be something more common among people who studied in the United States and had a lot more exposure to the North American culture, and not that common among people from rural areas that obviously do not know English so well. Although it can also have the opposite effect of the Nuyorican who is from a lower class and had to leave the Island. Limited codeswitching can be indicative of elite status, of education in the United 
States, but when it becomes so commonplace that you speak neither English nor Spanish, it's a mixture that is negative and nothing of an elite.

será algo más común en gente que estudió en Estados Unidos y tiene mucha más exposición a la cultura norteamericana y no tan común en alguien así del campo que obviamente no conoce tanto el inglés. Aunque también puede tener el efecto opuesto del Nuyorican, que son una clase baja que tuvo que salir de la Isla. Un codeswitching limitado puede ser indicativo de ese elitismo de educación en Estados Unidos pero cuando llega a un punto extenso que no saben hablar ni español ni inglés es una mezcolanza que es algo negativo y nada elite.

Ana was especially aware of the link between codeswitching and return migrants because her own parents left the Island in search of a better future for themselves and their children. Ana was born in Boston while her parents lived there, and came to PR with her family when she was a very young child. Ana is now a long way from her humble upbringings. Thanks in part to her linguistic skills, she is a now a successful lawyer at one of PR's top law firms. When asked about the relationship between codeswitching and an elite status she immediately mentioned the two "kinds" of Puerto Ricans who are likely to alternate languages. The first group is comprised of people who lived in the U.S. for a long time, or have parents who did, and the second group is composed of those who belong to an elite:

You have people from both backgrounds. There is certainly an elite. People like Helena, who studied at St. John's (School), and her education revolved around going to the United States, and continuing her education there. Those who belong to an elite here prepare their children to study in the United States. Studying in Puerto Rico is not an option for a certain group of people. Those types of people could be an elite and master 
English, yada, yada, yada, and they may codeswitch, but not all who codeswitch belong to that group. I can't mention a percentage because that's very difficult. Hay de los dos. Hay ciertamente una élite, hay gente como Helena que estudió en St. John's (School) y su educación giró en torno al inglés y en torno a ir a Estados Unidos a educarse allá. Los de la élite de aquí preparan a sus hijos para estudiar en Estados Unidos. El estudiar en Puerto Rico no es una opción para cierto grupo de personas. No para todos, pero para cierto grupo de personas, no es una opción. Ese tipo de personas, será una élite, dominará el inglés, chijí, chijá, y hará codeswitching pero no todos son de ese grupo. No te sé decir qué porcentaje hay, eso es bien difícil.

Ana is clear in that her English proficiency was not a result of an elite upbringing. She had the opportunity to begin learning the language in the U.S. as a very young child, and then invested in further developing her second language as a young adult. Ana and Alberto were adamant about being included in an elite category. At present, they hold an educational and economically privileged position in Puerto Rican society. They both have a university education and hold prestigious positions in their respective professional fields. However, they were not comfortable with being included in an elite group. Ana and Alberto expressed being acutely aware of the effects of elite closure in Puerto Rico. They talked about the differences in the opportunities to learn English on the Island, and mentioned the supposed availability of English in public schools, which, more often than not, does not translate into learning it.

In contrast, those who belong to the elite have the resources to promote the language, and to participate in an ideological milieu that fosters its learning and understands its advantages. Carlos, for example, mentioned that when he graduated from a public high school in Bayamón, it was a complete surprise for him that he would need English to succeed in his career. Carlos 
thinks that the root of the linguistic situation in Puerto Rico is found in the economy and politics: "If Puerto Rico, as a nation, understood that education is of utmost importance, that learning English is also extremely important, and if the Government established it as a priority, then we would see some evolution." The political and economic relationship with the United States does have an effect on education, and has had evident linguistic consequences. Since the start of this relationship, the elite have made sure that their linguistic choices are in accordance with maintaining their power and privilege. Their appropriation of the English language, as linguistic capital, reflects on their daily interactions in the form of codeswitching. Therefore, codeswitching may contribute to the creation of an elite identity for bilinguals in the present study. The next three sections will explore what codeswitching means in terms of their ethnic and personal identities.

\section{On Being American}

Appel and Muyksen (1987) presented two views on the relationship between language and ethnicity (p. 12-13). The first one was put forth by Fishman (1997) and includes three dimensions: paternity, an inherent constellation acquired from one's parents as they acquired it from theirs and so forth; patrimony, the legacy of a collectivity which includes behaviors and views; and phenomenology, which has to do with subjective attitudes of people toward their membership in an ethnic group. Fishman also thinks that language is the symbol par excellence of ethnicity because it is the expresser of patrimony and carrier of phenomenology. A second view is more subjective and emphasizes that ethnicity reflects a shared us-feeling. Members of a group may have considerable differences, but the subjective factor, the us-feeling or the usagainst-them-feeling, overrides the importance of other objective factors not shared. Language is a crucial ingredient of this us-feeling. For example, there are cultural items that find expression 
in a specific language, and speakers often think that they cannot be expressed in another language (p. 13). Language carries social meaning and social connotations. Thus, people evaluate it in relation to social categories that are dependent on the defining characteristics of each community.

Bucholtz and Hall (2005) explained that it is perhaps easier to recognize identity as emergent in cases where speakers' language use does not conform with the social category to which they are normally assigned. This is especially relevant to the present analysis. The category normally assigned to English in the Puerto Rican context is "American," while Spanish is associated with being "Puerto Rican." However, in this dissertation, it was found that the presence of English and Spanish in the recorded conversations does not necessarily entail a hybrid American-Puerto Rican identity. In the words of Bucholtz and Hall, participants may sever expected mappings between language and culture, that is, they "subvert the essentialist preconceptions of linguistic ownership" (p. 588). This is precisely what was observed when participants in this study engaged in codeswitching.

Given the political and historical reality of Puerto Rico, English readily indexes being "American" in the Puerto Rican context. However, all participants rejected the indexical association between English and an American identity. Speakers were asked if they thought including English in conversation implies being "American.” María says:

Under no circumstances. No, no. Not at all. I am Puerto Rican. I could understand how people may misinterpret it. But I am simply bilingual, and I consider myself Puerto Rican. 
Bajo ninguna circunstancia. No, no, para nada. Yo soy puertorriqueña. Ésa es la cosa, puedo entender cómo la gente puede malinterpretarlo. Pero simplemente soy bilingüe y me considero puertorriqueña.

Similarly, Lourdes was appalled by the possibility of her English referencing an American identity. She said: "I don't want to be an American, thank you. If I have to stop speaking English, I will." It is evident that, in some speakers, this question stirred negative sentiments toward being American. Backus (2005) explained that "most of the lexicon, including most function words, is shared between all registers of a language, so the majority of words cannot index any one register. In a bilingual situation virtually every word clearly originates in only one of the two languages, and by virtue of this language membership every one of them can index the values associated with that language" (p. 19). One possible reason for Lourdes' apparent dislike for being American is that it indexes negative values associated with English. This may in turn be related to her political views. Although she does not align herself with any political party on the Island, she did express her concern for the possibility of becoming a state because "there would be nothing left of Puerto Rico." Political views are bound to have an impact on participants' views on language. Alberto would like Puerto Rico to be an independent state. He said:

If people think that because I say two or three words in English I'm an American, then, deal with it! Because, I mean, I was born a Puerto Rican, my father was a nationalist, and I absorbed more English than, I would say, seventy percent of Puerto Rico. And I haven't stopped believing in independence for Puerto Rico and the right ideals.

Si la gente piensa que porque yo diga dos o tres palabras en inglés soy americano, pues, ¡breguen con eso! Porque yo, I mean, nací puertorriqueño, de padre nacionalista, y yo 
absorbí más inglés que casi, yo te diría, que el setenta por ciento de Puerto Rico. Y no dejo de creer en la independencia de Puerto Rico y los ideales que deben ser.

Although Alberto's family believed in Puerto Rico's independence from the Untied States, they also were able to circumvent negative values toward English that could have been fueled by their political ideals. Alberto embraced English, but not the American identity that could be ascribed to this language. Several other participants said that the presence of English in conversation does not imply being American, but instead, could be evidence of having been exposed to the American culture and having an "American influence." Janet makes it clear that this influence is not felt by all Puerto Ricans, but only "those who are like us," those who are constantly watching cable TV and American movies. Exposure to English is part of the lifestyle of Puerto Ricans who consume the "language of Americans" more than the average Puerto Rican.

Furthermore, in some cases, codeswitching will reveal having lived for a period of time in the United States. Diego mentions the stereotype of "the Puerto Ricans who go to the United States, then return and think they're gringos." Participants in general talked about "others" having these prejudiced attitudes, not themselves or their social group. Others are the ones who readily interpret their use of English, and think of them as Americans or "gringos," but certainly not themselves. Participants place the burden of interpretation on others, who may, on occasion, make reference to this stereotype in an attempt to regulate or criticize their linguistic behavior. In the following excerpt, Adrián talks about his cousin, who has drawn attention to his use of English use and calls it ridiculous.

In Puerto Rico, they tend to pass judgment on that. But I know that my cousin and other people say to me: "You're very gringo man." They've said that to me point blank. 
They've made fun of me. "Man, what's wrong with you, you're speaking English." When I speak English to my cousin, he says: "Come on, Adrián, don't be ridiculous." He says it like that. And I'm like, wait a minute, it's true.

En Puerto Rico, tienden a quizás, no sé si hacer un juicio sobre eso. Pero yo sé que mi primo y otras personas me dicen: "Estás bien gringo, mano". Me lo han dicho así. Como que me han relajado: "Diablo loco, qué te pasa, estás hablando en inglés". A mi primo, cuando yo le hablo en inglés, él me dice: "Ay, Adrián, no seas ridículo". Me lo dice así, y yo, como que, espérate, es verdad.

At the end of this excerpt, Adrián admits that his linguistic behavior is indeed incongruous with the linguistic reality of his cousin. Although codeswitching is part of Adrián's linguistic repertoire, he recognizes that it is not a normal part of the linguistic repertoire of all Puerto Ricans. Indexical associations between English and "being American" are also recognized by people from other countries who reside on the Island. Juliana works with many people from several Latin American countries, who have come to Puerto Rico for work reasons. To them, Puerto Rico is very American, in part because of the presence of English. Juliana has to constantly defend her own ethnicity, which in her mind is not compromised by her use of English. In fact, Juliana cannot understand this association, because Puerto Rico is not fully bilingual. She denies using English to index an American identity, but emphasizes that her Latin American coworkers do interpret it that way:

They may interpret it like that, but I don't. They see Puerto Rico as a very gringo place. And that's the type of discussion we have with them when they arrive. For them Puerto Rico is Gringoland. Not everyone speaks English here. We do use our Spanglish, that's true, but that does not mean that we're fully bilingual. 
Ellos lo pueden interpretar así, pero yo, para mí, no. Ellos ven a Puerto Rico como un sitio bien gringo. Y esas son las discusiones que tenemos cuando ellos llegan. Para ellos, Puerto Rico es Gringolandia. Nosotros no hablamos todos inglés. Nosotros hablamos nuestro Spanglish, que es verdad. Pero eso no quiere decir que nosotros seamos fully

\section{bilingual.}

Participants also made reference to physical appearance as indicative of "being American." Laura said that her use of English could identify her as an American only if her physical appearance corresponded with the "blonde with blue eyes" American stereotype. Rey and Juan both have dark eyes and hair, but it seems that their fair skin combined with their constant use of English causes some confusion among those around them. Juan resents it when people assume he's a gringo because he feels very Puerto Rican. Viviana also highlighted that, even though she and her friends speak English, their English does not "sound American." Their second language evidently displays the phonological influence of Spanish, their first language.

The final participant I will mention in this section is Rey. He provided a completely different perspective on this issue. When I asked him about the relationship between codeswitching and his identity as a Puerto Rican he said the following:

Let's do a bit of codeswitching: ¿Is that a trick question? The thing is... how do I answer that... I'm not a nationalist, like I told you before, I consider myself American and I consider myself Puerto Rican, on equal grounds. I don't think of myself as more Puerto Rican than American or more American than Puerto Rican. I'm Puerto Rican and American and that's it. Therefore, in my outlook on life, I don't think I'm more or less of a Puerto Rican, or more or less of an American because I use one language or the other. 
Vamos a hacer un poquito de codeswitching: ¿Eso es un trick question? Lo que pasa es que... cómo puedo contestarla... yo no soy una persona nacionalista, como te dije anteriormente, me considero americano y me considero puertorriqueño a igualdad de condiciones. Yo no considero que soy más puertorriqueño que americano, ni más americano que puertorriqueño. Soy puertorriqueño y soy americano, punto. Por lo tanto, en mi interpretación de la vida, a mí no me hace ni más ni menos puertorriqueño, ni más ni menos americano el que yo utilice un idioma u otro.

The bottom line for Rey is that he has embraced both ethnicities. His codeswitching style is ideal for claiming the two identities important to him. Unlike all other participants, who were not ready to admit that their codeswitching was indicative of claiming an American identity, Rey was very comfortable with this notion.

The previous discussion demonstrates that analysts who focus on the codeswitching phenomenon should not assume straightforward links between each language and a particular ethnicity. Codeswitching in interaction paves the way for the creation of new and heterogeneous identity positionings: "Such interactions highlight what is true of even the most predictable and noninnovative identities: that they are only constituted as socially real through discourse, and especially interaction" (Bucholtz and Hall, 2005, p. 591). When confronted with the indexical pairing between the use of English and an American identity, speakers were quick to interpret this association as an oversimplified construct, as a result of prejudiced attitudes, and not indicative of their own desire to identify with the American culture.

Nevertheless, speakers had varied reactions toward English as a marker of their American identity. Walter, for example, responded with an emphatic: "We are not Americans," while Rey was open to considering himself an American, but still distanced himself with the widespread 
"gringo" stereotype. What was common to all of them was a process of recognizing indexicality, and then reformulating it from their own perspective. Woolard (2004) stated that "what is needed is more work that shows just how and when indexicality emerges, and when it is reaffirmed, amplified, reformulated and even dissipated" (p. 90). The practice of codeswitching reveals a process of reformulation of indexicality. Speakers are clear in that English in conversation does not straightforwardly equal "being American." It is simply a product of their bilinguality, and they are still very much "Puerto Rican."

\section{On Being Puerto Rican}

This section perhaps best illustrates the concept of identity construction. Participants were asked about the relationship between codeswitching and their Puerto Rican identity. Perhaps more so than any other, this question produced the most interesting, unexpected and complicated answers, from the perspective of the analyst. Participant views about the relationship between codeswitching and an American identity did not show significant differences. However, their perspectives on codeswitching and "being Puerto Rican" were varied and intricate. Therefore, it was difficult to summarize their opinions into a few global explanations.

Previous discussions have demonstrated the strong connection between Spanish and Puerto Rican identity. Most participants in this study agree with this ideological construct, and see speaking Spanish as an important component of being Puerto Rican. However, participants do not communicate solely in Spanish with friends and family in their everyday lives. This is evidence of speakers actively producing "new forms of identity through language by disrupting naturalized associations between specific linguistic forms and specific social categories" 
(Bucholtz and Hall, 2005, p. 591). The first indication that Puerto Ricans who codeswitch are not the same as the "average" Puerto Rican came from Sandra:

When I was in law school (at the University of Puerto Rico) I found out that my friends and I were viewed by most people as a separate group, and they didn't like us because we spoke English. Nobody understood why we had to speak English.

Cuando estaba en escuela de leyes (en la Universidad de Puerto Rico) me enteré de que mis amigos y yo éramos vistos por la mayoría de las personas como un grupo diferente. No les caíamos bien porque hablábamos ingles. Nadie entendía por qué teníamos que hablar inglés.

Sandra makes reference to her free use of English, interspersed with Spanish, with her friends at law school. This practice was not shared by everyone around them. When questioned on the topic of her Puerto Rican identity Sandra said: "I feel as Puerto Rican as someone who does not speak English, has lived all his life in Jayuya, in the middle of the Island, and has never left his little town. I am equally Puerto Rican.” Bilinguals in the present study are co-creating their own version of what "being Puerto Rican" means on the Island. Their conceptualization of national identity is conditioned by their habitus, which includes the acceptance of English as a valid resource in their communicative repertoire. The use of English as a communicative resource is not shared by most Island Puerto Ricans. Lourdes confirms English attainment and codeswitching as a choice available only to a group of people.

First of all, in Puerto Rico they don't teach you, at least when I was in high school, they only teach you basic English. If you have to learn English, you have to do it on your own. In other words, the English influence that people my age may have is because they wanted to learn, or studied at a private school, or their parents gave them some sort of 
information, or they had cable TV. It's as simple as that. And about codeswitching, we do it because, literally, it's an option for a group of people, but I don't think we're snobs. It's an option. Being Puerto Rican has so many influences. I also think it has to do with the town you grew up in, it depends on who your parents are. You choose how to talk.

Número uno, en Puerto Rico no te enseñan, por lo menos cuando yo estaba en high school, te enseñan inglés bien básico. Si tú tenías que aprender inglés lo hacías tú solito, en otras palabras, la influencia del inglés que tenga cualquier persona de mi edad, es porque quiso aprender o estudió en un colegio, o los papás le dieron algún tipo de información, o tenía cable, tan sencillo como eso. Y hacer el codeswitching, lo hacemos porque literalmente es una opción y es un grupo de gente, ahora no creo que seamos unos come mierdas. Esto es una opción que yo hice como tal, ser puertorriqueño tiene tantas influencias. También que yo creo que depende de qué pueblo vengas, depende de quiénes son tus papás. Tú escoges cómo hablar.

Lourdes mentions what many participants consider as prerequisites for bilinguality on the Island, and which are not shared by the majority of the population: motivation, private schooling, parental influence, and exposure to the language. This situation, where only a sector of the population achieves mastery over their second language, inevitably sets the stage for social categorizations that disrupt the accepted community-wide discourse structure. Speakers in this study expressed their own theories to support a novel Puerto Rican identity, which embraces the appropriateness of English in everyday interaction.

Geographic and socioeconomic factors were mentioned by participants as determining factors for bilinguality. Mastery of English or lack thereof would eventually determine individuals' linguistic display of their Puerto Ricanness. Jacqueline made reference to several of 
her relatives who live in small towns on the Island, who, despite having a good education, do not codeswitch. They grew up in places where English is not necessary and ever-present, so they just do not use it. Another participant, Walter, said that a Puerto Rican who codeswitches is a Puerto Rican who belongs to the middle-upper classes. Walter concluded that you either belong to those social classes, or you codeswitch because you want to pretend you belong to them. Juliana, Walter's wife also said that social class determines who alternates languages, since codeswitching is a normal part of Puerto Ricans who belong to the highest social classes.

Juliana tells of a co-worker, Luis, who went around the office one day asking everyone how to say 'sweet potato' in Spanish. Luis, like many others in her office, went to a private school, pursued his university education in the U.S., and belongs to one of the highest social classes on the Island. This example is relevant to our discussion because, according to Juliana, people with other backgrounds would not even consider using the word "sweet potato," but, for Luis, it is completely normal. For him, use of the word 'sweet potato' [batata] is the equivalent of the use of 'parking' [estacionamiento] for other Puerto Ricans. 'Parking' is a borrowed word from English that is commonly used on the Island. While the use of borrowings is customary in PR, the inclusion of many more English words and phrases is customary for Puerto Ricans like Luis. The stylistic option of codeswitching becomes meaningful because of its opposition to the main pattern of language use on the Island, which is to speak solely Spanish. Codeswitching then becomes a means for Luis to self-display his identity as an urban, elite, bilingual Puerto Rican.

Speakers' self-conceptualizations as Puerto Ricans revealed conflictive feelings. Although Juliana codeswitches with regularity, her background is different from Luis'. She did not study in the U.S. and her family is not affluent, but she received most of her elementary education at a private school where English was recognized as an important form of cultural 
capital. Juliana has trouble deciding which "type" of Puerto Rican she is. She does not readily define herself as an elite bilingual:

I am a hard-core Puerto Rican. But if you take the stereotype of the hard-core Puerto Rican who goes to patron saint festivals, that's not who I am. That's not who I am as a Puerto Rican. I don't really know how I am as a Puerto Rican. They say we have identity problems, and right now I don't know how to categorize myself. I know I am not a hard core Puerto Rican, but neither do I belong to the high-end, like Mr. Sweet Potato. I'm middle-class, who maybe had access to an education at a school, which was maybe a little more sophisticated than that of the rest of the hard-core Puerto Ricans. Yo no soy la boricua de pura cepa. Pero el estereotipo de boricua de pura cepa, de que voy a las fiestas patronales, esa no es mi forma de ser. Eso no soy yo como puertorriqueña. Yo no sé cómo yo soy como puertorriqueña, dicen que tenemos problemas de identidad y ahora mismo no sé cómo catalogarme. Pero sé que no soy boricua de pura cepa, pero tampoco soy el high end como Mr. Sweet Potato. Soy de una clase media, que tal vez tuve acceso a una educación, por lo menos en la Academia, un poquito más elevadita que a lo mejor el resto del boricua de pura cepa.

Conflictive feelings about what codeswitching means in terms of their ethnicity were also shared by other participants. Like Juliana, Graciela is ambivalent about what codeswitching means for her as a Puerto Rican. She feels very Puerto Rican and believes her language should be Spanish, but at the same time she feels that she does not speak her native language as well as she should: "I don't feel less of a Puerto Rican, but sometimes I think I'm becoming a gringa." She subscribes to the ideology that a "true" Puerto Rican should speak Spanish "well," and codeswitching goes against that. In contrast, her husband, Leo, affirms that someone who does 
not include some English in his daily life is a "foreigner" in Puerto Rico. This difference of opinion highlights the on-going process of co-construction of identities. Speakers are aware of prevalent ideological discourses regarding language, and also create their own versions of what should contribute to building their Puerto Rican identity, in terms of language use.

One common thread in participant discussions about Puerto Ricanness and language was a view of codeswitching as a result of cultural influences from the United States. Darío says that codeswitching "is something cultural. It's already becoming something normal, part of our culture." When I suggested that for someone in a small town in the middle of the Island codeswitching was probably not normal, he said, “I really wouldn't know because I don't normally interact with them. But what you're saying is true." Darío admits that there may be different "kinds" of Puerto Ricans, but he is also sure that codeswitching does not make him any less of a Puerto Rican.

Viviana also made reference to the immense influence of the U.S. over Puerto Rico. She believes this influence is now an intrinsic part of who Puerto Ricans are, and this differentiates them from other Latin American countries. Finally, Alberto was insistent on referring to the cultural influence of the United States as a "problem." Although he has accepted codeswitching as a legitimate part of his verbal repertoire, he still recognizes the "problem" of having to use English to express himself. When asked about the meaning of codeswitching in terms of his identity as a Puerto Rican, he said: "What it means is that I'm a Puerto Rican who was born watching cable TV. It's the result of the cultural influences of the United States.” Political ideologies behind language perceptions possibly contribute to Alberto's view of English influence as a problem. Political processes and the languages associated with them have had an effect on the everyday lives of these individuals, and how they see themselves. Jaime explicitly 
said that if someone says you are not a Puerto Rican because you are speaking English, then that person is probably an independence supporter. He adds that statehood supporters think English is the cool language, and Commonwealth supporters are always in the middle. Adrián also makes a connection between codeswitching and politics:

I think that nowadays, I see it maybe as a phenomenon or a characteristic of being a colony, indirectly. Where one sometimes... it's not that your identity is not clear, but there are many elements that contribute to your language being mixed with another. Yo creo que hoy en día yo lo veo más bien como que quizás puede ser hasta un fenómeno de o una característica de ser una colonia indirectamente. Donde a veces uno, por decir, no que no tengas tu identidad clara, pero hay muchos elementos que contribuyen a que tu idioma esté bien mezclado con otro.

Adrián's words point toward the sociocultural ambiguities inherent to Puerto Rico's political status, which may have an effect on language. Laura disagrees with Adrián. She says codeswitching is a reflection of Puerto Ricans' lack of identity, which in turn is a result of our undefined political situation. She explains that Latin Americans speak Spanish because their identity is clear, but Puerto Ricans think they have an identity, but it is not real. Laura says:

For some things they are American citizens and use their passport, but for having a Miss Universe and an Olympic team they are Puerto Ricans. But for receiving American dollars, for that, they are Americans. That is not identity. And then, obviously, by being part of the United States, we have so much influence and even the television we watch is from there and... That's why I've learned so much English and the good pronunciation that I have is because of that American influence we have, because I have watched American television since I was a child, so that definitely has something to do with 
identity. If Puerto Rico were independent, I probably would not have watched so much cable TV as a child, and I wouldn't have the English I have.

Para unas cosas son ciudadanos americanos y usan el pasaporte, pero para tener Miss Universo y para tener un equipo olímpico, para eso son puertorriqueños. Pero para recibir los chavos americanos para eso son americanos. Eso no es identidad. Y entonces, obviamente al ser parte de Estados Unidos tenemos tanta influencia y hasta la televisión que vemos es de allá y... Por eso es que yo he aprendido tanto el inglés y la buena pronunciación que tengo fue por esa influencia americana que tenemos nosotros, porque yo veo televisión americana desde que yo era chiquita, pues eso definitivamente tiene que ver con la identidad. Si Puerto Rico fuera independiente, yo probablemente no vería tanto cable TV desde que yo era chiquita y no tuviera el inglés que tengo.

Although Laura places great emphasis on television as responsible for her English attainment, the present study has demonstrated there are many factors that worked together to bring about her balanced bilinguality. Nevertheless, Laura made key observations about the cultural and political reality of Puerto Rico, and what it means for identity. The following excerpt was taken from a conversation among Ray, Janet, Ana and me. It reveals the sometimes defensive attitude Puerto Ricans assume in relation to the United States. Ana tells of a congresswoman who expressed her views against granting rights to Puerto Ricans and referred to the island as a "foreign country." Ana was appalled by the congresswoman's ignorance. In the following excerpt she tells of a radio show host who called the congresswoman's office to confront her about what she had said about Puerto Rico. The radio host used Spanish to differentiate himself from her. Once he made it clear that he had the advantage of knowing two languages, he proceeded to further criticize her ignorance, in Spanish. 
01 A: Cuál fue la senadora que no sabía, que dijo que no debían de estar dándole

'Who was that senator who didn't know, who said that they shouldn't' derechos a un país extranjero, and I'm like, they are U.S. citizens. You idiot! 'grant rights to a foreign country, and I'm like, they are U.S. citizens. You idiot!' Tú sabes... la tuvieron que corregir. Estuvo genial porque Carlos puso ayer, 'You know... they had to set her straight. It was great because yesterday Carlos,' no se qué emisora de radio, y salió el Gangster con el 'tuned in to a radio show, and the Gangster and Funky Joe had' Funky Joe, habían llamado a la oficina de la Congresista y entonces ellos 'called the office of the congresswoman and then they'

06 hablándole y, you know miss whatever you said that Puerto Ricans... 'were talking to her, and you know Miss whatever you said that Puerto Ricans...'

07 M: ¿En español? 'In Spanish?'

08 A: No no, en inglés.

'No, no, in English.'

$09 \mathrm{M}: \quad$ ¿En inglés goleta?

'In bad English?'

10 A: No, el Gangster habla muy buen inglés. Dijo: You know what, at least we can 'No, the Gangster speaks good English. He said: You know what? at least we' can speak English and we can speak Spanish. Do you understand Spanish? Oh, 12 you don't? Then, you know what?... y siguió en español. 
'you don't? Then, you know what?... and he kept on talking in Spanish.'

Ana says in her interview that each day Puerto Ricans are more and more Americanized. She thinks it is ridiculous that there are Puerto Ricans who are adopting English as their first language. Ana speculates this phenomenon is related to Puerto Rico's political limbo: "We are not one or the other, and that represents who I am. I am not one or the other. I'm not more American because I codeswitch or less Puerto Rican because I codeswitch.”

Participants like Adrián, Rafael, María, Manuel, Janet, and Juan mentioned that what it means to be Puerto Rican has changed. Puerto Ricans reflect more American influence today than they did two generations ago. In the past, it was the Spaniards who exerted the greatest influence on Puerto Rican's conceptualization of themselves, and now the greatest influence comes from Americans, and with them, comes their language. Juan and Manuel, for example, mention American pop culture as responsible for much of the U.S. influence seen on the Island. Manuel says that after more than a hundred years of U.S. culture in Puerto Rico, "what the Puerto Rican culture was, the pure Puerto Rican culture no longer exists because now the culture of the United States is part of the Puerto Rican culture."

Marla adds that because of the intense U.S. influence on Puerto Rico, "being Puerto Rican" has become a mixture, and that mixture is reflected in language, in mixing English and Spanish. According to Marla, there is no way to completely separate the two languages when speaking of Puerto Rican identity: "That mixture is part of our identity." When asked if she thought this "mixed identity" was true for all Puerto Ricans, she admitted that her exposure to English is different than that of many other Puerto Ricans. These perspectives on identity reveal that there may be no indispensible requisites for being Puerto Rican. 
Speakers in the present study cannot control the prevalent discourse on the Island that favors Spanish conservation as a sign of being a "true" Puerto Rican, and they cannot control their habitus, which prompts the presence of English in their daily lives. Identity construction is bound by large scale structures that influence language use and attainment. These macro-social circumstances have an impact on micro-level interactions in which bilingual speakers deploy the resources available in their speech repertoire. Linguistic practices like codeswitching may serve to circumvent prescriptive notions of ethnicity, and serve to re-create new conceptualizations of self and others.

Bilinguals do not employ neutral codes that are disassociated from the broader social context. "Usually codeswitching stands for something else. It symbolizes identities beyond the linguistic fact" (Auer, 2005, p. 404). The use of English and Spanish among bilinguals is tied to ideologies which define their ethnicity and redefine what it entails. Codeswitching is a way of changing, rearticulating, and challenging these ideologies: "Ideological associations, once forged, may shape who does what and how in interaction, though never in a deterministic fashion" (Bucholtz and Hall, 2005, p. 591). Most participants are clear that they are Puerto Ricans in every sense of the word. Their linguistic practices do not subtract from their claims to this ethnicity, if anything, they add to it by redefining what it means to be Puerto Rican. Language, in this case, serves both to reproduce and transform social dimensions. Through codeswitching, speakers construct new identities and reflect the sociocultural processes that are underway on the Island. 


\section{On Being Bicultural}

The previous three sections explored three identity categories brought about by codeswitching: 'elite,' 'American,' and 'Puerto Rican,' which represent multiple and multifaceted social meanings for participants themselves, as well as those around them. The last identity category to be discussed is that of "bicultural." Codeswitching, as the meeting point of two languages and cultural systems, has often been said to automatically signal hybridity and biculturality. As demonstrated in the previous sections, in the context of the present study, English or Spanish do not automatically signal speakers' affiliation with a specific social group. Similarly, using both languages in interaction does not necessarily index a "bicultural" persona. Access to United States cultural imports has contributed to the learning of English, and has certainly contributed to the observed language competence of bilinguals in the present study. Although competence in codeswitching may signal the appropriation (habitus) of two languages and cultures, this does not mean that all participants in this study readily assume the hybrid cultural membership implied by their appropriation of English. One thing is to understand and be familiar with a cultural framework, and another to identify yourself fully with that culture.

In her discussion of overall codeswitching as the unmarked choice, Myers-Scotton (1988) argued that for codeswitching to become an overall pattern of interactions there needs to be a similar positive attitude toward both codes. She gave the example of her experience with bilingual instructors of English at the University of Panama. Their native language was Spanish and their interactions were solely in this language with no switches to English. Myers-Scotton speculated that this might have been influenced by hostility toward the United States at that moment, because of the Panama Canal situation. The identity of "an English speaker" might not have had positive associations: "These examples support the hypothesis that overall switching as 
an unmarked choice between bilingual peers is only frequent when both varieties are indexical of identities which are positively evaluated for the specific exchange type" (p. 166). Responses to the questionnaire in the present study confirmed that participants think of English and Spanish individually as languages indexical of positive values that they support and aspire to obtain. However, employing English and Spanish in their daily linguistic practices does not necessarily mean that they embrace a "bicultural" identity.

Lourdes, for example, admits to "participating" in the U.S. culture but does not assimilate it as her own. In fact, she downplays U.S. culture and characterizes it as boring and empty. Alternating English and Spanish in conversation in the Puerto Rican context may inevitably identify her as someone familiar with English and the U.S. culture, but this is definitely an identity she does not wish or intend to claim for herself.

Alejandro talks about the inevitable presence of English in the Puerto Rican cultural milieu:

Our identity is not bicultural, English is already part of our culture. We have implemented it up to a point in the Puerto Rican culture, in some sectors more than others. In San Juan, you are more exposed to that culture, even if you try to avoid it. In the metro area, and even in small towns, even if you don't want to be influenced, you will be influenced, and you will make it part of your culture because it's a mass movement, not an individual affair.

Nuestra identidad no es bicultural, es ya parte de nuestra cultura. Lo hemos implementado hasta cierto punto en la cultura puertorriqueña, en algunos sectores más que en otros, en San Juan te expones más a esa cultura, aunque lo trates de evitar. En el área metro, incluso en los pueblos, aunque no quieras ser influenciado, vas a ser 
influenciado y lo vas a hacer parte de tu cultura. Es un movimiento de masa, no de individuo.

Alejandro's words highlight cultural contact which brings about important language contact processes. Speakers are not only dealing with individual choices, but also respond to sociocultural processes in the wider community: "Code choice works to construct identities both micro and macro" (Bucholtz and Hall, 2005, 598). In her statement above, Lourdes may have chosen not to claim or highlight her bicultural persona, but as Alejandro points out, there are macro-social processes that inevitably have an impact on individuals as well as groups.

Biculturality is in some sense a byproduct of bilinguality, because the more adept a bilingual is in internalizing the conceptual and cultural systems that pertain to each of his or her languages, the more communicatively competent he or she will be. Juan is aware of this, and considers language an indicator of his bicultural self. He noticed that when he moved to the United States he felt somewhat out of place, but recognized that he understood the culture because of his linguistic knowledge. He understood slang expressions, quirky remarks, and dialectal differences between people from different parts of the U.S. Still, his understanding of U.S. culture did not translate into complete assimilation. He still considered himself Puerto Rican, and sought the company of other Spanish-speakers while living abroad.

Rey, Rafael, Jacqueline, Graciela, and Darío say that they consider themselves bicultural, not because of language, but because they lived in the United States. For Jacqueline, having lived in the U.S. gave her a heightened perspective on the differences between her culture and the one she experienced abroad. While she was there, she was able to assimilate it to the point of not wanting to come back to the Island. Her inability to speak solely Spanish following her return to the Island was linguistic evidence of her assimilation of the U.S. culture. Similarly, Graciela says 
that knowing English is not sufficient; in order to be bicultural one needs to have experienced the culture and developed an attachment to that culture. Diego also claims to know American culture very well. In fact, when he lived in Chicago with his girlfriend, one day she heard him talk on the phone in Spanish and commented that she sometimes forgot he knew Spanish, and was not from there. His cultural knowledge, facilitated by language, gave him the choice of total integration. However, Diego says this did not take away the fact that it was not his culture, and it was different from his.

Some participants, Juliana, Valeria, María, Roberto, and Marla were emphatic about the fact that they consider themselves Puerto Ricans, not bicultural. When I asked Laura if she considered herself bicultural because of her familiarity with English, she said:

No, because I am clear on which one is my own culture. I have been exposed to the American culture, but I know which one is mine. So, I don't consider myself bicultural. I do like many aspects of that culture, but I know it's not mine. I can say: "I like this more about their culture." But I am aware of my own culture. So I don't consider myself bicultural.

No, porque yo estoy clara de cuál es mi cultura. He estado expuesta a la americana, yo se cuál es la mía. So, no me considero bicultural. Que me gusten muchos aspectos de la otra cultura, sí, pero sé que no es la mía. Puedo decir: “Ay, me gusta esto más de la cultura de ellos”. Pero yo estoy consciente de cuál es la mía. O sea que no me considero bicultural.

Gibbons (1987) studied code mixing tendencies between Chinese and English in Hong Kong and provided three hypotheses to explain the presence of covert positive attitudes toward codeswitching: 1) There may be unique features in mixing languages that mark identity and 
solidarity in a specific speech community, 2) Mixing languages denotes status or prestige, 3) The mix might be a strategy of neutrality to not appear totally Chinese or totally western (p. 106). He concluded that, in the community he studied, language mixing marked a level of personal acculturation intermediate between Western and Chinese. In contrast, none of the participants in the present study referred to their linguistic practices as strategies of "neutrality" between the Puerto Rican and the American culture. One participant, Marla, did make reference to a process of assimilation. She does not consider herself bicultural, but recognizes that she has the ability to assimilate to the U.S. culture with ease:

I don't think I'm bicultural. I only have one culture, but it's about a phenomenon that has been mentioned about Puerto Ricans: assimilation. That some of us assimilate well when we go to the United States, when we're in that environment. I see it that way. I only have one culture, but it is easy for me to assimilate to the American culture. I don't feel out of place, I seem to be able to participate in all that they participate in.

Yo creo que no, que no soy bicultural. Como que nada más tengo una cultura, pero es como el fenómeno que han dicho de los puertorriqueños de asimilación, que nos asimilamos muy bien algunos de nosotros cuando vamos a Estados Unidos, cuando estamos en ese ambiente. Pues yo lo veo de esa forma: nada más tengo una cultura, pero se me hace bien fácil asimilarme a la cultura americana. No me siento fuera de sitio, como que puedo participar en todo lo que ellos participan.

Manuel considers himself bicultural, up to a point, and Rey was the only participant who readily claimed a bicultural identity. Manuel's assimilation of pop culture allows him to identify with someone who grew up in Ohio, for example, because they share cultural references that pertain to pop culture, but apart from that, he considers himself solely Puerto Rican. In contrast, 
Rey has completely assimilated his bicultural identity. He claims that both cultures are complementary, and there is no separation between the two:

I feel a hundred percent American and a hundred percent Puerto Rican. There is no difference. I am a hundred percent Puerto Rican because I was born in Puerto Rico, and a hundred percent American because Puerto Rico is part of the American nation. I do not consider it important in my life to police my language. I accept judgment over my Spanish and acknowledge that it is not the best, but I am also clear in that I don't care, guilty as charged, exactly.

$Y$ me siento cien por ciento americano y cien por ciento puertorriqueño. No hay diferencia, soy cien por ciento puertorriqueño porque nací en Puerto Rico y cien por ciento americano porque Puerto Rico es parte de la nación americana. Ni considero que sea importante en mi vida ser policía de mi idioma. Acepto el juicio sobre mi español y que no es el mejor, pero también entendiendo que no me importa, guilty as charged exactamente.

Rey's political views, which favor statehood for the Island, could influence his adamant defense of a bicultural identity. He claims to be completely capable of fully participating in the U.S. culture. Auer (2005) stated the following about codeswitching: "What could be more natural, we might say, for bilinguals living in or between two worlds (their home society and the receiving society) than to express this unstable status through bilingual speech style?" (p. 407). The political status of Puerto Rico is indeed unstable. There are two originally distinct cultures in contact, although there is a constant process of assimilation of U.S. cultural values that is taking place on the Island. Part of this assimilation is seen in language. Correspondingly, codeswitching becomes a window into social dynamics. Viviana explains: 
Precisely because of our situation as a country that stands as the best of both worlds, or however you want to see it. Let's say that we are neither this nor that, and the same happens with our language, neither pure Spanish nor pure English. It's a reflection of who we are. Because I think it's an inherent part of the culture we are living in. Precisamente por nuestra situación como país donde nosotros somos lo mejor de los dos mundos o como lo quieras ver. Digamos, ni somos esto ni somos aquello, pues así mismo nuestro lenguaje; ni español puro ni inglés puro. Es como un reflejo de lo que somos. Porque yo pienso que es tan inherente a la cultura que estamos viviendo.

Bailey (2007) explained that bilingual, bicultural individuals have both an expanded set of resources for "omnipresent social negotiations, and a broader range of social categories that can be made relevant through talk as compared to monolingual, monocultural bilinguals" (p. 29). It is true that the elite, bilingual Puerto Ricans in this study negotiate between two languages, two cultures, and two ways of being in the world. Their linguistic practice is a reflection of assimilation and struggle. They face a broader range of social categories that can be ascribed to their linguistic practices, but these social categories, or identities are not always readily embraced by the participant themselves.

The exploration of relevant ideologies, subjective feelings and beliefs, and their connections with linguistic practices allows a more thorough understanding of what codeswitching means in terms of individual and group identities. Li and Tse (2002) captured the notion of codeswitching as a natural product of sociocultural processes: "Given the enormous pressure of biculturalism and the tremendous extent of acculturation that has taken place as a result of sustained contact between Cantonese/Chinese and English in this former British colony for well over a century, it is unreasonable and unrealistic to expect educated Chinese bilinguals 
to maintain language purity in their informal interactions with each other. To do so would be to go against the laws of nature" (p. 184.) A similar situation can be observed in Puerto Rico. Language purity in informal interactions is not likely in a context of intense acculturation. Another of Li and Tse's (2002) findings that is relevant to this discussion is that the bilinguality exhibited in codeswitching by bilingual Chinese Hongkongers was perceived as an inalienable part of their personal identity (p. 170). Most bilinguals in the present study also expressed that codeswitching is part of "who they are" and eliminating it would entail taking away a part of how they normally express themselves in informal group encounters.

Bilinguals in the present study demonstrate an ongoing reformulation of identities within certain ideological frameworks. Their codeswitching style is characteristic of an exclusive group of speakers and is different from the wider society. This situation prompts the creation of identities that speakers may claim. In this process they may affirm or reshape existing personal and ethnic categories. 


\section{Chapter 10: Conclusion}

The present study offered a detailed analysis of codeswitching, as manifested in a network of competent bilinguals in Puerto Rico. There is a great need for small-scaled studies like the present one, that give a sense of general patterns of linguistic behavior among Island Puerto Rican bilinguals, particularly when it comes to their tendency to mix the two codes. Fontanella de Weinberg (1992) made reference to the use of codeswitching in certain socioeducational groups in Puerto Rico:

The situation of bilingualism in Puerto Rico is, without a doubt, extremely interesting, and it would be called for to advance in the study of language maintenance and communicative selection of both languages, as well as to conduct linguistic studies which address the degree of interference among the two systems and the use of codeswitching in various socioeducational groups [my translation]. (p. 265)

The context in which codeswitching happens includes the macro-social organization, and the large-scale, society-wide distribution of resources in relation to the group of speakers which is the focus of analysis. This level of analysis takes into account power relations within social formation, as they relate to language use. As demonstrated by the analysis presented in this dissertation, it is not enough to analyze the immediate pragmatic functions of codeswitching in conversation without reference to the wider social context. Since codeswitching is an intrinsically social phenomenon, it may be seen as an indicator of ideological and political developments in a given community. Therefore, codeswitching was treated in this dissertation as a society-specific phenomenon. Contextual details were considered crucial for understanding its manifestation in daily interaction: "Codeswitching is always a double-sided phenomenon. It has a macro dimension, that of the speech repertoires and their historical and sociocultural genesis 
and development, and also a micro dimension in that it plays a role in the management of interpersonal communication (Meeuwis \& Blommaert, 1994, p. 412).

Given the lack of similar studies on codeswitching in bilingual Puerto Rican communities on the Island, the present work contributes to our understanding of the language dynamics in this context, and serves as a starting point for larger scale studies. There are many questions that await further consideration. Some of them concern the influence that codeswitching can have on the Puerto Rican dialect: What role will codeswitching play in the future of the language contact situation of Puerto Rico? What impact can it have on the Spanish spoken on the Island? It is difficult to provide answers to these questions, since approaching codeswitching from a diachronic point of view is complicated, and most conclusions that could be drawn about its future impact are merely speculative.

Romaine (1995) suggested that borrowings in a bilingual community "start off as codeswitches, and achieve a status of loanwords by recurring over time in the speech of more and more individuals" (p. 124). This idea has important implications for the study at hand. If there are indeed, as this study indicates, bilingual communities in PR that engage in codeswitching, could they represent the starting point for this continuum? Could this potentially lead to adding more borrowed words into the Puerto Rican Spanish lexicon? A factor to consider is the relative prestige of the proposed social networks that engage in codeswitching, since this could also contribute to the subsequent addition of lexical forms (Myers-Scotton, 1992).

Backus (2005) explored the hypothesis that codeswitching is a cause of contact-induced language change. He specifically analyzed theories of how codeswitching may contribute to the innovation and propagation of new words or patterns in a language. Backus clarified that "whenever speakers conform to convention, the system remains stable. Whenever they do not, 
they either produce an innovation, or they reinforce ongoing change. If the innovative or ascendant element is a word of structure from another language, this change is contact-induced" (Backus, 2005, p. 319). He added that social factors cause people to use different languages at different situations in their everyday life. Speakers achieve conversational goals through the mechanism of code alternation, which in turn affects the "degrees of entrenchment of individual elements. These then do their work as nonintentional causal mechanisms of change or stability" (p. 327). If we apply this concept to the Puerto Rican context, the codeswitching practices of bilinguals, like the ones who participated in this study, could affect the degree of integration of English lexical items into their native language. However, this is very difficult to prove. Backus noted that when we speak of degree of integration we are referring to changes of the "frequencychanging" kind, and these types of changes are virtually impossible to demonstrate empirically. The researcher concluded that there is enough evidence to at least suggest that codeswitching can often function as one of the mechanisms for structural change (p. 334). The possible effects of codeswitching on grammar include single noun insertion, lexical items that result in calques, and clauses that pave the way for direct structural borrowing (p. 335).

Spanish is the preferred language of Puerto Ricans on the Island. Many do not see the need to learn English, and still others do not have the resources to learn it. Thinking of all Island Puerto Ricans as bilingual is not accurate. Vélez (1996) observed that "it is clear that to the extent that Spanish continues to fulfill a diversity of communicative functions in Puerto Rican society, ranging from the most casual and intimate to the most formal and structured, to that same extent we may feel confident of its survival among us regardless of what specialized functions English may acquire" (p. 17). Vélez was right in pinpointing the use of Spanish for most communicative functions on the Island, and his mention of the use of English for certain 
specialized functions, as in many other modern societies. However, the present study evidences that English, along with Spanish, is in fact being used in casual and intimate settings by a network of bilingual Puerto Ricans with particular sociocultural characteristics. We can also speculate that codeswitching among this group of bilinguals is not a temporary phenomenon that will eventually disappear. Gumperz (1982) gave the example of many colonial countries in Asia and Africa who freely alternate between their own language and that of the colonizing power. Puerto Rico's case is similar because English as a second language was introduced for political reasons in a previously stable monolingual society. However, the linguistic influences we are witnessing on the Island, which are manifested in codeswitching, are not only the result of colonialism. Codeswitching is a phenomenon characteristic of any modern society. Gumperz concluded that "there is little indication that codeswitching is merely a deviation from monolingual norms that will soon disappear. On the contrary, with the increasing displacement of formerly stable populations and the growing ethnic diversification of metropolitan centers, the communicative uses of codeswitching are more likely to increase than to decrease" (p. 64).

Although the results of the present study are exploratory in nature, there are indications that these twenty-seven people are part of larger network of speakers who have adopted a codeswitching style in daily interactions. All of them mentioned codeswitching as a habitual communication strategy among a wider community of friends and family. Toribio (2002) noted that although bilingual competence is a precondition for codeswitching, it is insufficient to determine successful codeswitching performance, and that membership in a community in which codeswitching is practiced may also be required (p. 103). This has important implications for language dynamics on the Island, since it suggests that participants codeswitch not simply 
because they are bilingual, but because they belong to a wider group or community of people who mix the two codes with relative frequency.

One of the main goals of the analysis presented here was to identify and describe discourse patterns that pertain to this bilingual network of speakers. The next step would be to explore how the tendencies found in these conversations manifest in a wider network of speakers, and especially in younger generations, who may have even more exposure to English. The fact that codeswitching did appear in these conversations is in itself a relevant finding. Like many sociolinguistic small scale case studies, the present analysis provides insights on the variables at play when speakers make use of linguistic resources. In-depth ethnographic studies of language behavior, like the one presented here, can reveal fundamental differences in social values among individual speakers, and serve to explain language usage in the community: "We need to be able to deal with degrees of differentiation and, through intensive case studies of key encounters, learn to explore how such differentiation affects individuals' ability to sustain social interaction" (Gumperz, 1982, p. 7).

In his 1992 book on Caribbean Spanish, Humberto López Morales stated that "it is necessary to recognize that the information we have about the mastery over English in Puerto Rico, on the one hand, and the functions that both languages carry out in the interaction of the different social groups, on the other hand, is not satisfactory" (p. 154). Years later, we are still faced with many questions about the language contact situation on the Island: Do Spanish and English exist in cooperation, resistance, or integration? Is codeswitching part of a continuum that points toward the Anglicization of the Puerto Rican linguistic scene?

Any conclusions drawn from the collected data must be considered speculative and preliminary. However, important tendencies among Puerto Rican bilinguals have been observed 
that should not be ignored. According to Hakuta (1986), bilingualism at the level of the individual "presents a packaging puzzle, as it were, in which two language-bounded mental and social systems must be housed in a single mind [in a] delicate pattern of coexistence, cooperation, and competition" (p. 3). The study and verification of the bilingual tendencies observed here is definitely warranted. Further data gathering of codeswitching patterns may help to further elucidate the arresting language dynamics on the Island, and what they mean in terms of personal and ethnic identities.

Tabouret-Keller (1997) pointed out that the dynamics of ever-changing language takes place in nonhomogenous "mainland, isles, and islets of relatively permanent usage based on a given linguistic stock, also only relatively permanent" (p. 316). In the case of Puerto Rico, the culturally prescribed code for everyday interaction is Spanish (Lopez Morales, 1992; Pousada, 1996; Resnick, 1993). The composition of the linguistic stock Tabouret-Keller referred to is indeed impermanent, and, in the case of Puerto Rico, codeswitching is evidence of an apparent change in the components of language stock in a network of speakers. Most bilinguals in the present study circumvent the preconception of Spanish as the principal medium of communication through their discourse practice of alternating English and Spanish in conversation. The use of English shows that these speakers are different from those who conform to the expected monolingual discourse mode. This allows them to create and recreate a particular set of identities in interaction. The research approach of this dissertation emphasized the various social constraints (historical, cultural, ideological, and economic) that permeate in bilingual social interactions, and which allow individuals to co-construct different identities.

One of the most important goals of the present study was to highlight that linguistic behavior carries social meaning, but not in a deterministic fashion. The identities that have been 
discussed (elite, American, Puerto Rican and bicultural), and that stem from the practice of codeswitching, were approached from the perspective of how members construct these identities. Eckert and McConnell-Ginet (1992) explained that speakers develop linguistic patterns as they act in their various communities, and sociolinguistics has traditionally seen this process as something relatively fixed. Like social identity, the symbolic value of a linguistic form was taken as a given. However, "in practice, social meaning, social identity, community membership, and the symbolic value of linguistic form are constantly and mutually constructed" (p. 473).

This dissertation serves as a way to track the transformations that have occurred and continue to occur on the island of Puerto Rico in terms of language contact and identity formation. The analysis demonstrates how speakers define and co-construct different identities through a codeswitching style. The linguistic resources available to this network of bilinguals, which allow them to invoke these identities, are historically contingent and subject to change. This study looked into their conversations, and also went beyond their words to explore the ideological, cultural, and political climate that has an impact on their linguistic practice. We were able to see how elite, bilingual Island Puerto Ricans understand, reject, or accept the social memberships indexed by codeswitching in conversation. Their bilingual speech style displays identities that respond to the reality of the two linguistic worlds that coexist in their habitus. Codeswitching provides fertile ground for the creation of multiple identities, with two languages, and between two worlds. 


\section{Appendix A-1}

Cuestionario y entrevista

\section{Perfil}

Sexo

Edad

Profesión/Uso del inglés

Experiencias de viaje

Ideal político para PR

\section{Aprendizaje de lenguas}

1) ¿Cuándo y dónde aprendiste tus lenguajes? (inglés y español)

2) ¿Qué lengua hablabas en casa y con quien? (padres, hermanos)

3) Describe tu sistema escolar:

¿¿Cuál era la lengua de enseñanza principal?

-¿En qué lengua eran los libros?

¿¿Tomaste alguna lengua como materia? ¿por cuánto tiempo?

4) ¿Tuviste alguna motivación especial para aprender inglés?

\section{III.Funciones internas y externas del lenguaje}

1. Contexto: En qué contextos usas cada lengua y con qué frecuencia:

Casa

Vecindario

Recreación

Profesión

Educación 
2. Exposición: Describe tu exposición a los medios de comunicación en cada lenguaje:

Televisión

Radio

Periódico

Magacines

Películas

Libros

3. Expresiones internas: Qué lenguaje usas típicamente para lo siguiente:

Contar

Rezar

Expresar sentimientos

Decir malas palabras

Soñar

\section{La alternancia de códigos}

1) ¿Alternas entre inglés y español cuando hablas?

2) ¿Con quién y en qué contextos?

3) ¿Evitas hacer codeswitching? ¿Cuándo y por qué?

4) En un día, ¿con cuánta frecuencia alternas los dos idiomas?

5) ¿Te das cuenta de que estás alternando idiomas?

6) ¿Te das cuenta cuando otros lo hacen?

7) ¿Por qué alternas tus idiomas?

8) ¿Usas los dos idiomas cuando escribes? 
9) ¿Puedes hablar exclusivamente en inglés o exclusivamente en español? ¿Se te hace fácil? ¿Difícil?

10) ¿Piensas que mezclar idiomas está mal?

11) ¿Crees que hacer esto está afectando/enriqueciendo tu español?

12) ¿Crees que el codeswitching es un indicio de saber mal/bien los dos idiomas?

\section{Identidad}

1) ¿Qué aspectos de personalidad, si alguno, asocias con el codeswitching?

(Ej: astuto, divertido, extrovertido, cómico, amigable, creativo, cool, no tan inteligente, reservado, serio)

2) ¿Crees que el incluir el inglés en tus conversaciones implica que eres americano?

3) ¿Cómo se relaciona el codeswitching con tu identidad como puertorriqueño/a?

4) ¿Crees que el codeswitching de alguna forma te define?

5) Para que alguien se considere a si mismo puertorriqueño, ¿tiene que saber español?

6) ¿Crees que el codeswitching se asocia con pertenecer a una "élite” social?

7) ¿Ves el codeswitching como algo positivo o negativo sobre ti?

8) ¿Cómo crees que los puertorriqueños monolingües ven a los que hacen codeswitching?

9) ¿Crees que los lenguajes que sabes o no sabes tienen algo que ver con tu posición socioeconómica?

10) ¿El lenguaje está atado a tus ideales políticos?

11) ¿Te consideras bicultural por tu familiaridad con el inglés de Estados Unidos?

\section{Ideologías del lenguaje}

1) La pureza del español debe ser protegida del inglés.

2) El español de Puerto Rico tiene demasiada influencia del inglés. 
3) El inglés enriquece el español de Puerto Rico.

4) Es bueno y deseable que todos los puertorriqueños sean bilingües.

5) Es indispensable que mis hijos sean bilingües.

6) El bilinguismo amenaza la unidad lingüística de Puerto Rico.

7) Todas las escuelas de Puerto Rico deberían ser bilingües.

8) Puerto Rico es bilingüe.

9) Hay una conexión muy grande entre una nación y su lenguaje.

10) El español es un símbolo indispensable para la puertorriqueñidad.

11) En Puerto Rico, el inglés es necesario para progresar profesionalmente.

12) En Puerto Rico, los lenguajes están muy atados a la política.

13) Si Puerto Rico se convierte en un estado, el inglés se impondrá y el español se va a perder.

14) Es probable que la situación lingüística de PR cambie por la influencia del inglés.

15) Las conexiones culturales y lingüísticas entre Estados Unidos y Puerto Rico, nos permiten tener lo mejor de dos mundos. 


\section{Appendix A-2}

Questionnaire and Interview

\section{Profile}

Sex

Age

Occupation/Use of English

Travel Experiences

Political ideal for PR

\section{Language Learning}

1) When and where did you first learn each language? (English and Spanish)

2) What language did you speak at home and with whom? (Parents, Siblings)

3) Describe your school system:

-What was the primary language of instruction?

-What was the primary language of textbooks?

-What language was taught as a subject and how long did you take it?

4) Did you have a special motivation to learn English?

\section{III.Internal and External Functions of Language}

1. Context: In what contexts do you use each language and how often:

Home

Neighborhood

Recreation

Occupation

Education 
2. Exposure: Describe your exposure to media in each language:

Television

Radio

Newspaper

Magazines

Movies

Books

3. Internal Expression: What language do you typically use to do the following:

Counting

Praying

Expressing feelings

Cursing

Dreaming

\section{Language Alternation}

1) Do you codeswitch?

2) With whom and in what contexts?

3) Do you avoid codeswitching? When and why?

4) During the course of one day, how often do you alternate the two languages?

5) Do you notice your own codeswitches as you say them?

6) Do you notice when others do it?

7) Why do you codeswitch?

8) Do you use both languages when you write? 
9) Can you speak only in English or only in Spanish? Is it easy? Difficult?

10) Do you think mixing languages is wrong?

11) Is it harming/enriching your Spanish?

12) Do you think codeswitching is a sign of proficiency or deficiency in one or both languages?

\section{Identity}

1) Which personality traits, if any, do you associate with mixing languages?

(Examples: witty, fun, outgoing, funny, friendly, creative, cool, not so intelligent, reserved, serious)

2) Do you feel including English in conversation signals that you are American?

3) How does codeswitching relate to your identity as a Puerto Rican?

4) Does codeswitching define you in any way?

5) In order for someone to consider himself Puerto Rican, does he or she need to speak Spanish?

6) Do you feel codeswitching can be associated with belonging to an "elite"?

7) Do you see codeswitching as something positive or negative about yourself?

8) How do you think monolingual Puerto Ricans feel about people who codeswitch?

9) Do the languages you know have something to do with your socioeconomic position in society?

10) Is language tied to your political ideals?

11) Do you consider yourself bicultural because of your familiarity with U.S. English?

\section{Language Ideology}

1) The purity of Spanish should be protected from English influence. 
2) The Spanish of Puerto Rico has too much English influence.

3) English enriches the Spanish of Puerto Rico.

4) Bilingualism is desirable for all Puerto Ricans.

5) It is necessary for my children to become bilingual.

6) Bilingualism threatens PR's linguistic unity.

7) All schools in PR should be bilingual.

8) Puerto Rico is bilingual.

9) There is a significant connection between a nation and its language.

10) Spanish is an indispensible symbol of Puerto Ricanness.

11) In PR, English is necessary for professional advancement.

12) In PR, language is very tied to politics.

13) If PR becomes a state, English will be imposed and Spanish will be lost.

14) The linguistic situation in PR is likely to change due to the influence of English.

15) PR's cultural and linguistic connection with the U.S. allows for Puerto Ricans to have the best of both cultures. 


\section{Appendix B}

"Guaynabitos"

by Marcos Pérez Ramírez

El Nuevo Día, April 8, 2007

La primera vez que escuché este ‘neogentilicio’ fue por boca de un examigo, quien decidió cambiar nuestra amistad por el cinismo y la amargura que lo consumen. Sucede que en la colindancia de San Juan y Guaynabo hay una gasolinera en la que se reúnen jóvenes que parecen ser adinerados para darse el trago y charlar, siempre bajo la mirada tutelar de sus autos europeos. Estaba allí empujado por la necesidad de combustible para mi carro y me topé con el fenómeno.

Casi sumaban cincuenta. Hablaban español, salpicando sus observaciones con un inglés colegial estadounidense coronado con el argot que comienza cada oración con 'It's like... [fill in the blank]... like...”. ¡Cáspita - pensé - que alto nivel metafórico tienen estas tertulias!, por lo que me acerqué para escuchar apresado por el morbo. Aunque soy diestro en el difícil, confieso que el cambio de registro de los jóvenes - Spanish, inglés back y pa' lante - me hacía perder el hilo...

¿Quién puso ese reggae roots con el que ahora todos contonean sus caderas? Me llega el olor a soga dulce quemada y voy comprendiendo el mambo. Ya me preguntaba extrañando por qué no montan ese fiestón en sus casas, de seguro espaciosas, con amplios jardines y tibias albercas. Es más, si en Garden Hills residen, solo un palmo de calle hay que cruzar para montar el vacilón hogareño. Pero recordé aquellas palabras de Lavoe, cuando en un soneo de 'El rey de la puntualidad' confesaba que "estaba atrás haciendo lo que no me dejan hacer aquî". Algo 
parecido hay entre manos aquí. Esto es más "safe". Estamos en San Juan, pero no en las entrañas de mi ciudad colmada de cacos que le dan el tumbe al riquitillo a la menor provocación. It's like, better, it's like, uff, thank God! 


\section{Appendix C}

"Idioma defectuoso, pensamiento defectuoso" - [Flawed language, flawed thinking] By. Luis López Nieves.

Advertising Campaign commissioned by the Communications Department of the Sacred Heart University, San Juan, Puerto Rico. (January, 1995)

Twenty Puerto Ricans (actors, politicians and other recognized figures) stand before the camera and say one or two words.

\begin{tabular}{|c|c|}
\hline 1. El idioma... & 1. Language... \\
\hline 2. es la sangre del espíritu ... & 2. is what feeds our spirit... \\
\hline 3. Háblalo bien. & 3. Speak it well. \\
\hline 4. Con orgullo. & 4. With pride. \\
\hline 5. No digas "nice"... & 5. Don't say "nice”... \\
\hline 6. di "chévere"... & 6. Say "chévere" \\
\hline 7. "tremendo". & 7. "tremendo" \\
\hline 8. No digas "size"... & 8. Don't say “size”... \\
\hline 9. di "talla"... & 9. Say "talla"... \\
\hline 10. “tamaño". & 10. "tamaño". \\
\hline 11. Tampoco digas... & 11. Don't say... \\
\hline 12. "estoy en shock"... & 12. I'm in shock... \\
\hline
\end{tabular}




\begin{tabular}{|l|l|}
\hline 13. mejor decir "atónito" o "perplejo". & 13. It's better to say "atónito" o "perplejo". \\
\hline 14. "Brown" es incorrecto... & 14. "Brown" is incorrect. \\
\hline 15. usa "marrón"... & 15. use "marrón"... \\
\hline 16. "castaño"... & 16. "castaño"... \\
\hline 17. "pardo". & 17. "pardo". \\
\hline 18. "Tuna" es la que canta. En español... & 18. "Tuna" is the one that sings. In \\
& Spanish... \\
\hline 19. se come "atún". & 19. "atún" is the one you eat. \\
\hline 20. Idioma defectuoso, pensamiento & 20. Flawed language, flawed thinking. \\
\hline
\end{tabular}




\section{References}

Acosta-Belén, E. (1975). "Spanglish": A case of language contact. In M. Burt \& H. Dulay (Eds.), New directions in second language learning, teaching and bilingual education: selected papers from the ninth annual TESOL convention, Los Angeles, California, March 4-9, 1975. Washington: Teachers of English to Speakers of Other Languages.

Agar, M. (1991). The biculture in bilingual. Language in Society, 20, 167-181.

Antaki, C., \& Widdicombe, S. (1998). Identities in talk. London; Thousand Oaks, CA.: SAGE. Appel, R. \& Muysken, P. (1987). Language contact and bilingualism. London; Baltimore: E. Arnold.

Auer, P. (1984). Bilingual conversation. Philadelphia: Benjamins.

Auer, P. (1995). The pragmatics of code-switching: a sequential approach. In L. Milroy \& P. Muysken (Eds.), One speaker, two languages: cross-disciplinary perspectives on codeswitching (pp. 115-135). New York: Cambridge University Press.

Auer, P. (1998). Code-switching in conversation: language, interaction and identity. New York: Routledge.

Auer, P. (2005). A postcript: code-switching and social identity. Journal of Pragmatics, 37, 403410.

Auer, P. (2007). Style and social identities: alternative approaches to linguistic heterogeneity. New York: Mouton de Gruyter.

Bakhtin, M. M., \& Holquist, M. (1981). The dialogic imagination: four essays. Austin: University of Texas Press. 
Barreto, A. A. (1995). Nationalism and linguistic security in contemporary Puerto Rico. Canadian Review of Studies in Nationalism, 22, 67-74.

Bauman, R. (2004). A World of Others' Words: Cross-cultural Perspectives on Intertextuality. Cambridge: Blackwell.

Becker, A. L. (1994). Repetition and otherness: an essay. In B. Johnstone (Ed.), Repetition in Discourse (Vol. 2, pp. 162-175). Norwood, NJ: Albex.

Backus, A. (2005). Codeswitching and language change; One thing leads to another? International Journal of Bilingualism, 8, 307-340.

Bailey, B. (2007). Language alternation as a resource for identity negotiations among Dominican American bilinguals. In P. Auer (Ed.), Style and social identities: alternative approaches to linguistic heterogeneity (pp. 29-55). New York: Mouton de Gruyter.

Beirne, C. J. (1975). The problem of "Americanization" in the Catholic schools of Puerto Rico. Rio Piedras, P.R.: Editorial Universitaria Universidad de Puerto Rico.

Bell, A. (1999). Styling the other to define the self: a study in New Zealand identity making. Journal of Sociolinguistics, 3, 523-541.

Blom, J. P., \& Gumperz, J. J. (1972). Social Meaning in Linguistic Structure: Code-Switching in Norway. In Gumperz, J. \& Hymes. D. (Ed.), Directions in Sociolinguistics: The Ethnography of Communication. New York: Holt, Rinehart and Winston.

Bloomfield, L. (1953). Language. London: Allen and Unwin.

Blommaert, J. (1992). Codeswitching and the exclusivity of social identities: some data from campus Kiswahili. Journal of Multilingual and Multicultural Development, 13, 57-70.

Bourdieu, P. (1991). Language and symbolic power (G. Raymond \& M. Adamson, Trans.). Cambridge, MA: Harvard University Press. 
Bucholtz, M., \& Hall, K. (2005). Identity and interaction: a sociocultural linguistic approach. Discourse Studies, 7, 585-614.

Cashman, H. (2005). Identities at play: language preference and group membership in bilingual talk in interaction. Journal of Pragmatics, 37, 301-315.

Chana, U., \& Romaine, S. (1984). Evaluative reactions to Panjabi/English code-switching. Journal of Multilingual and Multicultural Development, 5, 447-473.

Clachar, A. (1997). Resistance to the English Language in Puerto Rico: Toward a Theory of Language and Intergroup Distinctiveness. Linguistics and Education, 9, 69-98.

Clachar, A. (1998). Differential Effects of Linguistic Imperialism on Second Language Learning: Americanization in Puerto Rico versus Russification in Estonia. International Journal of Bilingual Education and Bilingualism, 1, 100-118.

Clachar, A. (2000). Redressing Ethnic Conflict through Morphosyntactic 'Creativity' in CodeMixing. Language and Communication, 20, 311-327.

Clampitt-Dunlap, S. (1995). Nationalism, native language maintenance and the spread of English: A comparative study of the cases of Guam, the Philippines and Puerto Rico., University of Puerto Rico, San Juan.

Clampitt-Dunlap, S. (2000). Nationalism and native-language maintenance in Puerto Rico. International Journal of the Sociology of Language, 142, 25-34.

De Fina, A. (1989). Code-switching: grammatical and functional explanations. Rassegna italiana di linguistica applicata, 21, 107-140.

De Fina, A. (2007). Style and stilization in the construction of identities in a card-playing club. In P. Auer (Ed.), Style and Social Identities: Alternative Approaches to Linguistic Heterogeneity. New York: Mouton de Gruyter. 
Delgado, José A. (2007, February 4). ¿Hay maestros suficientes para un plan bilingüe? El Nuevo Día Newspaper. Retreived May 11, 2008, from El Nuevo Día database.

Department of Education, Government of Puerto Rico, Project for the Development of a Bilingual Citizen, Santurce, Puerto Rico, 1997.

Eckert, P. (2004). The meaning of style. Texas Linguistic Forum, Proceedings of the Eleventh Annual Symposium about Language and Society, 47, 41-53.

Eckert, P., \& McConnell-Ginet, S. (1992). Think practically and look locally: Language and gender as community-based practice. Annual Review of Anthropology, 21, 461-490.

Eckert, P., \& Rickford, J. (2001). Style and sociolinguistic variation. New York: Cambridge University Press.

Edwards, J. (1999). Refining our understanding of language attitudes. Journal of Language and Social Psychology, 18, 101-110.

Fairclough, N. (1992). Discourse and social change. Cambridge, U.K.: Polity.

Falcón, S. M. (2004). Attitudes toward languages in contact: Spanish, English, and intellectuals in Puerto Rico. Ph.D. Dissertation Georgetown University, Washington, D.C.

Fasold, R. W. (1984). The sociolinguistics of society. Oxford, England; New York: Blackwell.

Fayer, J. M. (2000). Functions of English in Puerto Rico. International Journal of the Sociology of Language, 142, 89-102.

Figueroa, L. (1972). Tres puntos claves: Lares, idioma, soberanía. San Juan de Puerto Rico: Edil.

Fontanella de Weinberg, M. B. (1992). El español de America (1a ed.). Madrid: Mapfre. Fullana Acosta, M. (2008). Estrena comedia que representa la mujer de hoy. Primera Hora Neswpaper, p. 9. 
Gafaranga, J. (2005, December 11). Demythologising language alternation studies: conversational structure vs. social structure in bilingual interaction. Journal of Pragmatics, 37, 281-300.

Gardner, R., \& Lambert, W. E. (1972). Attitudes and motivation in second-language learning. Rowley, Mass.: Newbury House.

Gardner-Chloros, P. (1991). Language selection and switching in Strasbourg. New York: Oxford University Press.

Gee, J. P., Hull, G., \& Lankshear, C. (1996). The new work order: Behind the language of the new capitalism. Boulder Colorado: Westview Press.

Gibbons, J. (1987). Code-mixing and code choice: a Hong Kong case study. Clevedon, Avon, England; Philadelphia: Multilingual Matters.

Grosjean, F. (1982). Life with two language: an introduction to bilingualism. Cambridge, Mass.: Harvard University Press.

Gumperz, J. J. (1982). Discourse strategies. Cambridge, UK; New York: Cambridge University Press.

Hakuta, K. (1986). Mirror of Language. The Debate on Bilingualism. New York: Basic Books. Haiman, A. (1993). Spanish-English codeswitching in Puerto Rico: functional or problematic? In J. M. Fayer (ed.), Puerto Rican Communication Studies. San Juan: Fundación Arqueológica, Antropológica, e Histórica de Puerto Rico.

Hall, S. (1996). Who needs identity? In S. Hall \& P. Du Gay (eds.), Questions of cultural identity. London /Thousand Oaks, CA.: Sage.

Hamers, J. F., \& Blanc, M. (2000). Bilinguality and bilingualism (2nd ed.). Cambridge; New York: Cambridge University Press. 
Heller, M. (1988). Codeswitching: anthropological and sociolinguistic perspectives. Berlin; New York: Mouton de Gruyter.

Heller, M. (1992). The Politics of Codeswitching and Language Choice. Journal of Multilingual and Multicultural Development, 13, 123-142.

Hollingshead, A., \& Redlich, F. (1958). Social class and mental illness; a community study. New York: Wiley.

Hudson, R. A. (1996). Sociolinguistics. Cambridge: Cambridge University Press.

Institute of Field Studies, Teachers College, Columbia University. (1950). Public Education and the Future of Puerto Rico: A Curriculum Survey 1948-1949. New York: Bureau of Publications.

Irvine, J. (1989). When Talk isn't Cheap: Language and Political Economy. American Ethnologist, 16, 248-267.

Irvine, J. (2001). "Style" as distinctiveness: the culture and ideology of linguistic differentiation. In P. Eckert \& J. Rickford (Eds.), Style and sociolinguistic Variation. New York: Cambridge University Press.

Jacobson, R. (1977). The social implications of intra-sentential code-switching. The New Scholar, 6, 227-256.

Johnstone, B. (2002). Prior texts, prior discourses. In B. Johnstone (Ed.), Discourse Analysis. Oxford: Blackwell.

Jorgensen, J. (2005). Plurilingual conversations among bilingual adolescents. Journal of Pragmatics, 37, 391-402.

Kachru, B. (1992). The other tongue: English across Cultures. Illinois: University of Illinois Press. 
Kroskrity, P. (2004). Language Ideologies. In A. Durnati (Ed.), A companion to linguistic anthropology. Malden, MA: Blackwell.

Labov, W. (1972). Sociolinguistic patterns. Philadelphia: University of Pennsylvania Press.

Layder, D. (1993). New strategies in social research. Cambridge, UK: Polity Press.

Lambert, W.E. (1979). Language as a factor in intergroup relations. In H. Giles \& R. St. Clair (eds), Language and Social Psychology. Oxford: Basil Blackwell.

Lavendera, B. R. (1978). The variable component in bilingual performance. In J. E. Alatis (Ed.), International dimensions of bilingual education (pp. 391-409). Washington: Georgetown University Press.

Lawson, S., \& Sachdev, I. (2000). Codeswitching in Tunisia: Attitudinal and behavioral dimensions. Journal of Pragmatics, 32, 1343-1361.

Le Page, R., \& Tabouret-Keller, A. (1985). Acts of identity. Cambridge; New York: Cambridge University Press.

Li, D. (1996). Issues in bilingualism and biculturalism: A Hong Kong case study. New York: Peter Lang.

Li, D., \& Tse, E. (2002). One day in the life of a "purist." The International Journal of Bilingualism, 6, 147-203.

Lipski, J. M. (1980). Bilingual code-switching and internal competence: the evidence from Spanish and English. Le Langage et l'homme, 42, 30-39.

López Laguerre, M. M. (1997). El bilingüismo en Puerto Rico: actitudes socio-lingüísticas del maestro (2. ed.). San Juan, P.R.: Espuela.

López Morales, H. (1992). El español del Caribe. Madrid: MAPFRE.

López Morales, H. (1998). La aventura del español en América. Madrid: Espasa-Calpe. 
López Nieves, L. (1995, June). Guión Idioma defectuoso - (final) USC. Retrieved June 12, 2008 from http://www.ciudadseva.com/otros/guioymin.htm.

Memmi, A. (1991). The colonizer and the colonized. Boston: Beacon Press.

Meeuwis, M., \& Blommaert, J. (1994). The 'Markedness Model' and the Absence of Society: Remarks on Codeswitching. Multilingua: Journal of Cross Cultural and Interlanguage Communication, 13, 387-423.

Milroy, L. (2002). Social Networks. In J. K. Chambers, P. Trudgill \& N. Natalie Schilling-Estes (Eds.), The handbook of language variation and change. Malden, Mass: Blackwell.

Milroy, L., \& Gordon, M. J. (2003). Sociolinguistics: method and interpretation. Malden, MA: Blackwell.

Milroy, L., \& Milroy, J. (1992). Social Network and Social Class: Toward an Integrated Sociolinguistic Model. Language in Society, 21, 1-26.

Morales, A. (2000). ¿Simplificación o interferencia?: el español de Puerto Rico. International Journal of the Sociology of Language, 142, 35-62.

Morson, G. S., \& Emerson, C. (1990). Mikhail Bakhtin: Creation of Prosaics. Stanford: Stanford University Press.

Morris, N. (1995). Puerto Rico: culture, politics, and identity. Westport, Conn.: Praeger.

Myers-Scotton, C. (1988). Code switching as indexical of social negotiations. In M. Heller (Ed.), Codeswitching: Anthropological and Sociolinguistic Perspectives (pp. 151-186).

Myers-Scotton, C. (1992). Comparing codeswitching and borrowing. Journal of Multilingual and Multicultural Development, 13, 19-39.

Myers-Scotton, C. (1993a). Social motivations for codeswitching: evidence from Africa. Oxford: Clarendon. 
Myers-Scotton, C. (1993b). Elite closure as a powerful language strategy: the African case. International Journal of the Sociology of Language, 103, 149-163.

Nash, R. (1970). Spanglish: Language contact in Puerto Rico. American Speech, 45, 223-233.

National Science Foundation. (2003). Study of Statewide Education Reform in K-12 Science and Mathematics, Case Study Reports. Vol. 2. Maryland: Cosmos Corporation.

Negrón de Montilla, A. (1975). Americanization in Puerto Rico and the public-school system, 1900-1930 (2d ed.). Rio Piedras: Editorial Universitaria Universidad de Puerto Rico.

Nickels, E. (2005). English in Puerto Rico. World Englishes, 24, 227-237.

Nilep, C. (2006). Code Switching in Sociocultural Linguistics. Colorado Research in Lingusitics, 19.

Norris, S., \& Jones, R. (2005). Discourse as action: Introducing Mediated Discourse Analysis. New York: Routledge.

Pachev, A. (2002). Europeanisation Trends and Linguistic Diversity: Language Planning and Language Policies Perspectives. Paper presented at the World Congress on Language Policies, Barcelona, Spain.

Pandit, I. (1986). Hindi English code switching: mixed Hindi English (1st ed.). Delhi: Datta Book Centre.

Pérez Ramírez, Marcos. (2007, April 8). Guaynabitos. El Nuevo Día Newspaper, p. 04.

Pfaff, C. (1979). Constraints on Language Mixing: Intrasentential Code-Switching and Borrowing in Spanish/English. Language, 55, 291-318.

Pierce, B. (1995). Social Identity, Investment, and Language Learning. TESOL Quarterly, 29, 931. 
Podesva, R., Roberts, S., \& Campbell-Kibler, K. (2002). Sharing resources and indexing meanings in the production of gay styles. In R. Podesva, S. Roberts \& K. CampbellKibler (Eds.), Language and Sexuality: Contesting Meaning in Theory and Practice. Stanford: CSLI Publications.

Poplack, S. (1980). Sometimes I'll start a sentence in Spanish y termino en español. Linguistics, $18,581-618$.

Poplack, S. (2000). Sometimes I'll start a sentence in Spanish y termino en español: toward a typology of code-switching. In L. Wei (Ed.), The bilingualism reader (pp. 221-256). New York: Routledge.

Poplack, S., \& Sankoff, D. (1984). Borrowing: the synchrony of integration. Linguistics, 22, 99135.

Pousada, A. (1994). Achieving linguistic and communicative competence in two speech communities: The Puerto Rican return migrant student. In A. Carrasquillo \& R. Beacher (Eds.), Bilingual Education in Puerto Rico (pp. 51-59). Caguas: Puerto Rican Association for Bilingual Education.

Pousada, A. (1996a). New routes to fostering bilingualism: developing language awareness among the Puerto Rican people. In L. Fiet, A. Pousada \& A. Haiman (Eds.), Rethinking English in Puerto Rico (pp. 21-27). Río Piedras: University of Puerto Rico.

Pousada, A. (1996b). Puerto Rico: On the Horns of a Language Planning Dilemma. TESOL Quarterly, 30, 499-510.

Pousada, A. (2000). The Competent Bilingual in Puerto Rico. International Journal of the Sociology of Language, 142, 103-118. 
Primera Hora Newspaper. (2005, January 26). Feliciano objeta iniciativa de escuelas bilingües. San Juan, PR.

Rampton, B. (1999a). Styling the other: Introduction. Journal of Sociolinguistics, 3, 421-427.

Rampton, B. (1999b). Deutsch in Inner London and the animation of instructed foreign language. Journal of Sociolinguistics, 3, 480-504.

Resnick, M. C. (1993). ESL and language planning in Puerto Rican education. TESOL Quarterly, 27, 259-275.

Rodríguez Juliá, E. (2007, October 23). Parodia sobre los Estadistas Puertorriqueños. El Nuevo Día Newspaper. Retrieved June 16, 2008 from http://foro.univision.com/univision/board/message?hboard.id=mariaelenasalinas\&messa ge.id=15887 $\&$ page $=5$

Rodríguez Juliá, E. (2008, March 31). Playitas. El Nuevo Día Newspaper. Retreived March 31, 2008 from http://www.elnuevodia.com/noticias.

Romaine, S. (1995). Bilingualism (2nd ed.). Oxford, UK; Cambridge, Mass.: Blackwell.

Romaine, S. (1996). El lenguaje en la sociedad. Una introducción a la sociolingüística. Barcelona: Ariel.

Sacks, H. (1979). Hotrodder: a revolutionary category. In G. Psathas (ed.), Everyday language: Studies in Ethnomethodology. New York: Irvington Press.

Saville-Troike, M. (2003). The ethnography of communication: an introduction. Malden, MA: Blackwell.

Schegloff, E. (1991). Reflections on Talk and Social Structure. In D. Boden \& D. Zimmerman (Eds.), Talk and social structure: studies in ethnomethodology and conversation analysis. Berkeley: University of California Press. 
Schilling-Estes, N. (2002). Investigating Stylistic Variation. In P. Trudgill \& N. Schilling-Estes (eds.), The Handbook of Language Variation and Change (pp. 375-401). Malden, MA.: Blackwell.

Schilling-Estes, N. (2004). Constructing ethnicity in interaction. Journal of Sociolinguistics, 8, $163-195$.

Schweers, W. C., \& Hudders, M. (2000). The reformation and democratization of English education in Puerto Rico. International Journal of the Sociology of Language, 142, 6387.

Schweers, W. C., \& Vélez, J. A. (1992). To be or not to be bilingual in Puerto Rico: that is the issue. TESOL Journal, 2, 13-16.

Sebba, M., \& Wootton, T. (1998). We, they and identity: Sequential versus identity-related explanation of code-switching. In P. Auer (Ed.), Code-switching in conversation: language, interaction and identity (pp. 262-286). New York: Routledge.

Sepúlveda, I. (1993). Identificación nacional mediante la defensa del idioma: El caso de Puerto Rico. Espacio, tiempo y forma, Serie V Historia Contemporánea, 6, 461-500.

Sherwood, Maia. (2007, June 2). Un diccionario de anglicismos para Puerto Rico. El Nuevo Día Newspaper, p. 36.

Strauch, H. (1992). The Compelling Influence of Nonlinguistic Aims in Language Status Policy Planning in Puerto Rico. Working Papers in Educational Linguistics, 8, 107-131.

Stroud, C. (1992). The problem of intention and meaning in code-switching. Text, 12, 127-155.

Solís, J. (1994). Public school reform in Puerto Rico: sustaining colonial models of development. Westport, Conn.: Greenwood Press. 
Solís Jordán, J. (2000). Language as possibility: comments on identity and language. International Journal of the Sociology of Language, 142, 157-173.

Swigart, L. (1992). Two codes or one? The insiders' view and the description of codeswitching in Dakar. Journal of Multilingual and Multicultural Development, 13, 83-102.

Tabouret-Keller, A. (1997). Language and Identity. In F. Coulmas (Ed.), The Handbook of Sociolinguistics (pp. 313-326). Cambridge: Blackwell Publishers.

Tannen, D. (1984). Conversational style: analyzing talk among friends. Norwood, N.J.: Ablex. The tooth fairy. (2008, May). In Wikipedia, the free encyclopedia. Retrieved June 12, 2008 from http://en.wikipedia.org/wiki/Tooth_fairy\#cite_ref-Wynbrandt_0-1. Information obtained from: The Excruciating History of Dentistry, James Wynbrandt, St. Martin's Press, 1998.

Toribio, A. J. (2002). Spanish-English Code-Switching among US Latinos. International Journal of the Sociology of Language, 158, 89-119.

Toribio, A. J. (2004). Spanish/English Speech Practices: Bringing Chaos to Order. Bilingual Education and Bilingualism, 7, 133-154.

Torres, L. (2002). Bilingual discourse markers in Puerto Rican Spanish. Language in Society, 31, 65-83.

Torres-González, R. (2002). Idioma, bilingüismo y nacionalidad: la presencia del inglés en Puerto Rico (1st ed.). San Juan: Editorial de la Universidad de Puerto Rico.

Torruellas, R. (1990). Learning English in three private schools in Puerto Rico: issues of class, identity and ideology. New York: NYU Press.

Trias Monge, J. (1999). Puerto Rico: The Trials of the Oldest Colony in the World. Yale University Press. 
Tsui, A. (2004). Medium of instruction in Hong Kong: One country, two systems, whose language? In J. W. Tollefson \& A. B. M. Tsui (Eds.), Medium of instruction policies: Which agenda? Whose agenda? (pp. 97-116). Mahwah, NJ: LEA.

Uber, D. (2000). Dealing with bilingualism; Business Language in Puerto Rico. Southwest Journal of Linguistics, 19, 120-142.

U.S. Census Bureau; "Foreign-Born Population of the United States Current Population Survey March 2004 Detailed Tables (PPL-176), (Table) 1.1 Population by Sex, Age, and U.S. Citizenship Status: 2004;" published 22 February 2005; 'http://www.census.gov/population/www/socdemo/foreign/ppl-176.html'

U.S. Census Burau. Data Set: Census 2000 Summary File 4 (SF 4) - Sample Data. PCT38. AGE BY LANGUAGE SPOKEN AT HOME BY ABILITY TO SPEAK ENGLISH FOR THE POPULATION 5 YEARS AND OVER [67] - Universe: Population 5 years and over. http://www.census.gov/population/www/cen2000/SF4-pop.html

U.S. Census Bureau; 2005 Puerto Rico Community Survey. "Place of Birth by Language Spoken at Home and Ability to Speak English in Puerto Rico - Universe: Population 5 Years and over in Puerto Rico (B006007-PR)" 'http://factfinder.census.gov/'

Vaquero, M. and Morales, A. (2005). Tesoro lexicográfico del español de Puerto Rico. San Juan: Plaza Mayor.

Velez, J. A. (1996). Toward a language policy that addresses Puerto Rican reality. In L. Fiet, A. Pousada \& A. Haiman (Eds.), Rethinking English in Puerto Rico: exploring language myths and realities. Río Piedras: University of Puerto Rico. 
Vélez, J. A. (2000). Understanding Spanish-language maintenance in Puerto Rico: political will meets the demographic imperative. International Journal of the Sociology of Language, $142,5-24$.

Vidal-Ortiz, S. (2004). Puerto Ricans and the Politics of Speaking Spanish. Latino Studies, 2, 254-258.

Walsh, C. E. (1991). Pedagogy and the struggle for voice: issues of language, power, and schooling for Puerto Ricans. New York: Bergin \& Garvey.

Wei, L. (1998). The 'why' and 'how' questions in the analysis of conversational code-switching. In P. Auer (Ed.), Code-switching in conversation: language, interaction and identity (pp. 156-176). London; New York: Routledge.

Wei, L. (2000). The bilingualism reader. London; New York: Routledge.

Wei, L. (2002). 'What do you want me to say?' On the Conversation Analysis approach to bilingual interaction. Language in Society, 31, 159-180.

Wei, L. (2005). "How can you tell" Toward a common sense explanation of conversational codeswitching. Journal of Pragmatics, 37, 375-389.

Weinreich, U. (1953). Languages in contact, findings and problems. New York: Linguistic Circle of New York.

Wertsch, J. V. (1998). Mind as action. New York: Oxford University Press.

Widdicombe, S. (1998). Identity as an analysts' and a participants' resource. In C. Antaki \& S. Widdicombe (Eds.), Identities in talk (pp. 191-206). London; Thousand Oaks, CA: SAGE.

Williams, A. (2005). Fighting words and challenging expectations: language alternation and social roles in a family dispute. Journal of Pragmatics, 37, 317-328. 
Wolfram, W., \& Fasold, R. W. (1974). The study of social dialects in American English. Englewood Cliffs, N.J.: Prentice-Hall.

Woolard, K. (2004). Codeswitching. In A. Duranti (Ed.), A companion to linguistic anthropology (pp. 73-94). Malden, MA: Blackwell.

Zhang, W. (2005). Code-choice in bidialectal interaction: the choice between Putonghua and Cantonese in a radio phone-in program in Shenzhen. Journal of Pragmatics, 37, 355-374.

Zavala, M. (2000). Puerto Rican identity: What's language got to do with it? In S. Nieto (ed.), Puerto Rican students in U.S. schools (pp. 115-136). Mahwah, N.J.: Lawrence Erlbaum Associates.

Zentella, A. C. (1982). Spanish and English in contact in the United States: The Puerto Rican experience. Word, 33, 41-57.

Zentella, A. C. (1990). Returned migration, language, and identity: Puerto Rican bilinguals in dos worlds/two mundos. International Journal of the Sociology of Language, 84, 81-100.

Zentella, A. C. (1997). Growing up bilingual: Puerto Rican children in New York. Cambridge, Mass.: Blackwell.

Zuckermann, G. (2003). Language Contact and Globalization: The camouflaged influence of English in the world's languages - with special attention to Israeli and Mandarin. Cambridge Review of International Affairs, 16, 287-307. 